Computação em nuvem elástica auxiliada por agentes computacionais e baseada em histórico para web services 


\title{
Computação em nuvem elástica auxiliada por agentes computacionais e baseada em histórico para web services
}

\author{
Ariel da Silva Dias \\ Orientador: Prof. Dr. Marcos José Santana \\ Dissertação apresentada ao Instituto de Ciências \\ Matemáticas e de Computação - ICMC-USP, como parte \\ dos requisitos para obtenção do título de Mestre em \\ Ciências - Ciências de Computação e Matemática \\ Computacional. VERSÃO REVISADA
}


Ficha catalográfica elaborada pela Biblioteca Prof. Achille Bassi e Seção Técnica de Informática, ICMC/USP com os dados fornecidos pelo(a) autor(a)

da Silva Dias, Ariel Computação em nuvem elástica auxiliada por agentes computacionais e baseada em histórico para Web Services / Ariel da Silva Dias; orientador Marcos José Santana. - - São Carlos, 2015. $78 \mathrm{p}$.

Tese (Doutorado - Programa de Pós-Graduação em Ciências de Computação e Matemática Computacional) - Instituto de Ciências Matemáticas e de Computação, Universidade de São Paulo, 2015.

1. Computação em Nuvem. 2. Agentes Computacionais. 3. Elasticidade. 4. Computação Autônoma. 5. Web Service. I. José Santana, Marcos, orient. II. Título. 


\section{SUMÁRIO}

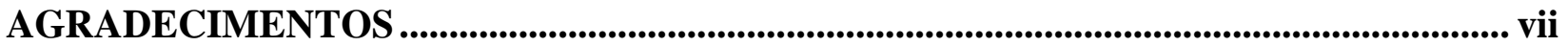

RESUMO

ABSTRACT

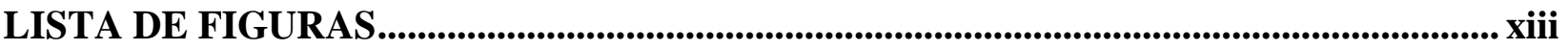

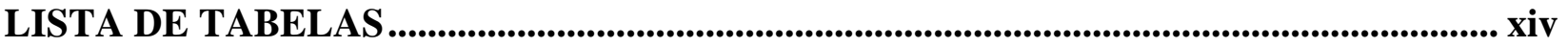

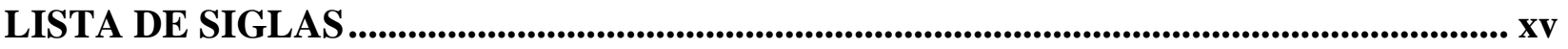

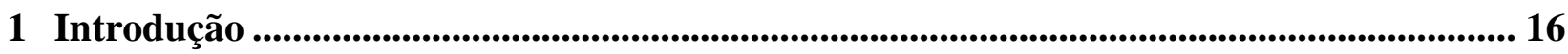

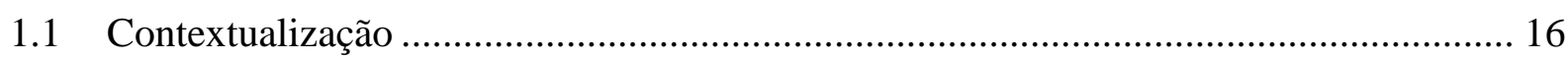

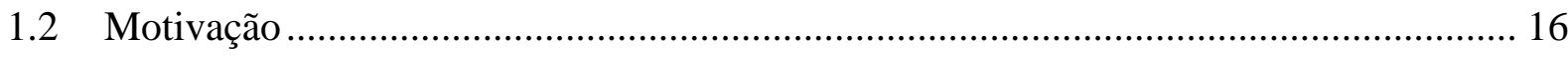

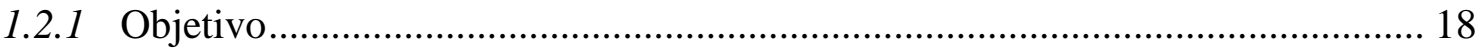

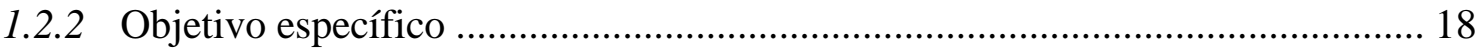

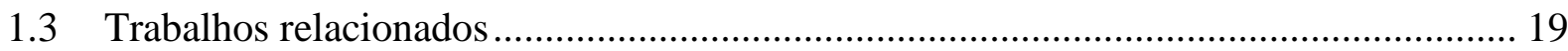

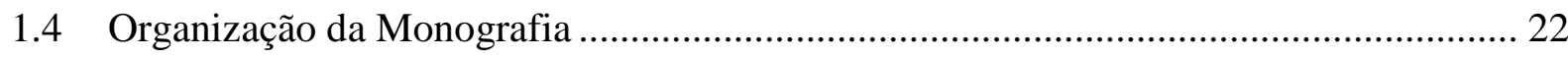

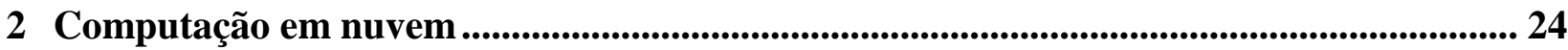

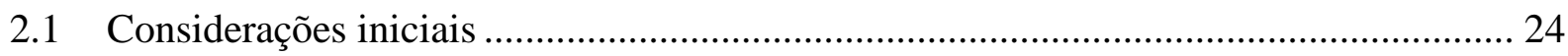

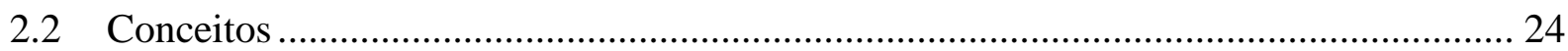

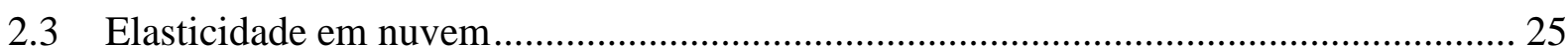

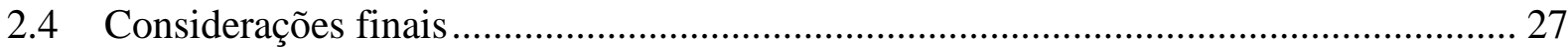

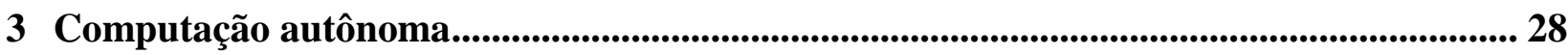

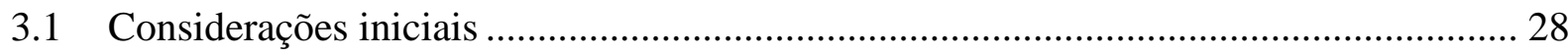

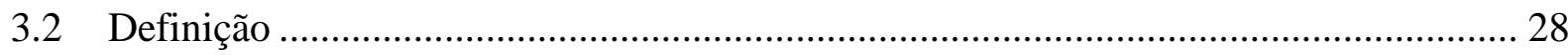

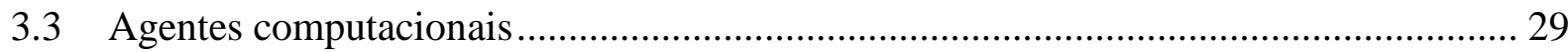




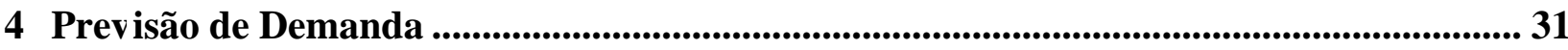

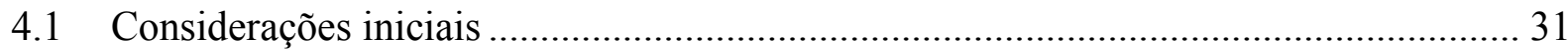

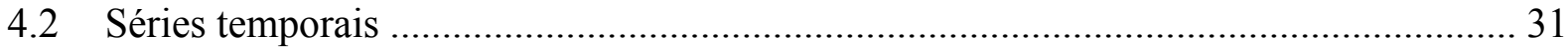

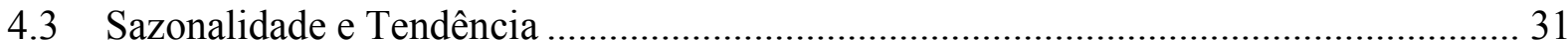

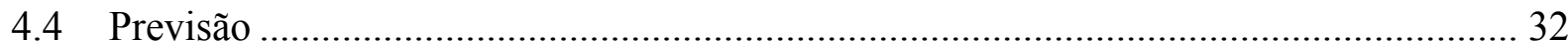

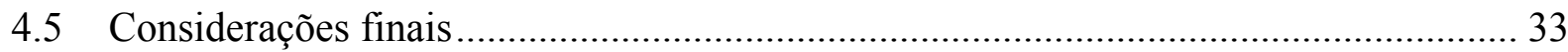

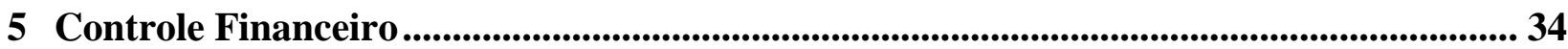

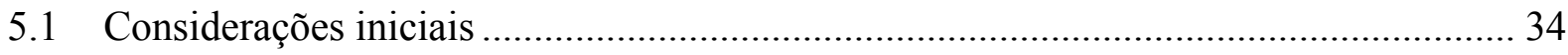

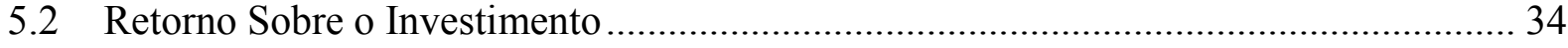

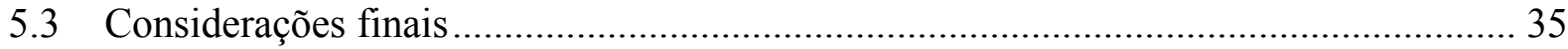

6 METODOLOGIA

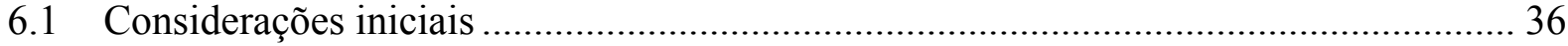

6.2 Desenvolvimento - Levantamento Bibliográfico....................................................... 36

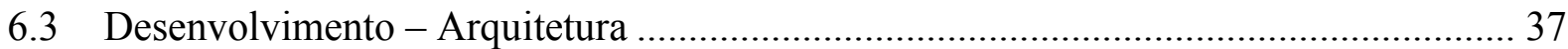

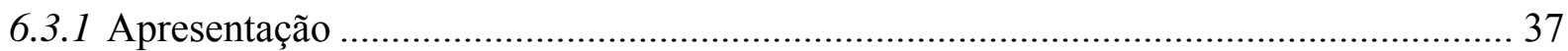

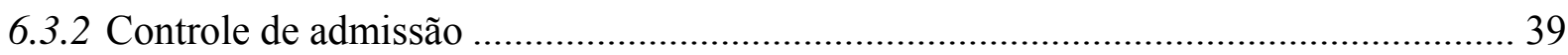

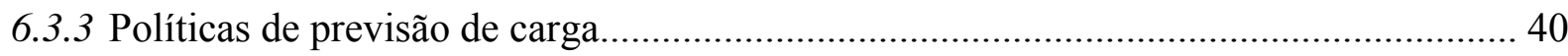

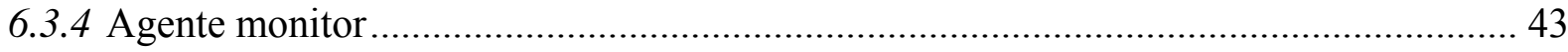

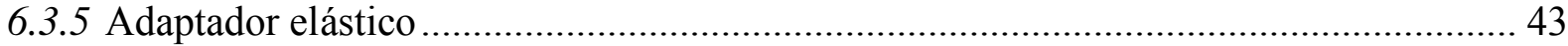

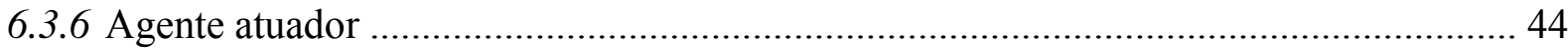

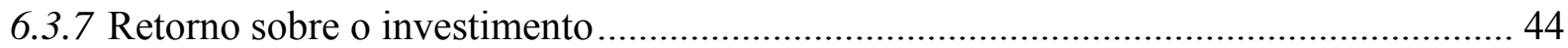

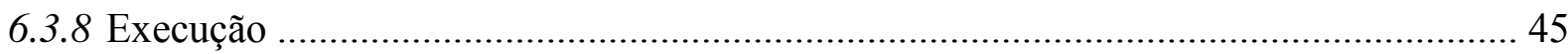

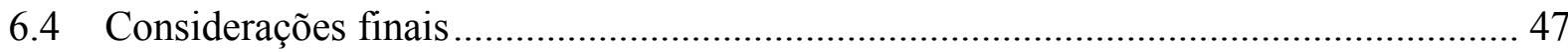

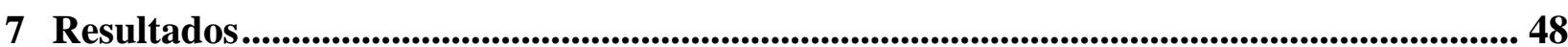

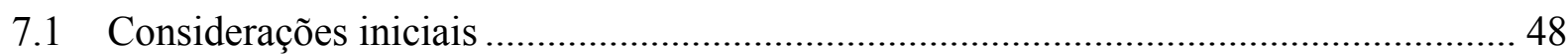

7.2 Fase 1: Resultados para escolha do modelo de previsão ............................................. 48

7.2.1 Influência dos fatores (Jain, 1991) .................................................................... 49 
7.2.2 Previsão de carga de trabalho com treinamento de 60 dias e prazo de 120 dias. 52

7.3 Fase 2: Avaliação de desempenho da reconfiguração em 15 períodos ........................... 56

7.4 Fase 3: Avaliação de desempenho da reconfiguração em 170 períodos ........................ 64

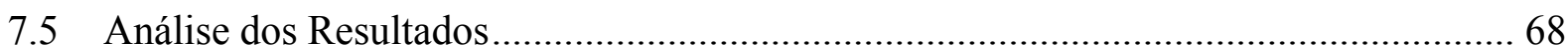

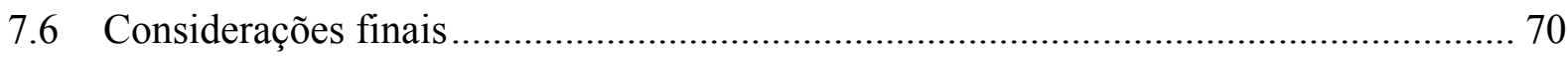

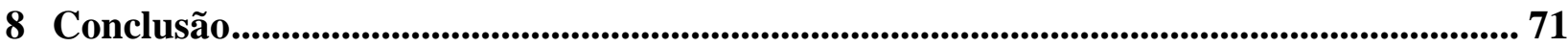

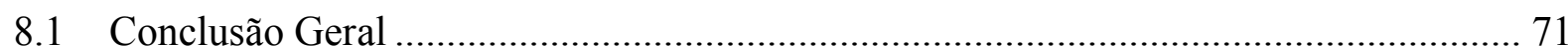

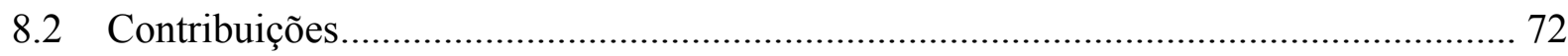

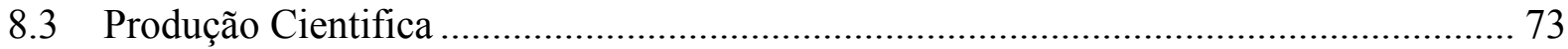

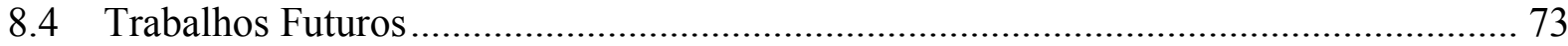

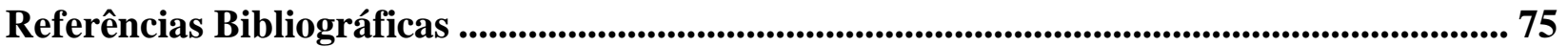




\section{AGRADECIMENTOS}

Agradeço ao meu orientador Prof. ${ }^{\circ}$ Marcos José Santana, que acreditou na proposta desta pesquisa e jamais poupou esforços no sentido de me ajudar a realizá-la. Agradeço sua criteriosa orientação para a satisfatória realização deste trabalho. Não me esqueço aqui de sua esposa, Prof. ${ }^{a}$ Regina Helena Carlucci Santana, que sempre se mostrou disposta a contribuir com a pesquisa, oferecendo em diversas oportunidades dicas de encaminhamento. Agradeço por me mostrarem o caminho da ciência. Muito obrigado!

Minha gratidão ao meu amigo de laboratório e companheiro nesta pesquisa Luis Nakamura, que gentilmente me convidou para este projeto, ajudando em todos os momentos. Sua intervenção e colaboração contriburam para a concretização deste projeto. Deixo aqui o agradecimento.

Aos professores, funcionários e colegas da Pós-Graduação do ICMC, principalmente ao professor Júlio Estrella pelas contribuições relacionadas com documentação. Aos professores Amilcar Carelli e Júlio Estrella, que gentilmente compuseram minha banca de qualificação, pelas sugestões significativas relacionadas a minha pesquisa e que nortearam para o estado que se conclui hoje. Agradecimentos também ao professor Celso Hirata que, juntamente com o professor Júlio compuseram minha banca de defesa.

Agradeço meus amigos do Instituto de Medicina Social e Criminologia de São Paulo (IMESC) pela ajuda e o incentivo. Agradeço especialmente ao meu diretor Domingos Silveira de Jesus e a minha superintendente Dra. Márcia Pereira Dobarro Facci pela compreenção nos momentos que tive que me ausentar do serviço para realizar este projeto.

Aos meus pais Abimael e Cleusa por terem me dado carinho, educação, ensinado valores e por acreditarem em mim. Agradeço a vocês que, em vários momentos, renunciaram seus sonhos para realizarem o meu. Hoje (e sempre) partilho com vocês a alegria de ser quem eu sou. Obrigado por me amarem e me tornarem o homem que sou.

Agradeço a minha esposa Cíntia que foi meu maior incentivo. Quando tudo parecia sem sentido você me deu amor e a compreenção necessária para continuar a caminhar. Graças a você e sua persistência hoje concluo este trabalho já almejando o próximo. Agradeço meu filho Yan que com seu sorriso me tira toda tristeza e alivia meu dia. 
Acima de tudo, agradeço a Deus pelo amor incondicional que Tens por mim, por sempre estar do meu lado, me protegendo e guiando meus passos. Obrigado por mais esta conquista Senhor.

Quero agradecer também à FAPESP pelo apoio fmanceiro concedido para a realização deste trabalho. 
"Mestre não é quem sempre ensina, mas quem de repente aprende"Grande Sertão: Veredas - João Guimarães Rosa 


\section{RESUMO}

A gestão eficaz de recursos computacionais em nuvem está diretamente ligada a gerir corretamente o desempenho das aplicações hospedadas na Máquina Virtual (Virtual Machine - VM), criando um ambiente capaz de controlá-la e redimensionar recursos de Memória, Disco, CPU e outros que se façam necessários, individualmente em resposta a carga de trabalho. Neste trabalho considerase também a gestão eficaz a qual é possível realizar o retorno sobre o investimento realizado para a contratação do serviço de IaaS. Nesta pesquisa de mestrado, foi proposto o gerenciamento da infraestrutura computacional em nuvem, através de dois modelos que facilitam o provisionamento auto-adaptativo de recursos em um ambiente virtualizado: alocação de recursos utilizando modelo para previsão da carga de trabalho futura e a gestão auto-adaptativa de capacidade utilizando agentes computacionais para monitorarem constantemente as VMs. Além disso, é proposto o retorno do investimento, que trata a relação entre o valor que o cliente contratou do serviço de IaaS e o quanto efetivamente ele está utilizando. Desta forma, a cada período é contabilizado a taxa do valor gasto em unidades monetárias. Para contemplar esta proposta, foram desenvolvidos algoritmos que são o núcleo de todo gerenciamento. Também foram realizados experimentos e os resultados mostram a capacidade do autogerenciamento das máquinas virtuais, com reconfiguração dinâmica da infraestrutura através de previsões baseadas em histórico e também da reconfiguração e monitoramento com o uso de agentes computacionais. Após a análise e avaliação dos resultados obtidos nos experimentos, é possível afirmar que houve uma significativa melhora da reconfiguração dos recursos com agentes computacionais se comparado a reconfiguração com previsão de carga futura. 


\section{ABSTRACT}

The efficient management of computational resources in the cloud is directly linked to correctly manage the performance of the applications hosted in the virtual machine (Virtual Machine $\mathrm{VM})$, creating an environment able to control it and resize features Memory, Disk, CPU and others resources, individually in response to workload. This work is also considered effective management which is possible to realize the return on investment for hiring the IaaS service. This Master thesis, is proposed the management of computing infrastructure in the cloud, using two models that facilitate self-adaptive resource provisioning in a virtualized environment using resource allocation model to predict the future workload and adaptive self-management capacity utilizing computational agents to continuously monitor the VMs. Furthermore, it is proposed return on investment, which is the ratio between the value that the client hired the IaaS service and how effectively it is using. Thus, each period is accounted for the rate of the amount spent in monetary units. To address this proposal, were developed algorithms that are the core of all management. Experiments were also conducted and the results show the ability of self-management for virtual machines with dynamic reconfiguration of infrastructure through predictions based on historical and also the reconfiguration and monitoring with the use of computational agents. After the analysis and evaluation of the results obtained in the experiments, is possible say that there was a significant improvement in reconfiguration of resources with computational agents compared with the workload forecast. 


\section{LISTA DE FIGURAS}

Figura 1 - Análise de uso de recurso computacional .........................................................................26

Figura 2 - Escopo da arquitetura principal envolvendo projeto de mestrado e doutorado..................................38

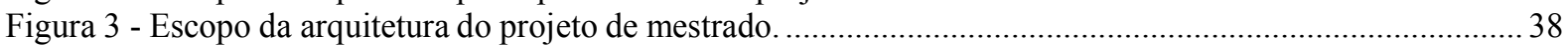

Figura 4 - Diagrama de Sequência: Controle de Admissão ..................................................................... 39

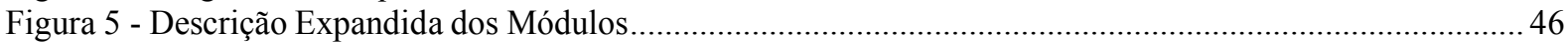

Figura 6 - Influência de fatores para a variável de resposta EMQ ........................................................50

Figura 7 - Influência de fatores para a variável de resposta Desvio Padrão ..................................................51

Figura 8 - Previsão de carga de trabalho para 120 dias com treinamento de 60 dias utilizando MME ................53

Figura 9 - Previsão de carga de trabalho para 120 dias com treinamento de 60 dias utilizando Holt-Winter .......54

Figura 10 - Gráfico de cubo para variável de resposta EMQ .....................................................................55

Figura 11 - Gráfico de cubo para variável de resposta Desvio Padrão ........................................................55

Figura 12 - Experimento 1: Memória, sem previsão e sem monitor............................................................59

Figura 13 - Experimento 1: Disco, sem previsão e sem monitor ...............................................................5

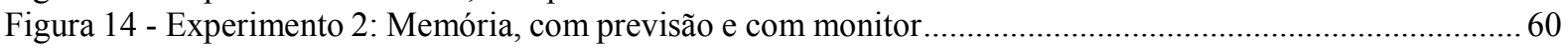

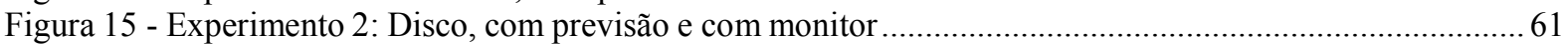

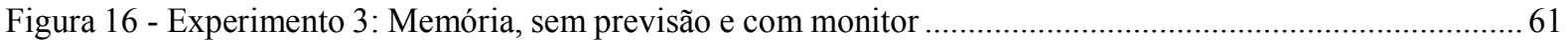

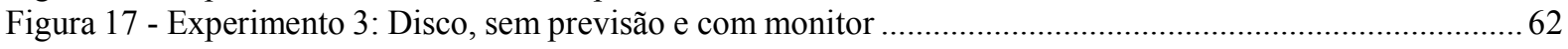

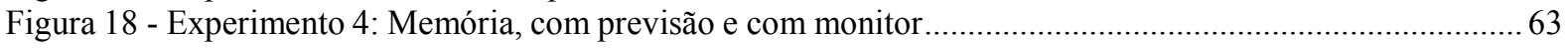

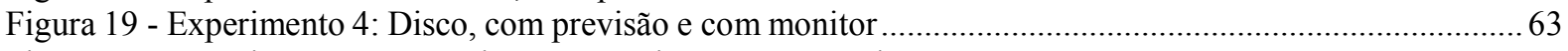

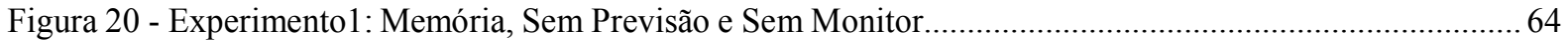

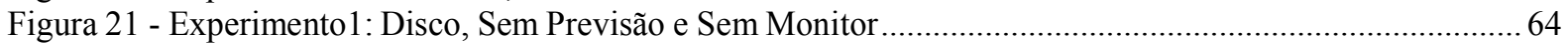

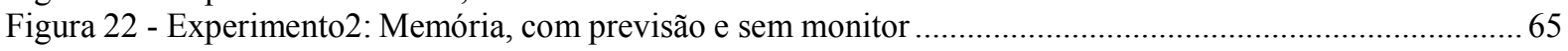

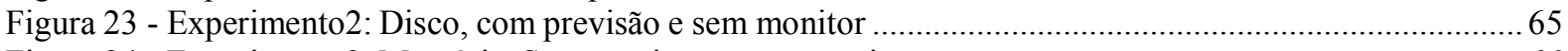

Figura 24 - Experimento3: Memória, Sem previsão e com monitor .........................................................6. 66

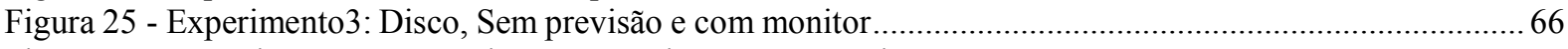

Figura 26 - Experimento4: Memória, Com previsão e com monitor ........................................................6 67

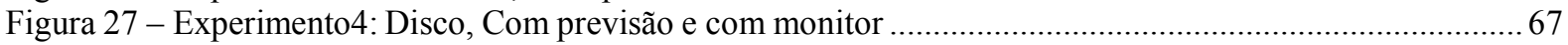




\section{LISTA DE TABELAS}

Tabela 1 - Trabalhos relacionados e recursos a contemplar

Erro! Indicador não definido.

Tabela 2 - Fatores e níveis

Erro! Indicador não definido.

Tabela 3 - Valores para a variável de resposta EMQ Erro! Indicador não definido.

Tabela 4 - Valores para a variável de resposta Desvio Padrão. Erro! Indicador não definido.

Tabela 5 - Cálculos ROI

Erro! Indicador não definido.

Tabela 6 - Comparativo entre Fase 2 e Fase 3

68 


\section{LISTA DE SIGLAS}

TI Tecnologia da Informação

CPU Central Processing Unit

HD Hard Disk

KVM Kernel-based Virtual Machine

IaaS Infrastructure as a Service

PaaS Platform as a Service

SaaS Software as a Service

SO Sistema Operacional

MV Máquina Virtual

MHW Modelo Holt-Winter

EMQ Erro Médio Quadrático 


\section{Introdução}

\subsection{Contextualização}

Os computadores tradicionais acompanham de forma desigual o avanço da tecnologia de software, o que obriga muitas vezes os usuários comuns e principalmente organizações empresariais, a optarem por arquiteturas de sistemas distribuídos, visando o aperfeiçoamento do ambiente computacional e a diminuição de custos.

Considerando a velocidade do crescimento de aplicações cada vez mais complexas aliada ao processamento e armazenamento de dados cada vez mais dependentes de hardware mais robustos, as organizações se deparam com um cenário em que são obrigadas a trocarem seus computadores e servidores, renovando a infraestrutura computacional periodicamente, gerando altos custos financeiros. Além disso, há a preocupação com backups, manutenções, licenças de software e principalmente de profissionais capacitados e sempre atualizados com as novas tecnologias do mercado.

Analisando esse contexto e conforme descrito por Souza (SOUZA et. al., 2010), a Computação em Nuvem deixa de ser apenas um conceito e passa a ser uma realidade aplicável de tecnologia, fornecendo os componentes básicos de Tecnologia da Informação (TI) como armazenamento de dados, processamento e memória como uma "mercadoria", por meio de servidores especializados por um baixo custo.

\subsection{Motivação}

Segundo Maluli (MALULI, 2010), o consumo de energia elétrica pelos servidores em datacenters e dos equipamentos relacionados à Tecnologia da Informação (TI) ultrapassa a margem de $60 \%$ do consumo médio das empresas em todo mundo, sendo que em média uma máquina física é utilizada de $5 \%$ a $15 \%$, entre seus picos e baixas, ficando o restante do tempo ociosa (MALULI, 2010). Como em uma organização há diversos servidores e computadores conectados a eles, certamente os recursos computacionais estão sendo subutilizados, gerando gasto de energia para manter um recurso em estado de ociosidade. 
Nesse contexto (economia de energia e ociosidade de servidores), a organização tem a opção de virtualizar seus servidores. Com isso, todo processamento estará alocado em um servidor principal na nuvem e, se uma máquina física utiliza cerca de $15 \%$ em seu pico de todo recurso computacional, várias máquinas virtuais dentro de um único servidor tendem a equilibrar os picos e baixas de utilização das máquinas (MALULI, 2010).

Em outro contexto, as organizações em geral passam por períodos de maior uso de recursos computacionais. Isso ocorre em razão de demandas sazonais como, por exemplo, a emissão de folha de pagamento de funcionários, o aumento de produtividade em determinado período do ano ou até mesmo o menor uso de recursos computacionais (por exemplo, no fim de semana quando nenhum ou poucos funcionários trabalham).

Não é satisfatório para uma organização pagar mensalmente por um recurso que não utilizou em sua totalidade, sendo esta uma questão de desperdício financeiro em um investimento que não está sendo utilizado totalmente.

Outra análise está relacionada com as aplicações on-line como YouTube, Flickr, FaceBook que apresentam carga de trabalho dinâmica dependendo de fatores previsíveis como tendências, periodicidade ou eventos programados, onde tais fatores são provisionados por meio de recursos próativos, já esperados e alocados anteriormente mediante a previsão de modelos fundamentados em uma base de conhecimento passado.

Provisionamento de recursos proativo exige modelos de previsões futuros e proporciona maior segurança, pois é conhecida (ou esperada) uma determinada carga de utilização. Por outro lado, pode surgir um volume inesperado e altos picos de utilização da aplicação sem prévio conhecimento. Quando neste caso a carga não pode ser prevista, há a necessidade da infraestrutura computacional se estender para que o serviço da aplicação não necessite ser interrompido ou haver queda do sistema. Por outro lado, surge a necessidade da infraestrutura diminuir os recursos oferecidos caso a utilização dos mesmos esteja superestimada (TIRADO et. al., 2011) (MALULI, 2010).

Observou-se a necessidade de mecanismos de reconfiguração dinâmica da infraestrutura computacional, sem a interferência humana, onde se permite aumentar e diminuir a capacidade do servidor contratado quando a demanda aumentar ou diminuir. Assim, a empresa economizará energia (apesar deste não ser o foco principal do trabalho), utilizará de forma adequada os recursos computacionais da infraestrutura contratada (evitando muitos momentos ociosos) e pagará um custo coerente com os recursos virtualizados utilizados no período determinado. 


\subsubsection{Objetivo}

Ao se tratar de Computação em Nuvem, muitas vantagens e características positivas são apontadas. Entretanto, a aplicabilidade deste conceito envolve diversos problemas como segurança, alta disponibilidade, consumo de energia, entre outros. Neste trabalho busca-se o foco em dois problemas que se complementam:

- Recurso subutilizado (ociosidade): o número de máquinas contratadas será relativamente grande e o investimento está direcionado a recursos não utilizados. Por exemplo, o recurso computacional máximo da nuvem que ela utiliza corresponde a dois computadores e ambos ficam ociosos, com pouco ou nenhuma atividade (TIRADO et. al., 2011).

- Falta de Recurso: em algum momento a organização precisará de mais recursos computacionais, por exemplo, memória. Uma opção apresentada é entrar em contato com o provedor do serviço de Computação em Nuvem e solicitar a atualização no tamanho da memória. Essa atualização pode não ser automática e obriga a organização a aguardar um determinado prazo de tempo que pode ser de horas ou até mesmo dias (BRANTNER et. al., 2008).

Este projeto de mestrado tem como finalidade pesquisar e contribuir com a comunidade acadêmica e científica apresentando soluções para a gestão eficaz dos recursos computacionais em nuvem. Esse objetivo será alcançado através da adoção de conceitos de elasticidade computacional, auxiliada por agentes computacionais, dando uma resposta ágil à carga de trabalho do usuário comum ou de organizações empresariais.

\subsubsection{Objetivo específico}

Considerando as motivações que levam a esse estudo e à aplicabilidade a posteriori, o objetivo deste projeto é desenvolver uma arquitetura voltada para a elasticidade da nuvem computacional através da reconfiguração dinâmica do ambiente virtualizado com a mínima necessidade da interferência humana, contribuindo com o autogerenciamento da infraestrutura computacional e com a melhor utilização dos recursos, que será feita por agentes computacionais e políticas de demanda de recurso baseadas em previsão e/ou monitoramento.

Toda a reconfiguração da infraestrutura será transparente aos usuários que continuarão utilizando as máquinas virtualizadas sem interrupções e sem notarem a troca do contexto. Para os 
experimentos que avaliam a arquitetura proposta neste mestrado, foram criadas máquinas virtuais, hospedadas em provedores de serviços, que executam Web Services responsáveis pela geração de carga de trabalho que é imposta pelos clientes.

\subsection{Trabalhos relacionados}

No trabalho (TIRADO et. al., 2011) os autores realizaram uma análise da carga de trabalho de um portal de música, propondo uma infraestrutura web elástica capaz de se adaptar dinamicamente de acordo com as variações de carga e demanda.

Os experimentos foram realizados em uma arquitetura de serviço web organizado em três niveis: dispather que consiste de servidores que recebem as requisições dos usuários; os web services que possuem a lógica da aplicação e recebem as solicitações do dispatcher, recupera os dados armazenados nos back-ends e servem o dispatcher; e o storage backend que é o local onde estão armazenadas as músicas. De acordo com as características da aplicação, cada uma recebe uma demanda intensiva de recursos específicos (disco, processador, etc) tornando-se um gargalo e propagando a degradação do desempenho de uma camada para a aplicação inteira.

Para solucionar esse problema, os autores propõem o agrupamento de dados realizando uma previsão de acesso futuro com base em um histórico de acessos, colocando os conteúdos mais populares e correlacionados em um mesmo servidor. Esse modelo facilita a busca, pois os artistas mais ouvidos certamente estarão nos mesmos servidores, os quais terão maior capacidade de recursos do que os artistas menos populares.

A infraestrutura se adapta de acordo com a previsão de carga de trabalho com base em um modelo de média móvel autoregressivo (ARMA) que, segundo (TIRADO et. al., 2011), "ajuda a fazer cumprir um provisionamento de recursos mais eficiente", capturando tendências e padrões de sazonalidade. Nos resultados desses experimentos, o erro de previsão foi de $6 \%$.

Dawoud (DAWOUD et. al., 2011) propõe uma arquitetura de máquinas virtuais elásticas, a qual será responsável pela escalabilidade dos recursos de uma MV dinamicamente de acordo com a carga de trabalho. $\mathrm{Na}$ escalabilidade dinâmica dos recursos, o núcleo elástico do hypervisor de máquinas virtuais é dimensionado por linguagens de programação sem interromper ou reiniciar os serviços. Como em (TIRADO et. al., 2011) os autores consideram uma arquitetura de aplicação web com: camada web, camada de aplicativo e camada de banco de dados. A dependência entre as camadas nesta proposta é novamente um gargalo, então o primeiro passo apontado pelo autor é prever 
em qual momento pode ocorrer o estrangulamento (maior número de acessos ou maior utilização de recursos) e em seguida realizar a escala dinâmica dos recursos disponíveis.

Segundo os autores, implementações atuais da Amazon EC2 e GoGrid recebem as solicitações dos usuários e direcionam para um balanceador de carga o qual encaminha a requisição para uma MV disponível. Um controlador monitora o desempenho de cada MV, expandindo ou reduzindo os recursos, porém tal tarefa não é executada em tempo real. O projeto do autor também constitui de um controlador monitorando o desempenho de cada camada. Entretanto, se as métricas de desempenho como processador exceder um determinado limite, o controlador de recursos de máquina virtual aumenta em tempo de execução os recursos da máquina virtual daquela camada para manter um sistema com um desempenho aceitável.

Rao et. al. (2011) apresentam o iBallon, um framework genérico que utiliza um algoritmo de reforço de aprendizagem que permite a alocação automática dos recursos computacionais de uma MV. Um agente computacional em um host físico é o responsável por gerenciar os recursos das MVs em tempo de execução. O agente computacional decide o quanto cada MV terá de capacidade de acordo com histórico anterior. O mecanismo de aprendizagem permite que cada MV aprenda sua política de gestão de capacidade de acordo com feedbacks enviados pelo nó do agente de aprendizagem e aumente ou decremente seus recursos automaticamente.

As organizações por todo mundo vêem a Computação em Nuvem como uma tendência transformadora de ter sua infraestrutura computacional distribuída e compartilhada, principalmente devido aos cortes de custo com mão de obra em TI e atualização/manutenção de software e hardware (DEXTRA, 2010) (AMAZON, 2010) (ARMBRUST et. al., 2009) (CARVALHO, 2010). Um dos grandes contratempos dos fornecedores de infraestrutura como serviço é a comunicação entre os departamentos financeiro e de TI. Enquanto o primeiro deseja reduzir custo e obter um retorno de investimentos, o segundo por sua vez, está sempre considerando investimentos em novas tecnologias, que nem sempre possuem valores acessíveis e fáceis de se encaixarem no orçamento de qualquer empresa. Em muitos casos, é crítico para o departamento de TI que está considerando a adoção da nuvem mostrar para o departamento financeiro que há possibilidade de obter retorno sobre o investimento realizado para os negócios da empresa.

Skilton (SKILTON, 2010) apresenta o ROI (Return on Investment ou retorno sobre o investimento), onde os fornecedores de serviço em nuvem podem analisar e desenvolver planos de negócios e implantar uma infraestrutura de serviços de forma mais rápida e pró-ativa. Em seus estudos Skilton apresenta uma série de considerações sobre possíveis formas de se construir uma infraestrutura em nuvem e mensurar o ROI, que é colocado como parte do processo de planejamento para a 
implementação de uma nuvem. Com isso, as empresas começarão a tirar vantagens sobre a Computação em Nuvem.

O ROI aplicado na Computação em Nuvem trará vantagens para os fornecedores e clientes de serviços em nuvens, pois ambos terão controle do quanto foi investido na infraestrutura e quanto está sendo o retorno. Com esta metodologia, ambos os lados saberão se o investimento está sendo satisfatório, se é necessário e possível financeiramente aumentar recursos, ou se não está tendo um retorno favorável e sendo assim haverá a necessidade de diminuir os recursos computacionais disponíveis.

Sousa (Sousa et. al., 2010) apresentam três principais desafios para desenvolver um ambiente em nuvem totalmente autônoma:

Desenvolvimento de um sistema autônomo para nuvens: de acordo com os autores, um sistema autônomo para nuvem deve monitorar o comportamento e desempenho do ambiente virtualizado, sendo capaz de tratar questões de tolerância a falhas, reconfiguração automática de software promovendo a elasticidade e o balanceamento da carga de trabalho através da modelagem de previsão de carga futura.

Políticas para computação em nuvem: os autores apresentam como principal desafio conceber políticas de alto nível que capturem tanto aspectos técnicos como os objetivos do negócio, pois consideram que as políticas devem representar as propriedades dos sistemas autônomos e o comportamento, objetivos, adaptação e interação entre eles, assim como relação entre a influência externa (usuário) e a demanda do sistema.

Monitoramento de ambientes em nuvem: para os autores, a principal questão é como gerenciar de forma automática os recursos disponíveis e a carga de trabalho do sistema para garantir a qualidade do serviço e melhorar a utilização destes recursos. Técnicas de monitoramento adaptativas e dinâmicas deverão ser desenvolvidas para tratar esta questão.

A Tabela 1 exibe alguns trabalhos relacionados citados anteriormente e o que cada um contempla. As lacunas não preenchidas na maior parte dos trabalhos foram contempladas no decorrer desta pesquisa.

Os trabalhos citados anteriormente foram aqui colocados por possuírem os principais aspectos da pesquisa realizada. Outros trabalhos foram estudados e os seus resultados permitiram evoluir no decorrer do desenvolvimento dos módulos do projeto como em (Jarraya, 2012) que disserta sobre segurança em ambiente na nuvem, principalmente por inconsistências que possam surgir no momento de uma reconfiguração da infraestrutura ou migração de máquinas. 
Apesar de não ser o objetivo deste trabalho, a segurança permite garantir que, após ser reconfigurada ou migrada, a máquina continue a fornecer serviços. (Jarraya, 2012) em sua pesquisa especificou métricas para uma reconfiguração ou migração de máquinas segura.

Tabela 1 - Trabalhos Relacionados

\begin{tabular}{|c|c|c|c|c|c|c|c|c|c|}
\hline & $\mathbf{1}$ & $\mathbf{2}$ & $\mathbf{3}$ & $\mathbf{4}$ & $\mathbf{5}$ & $\mathbf{6}$ & $\mathbf{7}$ & $\mathbf{8}$ & $\mathbf{9}$ \\
\hline (TIRADO, et al., 2011) & $\mathrm{X}$ & & $\mathrm{X}$ & & $\mathrm{X}$ & & & & \\
\hline (DAWOUD, et. al., 2011) & & $\mathrm{X}$ & & $\mathrm{X}$ & & & & & \\
\hline (RAO, et al., 2011) & & $\mathrm{X}$ & & & & $\mathrm{X}$ & $\mathrm{X}$ & & \\
\hline (SKILTON, 2010) & & & & & & $\mathrm{X}$ & & & $\mathrm{X}$ \\
\hline Projeto & $\mathrm{X}$ & $\mathrm{X}$ & $\mathrm{X}$ & $\mathrm{X}$ & $\mathrm{X}$ & $\mathrm{X}$ & $\mathrm{X}$ & $\mathrm{X}$ & $\mathrm{X}$ \\
\hline
\end{tabular}

(1) Previsão de demanda, (2) Elasticidade em tempo de execução, (3) Aplicação web, (4) Monitor, (5) Sazonalidade e tendência, (6) IaaS, (7) Computação Autônoma, (8) Agentes Computacionais, (9) Controle orçamentário.

\subsection{Organização da Monografia}

Esta monografia de mestrado está dividida da seguinte forma:

O Capítulo 2 trata do conceito de computação em nuvem que é um assunto altamente difundido e fonte de várias pesquisas em academias e organizações por todo mundo.

O Capítulo 3 engloba questões fundamentais e diretas sobre computação autônoma, apresentando os agentes computacionais que no projeto, dentre outras finalidades, serão responsáveis por monitorar máquinas virtuais. Cabe ao framework Jade oferecer um ambiente propício para o trabalho com multiagentes. Tal framework também será tratado no mesmo capítulo.

O Capítulo 4 apresenta brevemente considerações a respeito de pontos fundamentais da previsão da demanda como o agrupamento de dados formando séries temporais, as possíveis sazonalidades e tendências encontradas nessas séries e, por fim, uma explicação sobre previsão de demanda.

O Capítulo 5 tem como conteúdo principal o Retorno Sobre Investimento dentro do conceito de Controle Financeiro.

O Capítulo 6 dissetará a respeito do projeto, toda a sua estrutura e seus módulos.

No Capítulo 7 está contida a metodologia e algumas ferramentas que são utilizadas.

O Capítulo 8 apresenta os resultados dos experimentos e avaliação dos dados obtidos. 
Por fim, é apresentada a conclusão sobre o projeto como um todo, as contribuições alcançadas e sugestões para trabalhos futuros. 


\section{Computação em nuvem}

\subsection{Considerações iniciais}

A Computação em Nuvem surgiu a partir da necessidade das organizações de construir uma infraestrutura computacional complexa, deixando a cargo de terceiros o controle de toda arquitetura computacional, utilizando plataformas computacionais em nuvem contratada como serviços, permitindo uma utilização transparente de todo recurso computacional.

Nas empresas, computadores simples de baixa capacidade podem ser utilizados para se conectarem a uma máquina virtual na nuvem e utilizarem o serviço contratado. No fornecedor do serviço concentra-se todo o controle como backups, manutenção e controles de acesso. Assim, os usuários e as empresas passaram a acessar os serviços sob demanda e independente de localização, o que aumenta a quantidade de serviços disponíveis.

Com a Computação em Nuvem, todas as questões relacionadas a hardware, backup, segurança, entre outros fatores são de responsabilidade do provedor do serviço. $\mathrm{O}$ usuário pode adquirir recursos computacionais de acordo com suas necessidades (sob demanda), bastando apenas entrar em contato com o provedor.

Considerando ainda a proposta de Computação em Nuvem, a organização não precisará se preocupar com perda de dados ou indisponibilidade, pois se houver falha em qualquer componente na estrutura computacional em nuvem, o provedor do serviço é responsável por substituí-lo e tornar os dados disponíveis em tempo hábil (BRANTNER, 2008).

\subsection{Conceitos}

A Computação em Nuvem é dividida em vários conceitos diferentes, cada uma caracterizando formas diferentes de se aplicar e utilizar este conceito. As três principais tipologias são:

- SaaS (Software como um Serviço) - Softwares de propósitos específicos são disponibilizados na Internet. Como os softwares (aplicações) estão na Web, o usuário pode acessá-los a partir de qualquer lugar e a qualquer momento, permitindo maior integração entre unidades de 
empresas ou de serviços. Como exemplo cita-se o Google Docs, oferecendo softwares como editores de texto e planilhas eletrônicas (CIURANA, 2009);

- PaaS (Plataforma como um Serviço) - Oferece uma plataforma para desenvolvimento e teste de aplicações na nuvem. Como exemplo cita-se o Google App Engine (CIURANA, 2009).

- IaaS (Infraestrutura como um Serviço) - Neste tipo de nuvem, toda infraestrutura de hardware primária como processamento, memória e armazenamento é oferecida aos utilizadores como um serviço virtual sob demanda (RAO, BU, et al., 2011). Com isso é permitida a utilização de boas soluções de tecnologia sem a necessidade de investimentos por parte do cliente, em computadores de alta qualidade e sem se preocupar com o hardware que possui (PINHEIRO, 2010). O foco deste trabalho de mestrado está centrado nesse tipo de nuvem.

\subsection{Elasticidade em nuvem}

O ambiente computacional local possui diversas desvantagens, entre elas em relação ao dimensionamento de recursos computacionais. Se uma organização em determinado período do mês precisar, por exemplo, de mais recursos de disco no seu servidor, ela terá que adquirir um novo dispositivo de disco com maior capacidade.

Para manter os recursos computacionais funcionando com o esperado, os administradores devem prover recursos adequados que acompanhem as flutuações da demanda de carga de trabalho exigida. O excesso de recurso computacional (por exemplo, muito disco ou muita memória) implica que em algum momento ele ficará ocioso, pois será muito recurso para pouca demanda, gerando prejuízo de investimento na arquitetura computacional. Por outro lado, recursos computacionais limitados deixam a arquitetura computacional mais lenta, gerando a insatisfação do cliente (DAWOUD, TAKOUNA e MEINEL, 2011).

A correta utilização dos recursos oferecidos em uma infraestrutura computacional é um dos principais fatores por trás do êxito da implantação da Computação em Nuvem Elástica. Uma infraestrutura mal gerenciada pode levar a custos enormes, o que seria ainda maior que o custo da implantação física (KHATUA, 2010).

A atualização de hardware implica em excesso de recursos, conforme apresentado na Figura 1. Porém, em algum momento o hardware atual não será capaz de lidar com a demanda real o que resulta em degradação e necessidade de nova atualização para acompanhar a demanda. 


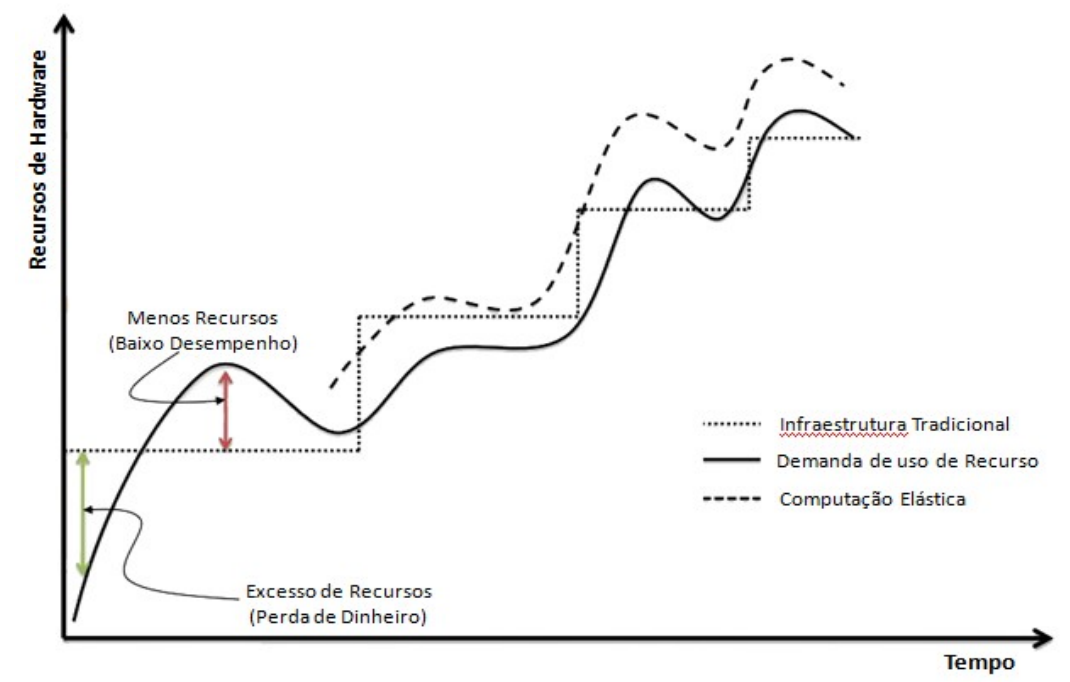

Figura 1 - Análise de uso de recurso computacional

Fonte: Adaptado de (DAWOUD, TAKOUNA e MEINEL, 2011)

Conforme se observa na Figura 1, a infraestrutura tradicional não acompanha o avanço da demanda por recurso computacional, ocasionando em alguns momentos de baixo desempenho (pouco recurso) e em outros acarretando ociosidade e perda de investimento (muito recurso para pouca demanda).

A computação elástica em nuvem acompanha através de monitoramento por agentes computacionais toda a demanda requerida em um dado momento, sempre com o propósito de oferecer uma infraestrutura ágil, escalável e dinâmica, sem a interferência humana diretamente.

A elasticidade da Computação em Nuvem possui aspectos distintos quando vista pelo consumidor e pelo provedor de serviço. O usuário (consumidor) está interessado apenas em ter um ambiente funcional, sem se preocupar com as tecnologias empregadas. Já o provedor tem todo o foco e atenção voltada para a operação dos algoritmos que fazem a elasticidade acontecer (IBM, 2009).

O fornecimento de recurso computacional adequado é estudado por vários autores. Khatua (KHATUA, 2009) propõe duma previsão de carga de trabalho em uma infraestrutura computacional onde há incerteza da demanda. Mattess (MATTESS, 2010) propõe um algoritmo heurístico para acomodar demandas pontuais, permitindo que uma infraestrutura estática seja dimensionada para lidar com um aumento de carga.

A elasticidade neste trabalho é tratada do ponto de vista do provedor de serviços, através do fornecimento de recursos sob incerteza da demanda computacional requerida pelo usuário, o qual será 
também beneficiado por ter, de forma transparente, uma infraestrutura adaptada a demanda requerida e também uma economia financeira, pois pagará apenas pelos recursos utilizados.

\subsection{Considerações finais}

Com a disseminação do conceito de Computação em Nuvem, o ambiente computacional como um todo evoluiu para fora da empresa, não sendo mais necessário que a mesma possua um servidor e diversas máquinas de alto desempenho dentro do ambiente de trabalho. Basta que a empresa contrate um provedor de serviços de Computação em Nuvem que ofereça, como caso deste projeto, a infraestrutura de hardware como serviço.

Para alguns usuários, a computação em nuvem soa como uma fonte inesgotável e com disponibilidade infinita de recursos computacionais, porém em seu estado original ela possui um limite físico de hardware em um dado momento. Este projeto visa aumentar os recursos em tempo de execução para que o cliente utilize seu serviço contratado sem muitos problemas de falta de recursos (por exemplo, lentidão de processamento) por meio da monitoração e aplicação da elasticidade, que será realizada pelos agentes computacionais dentro do conceito de computação autônoma conforme consta no capítulo 3. 


\section{Computação autônoma}

\subsection{Considerações iniciais}

Sistemas computacionais enfrentam um rápido crescimento de tamanho e complexidade. Em 2001 a IBM (CORRÊA, 2008) publicou um manifesto onde destacava que com o passar dos tempos os sistemas tenderiam a ficar cada vez mais complexos, ocasionando dificuldade para se trabalhar com esses softwares (instalação, configuração, otimização e manutenção) devido à inevitável falta de capacidade humana para os gerenciarem (CORRÊA, 2008). Para tratar esse tipo de problema, foi proposto (pela própria IBM) o conceito de Computação Autônoma, que abrange sistemas capazes de se autogerenciarem dado um conjunto abstrato de objetivos definidos pelo administrador. O termo faz conotação com o sistema nervoso biológico, que é responsável pelo controle de funções vitais e, por ser autônomo, é capaz de adaptar o corpo humano às suas necessidades e às necessidades geradas pelo ambiente.

Em 2001 o problema visto pela IBM era a falta de profissionais qualificados no ambiente de TI e a possível saturação da capacidade técnica em vista ao grande avanço tecnológico. No fim da mesma década em 2010, algumas estatísticas do trabalho nos Estados Unidos (Bureau of Labor Statistics) sugeriram que havia cerca de 260.000 trabalhadores na área de TI no país, contudo esse número estaria em constante e leve declínio (DOBSON, 2010). Nos primeiros anos desta década a falta de profissionais na área de TI ainda persiste. Atualmente no Brasil é possível encontrar vagas de emprego na área de TI com salários próximos ou iguais aos dos Estados Unidos, porém o problema da falta de profissionais especializados e constantemente atualizados permanece em todo mundo uma década após o manifesto da IBM (ANGELO, 2011). Portanto, uma alternativa é aliar o conceito de Computação em Nuvem e de Computação Autônoma a fim de combater a escassez de profissionais na área de TI.

\subsection{Definição}

A Computação Autônoma provê mecanismos para se autogerenciar sem a necessidade de intervenções externas. Ressalta-se que autogerência não é desempenhada involuntariamente (diferentemente do corpo humano que se adapta involuntariamente aos estímulos frente a alguma necessidade). $\mathrm{O}$ autogerenciamento ocorre através de tarefas delegadas aos sistemas pelo 
administrador, de acordo com políticas adaptativas que determinam o tipo de ação a ser executada em diferentes situações (CORRÊA, 2008).

O sistema autônomo resume-se nas propriedades gerais apontadas pela IBM como necessárias para que um sistema computacional complexo alcance o objetivo de autogerenciamento. Para atingir tal objetivo, é necessário cumprir os quatro requisitos essenciais (CORRÊA, 2008):

Autoconfiguração: propriedade de o sistema ajustar-se automaticamente a novas circunstâncias percebidas durante seu próprio funcionamento de acordo com políticas pré-definidas ou com o apoio de processos de Autocura, Auto-Otimização ou Autoproteção. Esta propriedade será a única pesquisada e utilizada dentro do escopo deste projeto.

Autocura: propriedade de o sistema ser capaz de detectar, diagnosticar e recuperar-se de falhas automaticamente;

Auto-Otimização: propriedade do sistema que o torna capaz de monitorar e ajustar automaticamente seus recursos computacionais satisfazendo a demanda do usuário.

Autoproteção: propriedade de o sistema ser capaz de identificar e defender-se de ataques acidentais ou maliciosos.

O objetivo da computação autônoma não é retirar o papel representado pelo homem, mas sim, automatizar processos repetitivos e também se preparar para casos inesperados como um ataque ao sistema.

\subsection{Agentes computacionais}

Para que o ambiente computacional se caracterize como autônomo, são utilizados agentes computacionais. Há diversas definições sobre agentes, onde cada autor define de acordo com suas aplicações desenvolvidas e suas linhas de pesquisa. Segundo Jennings (BIGUS, 2002) um agente é um sistema computacional capaz de agir com autonomia flexível visando a atingir os objetivos para os quais foi projetado.

A programação de sistemas multiagentes é uma técnica de desenvolvimento de sistemas distribuídos, e neste contexto há questões de como distribuir as várias partes de um sistema, como realizar a comunicação entre elas e principalmente, como administrá-las.

Os agentes são entidades de software persistentes, atômico, com comportamento autônomo, capazes de realizar a percepção do ambiente, adaptáveis a mudanças, com capacidade de assumir metas e desenvolvidos para serem dedicados a um propósito específico (COPPIETERS, 2005). 


\subsection{Considerações finais}

Neste projeto as ações dos agentes são: monitorar a utilização dos recursos de cada máquina virtual (agente monitor); efetuar o processo de elasticidade da infraestrutura de acordo com as políticas (agente elástico); realizar previsão (agente previsor).

A comunicação entre agentes é o que garante ao sistema ser considerado como autônomo pois atividades desenvolvidas pelo homem e passíveis de serem desempenhadas por esses agentes, serão aplicadas com o objetivo de garantir a autonomia do sistema, garantindo principalmente o autoconfiguração. Para a comunicação e interação entre agentes será utilizado o framework Jade. 


\section{Previsão de Demanda}

\subsection{Considerações iniciais}

Para se realizar uma previsão, primeiramente é necessário que os valores observados se encontrem dispostos na forma seqüencial e ordenados cronologicamente, formando um conjunto denominado série temporal. Este capítulo apresenta conceitos relacionados a séries temporais bem como implicações como sazonalidade e tendência que podem ou não serem encontradas nessas séries. As principais questões deste capítulo são: “existem técnicas de previsão específica para cada tipo de série?" e “como é o comportamento destas técnicas?". Buscou-se na literatura respostas para estas e outras questões.

\subsection{Séries temporais}

De acordo com (Latorre, 2001) série temporal é um conjunto de observações realizadas de forma seqüencial ao longo de um período definido, tendo como principal característica a dependência entre os dados vizinhos. Essa dependência é o foco principal da análise e modelagem da série de dados onde a ordem das observações é relevante e crucial.

Ehlers (Ehlers, 2012) menciona como principal característica das séries temporais a importância da ordem cronológica das observações, uma vez que observações vizinhas são dependentes uma das outras, diferentemente de modelos de regressão onde a ordem cronológica não importa.

Dados provindos de séries temporais surgem de diversos campos do conhecimento como economia (bolsa de valores), indústria (controle de processo de produção), meteorologia (temperatura diária), entre outros.

\subsection{Sazonalidade e Tendência}

Algumas séries temporais assumem um comportamento que tende a repetir a cada intervalo $t$ do tempo o que se denomina sazonalidade (Latorre, 2001). Por exemplo, o site de gerenciamento acadêmico de uma faculdade tende a ter maior pico de acesso em períodos de fim de semestre como Julho e Dezembro, momentos estes onde os professores lançam as notas e os alunos podem visualizálas. Em Agosto e Janeiro, certamente o número de acesso é reduzido, visto que estes períodos são 
subsequentes às férias. Assim, pode-se observar um padrão que tende a se repetir por longos anos, exceto haja alguma alteração na divulgação de notas ou no ano letivo.

Não existe uma definição concreta sobre o que é tendência. Ehlers (Ehlers, 2012) diz que tendência é a característica global que uma série pode possuir de crescimento ou diminuição com possíveis padrões.

A série temporal pode assumir crescimento ou diminuição linear ou exponencial. No exemplo do site de gerenciamento acadêmico, considere que a cada semestre seja esperado um aumento, por exemplo, de 300 novos acessos ao site da instituição. Este é um crescimento linear. Por outro lado, a instituição estima que a cada ano o aumento do número de acesso terá, por exemplo, um fator 2,2 sobre o valor total de acessos do ano anterior. Este será um crescimento exponencial. Ambos são exemplos de tendências, seja por crescimento linear ou exponencial.

\subsection{Previsão}

A previsão da demanda é a base para o planejamento estratégico da produção, vendas, finanças, entre outros. Permite que administradores desses sistemas antevejam o futuro e planejem adequadamente suas ações. Conforme (Marins, 2012), existem cinco etapas para se elaborar um modelo de previsão:

- Objetivo do Modelo: Definir a razão pela qual se necessita realizar a previsão;

- Coleta e Análise de Dados: Identificar e desenvolver a técnica de previsão que melhor se adapte. Quanto mais dados históricos forem coletados e analisados, mais confiável será a técnica de previsão e o resultado obtido;

- Seleção da técnica de previsão: técnicas qualitativas privilegiam principalmente dados subjetivos, os quais são difíceis de representar numericamente e são provindos de opiniões e palpites pessoais. Técnicas quantitativas envolvem análise numérica dos dados passados, sem relação de opiniões ou palpites pessoais. Como exemplos de técnicas quantitativas estão as séries temporais;

- Obtenção das previsões: com o uso das técnicas de previsões sob os dados passados das séries temporais, se obtêm as projeções futuras da demanda.

- Monitoração do modelo: consiste em acompanhar e analisar o comportamento dos dados previstos frente aos dados observados. Espera-se que a técnica de previsão gere valores acima e abaixo dos reais observado. O erro acumulado deve ser comparado com um múltiplo do desvio médio absoluto por meio da fórmula: 


$$
\text { DMA }=\left(\sum\left|\mathrm{D}_{\text {observado }}-\mathrm{D}_{\text {previsto }}\right|\right) / \mathrm{n}
$$

Onde: n é o conjunto total de observações e DMA é o Desvio Médio Absoluto.

Algumas áreas do conhecimento usam as séries temporais com o objetivo de fazer previsões de valores futuros, porém a presença de tendências e variação sazonal são considerados fatores complicadores e podem ser difíceis de estimar ou remover.

As cinco etapas listadas estão presentes no Capítulo 5 referente à proposta do projeto.

Como existem objetivos diversos, cada conjunto de observações que formam uma série temporal requer o uso de técnicas específicas, seja para previsão com ou sem tendência e/ou sazonalidade, ou apenas para confrontar duas séries distintas (Ehlers, 2012).

\subsection{Considerações finais}

Prever futuras oscilações e comportamentos sazonais é fundamental para o correto funcionamento do sistema dentro do objetivo proposto. O sistema é capaz de prever a demanda futura de um dado cliente e ajustar a infraestrutura computacional de acordo com a previsão. Com isso, o cliente já inicia suas atividades com o minimo necessário para que o trabalho seja executado sem interpéries e contratempos. 


\section{Controle Financeiro}

\subsection{Considerações iniciais}

O Controle Financeiro é uma metodologia empregada para que o cliente que contratou o serviço na nuvem tenha conhecimento do quanto está gastando do valor investido. O retorno sobre o investimento ou ROI (Return on Investiment) é uma das alternativas para o controle financeiro, pois permite ao cliente conhecer o quanto está gastando, evitando gastos desnecessários.

\subsection{Retorno Sobre o Investimento}

No escopo deste trabalho de mestrado, o ROI trata a relação entre o valor financeiro que o cliente contratou do serviço de IaaS e o quanto ele está utilizando deste valor. A cada período é contabilizado a taxa do valor gasto em Unidades Monetárias.

De acordo com (Linthicum, 2013), os cálculos de ROI da computação em nuvem da maioria dos servidores de IaaS, são "simplificações drásticas dos problemas que a nuvem pode resolver" e acaba por "enganar as informações financeiras tanto para a TI quanto para as unidades de negócio ".

Neste projeto, são propostas duas fases para a obtenção do ROI. A primeira fase para o cálculo do ROI deve começar antes de adquirir o serviço na nuvem, momento oportuno para as empresas conhecerem todos os gastos envolvidos desde a implantação dos serviços em nuvem (envio dos dados, treinamento) até o final do contrato (ISACA, 2013). Essa primeira fase é feita antes da implantação e se deve conhecer alguns custos que são ocultos como, por exemplo, despesas inesperadas envolvendo a migração inicial dos sistemas para a nuvem e questões relacionadas com o fim do contrato do serviço e a necessidade de trazer de volta para a empresa os dados que estavam na nuvem, bem como converte-los, segundo o relatório da Information Systems Audit and Control Association (ISACA) (ISACA, 2013).

Ao conhecer os gastos ocultos citados, a empresa estará apta a tomar a decisão de contratar ou não os serviços de computação em nuvem. Em alguns casos, os gastos ocultos podem ser maiores se comparados com a implantação local de um departamento de tecnologia de informação na empresa. Se a empresa adotar a computação em nuvem, o ROI será calculado de acordo com a elasticidade da arquitetura, mediante a uma tarifa por transferência de Megabytes (MB). 
A elasticidade da arquitetura proposta permite que a infraestrutura se reconfigure de acordo com as necessidades do cliente que terá sempre a configuração necessária dos recursos de Disco, CPU e Memória.

A segunda fase proposta neste trabalho de mestrado para o cálculo do ROI é considerar as diferentes necessidades dos clientes através da aplicação da elasticidade computacional. Desta forma, a taxa cobrada não será por hora de uso, mas sim, pela carga de trabalho utilizada por dia, sendo mais justo com o cliente que só pagará o que usar e no dia em que usar, fornecendo melhor resultado para o ROI.

O ROI é dividido em duas categorias: o tempo que levará (quantos períodos levarão) para o cliente obter o retorno do investimento e o quanto o cliente possui disponível do valor investido no período atual recebendo o retorno do investimento.

Como exemplo dos resultados obtidos em um dos experimentos, no segundo período foi gasto $8,2 \%$ do valor investido e, se continuar nesta tendência, em 12,1 períodos o cliente terá utilizado, sem disperdicio, os $15 \mathrm{mil}$ UM investidos inicialmente. Assim se segue. No $15^{\circ}$ período o cliente terá gasto $53,5 \%$ do valor efetivo total, ou seja, tudo aquilo que foi gasto, entre elevações e quedas da carga de trabalho. Porém, não foi gasto tudo, pois precisaria de mais 1,6 períodos para que fosse possível utilizar todos os $20 \mathrm{mil} \mathrm{UM}$.

\subsection{Considerações finais}

Dentro do projeto são utilizados dois termos "Investimento" e "Rentabilidade". Trata-se de investimento, pois, o cliente contratou um serviço na nuvem para ter um resultado melhor do que a infraestrutura inloco, com o objetivo de se ter menos prejuízo possível em todas as esferas. Rentabilidade é o retorno esperado de um investimento descontando custos, tarifas e inflação. No projeto, espera-se que o valor investido seja utilizado em $100 \%$ dentro do período definido. 


\section{METODOLOGIA}

\subsection{Considerações iniciais}

Neste capítulo está contida a descrição do desenvolvimento do projeto proposto, bem como as ferramentas utilizadas para monitorar o sistema. O projeto tem como principal linguagem de programação a Java, e possui como ferramenta de auxílio o framework Jade que trabalha diretamente com sistemas multiagentes e bibliotecas nativas do Linux.

\subsection{Desenvolvimento - Levantamento Bibliográfico}

O primeiro estágio de desenvolvimento foi realizar o levantamento bibliográfico e o estado da arte a fim de estudar e analisar as arquiteturas que possibilitam a elasticidade sem intervenção humana em uma infraestrutura virtualizada, sendo a mesma capaz de se reconfigurar, promovendo a alocação dinâmica de recursos. Após este estudo inicial, deu-se início a modelagem e desenvolvimento do sistema proposto. Também nessa primeira fase, constou o estudo de modelos de previsão de carga para o desenvolvimento de políticas a serem aplicadas no projeto.

Foram desenvolvidos três algoritmos que são responsáveis pela alocação de recursos, os dois primeiros serão baseados em Média Móvel Exponencial e Modelo de Holt-Winter e o terceiro baseado em Monitoração constante da demanda computacional.

Para que seja possível monitorar e executar o autogerenciamento da infraestrutura virtualizada, foi necessário o desenvolvimento de elementos autônomos que compõe o sistema. Alguns pesquisadores apontam o uso de agentes computacionais como sendo esses elementos autônomos (Stathis, 2010) (Brazier, 2009) (Caprarescu, 2009). Eles gerenciam a si próprios a obter informações dos seus sensores de acordo com as políticas e acordos estabelecidos com outro elemento autônomo. Essa proposta foi mantida neste projeto desde o início e os elementos autônomos são representados por agentes computacionais. Esses agentes contam com recursos e ferramentas para realizar a monitoração. A extração de dados foi realizada pelos sensores dos agentes e os dados são utilizados em tempo de execução para promover uma arquitetura dinâmica. Segue alguns exemplos de funções/aplicativos que podem ser utilizados como ferramentas para coleta de dados no Linux: 
- cpufreq-selector: permite ajustar a freqüência do processador via sistema operacional. pode ser alterada para uma frequência pré-estabelecida (--governor= "powersave", "performance”, etc) ou para uma freqüência específica (--freq= "frequência em kHz");

- top: fornece uma visão dinâmica em tempo real de um sistema em execução. É possível coletar informações sobre a carga de CPU, Memória e Swap. Além de verificar quais processos estão sendo executados e quem os executaram, esta ferramenta permite verificar os estados dos processos (executando, parados, dormindo, zumbis);

- vmstat: exibe relatórios com estatísticas sobre threads de kernel, processos, memória, paginação, IO bloco, traps e atividade do processador.;

- virt-top: exibe a estatística de máquinas virtualizadas, sendo similar ao top do Linux em máquinas convencionais;

- virt-manager: responsável pelo gerenciamento por parte do administrador e o objetivo é minimizar o trabalho deste profissional.

Tanto o virt-top como a virt-manager utilizam a API libvirt que trabalha com os mais diversos tipos de tecnologias de virtualização (Xen, KVM, VMWare, Virtual Box, entre outras). Com essas ferramentas os agentes são capazes de monitorar e gerenciar as máquinas virtuais (ligar, desligar, reiniciar, etc).

\subsection{Desenvolvimento - Arquitetura}

\subsubsection{Apresentação}

Este projeto de mestrado está relacionado ao projeto de doutorado de Luis Hideo Vasconcelos Nakamura (Processo FAPESP $n^{\circ}$ 2011/12670-5), e que ambos os projetos se complementam, sendo este projeto mais atuante na parte de autoconfiguração de arquiteturas virtualizadas.

A figura 2 apresenta a arquitetura composta pelo projeto de doutorado e de mestrado. O conteúdo envolvido pela linha tracejada preta é a parte que cabe ao projeto de mestrado e o restante envolvido em vermelho é incubido ao projeto de doutorado.

O projeto de mestrado tem a finalidade de gerenciar a infraestrutura por meio da reconfiguração dos recursos das máquinas virtuais. O projeto de doutorado utilizará de regras para tomadas de decisão por meio do emprego da ontologia, propondo assim qualidade no serviço prestado. 
A figura 3 apresenta a arquitetura do projeto de mestrado com os módulos que o compõe. Cada módulo será explicado neste capítulo.

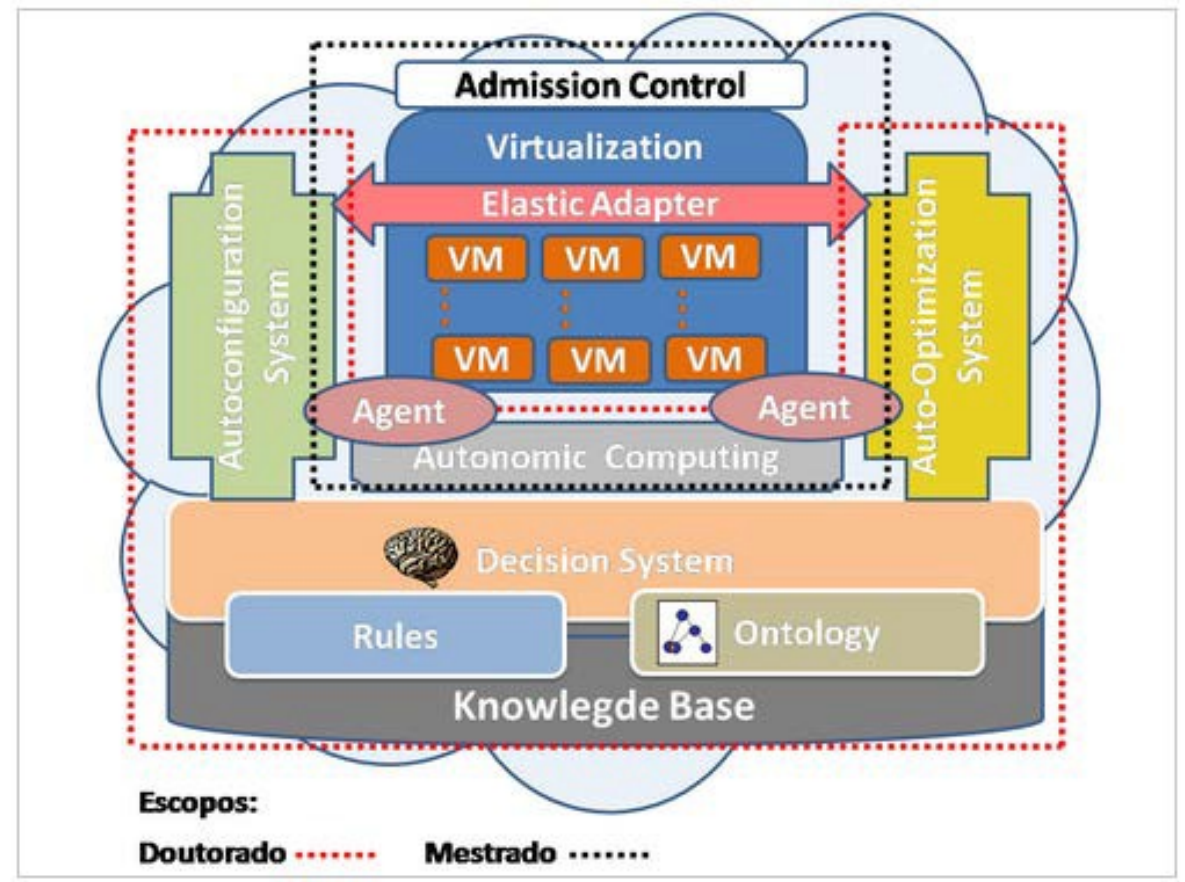

Figura 2 - Escopo da arquitetura principal envolvendo projeto de mestrado e doutorado.

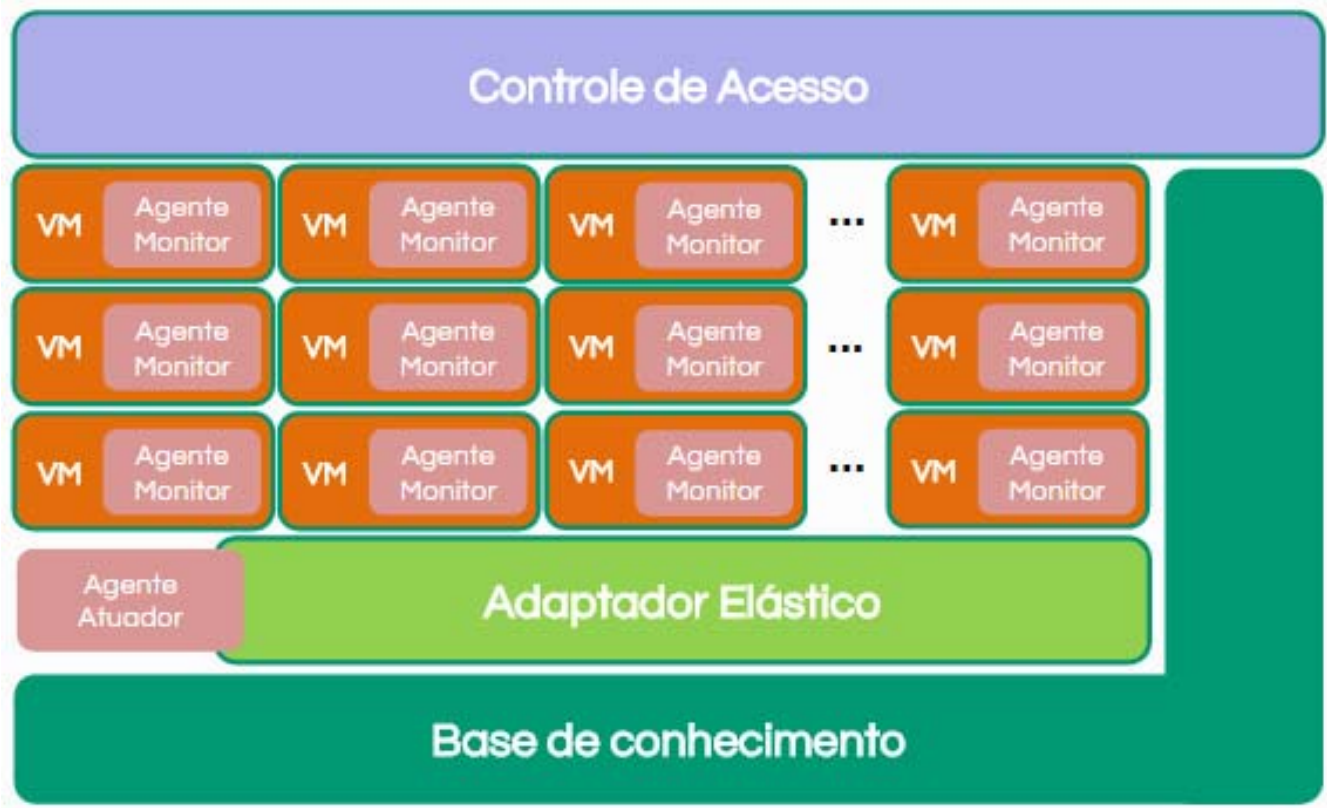

Figura 3 - Escopo da arquitetura do projeto de mestrado. 


\subsubsection{Controle de admissão}

Módulo responsável por receber as requisições dos usuários e liberar ou não seu acesso à máquina virtual. A figura 4 é o diagrama de sequencia do módulo de controle de admissão.

- Verificar se existe máquina virtual disponível para ser utilizada pelo cliente;

o Se houver, o controle de admissão consulta o módulo de políticas orçamentárias, e caso o saldo do cliente esteja positivo, libera o acesso do cliente para a máquina virtual. Em seguida ele registra a informação da nova requisição em uma base de conhecimento (a qual será utilizada para a verificação de históricos).

o Se houver máquina virtual disponível, mas o crédito estiver baixo, o cliente será informado sobre isso através de um relatório; se não houver mais crédito, a requisição do cliente será negada;

o Se não houver máquina virtual disponível, isso significa que a infraestrutura física chegou ao seu limite e o controle de admissão deve então bloquear o acesso por um curto intervalo de tempo até que haja recursos disponíveis. Nesse caso, um relatório informando a indisponibilidade será encaminhado ao administrador da infraestrutura.

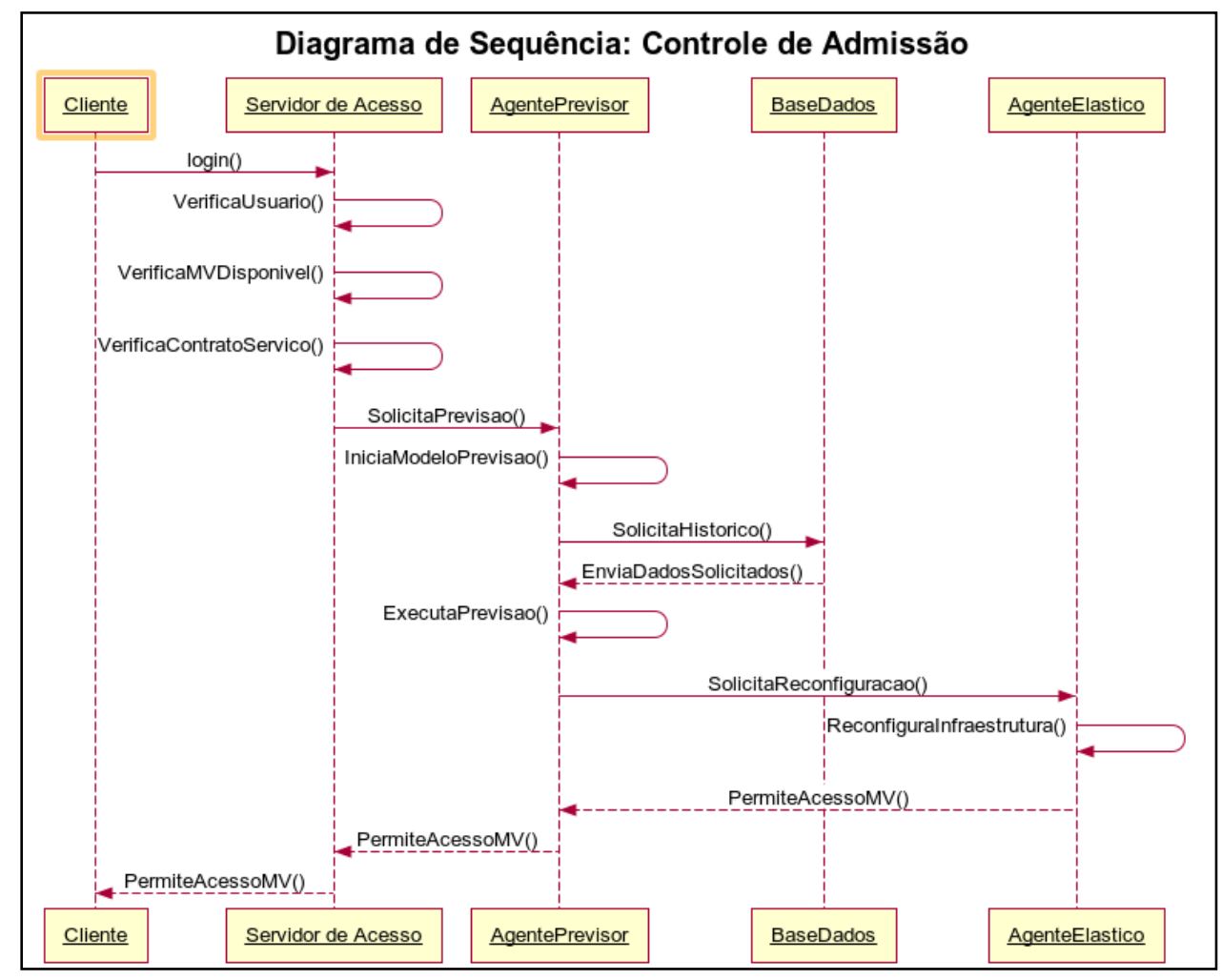

Figura 4 - Diagrama de Sequência: Controle de Admissão 


\subsubsection{Políticas de previsão de carga}

Este módulo tem como finalidade gerar uma previsão de curto a longo prazo da possível demanda a ser requisitada.

São duas técnicas a serem utilizadas: média móvel exponencial (MME) e modelo de HoltWinter que aqui será tratado como MHW .

A MME elimina grandes oscilações de valores, filtrando apenas o movimento principal através da utilização da média móvel simples (Corrar e Teóphilo, 2004). A MME foi escolhida por dar mais ênfase aos valores mais recentes, dando pesos maiores para esses valores e menores para valores mais antigos, que serão esquecidos mais rapidamente, possibilitando que o valor observado esteja mais próximo do resultado previsto anteriormente.

A fórmula para este cálculo é dada por:

§IIII Média Móvel Exponencial: $\mathrm{MME}_{\mathrm{x}}=\mathrm{ME}_{(\mathrm{x}-1)}+\mathrm{K}_{\mathrm{x}}\left\{\mathrm{Fech}_{(\mathrm{x})}-\mathrm{ME}_{(\mathrm{x}-1)}\right\}$

Onde:

$\mathrm{MME}_{\mathrm{x}}$ representa a média móvel exponencial no dia x;

$\mathrm{ME}_{(\mathrm{x}-1)}$ representa a média móvel exponencial no dia $\mathrm{x}-1$;

Constante $\mathrm{K}=\{2 /(\mathrm{N}+1)\}$;

$\mathrm{N}$ é o número de dias para os quais se quer o cálculo;

Fech = é o fechamento atual ou valor atual;

O modelo de Holt-Winter possui um comportamento diferente da MME e é explicado na literatura como um método destinado ao tratamento de demandas como séries temporais que apresentam tendências e sazonalidade (Corrar e Teóphilo, 2004). Segundo Lewis (Lewis, 1997), a demanda que é baseada pela tendência e sazonalidade é composta dos elementos:

"IIII' Nível: é estacionário sem tendência e sazonalidade, mas pode possuir alguma variação aleatória;

"'III' Tendência: é adicionado ao elemento de nível;

"IIII' Sazonalidade: é adicionado aos elementos de nível e tendência.

Para calcular a previsão, Makridakis (Makridakis et al., 1998) apresenta as seguintes fórmulas:

"IIII' Nível: $\mathrm{L}_{\mathrm{t}}=\alpha\left(\mathrm{Y}_{\mathrm{t}} / \mathrm{S}_{\mathrm{t}-\mathrm{s}}\right)+(1-\alpha)\left(\mathrm{L}_{\mathrm{t}-1}+\mathrm{b}_{\mathrm{t}-1}\right)(2.1)$ 
"IIII' Tendência: $b_{t}=\beta\left(L_{t}-L_{t-1}\right)+(1-\beta)\left(b_{t-1}\right)(2.2)$

"IIIII Sazonalidade: $\mathrm{S}_{\mathrm{t}}=\gamma\left(\mathrm{Y}_{\mathrm{t}} / \mathrm{L}_{\mathrm{t}}\right)+(1-\gamma)\left(\mathrm{S}_{\mathrm{t}-\mathrm{s}}\right)(2.3)$

§!III' Previsão: $\mathrm{F}_{\mathrm{t}+\mathrm{m}}=\left(\mathrm{L}_{\mathrm{t}}+\mathrm{b}_{\mathrm{t}} \mathrm{m}\right)\left(\mathrm{S}_{\mathrm{t}-\mathrm{s}+\mathrm{m}}\right)(2.4)$

Onde:

$\mathrm{L}_{\mathrm{t}}$ representa o elemento nível para o período t;

$b_{t}$ representa o elemento tendência para o período t;

$\mathrm{S}_{\mathrm{t}}$ representa o elemento sazonalidade para o período t;

$\mathrm{F}_{\mathrm{t}+\mathrm{m}}$ representa o valor da previsão para o período m;

$Y_{t}$ representa o valor observado no período t;

s é o intervalo de tempo da sazonalidade;

m é o número do período previsto;

$\alpha, \beta$ e $\gamma$ são constantes que representam respectivamente ajustes de nível, tendência e sazonalidade, com valores entre 0 e 1 . Este modelo é ideal para previsão de médio a longo prazo.

Para realizar a previsão utilizando o modelo de Holt-Winter, desenvolveu-se um algoritmo denominado HW1 em Java, utilizando arquivo XML.

O HW1 possui todos os cálculos necessários para conhecer o valor da previsão e é dividido em duas etapas. A primeira é responsável por obter o primeiro valor para nível, para a tendência e para a sazonalidade. Um exemplo, deseja-se obter uma previsão para o $6^{\circ}$ período após cinco períodos consecutivos. Neste exemplo, calcula-se o elemento nível, tendência e sazonalidade dos 5 primeiros períodos e, o resultado de cada um será utilizado para obter a previsão do $6^{\circ}$ período.

O pseudocódigo a seguir apresenta a forma de se obter esses três elementos. Essa etapa é importante pois é responsável por obter os três principais elementos que compõem a série temporal.

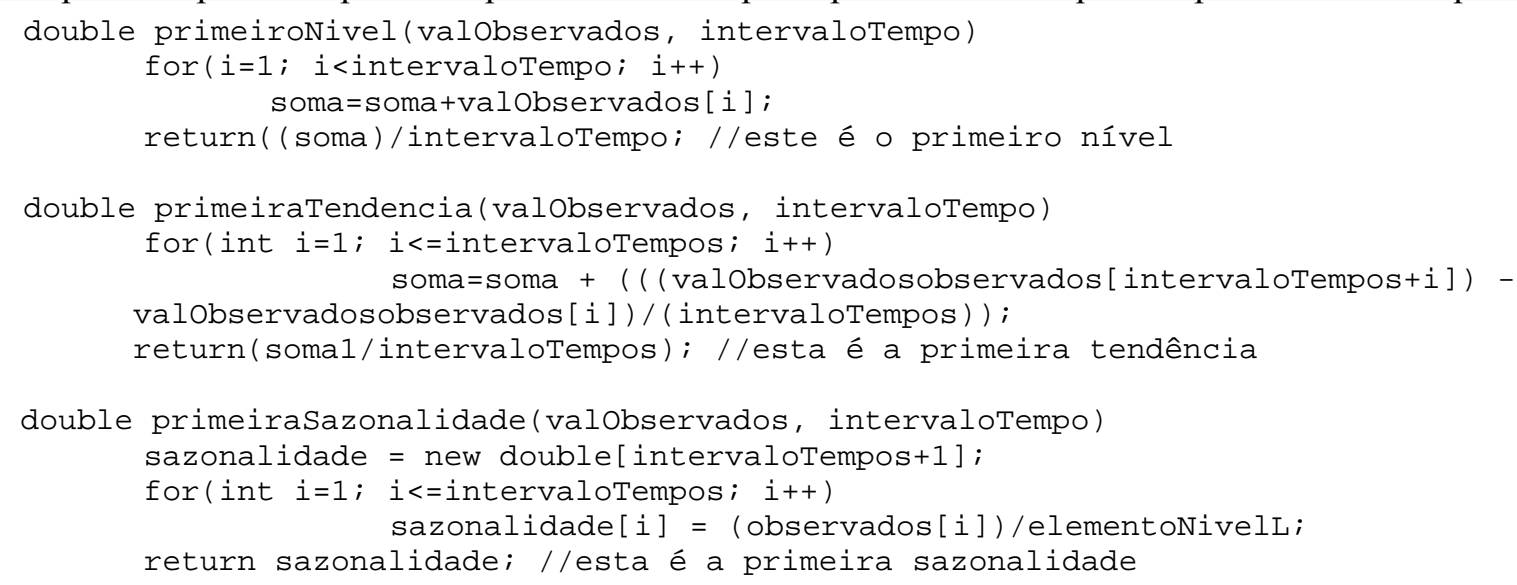


Obtido os três elementos, a segunda etapa será responsável por obter o valor da previsão. Lopes (Lopes, 2002) concluiu em seus experimentos de previsão de peças em estoque que os métodos exponenciais possuem vantagem sobre métodos mais simples como médias móveis. Barbosa (Barbosa, 2005) por sua vez, utilizou médias móveis e métodos exponenciais na previsão da demanda de álcool e concluiu que médias móveis apresentam menor Erro Médio Quadrático (EMQ) do que os métodos exponenciais, apresentando melhores resultados. Esses são dois casos de previsão de demanda, entretanto para o primeiro os métodos exponenciais tiveram melhores resultados do que para o segundo. Conclui-se então que não existe a técnica ideal global, mas sim, a técnica certa para cada caso de estudo.

Assim, dentre as técnicas existentes, foram selecionadas duas para a realização dos experimentos deste projeto: Média Móvel Exponencial e Holt-Winter. É importante ressaltar que para as duas técnicas serão considerados alguns prazos já conhecidos e classificados na literatura (ADVFN, 2012), sendo eles: curtíssimo (5 e 13 dias), curto (14 e 25 dias), médio ( 26 e 74 dias), longo (75 a 200 dias).

Conforme será visto no capítulo sobre Experimentos e Resultados, o modelo de previsão escolhido foi o de Holt-Winter. O seguinte algoritmo foi desenvolvido para o modelo de Holt-Winter com a finalidade de obter a previsão de carga de trabalho. Ele utiliza as três variáveis obtidas no algoritmo apresentando anteriormente.

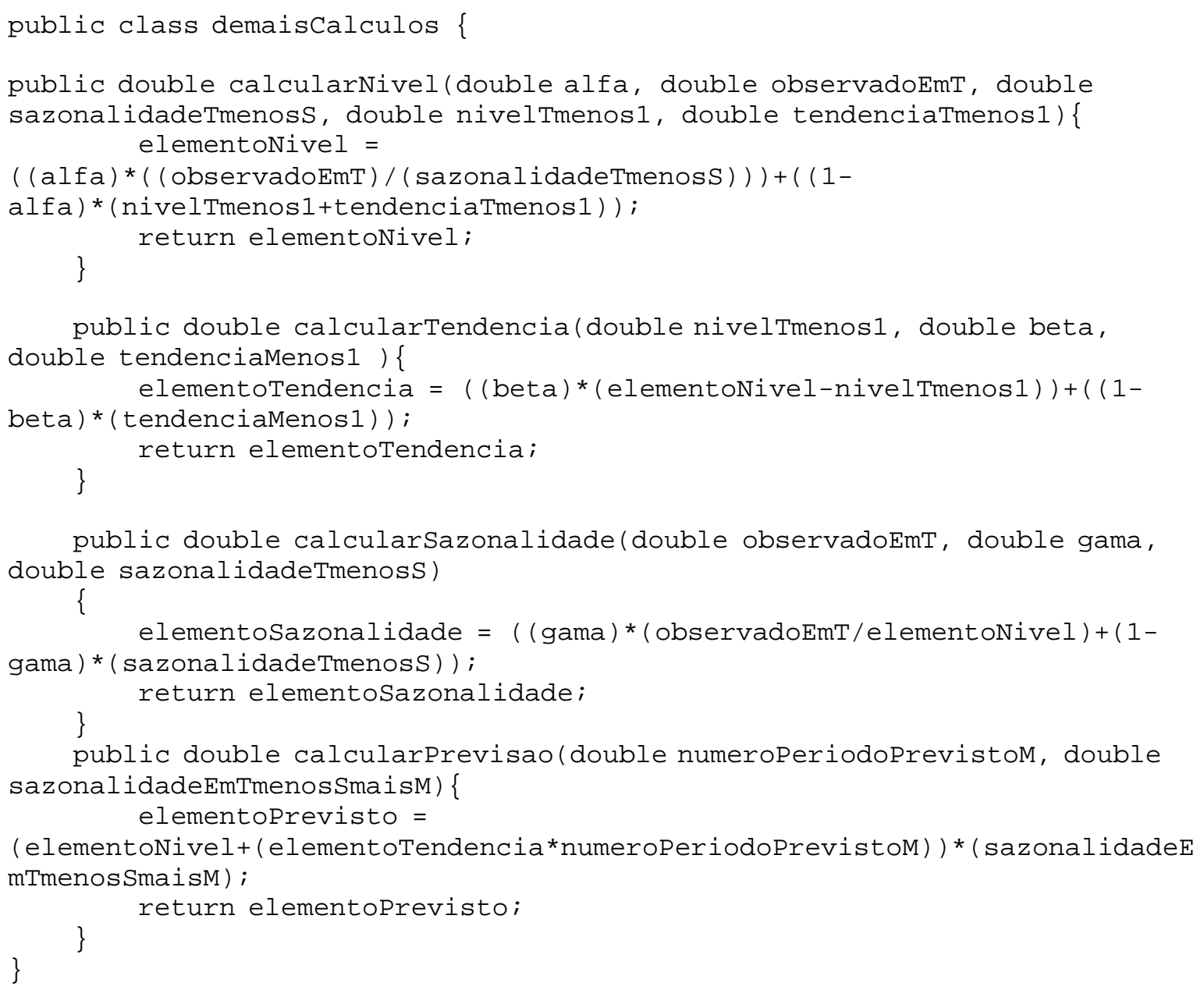




\subsubsection{Agente monitor}

$\mathrm{Na}$ arquitetura existe um conjunto de máquinas virtuais para que o cliente possa acessá-las. Cada máquina em uso tem a supervisão e o acompanhamento dos Agentes Monitores que têm as seguintes responsabilidades:

- Verificar constantemente a carga de trabalho imposta pelo cliente, por exemplo, verificar o quanto está utilizando de disco, memória e processamento;

- Verificar se o recurso está sendo bem utilizado, sem ociosidade ou se a carga de trabalho é maior que os recursos disponíveis, causando assim lentidão;

o Se houver ociosidade, o Agente Monitor de Recurso envia uma mensagem para o Adaptador Elástico sobre o estado atual da infraestrutura a fim de diminuir o recurso ocioso;

o Se houver pouco recurso disponível, o Agente Monitor de Recurso envia uma mensagem para o Adaptador Elástico informado sobre a necessidade de aumentar o recurso que está sendo insuficiente.

\subsubsection{Adaptador elástico}

Após o Agente Monitor informar o que é necessário ser feito, caberá ao Adaptador Elástico analisar o tipo de requisição:

Ociosidade de recurso: o adaptador elástico verifica a quantidade ideal que deve diminuir do recurso, deixando uma capacidade suficiente para execução.

Excesso de carga de trabalho (falta de recurso): ele verifica na mensagem que o Agente Monitor enviou, o quanto de recurso que a carga de trabalho está exigindo. Após isso o Adaptador Elástico poderá estender o recurso virtualmente na própria máquina virtual ou ligar novas máquinas virtuais e balancear a demanda entre elas.

O Adaptador elástico é responsável pela gestão auto-adaptativa de capacidade de recursos. Foi utilizado o conceito de agentes computacionais que está inserido nos principais tópicos de Computação Autônoma. Com ele a infraestrutura será capaz de se adaptar com as cargas de trabalho em tempo real. Todo monitoramento e reconfiguração da VM será em tempo de execução, evitando que o usuário necessite parar seus trabalhos para que haja a reconfiguração. 


\subsubsection{Agente atuador}

O Agente atuador têm duas ações definidas:

- De tempos em tempos (de acordo com o definido pelo administrador), é gerado um log de acesso o qual é inserido na Base de Conhecimento com todas as informações referente à demanda utilizada naquele dado momento;

- Realizar as alterações necessárias requisitadas pelo adaptador elástico.

\subsubsection{Retorno sobre o investimento}

Um monitor financeiro está presente na arquitetura e sua função é constantemente verificar a utilização dos recursos e, no final do período de uso, fornecer um relatório sobre o quanto foi gasto do valor contratado (investido), o quanto ainda pode se utilizar do valor contratado e se o uso dos recursos está sendo consciente ou inconsciente (dentro ou acima do valor contratado).

Para o ROI foram desenvolvidas neste projeto as seguintes fórmulas para os cálculos propostos no conceito de controle financeiro:

$$
\begin{aligned}
& v g=\Sigma_{p \omega \theta}^{v \sigma-(t m b w)} \\
& r e s t=\Sigma_{p \omega e}^{v e-\left(\frac{v e}{p d e}\right)-v g} \\
& r e n t=r e s t / v c(3.3)
\end{aligned}
$$

Onde,

vc: é o valor do contrato;

t: é a tarifa aplicada;

mbu: é a quantidade de MB utilizados no período (dia) calculado;

pdc: é a quantidade de períodos (dias) de duração do contrato; 
A fórmula 3.1 retorna o valor gasto no período contratado. A fórmula 3.2 é o quanto ainda pode se utilizar do valor investido. A fórmula 3.3 é a porcentagem de uso do valor contratado, que permite informar se o uso dos recursos e do valor investido está sendo consciente ou inconsciente. Para os experimentos, considerou o período de duração do contrato (pdc) igual a 15 dias, o valor da taxa ( $\mathrm{t}$ ) igual a 0.5 unidades monetárias (média do valor cobrado pelos principais provedores) e o valor contratado (vc) igual a 15.000 unidades monetárias.

\subsubsection{Execução}

A execução inicia-se a partir do cliente que realiza uma solicitação de acesso para consumir o Web Service da Máquina Virtual. A Figura 5 apresenta a organização expandida dos módulos, apresentando as principais classes (retângulos). A explicação da execução está descrita a seguir.

No cliente existe o StressClient, responsável por ler um arquivo XML. Este por sua vez, contém uma série temporal com as cargas de trabalho para stressar a máquina virtual.

Assim que o cliente realiza uma solicitação, se houver máquina virtual disponível a mesma será liberada para o uso, independente de sua configuração.

$\mathrm{Na}$ máquina virtual existem o WebServiceStress e o Agente Monitor. O primeiro é responsável por executar 3 benchmarks (Processador, Disco e Memória) conforme a carga imposta pelo cliente. O WebServiceStress recebe a cada período, uma carga de trabalho e esta carga é executada repetidas vezes até o final do período. 


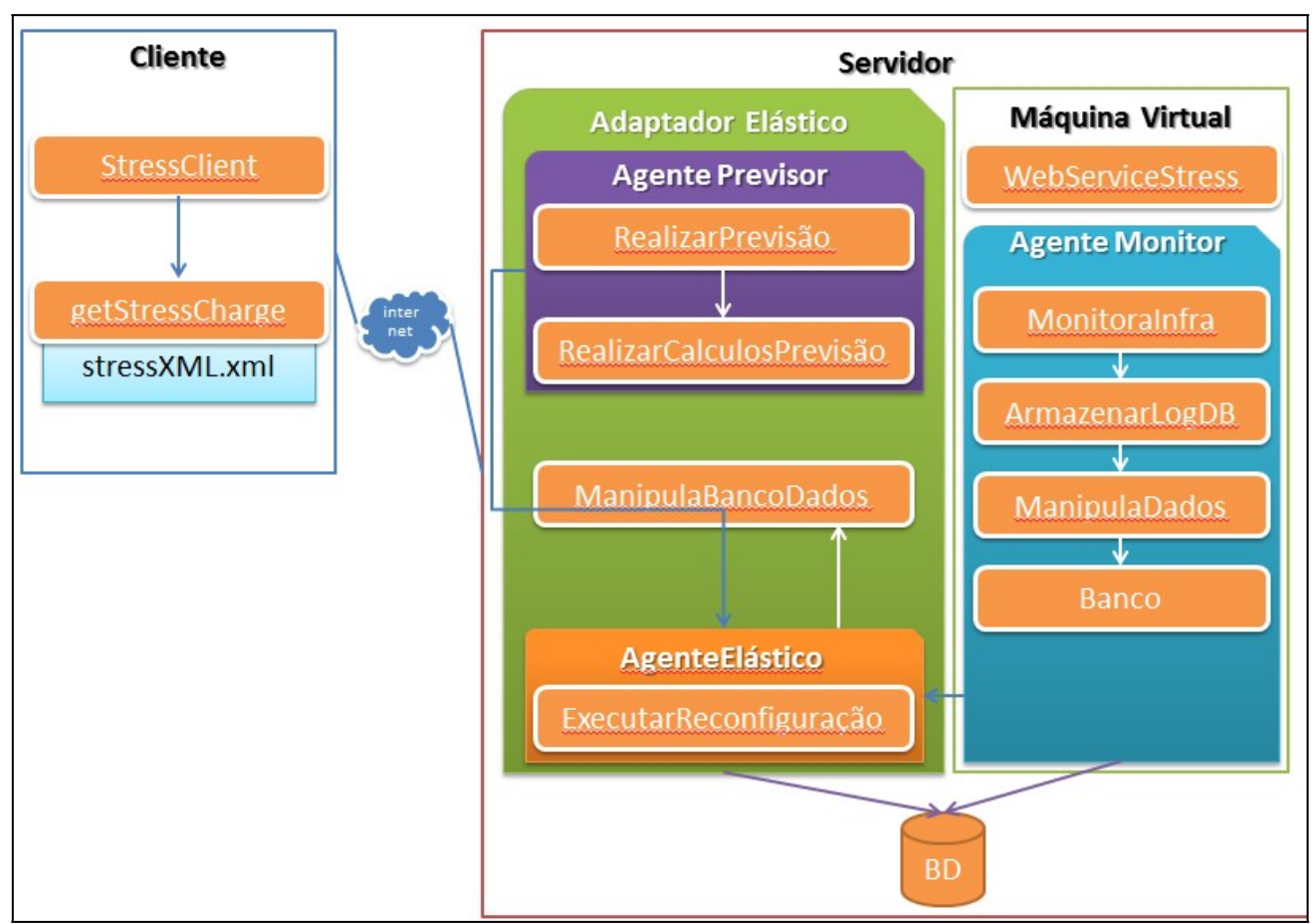

Figura 5 - Descrição Expandida dos Módulos

Durante todo o tempo que o WebServiceStress está em execução, o Agente Monitor verifica o uso dos recursos da máquina virtual e os grava no banco de dados. Esses dados gravados servirão como base para previsões futuras.

No instante que a máquina virtual é ligada, o Agente Monitor é acionado pelo crontab do linux, o mesmo também é responsável por acionar o WebServiceStress, além dos scripts em shell que verificam a memória, o disco e o Processador.

O Adaptador Elástico é responsável por realizar a previsão e a reconfiguração da infraestrutura. Ele está no mesmo servidor da Máquina Virtual, porém sua localização é independente, sendo possível executá-lo através de qualquer terminal, para isso seria necessário apenas realizar comandos remotos de reconfiguração.

O Adaptador Elástico está em constante execução e também é iniciado pelo crontab, comando que agenda tarefas a serem executadas pelo sistema operacional (Linux) periodicamente (Suryawanshi, 2014). Assim que iniciado, ele chama o Agente Previsor que, por sua vez, realizará todos os cálculos para a previsão. Assim que previsto o valor de reconfiguração para o próximo período, o Agente Previsor o envia para o Agente Elástico que por sua vez executa a reconfiguração da 
máquina virtual e grava a nova capacidade do recurso (memória, disco, processador) no banco de dados.

Toda a arquitetura é dividida em módulos, assim, as partes trabalham de forma independente. Outra característica é que o Agente Monitor executa a reconfiguração diversas vezes dentro do mesmo período. Entretanto, o Agente Previsor executa apenas uma vez no início do período. Além disso, o Agente Previsor e o Agente Monitor são dois módulos distintos e, como seus nomes dizem, um é responsável apenas pela previsão e o outro responsável apenas por monitorar o uso dos recursos, respectivamente.

\subsection{Considerações finais}

Foram apresentadas duas políticas de previsão de carga: Modelo Holt-Winter e Média Móvel Exponencial. Ainda nesta dissertação de mestrado, no Capítulo 8, é apresentada a avaliação de desempenho de ambas as políticas realizadas em um cenário real.

A previsão, juntamente com a interação entre os agentes computacionais são a base para o conceito de elasticidade proposta neste trabalho. Enquanto a previsão inicializa a infraestrutura de acordo com utilizações passadas baseada em históricos, os agentes serão responsáveis por monitorar e aplicar as devidas alterações nos recursos disponíveis. 


\section{Resultados}

\subsection{Considerações iniciais}

Na primeira fase do projeto, escolheu-se avaliar o desempenho de dois modelos de previsão de demanda computacional: Holt-Winter e Média Móvel Exponencial. Os resultados serão apresentados na seção 7.2. Como resultado desses experimentos o modelo de previsão Holt-Winter foi o escolhido para uso neste projeto.

$\mathrm{Na}$ segunda fase, foram realizados experimentos que deram origem a um artigo publicado no “Nineteenth IEEE Symposium On Computers And Communications (ISCC 2014)” (DIAS, 2014). Estes experimentos validaram a proposta de gerenciamento da infraestrutura em nuvem e os modelo de previsão e de monitoramento da infraestrutura. Essa fase se caracteriza pela avaliação de desempenho dos algoritmos para reconfiguração da infraestrutura. Também nessa fase iniciou-se a abordagem do conceito de ROI (Return On Investiment) e os experimentos com os respectivos resultados estão no subcapítulo 7.3.

A terceira e última fase cujos experimentos estão apresentados na seção 7.4 contemplou a previsão, monitoramento e o ROI, porém, considerou um número maior de períodos e várias sazonalidades dentro de uma série temporal.

\subsection{Fase 1: Resultados para escolha do modelo de previsão}

Conforme o objetivo apresentado no Capítulo 1, este projeto contribui com a elasticidade em nuvem, e para tanto, um dos métodos a serem utilizados é a previsão da demanda computacional.

Foram realizados experimentos para a análise do desempenho de duas técnicas (aqui denominadas políticas) de previsão de demanda diferentes: Média Móvel Exponencial e o modelo de Holt-Winter, para que fosse possível conhecer o comportamento de cada uma.

Para a validação dessas políticas foi escolhido a base de registro de acessos do site da Pontifícia Universidade Católica de Minas Gerais campus de Poços de Caldas com autorização do senhor Prof. MSc. Cláudio Corrêa e o período observado compreende do dia $1^{\circ}$ de Janeiro de 2012 até o dia 28 de Julho de 2012 totalizando 210 dias de observação. 
O valor a ser previsto é a taxa de transferência diária em Gigabytes realizada no portal que, entre outras funcionalidades, tem acesso dos professores para lançar notas e proporciona ao aluno visualizar seu desempenho escolar.

O uso de políticas já caracterizadas pela literatura como ideais para séries com e sem sazonalidade fornecem maior confiabilidade para que fosse realizada uma avaliação de desempenho, possibilitando uma comparação justa a fim de um único objetivo que é a previsão ideal.

A Tabela 2 apresenta os três fatores e os dois níveis para cada fator, com experimento analítico totalmente fatorial (Jain, 1991), totalizando oito testes. Por se tratar de experimento analítico, o número de repetições dos testes não modifica o resultado, uma vez que gerado o cálculo da previsão mediante a uma fórmula matemática, o resultado será sempre o mesmo por experimento.

Tabela 2 - Fatores e Níveis

\begin{tabular}{|c|c|}
\hline Fatores & Níveis \\
\hline \multirow{2}{*}{ Política } & Média Móvel Exponencial \\
\cline { 2 - 2 } & Holt-Winter \\
\hline $\begin{array}{c}\text { Janela de } \\
\text { Treinamento }\end{array}$ & 30 Dias \\
\cline { 2 - 2 } & Médio (50 dias) \\
\hline \multirow{2}{*}{ Prazo } & Longo (120 dias) \\
\cline { 2 - 2 } & \\
\hline
\end{tabular}

\subsubsection{Influência dos fatores (Jain, 1991)}

O Erro Médio Quadrático é uma das principais variáveis de resposta obtida nos testes, pois é a diferença entre o valor observado e o valor previsto que no fim resulta na média dos erros.

É possível observar na Figura 6 que o fator que mais tem influência sobre o Erro Médio Quadrático são as políticas. Essa forte influência de mais de 30\% já era esperada uma vez que ambas políticas são destinadas para tipos diferentes de séries temporais: com sazonalidade e com tendência, e sem sazonalidade e sem tendência. 


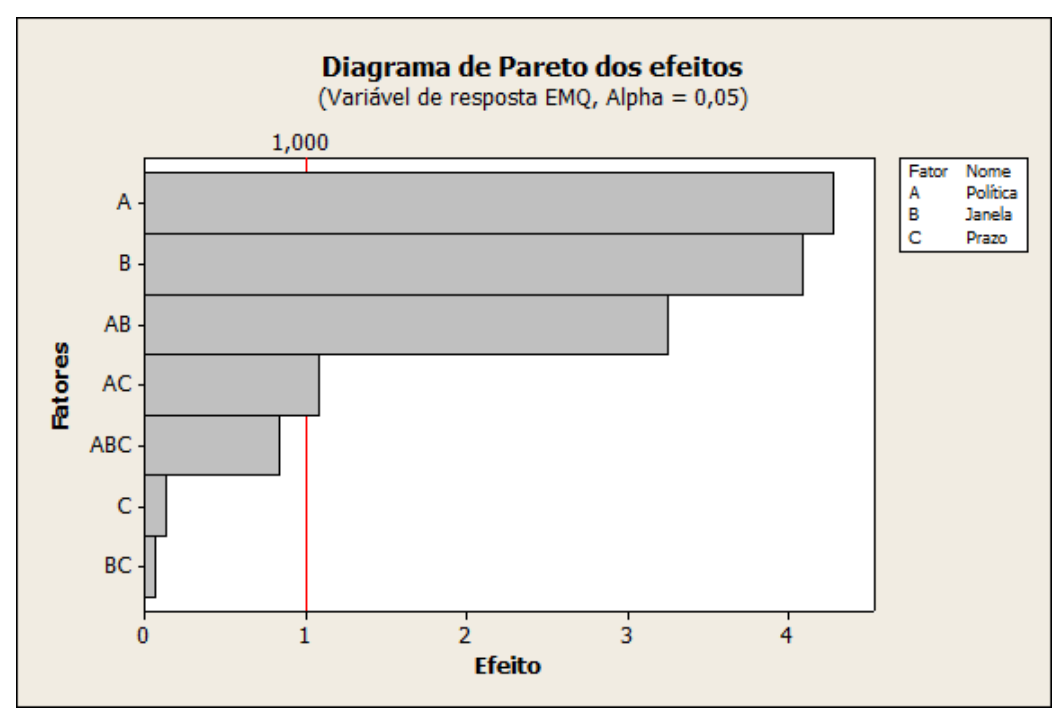

Figura 6 - Influência de fatores para a variável de resposta EMQ

A política Holt-Winter foi a que apresentou os piores valores para o Erro Médio Quadrático conforme pode ser observado nas tabelas 3 e 4 . Os experimentos 3 e 7, ambos utilizam as mesmas janelas de treinamento e prazo, modificando apenas o fator política. No experimento 3, onde utilizouse a Média Móvel Exponencial, foi obtido o menor Erro Médio Quadrático 1,32, enquanto que com o HoltWinter obteve-se o valor de 10,47, o pior entre todos. Pela tabela 4 é possível observar essa diferença.

Em todos os experimentos o modelo de Holt-Winter obteve maior Erro Médio Quadrático que a Média Móvel Exponencial, o que afetou diretamente o valor do desvio padrão onde o HoltWinter também teve valores maiores que a Média Móvel Exponencial.

Tabela 3 - Valores para variável de resposta EMQ

\begin{tabular}{|c|c|c|c|c|}
\hline \multirow{2}{*}{ Experimentos } & \multicolumn{3}{|c|}{ Fatores } & Respostas \\
\cline { 2 - 5 } & Políticas & Janela & Prazo & EMQ \\
\hline 1 & MME & 30 & médio & 1,39 \\
\hline 2 & MME & 30 & longo & 1,43 \\
\hline 3 & MME & 60 & médio & 1,32 \\
\hline 4 & MME & 60 & longo & 3,18 \\
\hline 5 & HW & 30 & médio & 2,66 \\
\hline 6 & HW & 30 & longo & 2,22 \\
\hline 7 & HW & 60 & médio & 10,77 \\
\hline 8 & HW & 60 & longo & 8,79 \\
\hline
\end{tabular}


Tabela 4 - Comparativo entre variável de resposta EMQ na Média Móvel Exponencial (ME) e no HoltWinter (HW)

\begin{tabular}{|c|c|}
\hline \multicolumn{2}{|c|}{ Variáveis de Resposta } \\
\hline EMQ (MME) & EMQ (HW) \\
\hline 1,39 & 2,66 \\
\hline 1,43 & 2,22 \\
\hline 1,32 & 10,77 \\
\hline 3,18 & 8,79 \\
\hline
\end{tabular}

A influência dos três fatores sob o desvio padrão também não foi diferente. A política também é a que mais contribuiu para os valores finais do desvio padrão. Porém aqui cabe uma observação, enquanto na Figura 6 a política e o tamanho da janela de treinamento influenciaram no valor do Erro Médio Quadrático, na Figura 7 a política e a interação política e janela influenciaram muito no resultado do desvio padrão, respectivamente $44,3 \%$ e $34,48 \%$. O fator prazo teve uma influência de apenas $0,08 \%$ sob o desvio padrão, enquanto que para a Erro Médio Quadrático a influência foi de $0,08 \%$.

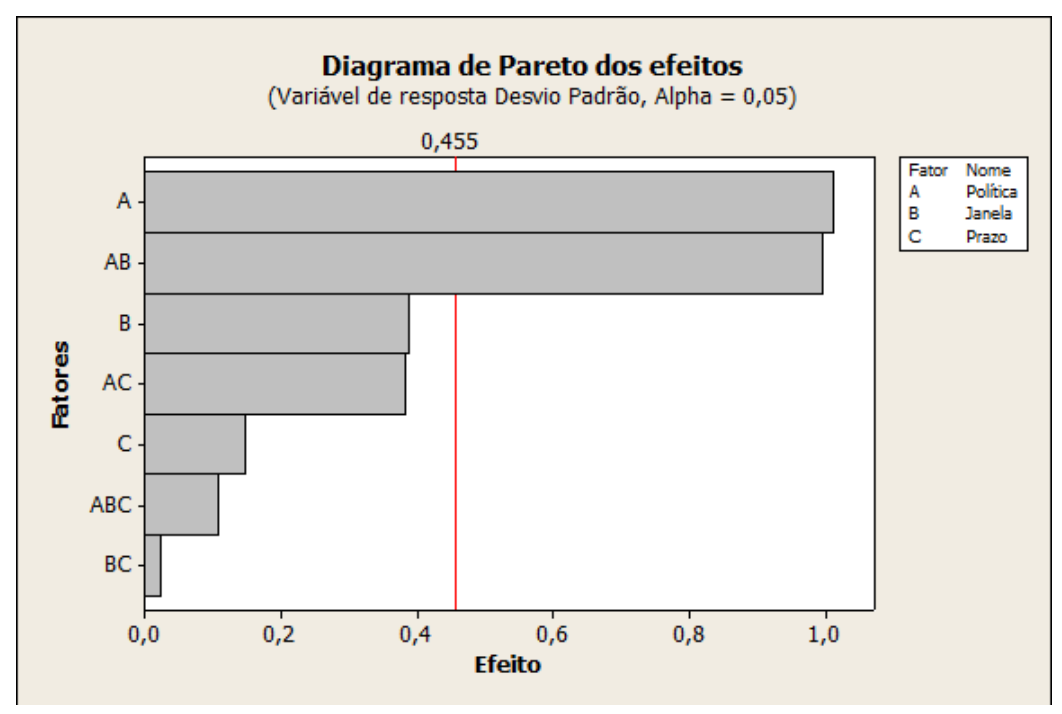

Figura 7 - Influência de fatores para a variável de resposta Desvio Padrão 
Tabela 5 - Valores para variável de resposta Desvio Padrão

\begin{tabular}{|c|c|c|c|c|}
\hline \multirow{2}{*}{ Experimentos } & \multicolumn{3}{|c|}{ Fatores } & Respostas \\
\cline { 2 - 5 } & Políticas & Janela & Prazo & $\begin{array}{c}\text { Desvio } \\
\text { Padrão }\end{array}$ \\
\hline 1 & MME & 30 & médio & 1,03 \\
\hline 2 & MME & 30 & longo & 1,09 \\
\hline 3 & MME & 60 & médio & 0,29 \\
\hline 4 & MME & 60 & longo & 0,95 \\
\hline 5 & HW & 30 & médio & 1,32 \\
\hline 6 & HW & 30 & longo & 1,17 \\
\hline 7 & HW & 60 & médio & 2,47 \\
\hline 8 & HW & 60 & longo & 2,79 \\
\hline
\end{tabular}

Tabela 6 - Comparativo entre variável de resposta Desvio Padrão na Média Móvel Exponencial (ME) e no Holt-Winter (HW)

\begin{tabular}{|c|c|}
\hline \multicolumn{2}{|c|}{ Variáveis de Resposta } \\
\hline Desvio Padrão (MME) & Desvio Padrão (HW) \\
\hline 1,03 & 1,32 \\
\hline 1,09 & 1,17 \\
\hline 0,29 & 2,47 \\
\hline 0,95 & 2,79 \\
\hline
\end{tabular}

As Tabelas 5 e 6 apresentam a variável de resposta desvio padrão. Nelas é possível observar que o desvio padrão foi maior no modelo de Holt-Winter, o que era esperado conforme observou-se nas Tabelas 3 e 4 onde o Erro Médio Quadrático para esta política também foi alta. A tabela 6 apresenta o comparativo dos valores do desvio padrão para ambas políticas.

\subsubsection{Previsão de carga de trabalho com treinamento de 60 dias e prazo de 120 dias}

Na Figura 8, utilizando a política de Média Móvel Exponencial, não houve uma previsão de demanda futura, mas sim, uma previsão do provável comportamento dessa demanda. Para o projeto de mestrado este tipo de resultado se torna inviável, uma vez que busca-se obter uma previsão fiel que acompanhe a tendência da série temporal e que seja capaz de indicar o melhor valor da demanda para alocação dos recursos que serão necessários para suportá-la. Assim, mesmo o Erro Médio Quadrático 
sendo menor para todos os experimentos com Média Móvel Exponencial, não pode-se atribuir que ela é a melhor política de previsão para este tipo de série temporal que possui características de sazonalidade e tendência.

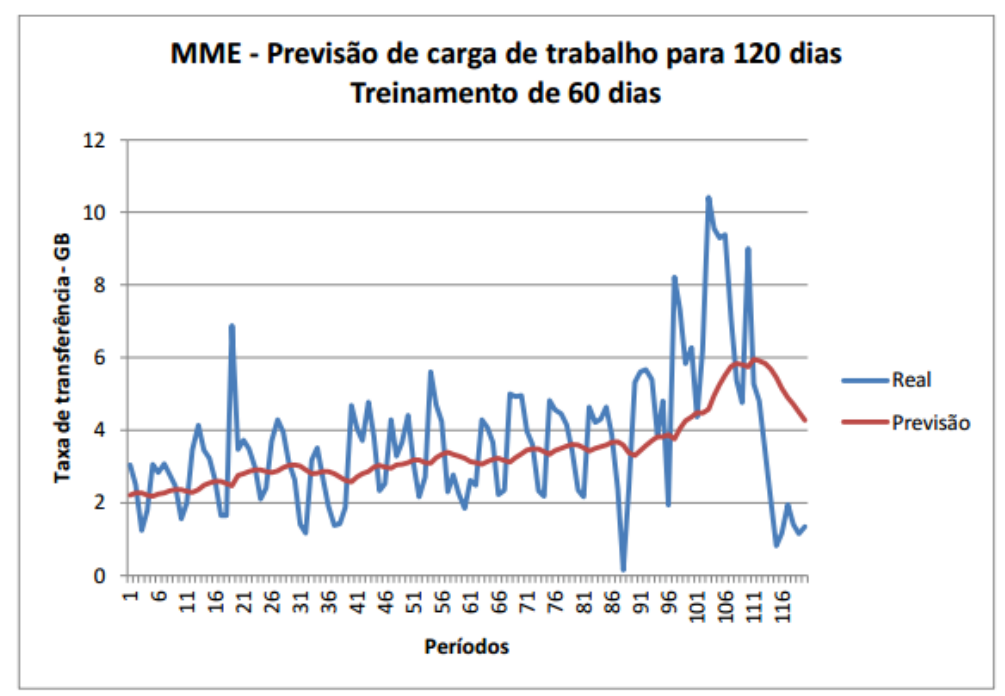

Figura 8 - Previsão de carga de trabalho para 120 dias com treinamento de 60 dias utilizando MME

A Figura 9 apresenta uma previsão para o longo prazo de 120 dias. A linha vermelha sofre oscilações, porém diferentemente do experimento da Figura 8, na Figura 9 o desvio padrão foi de 2,47 e o Erro Médio Quadrático foi de 8,79. Ainda na Figura 9 é possível observar que, com o decorrer dos períodos, a previsão começa a se ajustar aproximando-se do valor observado.

O período de treinamento de 60 dias apresentou uma variação grande, pois iniciou nas férias de janeiro e terminou no começo do mês de março, então a média da taxa de transferência que no início era de 1,01 GB, passou para 1,85 GB, o que justifica os picos previstos entre os períodos 95 e 102. 


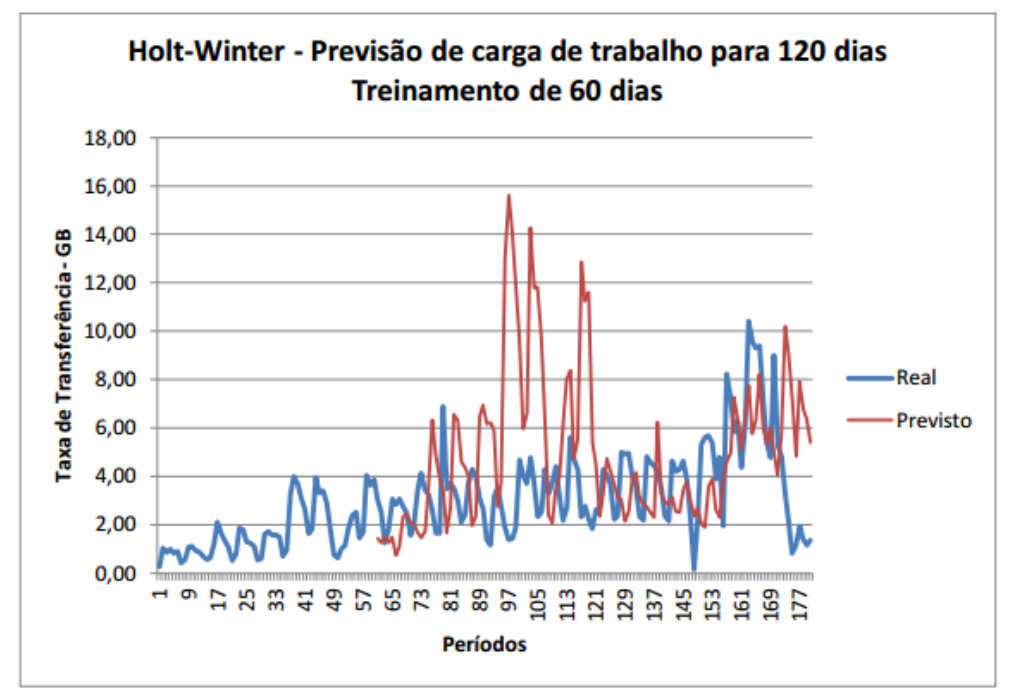

Figura 9 - Previsão de carga de trabalho para 120 dias com treinamento de 60 dias utilizando Holt-Winter

Com os gráficos apresentados, verificou-se que a Média Móvel Exponencial obteve o menor desvio padrão e o menor erro médio quadrático para todos os experimentos realizados, principalmente analisando os experimentos 3 e 4 onde são exibidos seus melhores resultados. No entanto, este tipo de política de previsão de carga torna-se inviável para este trabalho de mestrado, uma vez que se busca obter uma previsão fiel que acompanhe a tendência da série temporal e que seja capaz de indicar o melhor valor da demanda para alocação dos recursos que serão necessários para suportá-la. Vale ressaltar que para os experimentos 1 e 2 onde a previsão da Média Móvel Exponencial acompanha a demanda de requisições, só obteve-se este resultado devido ao fator de correção da previsão (alfa) ser próximo de $1(0,78)$ e estar quase anulando o verdadeiro sentido da Média Móvel Exponencial, a suavização de valores extremos. No entanto, a Média Móvel Exponencial é um excelente indicador para a expectativa da carga que será processada, ou seja, se a carga será alta ou baixa para um determinado período, sem indicar o seu valor preciso.

Por outro lado, com a política de previsão Holt-Winter que se caracteriza por realizar suavização exponencial em séries temporais com sazonalidade e/ou tendências, validou-se que se a janela de treinamento é maior que o período a ser previsto, o melhor resultado será inviabilizado pois, de acordo com este modelo, a janela de treinamento deve ser menor e o tempo de previsão tem que ser de médio a longo prazo para um resultado ideal. Isso pode ser comprovado no Gráfico 4 que apresenta uma previsão para o longo prazo de 120 dias, onde esta previsão sofre oscilações e é perfeitamente possível observar que, com o decorrer dos períodos, ela começa a se ajustar aproximando-se do valor observado tornando-se um eficiente método de previsão de carga que deve ser melhor explorado no projeto de mestrado. 
As Figuras 10 e 11 (Gráfico de Cubo ${ }^{1}$ ) melhor caracterizam este ajuste em relação ao valor observado. ${ }^{1}$ Para o EMQ, o MHW com janela de 60 dias em médio prazo estava em 10,77, porém em longo prazo o valor diminuiu caindo para 8,77. Conclui-se com isso que com o passar do tempo o EMQ tende a diminuir. O mesmo é válido dizer sobre o gráfico do desvio padrão.

Os gráficos apresentam melhores resultado para a política de MME, porém conforme aumenta o prazo de previsão, pior é o resultado tanto do EMQ quanto de Desvio Padrão.

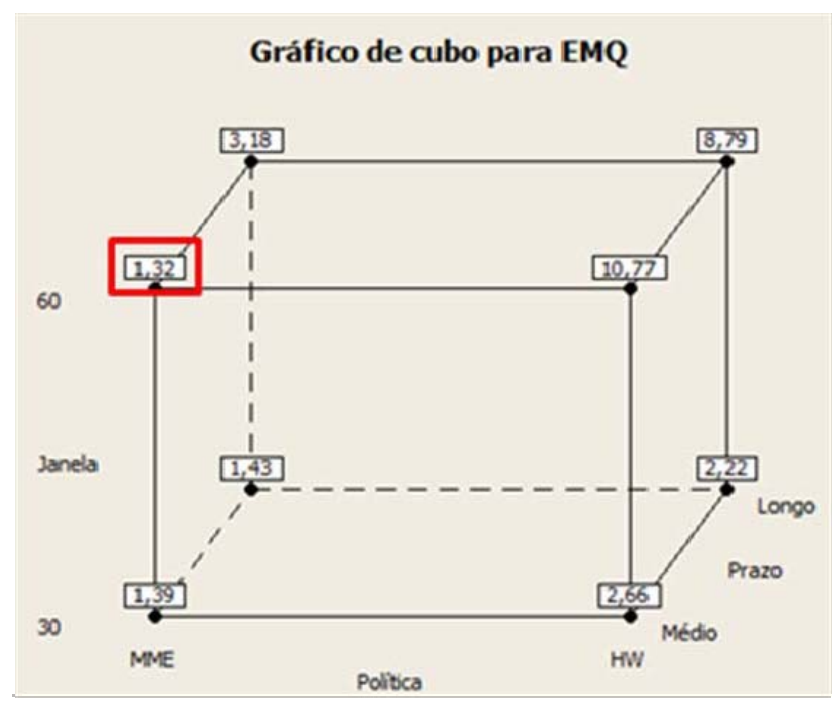

Figura 10 - Gráfico de cubo para variável de resposta EMQ

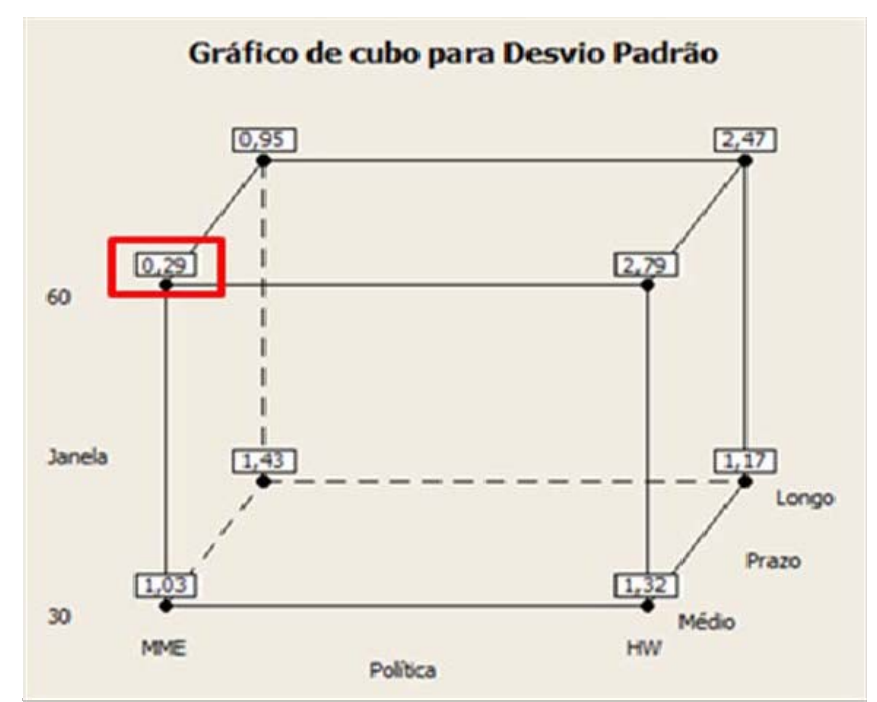

Figura 11 - Gráfico de cubo para variável de resposta Desvio Padrão

${ }^{1}$ O Gráfico de Cubo foi gerado no Minitab@ 15. Para detalhamento é sugerido consultar o manual. 


\subsection{Fase 2: Avaliação de desempenho da reconfiguração em 15 períodos}

Para estes experimentos, foi criada uma série temporal com 15 períodos (dias) distintos. Também existem dois tipos de reconfiguração, como já visto anteriormente: Previsão e Agente Monitor. Para os experimentos, considerou avaliar os dispositivos Memória e Disco. Os experimentos foram realizados considerando os fatores e níveis da Tabela 7. As variáveis de resposta foram Erro Médio Percentual, Erro Quadrático Médio e Valor de Unidades Monetárias Efetivamente Consumidas.

Tabela 7 - Fatores e Níveis

\begin{tabular}{|c|c|}
\hline Fatores & Níveis \\
\hline \multirow{2}{*}{ Dispositivo } & Memória \\
\cline { 2 - 2 } & Disco \\
\hline \multirow{2}{*}{ Monitor } & Com \\
\cline { 2 - 2 } & Sem \\
\hline \multirow{2}{*}{ Previsão } & Com \\
\cline { 2 - 2 } & Sem \\
\hline
\end{tabular}

Foi assumido que a variável "Disponível" corresponde ao valor previsto (ou reconfigurado segundo o agente monitor) e a variável "Observado" é a carga de trabalho imposta (o valor que foi consumido do recurso).

A diferença entre o valor disponível e observado será amontoado e dará o Erro Médio Quadrático, que cálcula o erro da previsão frente a carga de trabalho. O Erro percentual médio é o erro percentual do valor observado comparando-o com o valor disponível. Quanto menor este valor, melhor é a previsão (ou monitoramento).

O Erro Quadrático Médio e o Erro Médio Percentual são parecidos mas são destinados para fins diferentes. O primeiro avalia a diferença entre uma previsão e o valor observado possibilitando uma medida de precisão, enquanto o segundo mede a porcentagem do erro em relação ao valor real. $\mathrm{O}$ EQM é um modo de escolher o melhor estimador, no caso temos dois: previsão e monitor. 
O ROI é dividido em duas categorias: o tempo que levará (quantos períodos levarão) para que o cliente obtenha o retorno do investimento e o quanto o cliente está no período atual recebendo do retorno do investimento.

A tabela 8 apresenta os resultados do ROI nos experimentos. Cada linha é um período. Neste experimento foram investidos 15mil UM (Unidades Monetárias). Na primeira linha do experimento Sem Previsão e Sem Monitor observa-se que, se continuar com a mesma carga de trabalho, em 19,8 períodos o cliente terá o retorno dos 15 mil UM investidos, assim, em 19,8 períodos o valor investido será utilizado da forma correta, sem ociosidade e sem excessos. A segunda coluna (Rentabilidade) não tem nenhuma relação direta com a primeira. A rentabilidade indica que, no primeiro período o cliente (Contratante) utilizou 5\% do valor investido, ou seja, dos $20 \mathrm{mil}$ contratado, no primeiro período ele já gastou $750 \mathrm{UM}$.

Tabela 8 - Cálculos do ROI

\begin{tabular}{|c|c|}
\hline \multicolumn{2}{|c|}{$\begin{array}{c}\text { Sem Monitor e } \\
\text { Sem Previsão }\end{array}$} \\
\hline Período ROI & Rentabilidade \\
\hline 19,8 & 5 \\
\hline 12,1 & 8,2 \\
\hline 8,89 & 11,24 \\
\hline 6,69 & 14,93 \\
\hline 5,52 & 18,09 \\
\hline 4,63 & 21,58 \\
\hline 4 & 24,96 \\
\hline 3,45 & 28,98 \\
\hline 3,06 & 32,62 \\
\hline 2,7 & 36,54 \\
\hline 2,51 & 39,75 \\
\hline 2,3 & 43,36 \\
\hline 2,14 & 46,7 \\
\hline 2 & 49,2 \\
\hline $\mathbf{1 , 6}$ & $\mathbf{5 3 , 2 5}$ \\
\hline
\end{tabular}




\begin{tabular}{|c|c|}
\hline \multicolumn{2}{|c|}{$\begin{array}{c}\text { Com Monitor e } \\
\text { Sem Previsão }\end{array}$} \\
\hline Período ROI & Rentabilidade \\
\hline 11,68 & 9 \\
\hline 6,18 & 16 \\
\hline 4,48 & 22 \\
\hline 3,51 & 28 \\
\hline 2,92 & 34 \\
\hline 2,48 & 40 \\
\hline 2,15 & 46 \\
\hline 1,9 & 53 \\
\hline 1,63 & 61 \\
\hline 1,44 & 69 \\
\hline 1,3 & 77 \\
\hline 1,2 & 83 \\
\hline 1,12 & 89 \\
\hline 1,05 & 95 \\
\hline $\mathbf{0 , 9 9}$ & $\mathbf{1 0 1}$ \\
\hline
\end{tabular}

\begin{tabular}{|c|c|}
\hline \multicolumn{2}{|c|}{$\begin{array}{c}\text { Com Monitor e } \\
\text { Com Previsão }\end{array}$} \\
\hline Período ROI & Rentabilidade \\
\hline 12,14 & 8 \\
\hline 6,9 & 14 \\
\hline 4,9 & 20 \\
\hline 3,8 & 26 \\
\hline 3,16 & 32 \\
\hline 2,68 & 37 \\
\hline 2,31 & 43 \\
\hline 2 & 49 \\
\hline 1,7 & 58 \\
\hline 1,5 & 66 \\
\hline 1,4 & 72 \\
\hline 1,3 & 78 \\
\hline 1,2 & 84 \\
\hline 1,12 & 89 \\
\hline $\mathbf{1 , 0 5}$ & $\mathbf{9 5}$ \\
\hline
\end{tabular}

De forma geral, o cliente tinha 15 mil UM para gastar em 15 períodos, o que seria cerca de 1000 UM para gastar por período. O melhor caso sempre será gastar 1000 UM por período para que, no final dos 15 contratados tenha sido gasto todo o valor investido sem desperdicio ou falta. Porém no primeiro período não foram gastos os $1000 \mathrm{UM}$, logo, se ainda haviam 14 períodos adiante, (o algoritmo corretamente pressupõe que a tendência é continuar a gastar apenas 1000 UM por período) com a sobra o algoritmo apresenta que o valor que se tem investido é para mais 19,8 períodos e que, neste período atual foi gasto $5 \%$.

No segundo período foi gasto $8,2 \%$ do valor investido e, se continuar como está, em 12,1 períodos o cliente terá utilizado, sem disperdicio, os $15 \mathrm{mil}$ UM. Assim se segue. No $15^{\circ}$ período terá gasto $53,5 \%$ do valor total. Porém, não foi gasto tudo, pois precisaria de mais 1,6 períodos para que fosse possível utilizar todo os $20 \mathrm{mil}$. Se no primeiro período foi gasto $5 \%$ isso quer dizer que, de todo o valor investido o cliente utilizou ou "recuperou" 5\%, essa então é a rentabilidade.

Foram 15 períodos por experimento e cada período ficou em execução por 5 minutos. A simulação foi feita utilizando um cliente que requisita o benchmark em um Web Service. São 2 tipos de benchmark: para disco (leitura, escrita, releitura, reescrita e remoção de arquivo) e para memória, onde são criados vetores de string de 8bytes cada. Para a requisição dos benchmarks: o cliente envia, de forma senoidal, 15 valores da seguinte forma: 5, 10, 15, 20, 25, 20, 15, 10, 5, 5, 10, 15, 20, 25, 20. 
No Web Service existe um gerador de números aleatórios. A carga, ou seja, o tamanho do arquivo ou a quantidade de vetores é definida por período multiplicando o valor enviado pelo cliente vezes o valor aleatório gerado. A variável aleatória permite que a cada execução, o gráfico do observado (ou seja, a carga de trabalho imposta) seja diferente.

O primeiro experimento foi realizado sem previsão e sem monitor e é observado nos gráficos das Figuras 12 e 13.

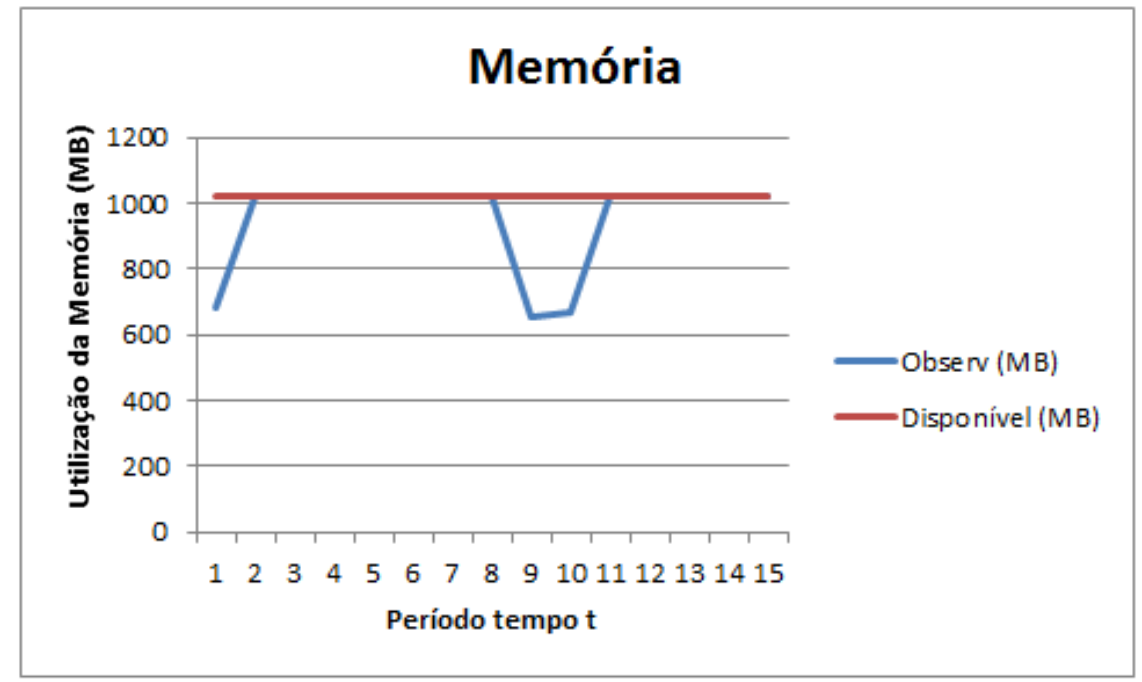

Figura 12 - Experimento 1: Memória, sem previsão e sem monitor

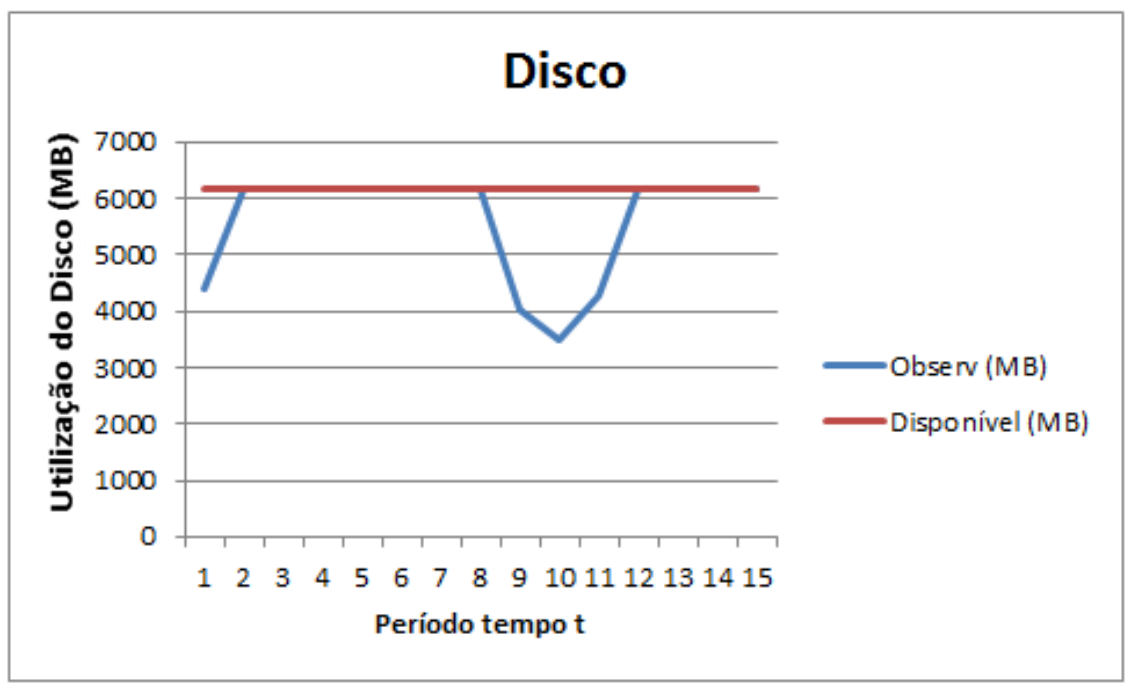

Figura 13 - Experimento 1: Disco, sem previsão e sem monitor

A linha vermelha é o valor disponível. A Memória apresenta 1GB de capacidade disponível e o Disco 6GB de capacidade disponível. A linha azul foi a carga de trabalho senoidal observada no decorrer de 15 períodos. Em dois momentos a linha azul é interrompida, isso ocorre pois houve falta de recurso de Memória e de Disco. Em relação ao retorno sobre o valor investido, no final dos 15 
períodos o cliente gastou $53 \%$ do que havia contratado, disperdiçando $47 \%$ do valor investido ou 9400 unidades monetárias (Tabela 5).

O segundo experimento considerou a execução apenas da previsão. Conforme observa-se nos gráficos das Figuras 14 e 15. Nestes gráficos a linha vermelha da capacidade disponível não é fixa como no primeiro experimento. Aqui os recursos Memória e Disco tiveram suas capacidades previstas através de histórico e o mecanismo de reconfiguração permitiu atender a todas as requisições como pode ser visto pela linha azul. Neste experimento, no final do $15^{\circ}$ período o cliente gastou efetivamente $92 \%$ do valor contratado, deixando de gastar $8 \%$ (Tabela 5). O Erro Médio Percentual (EMP), que mede a porcentagem de erro em relação ao valor real foi de 17.92\% para a Memória e de 31.44\% para o Disco. Pelo gráfico nota-se a distância entre as curvas dos valores observados e disponíveis, essa diferença é calculada pelo Erro Quadrático Médio (EQM). O EQM foi de 247.78 e 1640.85 para a Memória e para o Disco respectivamente.

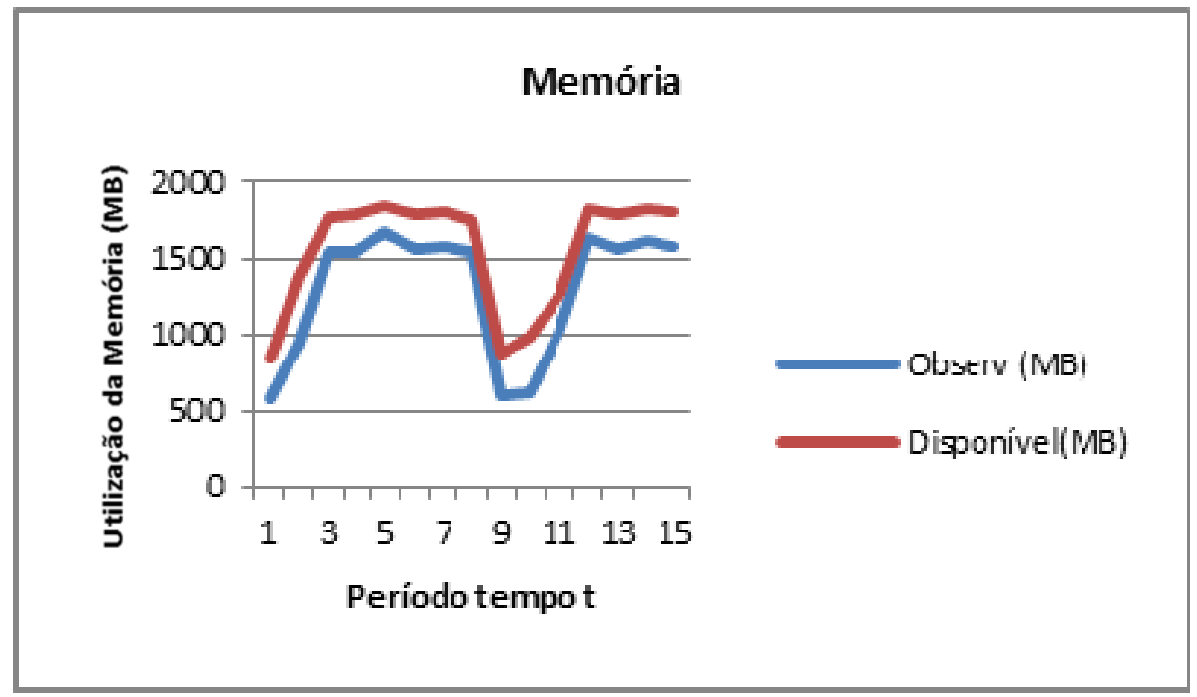

Figura 14 - Experimento 2: Memória, com previsão e com monitor 


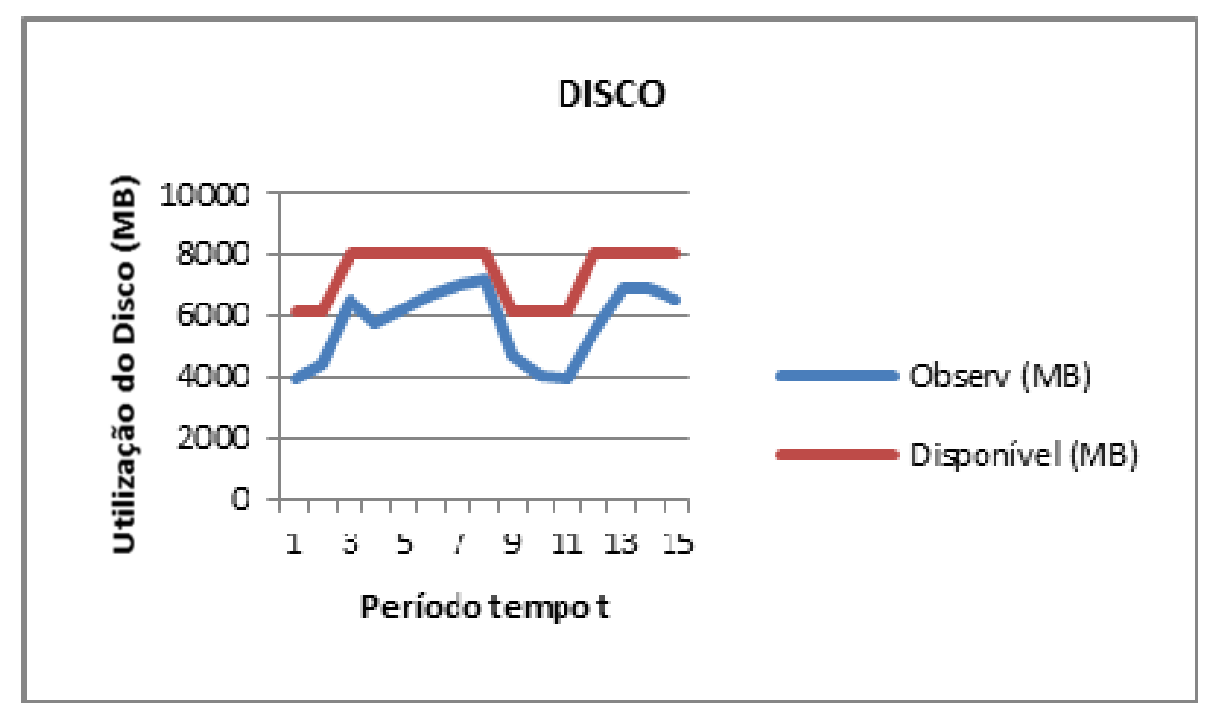

Figura 15 - Experimento 2: Disco, com previsão e com monitor

A previsão reconfigura os recursos da VM no início do período. O terceiro experimento verificou o comportamento da VM durante o monitoramento da carga de trabalho imposta. Desta forma, considerou apenas o uso do Agente Monitor, não aplicando a previsão, e o resultado é o observado nos gráficos das Figuras 16 e 17.

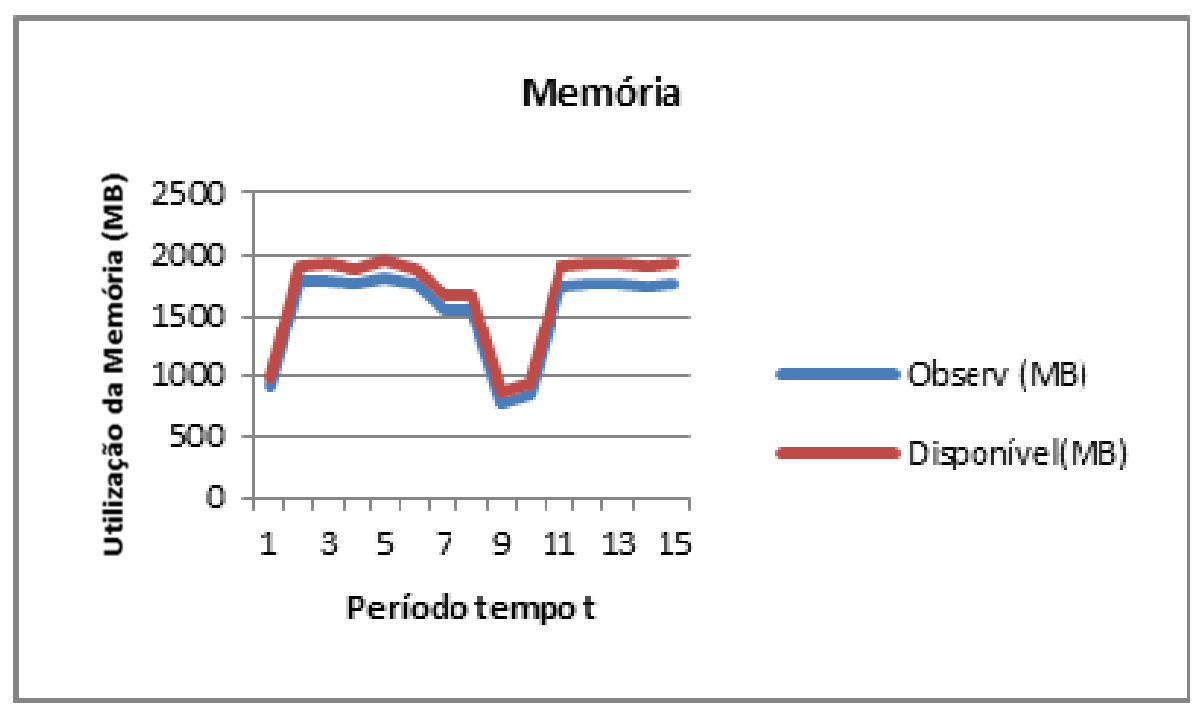

Figura 16 - Experimento 3: Memória, sem previsão e com monitor 


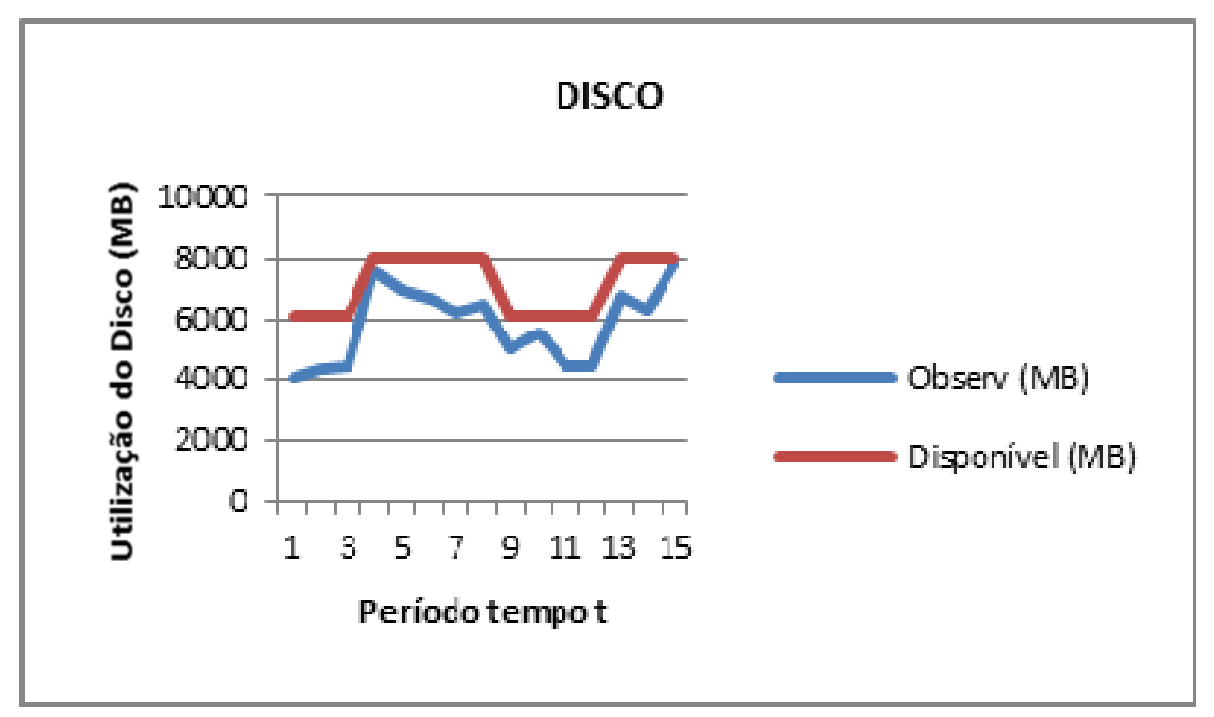

Figura 17 - Experimento 3: Disco, sem previsão e com monitor

Tanto para o Disco quanto para a Memória, o agente foi capaz de monitorar o uso dos recursos, propondo uma nova reconfiguração para estes recursos que satisfez a carga de trabalho imposta. Especificamente para a Memória no gráfico da Figura 16 houve uma aproximação maior do valor observado e do valor disponível, em comparação com o gráfico da Figura 14. Essa aproximação, expressa numericamente, mostra que para este experimento o EQM foi de 125.45 para a Memória e 1345.69 para o Disco e o EMP foi respectivamente de $7.60 \%$ e $26.00 \%$ para a Memória e Disco. Em média, o uso do agente monitor proporcionou que os dados observados (para a Memória) se aproximassem $49 \%$ do valor disponível neste experimento em relação ao experimento anterior. Essa aproximação média foi maior para os dados observados em relação ao disponível no Disco, que se aproximaram $17.9 \%$. Isso ocorre, pois neste experimento o agente monitor está constantemente verificando a utilização dos recursos e realizando a reconfiguração, diferente do segundo experimento no qual a reconfiguração é apenas no início do dia e não considera as cargas de trabalho que ocorrem durante todo o tempo até a próxima previsão. No final do $15^{\circ}$ período foi gasto efetivamente $100 \%$ do valor aplicado, isso se deve pela maior aproximação do valor observado frente ao valor disponível (Tabela 5).

Foi executado um quarto experimento no qual foi proposto o uso da previsão (experimento 2) e também o uso dos agentes computacionais (experimento 3). Os resultados obtidos são observados nos gráficos das Figuras 18 e 19. 


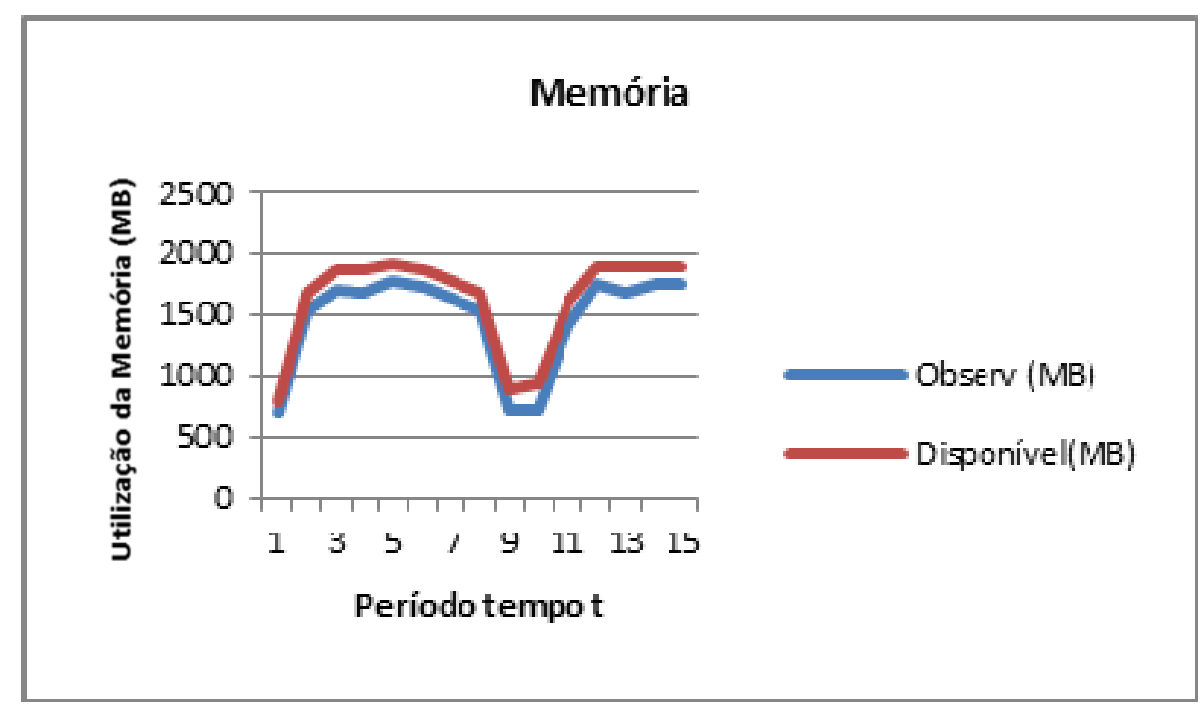

Figura 18 - Experimento 4: Memória, com previsão e com monitor

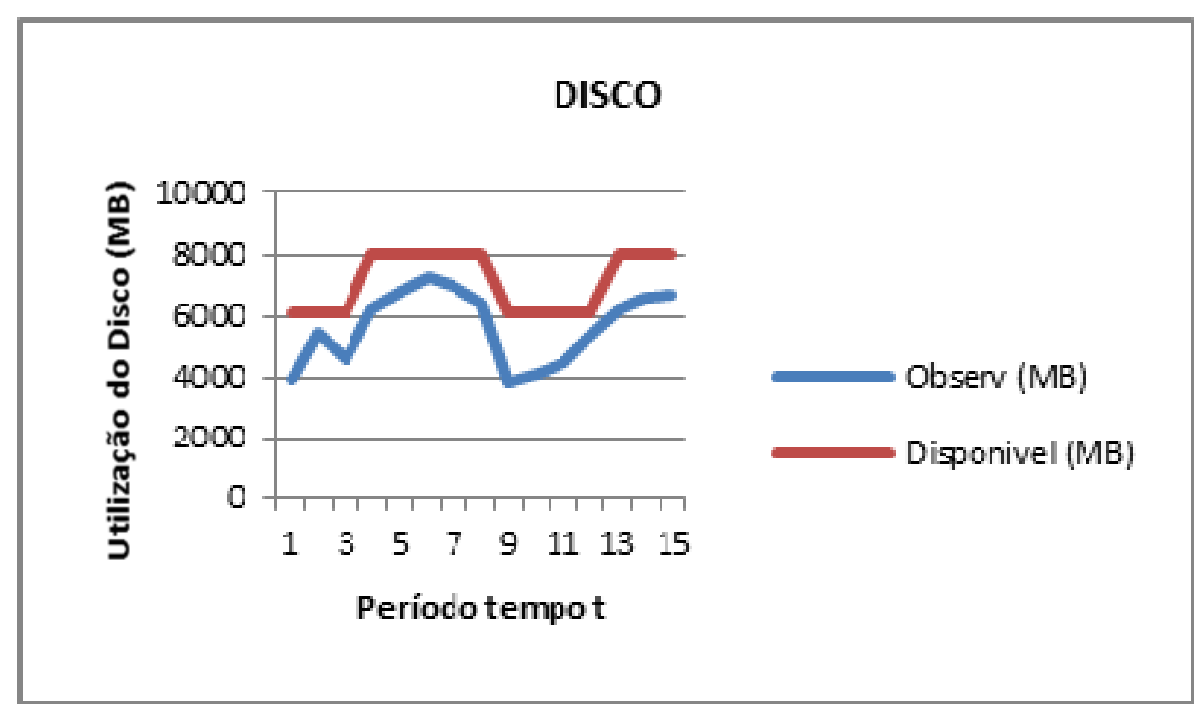

Figura 19 - Experimento 4: Disco, com previsão e com monitor

Neste último experimento o EQM foi respectivamente de 156.29 e 1480.24 para a Memória e Disco. O EMP da Memória e do Disco foi respectivamente de $10.33 \%$ e 28.69\% para Memória e Disco. Em relação ao experimento 2 houve uma aproximação de $36.92 \%$ e de $9.78 \%$ respectivamente para Memória e Disco em relação ao experimento 2, considerando uma melhora relativa. Se comparado o experimento 4 com o experimento 3, houve um afastamento de $24 \%$ e $10 \%$ respectivamente para os recursos Memória e Disco. O afastamento ocorre devido a previsão que, no início do período estipula cargas mais baixas ou mais altas do que a necessária. Cabe então ao agente monitor realizar o ajuste de acordo com a carga de trabalho que está ocorrendo naquele dado instante. Neste experimento o cliente gastou efetivamente $95 \%$ do valor investido (Tabela 5). 


\subsection{Fase 3: Avaliação de desempenho da reconfiguração em 170 períodos}

Na fase 3, a carga de trabalho é fixa e se difere da fase 2 que teve auxílio de uma variável aleatória. Foi considerado o valor investido para o ROI de 1 milhão UM.

Sem o uso de previsão e de monitor, a capacidade máxima dos recursos memória e disco não foram suficientes para suprir as necessidades do cliente que teve suas requisições negadas em alguns momentos conforme observado nos gráficos das Figuras 20 e 21.

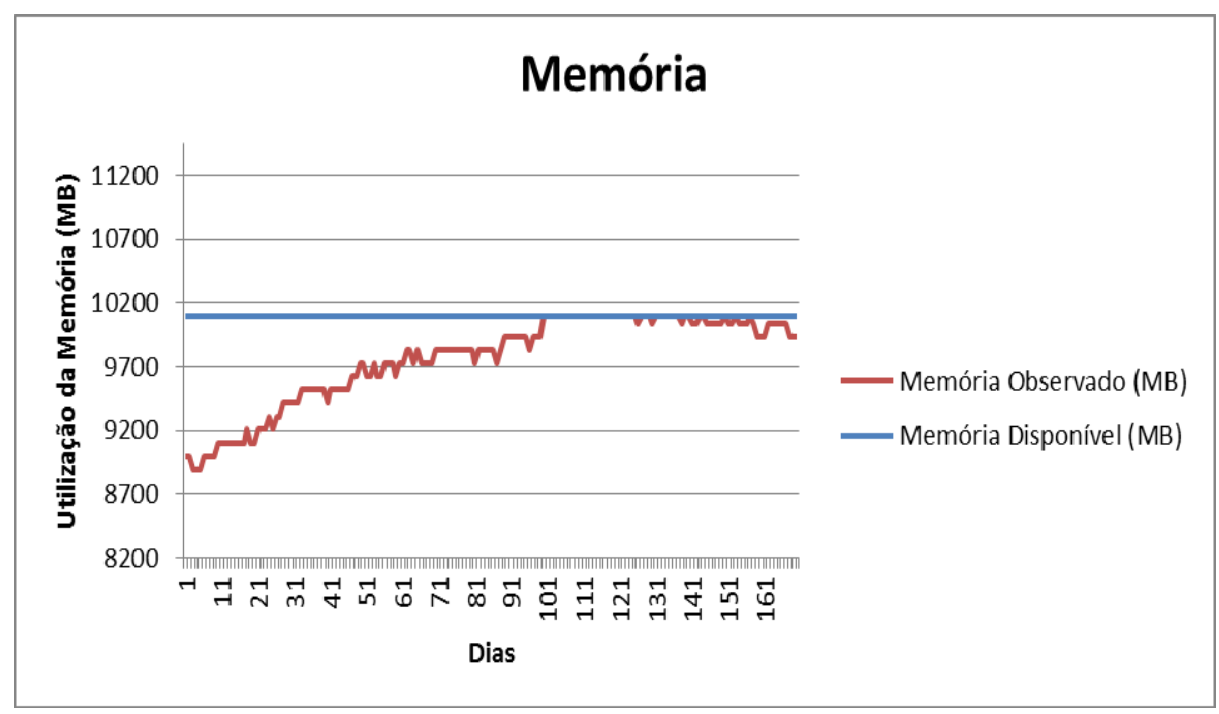

Figura 20 - Experimento1: Memória, Sem Previsão e Sem Monitor

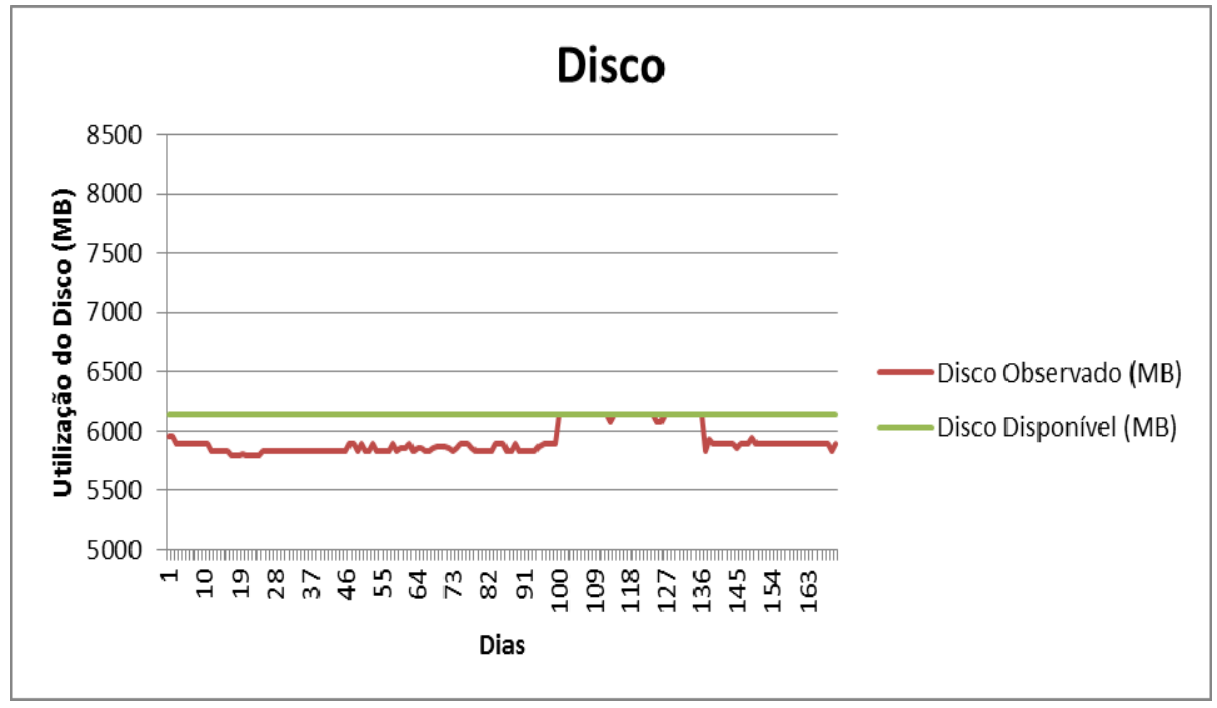

Figura 21 - Experimento1: Disco, Sem Previsão e Sem Monitor 
No experimento 2 (Figuras 22 e 23) foi considerada a mesma carga de trabalho e foi utilizada a previsão sem agente monitor. O EQM foi de 251124 e 337801 respectivamente para memória e disco. O EMP foi de 4,83 e 7,84, respectivamente para memória e disco. Neste experimento, no final do $170^{\circ}$ o cliente gastou $95 \%$ do valor contratado, deixando de gastar 50mil UM. Logo, o cliente investiu neste caso $5 \%$ a mais do que lhe seria necessário. Com o valor restante seria possível suprir, se continuasse nessa tendência, mais 8 períodos.

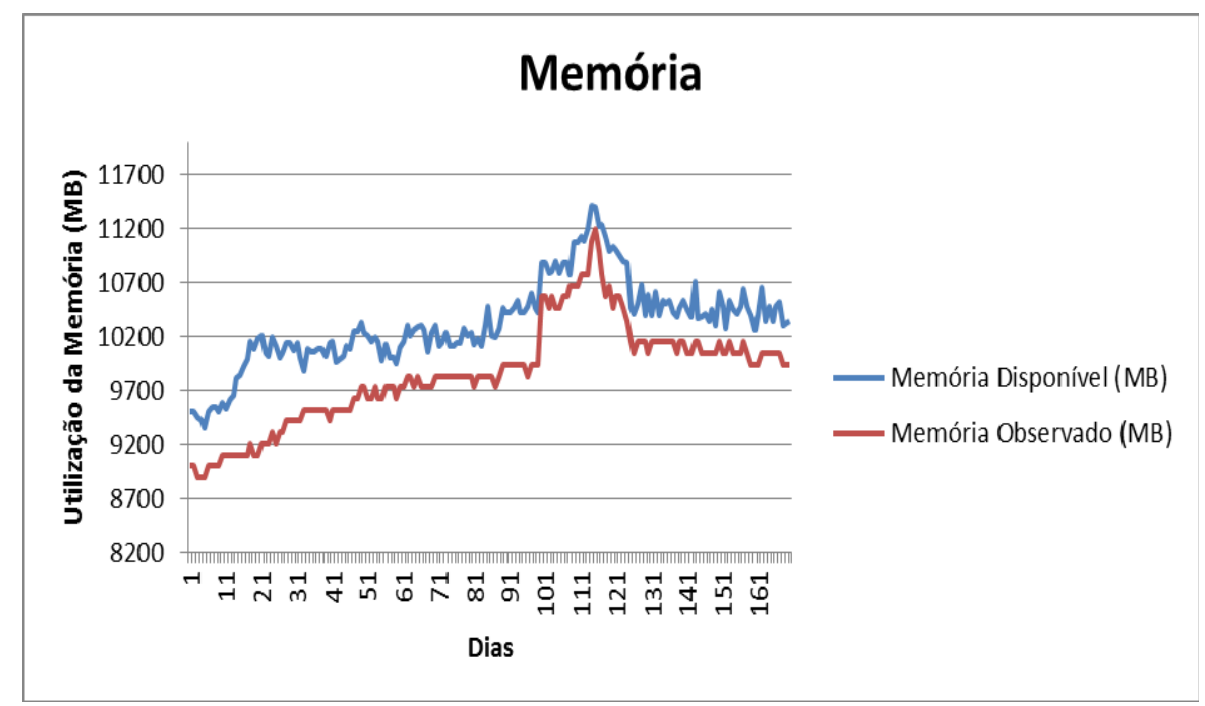

Figura 22 - Experimento2: Memória, com previsão e sem monitor

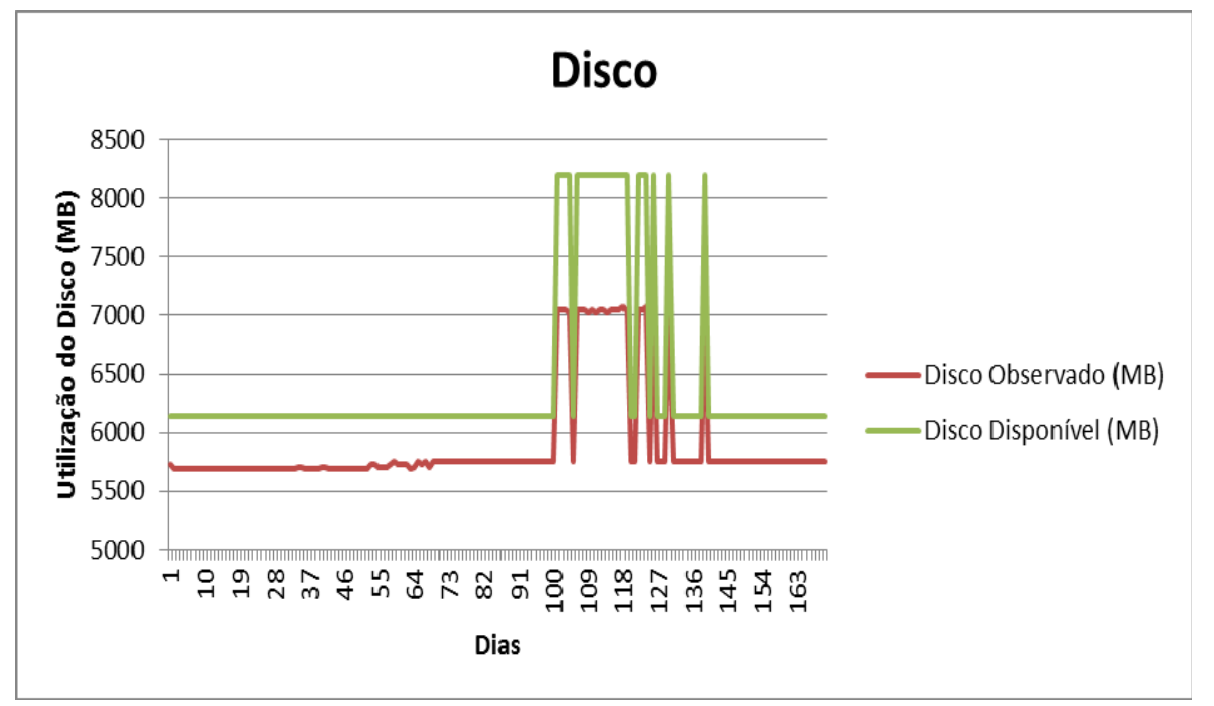

Figura 23 - Experimento2: Disco, com previsão e sem monitor

As figuras 24 e 25 são resultados do experimento 3 sem previsão mas com monitor. Neste experimento, o EQM da memória foi de 59024 e o EMP foi de 2,41\%. Se comparado o resultado do EQM do experimento 2 (Memória) com o experimento 3 (Memória), houve uma aproximação de 
mais de 75\%. O EQM e o EMP baixos são resultados das diversas reconfigurações que ocorrem na infraestutura (memória e disco) durante todo o decorrer do período. O agente monitor é capaz de perceber qualquer evento e realizar a reconfiguração, diferente do uso da previsão que realiza a reconfiguração no início do período apenas não considerando eventos no decorrer do período.

O EQM do disco foi de 174960 e o EMP foi de 5,14\%. Este experimento resultou em uma melhora de 48,2\% para o disco se comparado com o experimento 2. Neste experimento o cliente gastou $98 \%$ do valor contratado, restando $2 \%$ do valor investido para ser gasto. Esse também é um resultado melhor do que o do experimento 2 pois o valor gasto está mais próximo de $100 \%$.

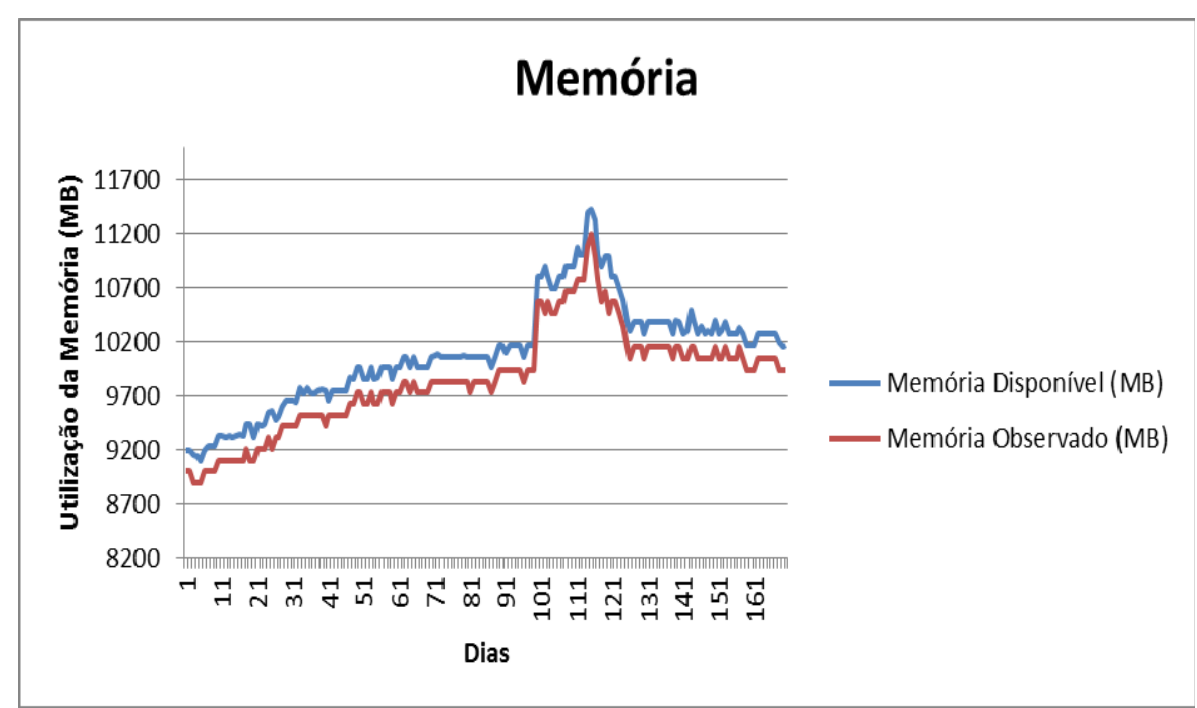

Figura 24 - Experimento3: Memória, Sem previsão e com monitor

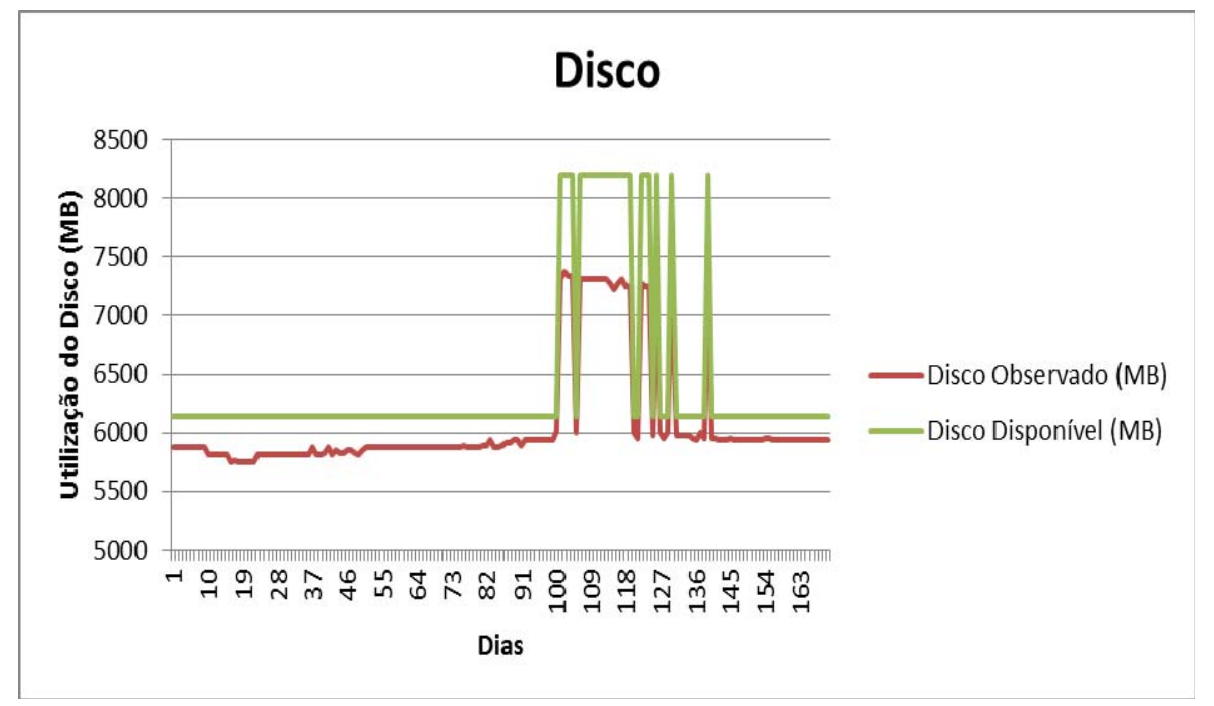

Figura 25 - Experimento3: Disco, Sem previsão e com monitor 
No experimento 4, o último experimento, considerou-se o uso da previsão e do agente monitor o EQM para a memória foi de 248182 e para o disco foi de 189750. Ao confrontar o EQM da memória do experimento 4 com os anteriores, nota-se uma aproximação de 4,98\% para o experimento 2 e um distanciamento de $320,48 \%$ em relação ao experimento 3. Com o disco o EQM no experimento 4 teve um distanciamento de $8,45 \%$ em relação ao experimento 3 e uma aproximação de $43 \%$ em relação ao experimento 2. Esse resultado para o disco ocorre pois no experimento 4 este dispositivo se manteve mais tempo reconfigurado se comparado com o experimento anterior devido a presença do agente monitor.

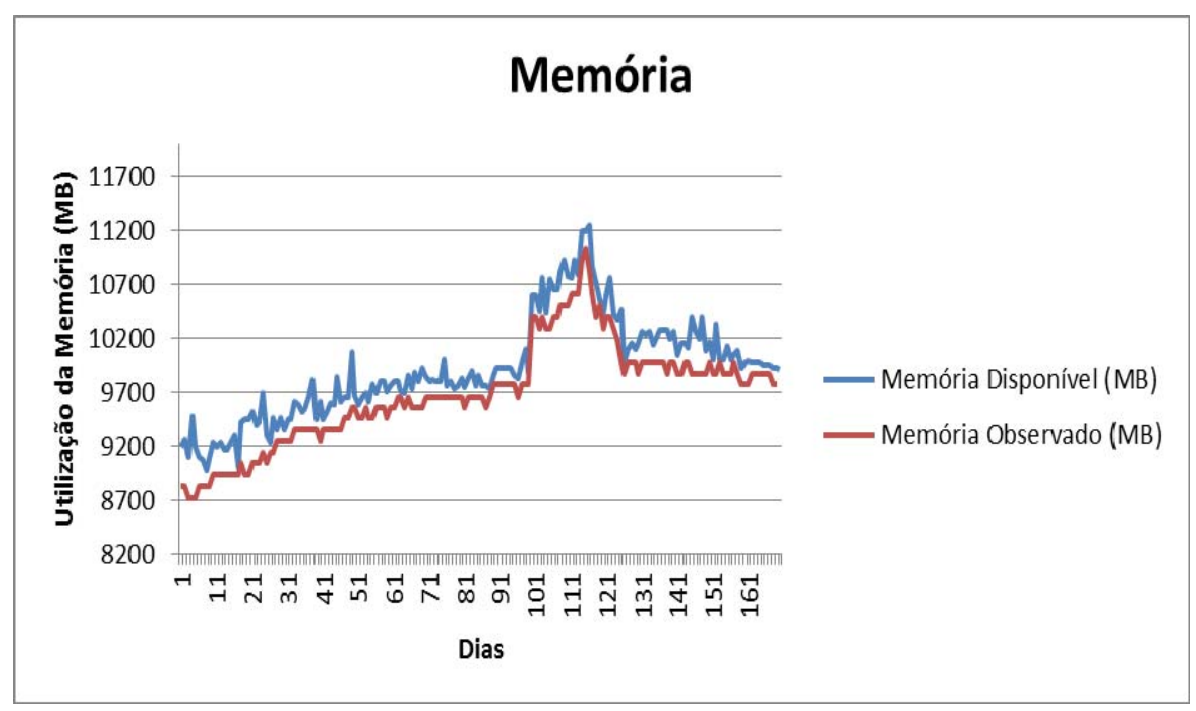

Figura 26 - Experimento4: Memória, Com previsão e com monitor

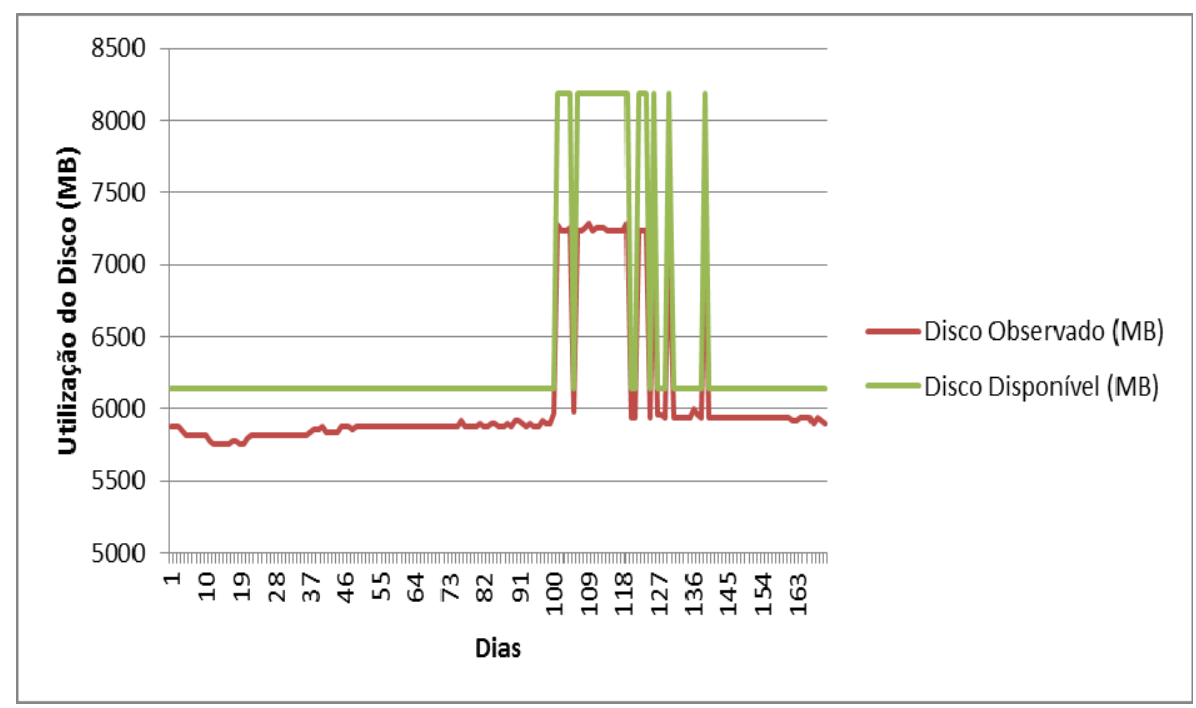

Figura 27 - Experimento4: Disco, Com previsão e com monitor 
A Tabela 6 apresenta um comparativo entre os EMQ nas fases 1 e 2 . Tanto na fase 2 como na fase 3 o EMQ foi menor no experimento 3 que foi realizado sem previsão e com agente monitor. $\mathrm{O}$ EMQ é um meio de escolher o melhor estimador, neste caso previsão e monitor. A conclusão se previsão é melhor ou pior do que agente monitor só é confiável estatisticamente, se utilizado o EMQ (que é um cálculo que tem exatamente essa finalidade).

$\mathrm{Na}$ Tabela 9 observa-se que o agente monitor possibilitou uma melhora significativa na reconfiguração dos recursos, apresentando um menor EMQ em ambas as fases, tanto para disco quanto para memória.

Tabela 9 - Comparativo entre Fase 2 e Fase 3

\begin{tabular}{|c|c|c|c|c|c|c|c|c|}
\hline \multirow{6}{*}{$\begin{array}{c}\mathbf{N} \\
\underset{\mathbf{U}}{\tilde{U}} \\
\mathbb{U}\end{array}$} & & & \multicolumn{3}{|c|}{ Memória } & \multicolumn{3}{|c|}{ Disco } \\
\hline & & & \multirow{2}{*}{$\frac{E Q M}{243,84}$} & \multicolumn{2}{|c|}{ Diferença } & \multirow{2}{*}{$\frac{E Q M}{1571,66}$} & \multicolumn{2}{|c|}{ Diferença } \\
\hline & Exp1 & $S P-S M$ & & & & & & \\
\hline & Exp2 & CP-SM & 247,78 & 3,94 & $1,62 \%$ & 1640,85 & 69,19 & $4,40 \%$ \\
\hline & Exp3 & $S P-C M$ & 125,45 & 122,33 & $49,37 \%$ & 1345,69 & 295,16 & $17,99 \%$ \\
\hline & Exp4 & $C P-C M$ & 156,29 & 30,84 & $24,58 \%$ & 1480,24 & 134,55 & $10,00 \%$ \\
\hline \multirow{6}{*}{ 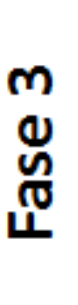 } & & & \multicolumn{3}{|c|}{ Memória } & \multicolumn{3}{|c|}{ Disco } \\
\hline & & & EQM & \multicolumn{2}{|c|}{ Diferença } & EQM & \multicolumn{2}{|c|}{ Diferença } \\
\hline & Exp1 & $S P-S M$ & 236789 & & & 261703 & & \\
\hline & Exp2 & $C P-S M$ & 251124 & 14335 & $6,05 \%$ & 337801 & 76098 & $29,08 \%$ \\
\hline & Exp3 & $S P-C M$ & 59024 & 192100 & $76,50 \%$ & 174960 & 162841 & $48,21 \%$ \\
\hline & Exp4 & $C P-C M$ & 648182 & 589158 & $998,17 \%$ & 189750 & 14790 & $8,45 \%$ \\
\hline
\end{tabular}

Observa-se ainda que o uso do agente monitor melhorou a reconfiguração realizada pela previsão, uma vez que o EMQ no experimento 4 foi menor se comparado ao EMQ do experimento 2 em todas as fases. Isso ocorre pois, como dito anteriormente, a previsão realiza apenas uma reconfiguração no início do período enquanto o agente monitor constantemente reconfigura a infraestrutura.

\subsection{Análise dos Resultados}

O modelo de Holt-Winter é capaz de acomodar um único ciclo sazonal. Na série temporal utilizada na fase 1 existem 3 ciclos sazonais: férias, início das aulas e período de entrega de notas. $\mathrm{O}$ primeiro é um período curto ( 35 dias), onde possui o menor número de acessos. O segundo é um período maior (cerca de 4 meses) e possui um número de acesso variante em média de 2,4 GB, o terceiro e último é menor período (4 dias) e a média de tráfego é de 9,3GB. 
Como o período de treinamento para o Holt-Winter foi realizado entre dois ciclos sazonais diferentes e como a série temporal possui mais de um ciclo, o valor previsto tende a sofrer grandes oscilações durante um determinado período, porém com o passar do tempo o valor previsto tende a se ajustar com o valor observado ficando bem próximo.

A Média Móvel Exponencial também apresenta um bom resultado, no entanto, é um excelente indicador para a expectativa da carga que será processada, ou seja, se a carga será alta ou baixa para um determinado período, sem indicar o seu valor aproximado ou exato, diferente do Holt-Winter.

A partir dos resultados obtidos na fase 1, foi escolhido a utilização do modelo Holt-Winter para realizar as previsões de demanda.

Os experimentos realizados com os algoritmos de previsão e com os agentes monitores nas fases 2 e 3 proporcionaram uma reconfiguração automática dos recursos da infraestrutura. Desta forma, é possível considerar que a elasticidade da nuvem proposta no início desta pesquisa foi alcançada.

Os primeiros experimentos mostraram que para se conectar a um Web Service o cliente precisa aguardar cerca de $2467 \mathrm{~ms}$ em média, o restante do tempo é para a VM ser ligada ou sair do estado de suspensa.

Os quatro experimentos seguintes mostraram o comportamento da infraestrutura frente a chegada de carga de trabalho. A menor diferença média entre a carga de trabalho observada e a configuração reconfigurada foi com o uso de monitor sem previsão. Isso ocorre, pois o monitor está constantemente verificando o uso dos recursos e, caso algum deles esteja em estado crítico, automaticamente é solicitada a reconfiguração. Diferentemente do uso de previsão, que apenas reconfigura uma vez no início do período e a próxima será somente no período seguinte.

O retorno sobre o investimento permite ao cliente observar os gastos. Nos experimentos o melhor retorno foi para o uso de monitores sem previsão, pois em todos os períodos o uso dos recursos como Memória e Disco sempre estiveram muito próximos da carga máxima suportada por cada recurso, assim sendo, foi consumido aquilo que era o necessário, sem muitas sobras ou perdas.

Os experimentos da fase 1 e fase 2 validaram os algoritmos de previsão e monitoração. Conhecendo a funcionalidade dos algoritmos desenvolvidos, bem como o uso do retorno sobre o investimento, foi possível propor a utilização de cargas reais de serviços conhecidos como sites de ecommerce e portais web na fase 3 dos experimentos. 
Na fase 2 a carga de trabalho era auxiliada por uma variável randômica, entretanto na fase 3 não houve. A diferença é que, com a carga de trabalho fixa é possível observar melhor a elasticidade e principalmente o comportamento do agente monitor e da previsão, já com a carga de trabalho aleatória é replicado o que ocorre na realidade, pois a carga de trabalho é variável.

\subsection{Considerações finais}

$\mathrm{O}$ agente monitor se mostra nos experimentos realizados como um grande mecanismo para reconfiguração da infraestrutura.

Como a previsão é baseada em dados passados ela não trata eventos ocasionais, diferente do agente monitor. Assim sendo, para estes experimentos, de acordo com os dados obtidos, a previsão não é a melhor opção para este caso. Todavia, a previsão torna-se útil para se simular os gastos futuros que o cliente possa ter com o uso da infraestrutura. 


\section{Conclusão}

\subsection{Conclusão Geral}

A gestão de recursos computacionais em nuvem proposto no início deste projeto foi realizada utilizando a elasticidade computacional. Entretanto, diversas atividades de alta relevância foram realizadas, antes mesmo da concepção do projeto e desenvolvimento dos módulos.

Inicialmente foi realizado o levantamento bibliográfico com o objetivo de se conhecer o estado da arte na área. As pesquisas iniciais estavam relacionadas com computação em nuvem e elasticidade computacional. Os resultados dessas pesquisas mostraram que diversos trabalhos estão relacionados à elasticidade, entretanto, em sua maioria, há algum tipo de interferência humana. Desta forma, amparado pelo manifesto da IBM de 2001, observou-se a oportunidade de empregar o uso de Agentes Computacionais que estão contidos dentro do conceito de Computação Autônoma para gerir a infraestrutura computacional.

Após definido os Agentes Computacionais para gerirem a elasticidade da nuvem, o passo seguinte foi conhecer as principais ferramentas que permitissem a reconfiguração da infraestrutura. Alguns comandos em Linux como o virsh possibilitaram a reconfiguração das máquinas virtuais. Posteriormente, as principais técnicas de previsão de carga de trabalho foram estudadas e, durante o levantamento bibliográfico, destacaram-se duas técnicas: Média Móvel Exponencial e Modelo de Holt-Winter, sendo o último a técnica empregada neste trabalho.

O desenvolvimento dos módulos de reconfiguração é uma das contribuições deste trabalho. Foram empregadas duas técnicas para a reconfiguração da infraestrutura, a primeira utilizando monitoramento constante e a segunda realizando a previsão. Outras técnicas de reconfiguração também poderiam ser utilizadas como autoaprendizagem por meio de redes neurais. Mas, optou-se pela previsão e monitoramento, uma vez que possui baixo tempo de latência para a reconfiguração e não é necessária uma base com muitos dados (para a previsão o mínimo é uma janela de 5 a 13 períodos).

Durante as pesquisas, o tópico sobre Retorno Sobre o Investimento despertou a atenção. Sua grande viabilidade é proporcionar um controle financeiro sobre os gastos oriundos do contrato de serviço em nuvem. O Retorno Sobre Investimento, dentro do que se trata sobre Controle Financeiro, 
foi uma funcionalidade adicionada durante o desenvolvimento do projeto e contribuiu com a proposta inicial, uma vez que se encaixa dentro do conceito de gestão eficaz da infraestrutura.

Após a conclusão do desenvolvimento dos módulos, a maior preocupação foi manter o ambiente de teste configurado corretamente para a realização dos testes. O Agente Monitor foi o responsável pela reconfiguração reativa da infraestrutura. Dessa forma, a partir dos experimentos é possível afirmar que, de acordo com os resultados obtidos, houveram significativas melhoras da reconfiguração dos recursos ao executar esse tipo de agente.

Por sua vez, a reconfiguração pró-ativa cuja responsabilidade é da previsão (ou Agente Previsor), não teve um resultado tão positivo quanto ao Agente Monitor, todavia teve resultado relevante dentro do contexto geral, uma vez que diminuiu a ociosidade da infraestrutura em alguns momentos e em outros é capaz de impedir que a carga de trabalho imposta fosse negada por falta de recursos.

Este estudo produziu resultados importantes em relação a Computação em Nuvem, com um enfoque maior na gestão eficaz dos recursos computacionais através do conceito de elasticidade e auxiliada por agentes computacionais e histórico de carga de trabalho, conforme o objetivo inicial desta pesquisa. Os resultados dos experimentos indicam uma melhora na utilização dos recursos, uma vez que, sem o gerenciamento há a ociosidade ou perda das requisições do cliente.

A avaliação de desempenho teve um papel fundamental, servindo não apenas para a verificação do desempenho do projeto, mas também para destacar as vantagens e desvantages dos módulos de reconfiguração (previsão e monitor) dentro da proposta inicial da elasticidade em nuvem.

\subsection{Contribuições}

As principais contribuições deste projeto de mestrado foi o gerenciamento da infraestrutura computacional auxiliada por agentes computacionais dentro do conceito de computação autônoma. $\mathrm{O}$ desenvolvimento dos algoritmos de previsão e monitoramento acrescentando também o ROI possibilitou o autogerenciamento da infraestrutura com o mínimo de intervenção humana.

Todos os módulos desenvolvidos são independentes, o que permite que sejam utilizados por outros projetos, por exemplo, o módulo monitor pode ser utilizado para monitorar qualquer outro ambiente. 
Existem outros trabalhos em andamento no grupo de pesquisa que utilizaram os módulos e algoritmos desenvolvidos. Um destes trabalhos está relacionado a propor a qualidade de serviço (QoS) que não foi tratado neste projeto.

Os resultados dos experimentos apontam que, com o gerenciamento proposto utilizando previsão e/ou monitoramento resulta em uma melhora na utilização dos recursos computacionais, uma vez que, sem o gerenciamento, há a ociosidade ou perda das requisições do cliente.

\subsection{Produção Cientifica}

Este projeto de mestrado permitiu a produção de um artigo que foi publicado no evento: "The Nineteenth Ieee Symposium On Computers And Communications". O referido artigo trata do gerenciamento da infraestrutura.

DIAS, A. S.; NAKAMURA, L. H. V.; ESTRELlA, J. C.; SANTANA, M. J.; SANTANA, R. H. C. Providing IaaS Resources Automatically through Prediction and Monitoring Approaches. Proceedings of the nineteenth IEEE Symposium on Computers and Communications, 2014, Madeira, Portugal.

\subsection{Trabalhos Futuros}

As contribuições alcançadas neste projeto foram significativas, entretanto, em sequência ao trabalho desenvolvido, sugere-se a adoção de algumas melhorias para a obtenção de novos resultados, destacando as seguintes sugestões:

- A elasticidade presente neste artigo obtida nos experimentos é a Vertical, ou seja, as VMs são reconfiguradas para expandir ou reduzir seus recursos de acordo com o uso. Como trabalho futuro é proposto a elasticidade Horizontal. Assim, quando uma VM estiver com alta utilização dos recursos, será criada uma nova instância e pode-se ainda realizar a migração da VM atual para a nova instância com maior capacidade;

- O ROI é obtido apenas durante a execução, desta forma o cliente não consegue ter uma perspectiva prévia do quanto gastará durante o período do contrato. Assim, propõe-se o desenvolvimento de uma ferramenta que realize a previsão dos gastos com o objetivo de se estipular, mediante ao banco de dados, o quanto o cliente gastará no final do período contratado; 
- Desenvolvimento de novos algoritmos utilizando redes neurais. Com isso será possível avaliar se é vantajoso a utilização desta técnica frente as apresentadas neste trabalho;

- Aprimorar a proposta de gerenciamento utilizando as regras de ITIL (Information Technology Infrastructure Library) associada ao conceito de DCIM (Data Center Infrastructure Management), desta forma será possível promover melhor gestão da infraestrutura promovendo qualidade no serviço ofertado. 


\section{Referências Bibliográficas}

(ADVFN, 2012) ADVFN. Média móvel exponencial. Disponível em: < http://br.advfn.com/educacional/analisetecnica/media-movel-exponencial> Acesso em 03 ago. 2012.

(ÁLVARES et. al., 2010) ÁLVARES, Alberto; FERREIRA, João. Uma metodologia para integração CAD/CAPP/CAM voltada para manufatura remota de peças rotacionais via web. Imediata, 2010. Disponível em: < gate.lab.unb.br/pub/docs/books/webmachining.graco.unb.br/papers/cadcappcam.pdf $>$ Acesso em: 17 abr. 2012.

(AMAZON, 2010) AMAZON. Visão Geral da Amazon Web Services. Dispoível em: < http://d36cz9buwru1tt.cloudfront.net/pt/wp/AWS+Overview_120610.pdf>. Acesso em: 03 abr. 2012.

(ANGELO, 2011) ANGELO, F. No Brasil, falta de profissionais eleva salários a níveis dos EUA. IT Careers, 2011. Disponível em:

$<$ http://convergenciadigital.uol.com.br/cgi/cgilua.exe/sys/start.htm?infoid=26579\&sid=46> Acesso em: 11 jun. 2011.

(ARMBRUST et. al., 2009) ARMBRUST, Michael; FOX, Armando; GRIFFITH, Rean; JOSEPH, Anthony; KATZ, Randy; KONWINSKI, Andy; LEE, Gunho; PATTERSON, David; RABKIN, Ariel; STOICA, Ion; ZAHARIA, Matei. Above the Clouds: A Berkeley view of cloud computing. Imediata, 2009. Disponível em: < http://www.eecs.berkeley.edu/Pubs/TechRpts/2009/EECS-2009-28.pdf> Acesso em: 29 mar. 2012.

(BARBOSA, 2005) BARBOSA, A. Análise da demanda do álcool utilizando os métodos de suavização exponencial. 2005. Monografia, Departamento de Estatística, Universidade Estadual de Maringá, Maringá, PR.

(BATISTA et al. 2010) BATISTA, A. F. D. M. et al. Principles of Agent-Oriented Programming. [S.1.]: Federal University of ABC (UFABC) - Brazil, 2010.

(BRANTNER et. al., 2008) Brantner, M., Florescu, D., Graf, D., Kossmann, D., and Kraska, T.. Building a database on s3. In Proceedings of the 2008 ACM SIGMOD international conference on Management of data SIGMOD '08, page 251, New York. ACM Press.

(BRAZIER et. al., 2009) BRAZIER, F.M.T.; KEPHART, J.O.; VAN DYKE PARUNAK, H.; HUHNS, M.N. Agents and Service-Oriented Computing for Autonomic Computing: A Research Agenda Internet Computing, IEEE, vol.13, no.3, pp.82-87, May-June 2009 doi: 10.1109/MIC.2009.51

(CAPRARESCU, 2009) CAPRARESCU, B.A.; PETCU, D. A Self-Organizing Feedback Loop for Autonomic Computing. Future Computing, Service Computation, Cognitive, Adaptive, Content, Patterns, 2009. COMPUTATIONWORLD '09. Computation World pp.126-131, 15-20 Nov. 2009 Doi: 10.1109/ComputationWorld.2009.21

(CARNEIRO et. al., 2010) CARNEIRO, R.; RAMOS,C.. A segurança na preservação e uso das informações na computação nas nuvens. Disponível em: <www.fatecjp.com.br/revista/art-ed02-001.pdf $>$ Acesso em: 20 mar. 2010.

(CARVALHO, 2010) CARVALHO, Paulo Soeiro de. “COMPUTORIZAÇÃO”, “DIGITALIZAÇÃO” E “VIRTUALIZAÇÃO” DA ECONOMIA DOS EUA. Disponível em:

<www.dpp.pt/pages/files/infor_inter_2000_I_V.pdf> Acesso em: 07 mai. 2012.

(CHARLtON et. al., 2010) CHARLTON, P.; MAGOUlAS, G.D.; Autonomic Computing and Ontologies to Enable Context-aware Learning Design. Tools with Artificial Intelligence (ICTAI), 2010 22nd IEEE International Conference on, vol.2, no., pp.286-291, 27-29 Oct. 2010 doi: 10.1109/ICTAI.2010.113. 
(CORRAR, 2004) CORRAR, L. J.; THEÓPHILO, C.R. Pesquisa operacional para decisão em contabilidade e administração: contabilometria. São Paulo, SP. Atlas, 2004.

(CORRÊA et. al., 2008) CORRÊA, Sand L., CERQUEIRA, Renato F. G.. Computação Autônoma: uma visão sobre arquiteturas e infraestruturas. Disponível em: Acesso em: 07 abr. 2012.

(DAWOUD et. al., 2011) DAWOUD, Wesam; TAKOUNA, Ibrahim; MEINEL, Christoph. Elastic VM for rapid and optimum virtualized Resources' allocation. Hasso Plattner Institute. Disponível em: $<$ http://ieeexplore.ieee.org/stamp/stamp.jsp?arnumber=06096465> Acesso em: 23 mai. 2012.

(DIAS, 2014) DIAS, A. S. ; NAKAMURA, L. H. V.; ESTRELLA, J. C.; SANTANA, R.H.C.; SANTANA, M.J.. Providing IaaS Resources Automatically through Prediction and Monitoring Approaches. In: IEEE Symposium On Computers And Communications, 2014, Madeira - PT. The Nineteenth Ieee Symposium On Computers And Communications, 2014.

(DEXTRA, 2010) Dextra. Web Services na Integração de Sistemas Corporativos. Disponível em: $<$ http://www.dextra.com.br/empresa/artigos/webservices.htm> Acesso em: 30 mar. 2012.

(DOBSON et. al., 2010) DOBSON, S.; STERRITT, R.; NIXON, P.; HINCHEY, M.; Fulfilling the Vision of Autonomic Computing Computer, vol.43, no.1, pp.35-41, Jan. 2010. doi: 10.1109/MC.2010.14

(EHLERS, 2012) EHLERS, Ricardo. Análise de séries temporais. Disponível em: <

http://www.each.usp.br/rvicente/AnaliseDeSeriesTemporais.pdf> Acessado em: 20 nov. 2012.

(ENDREI et. al., 2004) Endrei, M.; Ang, J.; Arsanjani, A.; Chua, S.; Comte, P.; Krogdahl, P.; Luo, M.; Newling, T.; Patterns: Service-Oriented Architecture and Web Services. IBM Redbooks, 2004. Disponível em: $<$ http://www.redbooks.ibm.com/redbooks/pdfs/sg246303.pdf >. Acesso em: 02 abr. 2012.

(ERL, 2009) ERL, Thomas. SOA Princípios de design de serviços. Pearson Prentice Hall PTR, 2009.

(FIPA, 2012) FIPA. Welcome to FIPA!. Disponível em < http://www.fipa.org/>. Acesso em: 10 Out. 2012.

(FATTORETO, 2010) FATTORETO, Vinicius. O que é Cloud Computing (Computação nas Nuvens)?. Disponível em < http://f5infotec.blogspot.com/2010_11_01_archive.html>. Acesso em: 20 nov 2012.

(HUEBSCHER et. al., 2008) HUEBSCHER, M. C.; MC CANN, J. A.. A Survey of Autonomic ComputingDegrees, Models, and Applications. ACM Computing Surveys, 40(3):1-28, 2008.

(IBM, 2001) Autonomic Computing: IBM Perspective on the State of Information Technology. IBM T. J. Watson Labs, NY, 15th October 2001. Presented at AGENDA 2001, Scotsdale, AR., 2001. Disponível em: $<$ http://www.research.ibm.com/autonomic/> Acesso em: 02 abr. 2012.

(JAIN, 1991) Jain, R.. The Art of Computer Systems Performance Analysis: Techniques for Experimental Design, Measurement, Simulation, and Modeling. J. Wiley, 1991, ISBN 0471503363.

(JOSUTTIS, 2008) Josuttis, N. M. SOA na prática - A Arte da Modelagem de Sistemas Distribuídos. 1 st. ed. Oreill'y, 2008.

(KHATUA et. al., 2010) KHATUA, S.; GHOSH , A.; MUKHERJEE, N. “Optimizing the Utilization of Virtual Resources in Cloud Environment," in IEEE Int. Conference on Virtual Environments HumanComputer Interfaces and Measurement Systems (VECIMS), 2010.

(KOMODA, 2006) Komoda, N., Service Oriented Architecture (SOA) in Industrial Systems. Department of Multimedia Engineering. In: 2006 IEEE International Conference on Industrial Informatics, 2006. 
(LEWIS, 1997) LEWIS, C. D. Demand forecasting and inventory control: a computer aided learning approach. New York, USA. John Wiley \& Sons, 1997.

(LOPES, 2002) LOPES, R. D. Previsão de autopeças: estudo de caso em uma concessionária de veículos. 2002. Dissertação, Programa de Pós-Graduação em Engenharia de Produção, Universidade Federal de Santa Catarina, Florianópolis, SC.

(MAKRIDAKIS el. al., 1998) MAKRIDAKIS, S.G.; WHEELWRIGHT, S.C.; HYNDMAN, R.J. Forecasting: methods and applications. 3a. ed. New York, USA. Wiley, 1998.

(MALULI, 2010) MALULI, Arlindo. Virtualização de computadores e a importante queda no consumo de energia. Disponível em: < http://olhardigital.uol.com.br/blog_post/12994> Acesso em: 30 mar. 2012.

(MATTESS et. al., 2010) M. Mattess, C. Vecchiola, and R. Buyya, "Managing Peak Loads by Leasing Cloud Infrastructure Services from a Spot Market," in 12th IEEE Int. Conference on High Performance Computing and Communications (HPCC), 2010.

(NOGUEIRA at. al, 2010) NOGUEIRA, Matheus Cadori; PEZZI, Daniel da Cunha. A computação agora é nas nuvens. Disponível em: <under-linux.org/attachments/f98/8369d1257953490-invasao-cloud-computing.pdf > Acesso em: 17 abr. 2012.

(PAPAZOGLOU et. al., 2003) Papazoglou, M. P.; Georgakopoulos, D. Service-oriented computing. Commun. ACM, v. 46, n. 10, p. 24-28, 2003.

(PINHEIRO, 2010) PINHEIRO, Fernando. Tipos em Cloud Computing. Disponível em: < http://www.gta.ufrj.br/ensino/eel879/trabalhos_vf_2010_2/fernando/tipos_em_cc.html > Acesso em: 02 abr. 2012.

(RAO et. al.,2011) RAO, Jia; BU, Xiangping; XU, Cheng-Zhong; WANG, Kun. A distributed self-learning approach for elastic provisioning of virtualized cloud resources. 19th Annual IEEE International Symposium on Modelling, Analysis, and Simulation of computer and telecommunication systems. Disponível em: $<\mathrm{http}$ ://ieeexplore.ieee.org/stamp/stamp.jsp?tp=\&arnumber=6005367> Acesso em: 23 mai. 2012.

(RYDLEWSKI, 2009) RYDLEWSKI, Carlos. Computação sem fronteiras. Revista Veja, ano 42, n. 32,12 ago. 2009. São Paulo: Abril 2009.

(SEO, 2009) SEO, Carlos E.. Virtualização - Problemas e Desafios. Disponível em: $<$ http://www.ic.unicamp.br/ ducatte/mo401/1s2009/T2/008278-t2.pdf > Acesso em: 30 mar. 2012.

(SKILTON, 2010) SKILTON, Mark. Building Return on Investment from Cloud Computing. Disponível em: <http://www.opengroup.org/cloud/whitepapers/ccroi/index.htm> Acesso em: 12 jun. 2012.

(SOUZA et. al., 2010) SOUZA, Flávio R. C.; MOREIRA, Leonardo O.; MACHADO, Javam C.. Computação em Nuvem: Conceitos, Tecnologias, Aplicações e Desafios. Disponível em:

$<$ http://www.es.ufc.br/ flavio/files/Computacao_Nuvem.pdf $>$ Acesso em: 29 mar. 2012.

(SOUZA et. al., 2011) SOUZA, Flávio R. C.; MOREIRA, Leonardo O.; MACHADO, Javam C.. Computação em Nuvem Autônoma: Oportunidades e Desafios. Disponível em: <

http://sbrc2011.facom.ufms.br/files/workshops/wosida/ST01_2.pdf > Acesso em: 15 mai. 2012.

(STATHIS, 2010) STATHIS, K. Autonomic computing with self-governed super-agents. Self-Adaptive and Self-Organizing Systems Workshop (SASOW), 2010 Fourth IEEE International Conference on , vol., no., pp.7679, 27-28 Sept. 2010 doi: 10.1109/SASOW.2010.18. 
(STERRITT et. al., 2003) STERRITT, R.; BUSTARD, D.. Autonomic Computing- A Means of Achieving Dependability? In: Proceedings of the 10 th IEEE International Conference and Workshop on the Engineering of Computer-Based System, p. 247-251, Los Alamitos, CA, USA, 2003. IEEE Computer Society.

(SURYAWANSHI, 2014) SURYAWANSHI, P.. Automation of Enterprise Audit Management System. Department of Computer Science. B.V.B. College of Engg \& Technology, Hubli, India. CS \& IT-CSCP 2014. Doi: $105121 /$ csit.2014.4805.

(Tanenbaum, 2003) Tanenbaum, A. S. Redes de computadores. Editora Campus, Tradução da quarta edição, 2003.

(THOMAS et. al., 2003) Thomas, J. P.; Thomas, M.; Ghinea, G. Modeling of web services flow. E-Commerce Technology, IEEE International Conference on, v. 0, p. 391, 2003.

(TIRADO et. al., 2011) TIRADO, Juan M.; HIGUERO, Daniel; ISAILA, Florin; CARRETERO, Jesús. Predictive Data Grouping and Placement for Cloud-based Elastic Server Infrastructures. $11^{\text {th }}$ IEEE/ACM International Symposiym on Cluster, Cloud and Grid Computing, 2011. doi: 10.1109/CCGrid.2011.49

(WHITE et. al., 2004) WHITE, S. R.; HANSON, J. E.; WHALLEY, I.; CHESS, D. M. ; KEPHART , J. O.. An Architectural Approach to Autonomic Computing. In: PROCEEDINGS OF THE INTERNATIONAL CONFERENCE ON AUTONOMIC COMPUTING (ICAC '04), p. 2-9, Los Alamitos, CA, USA, 2004. I EEE Computer Society. 


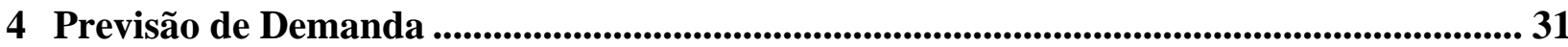

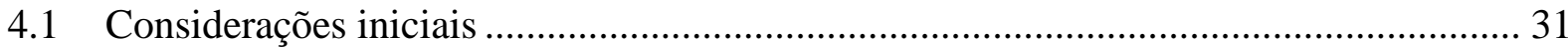

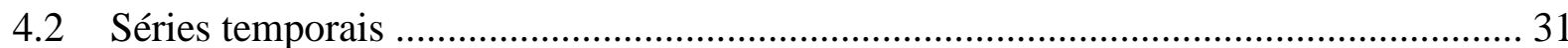

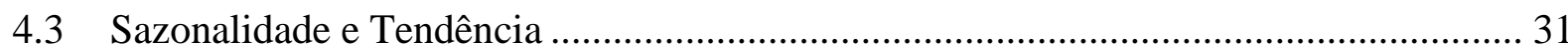

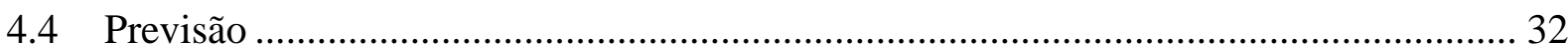

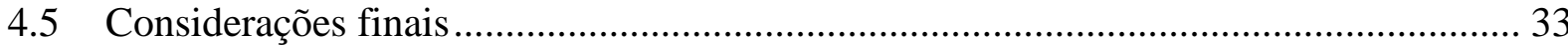

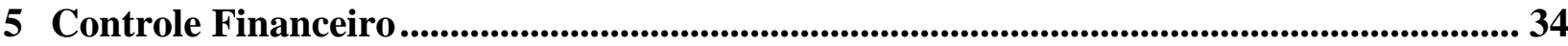

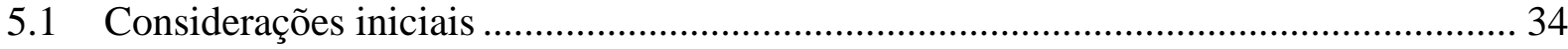

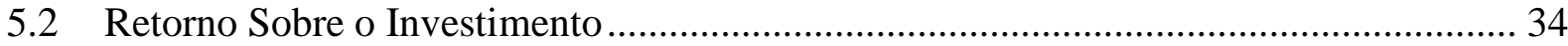

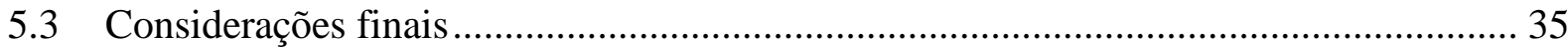

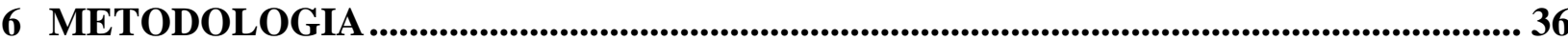

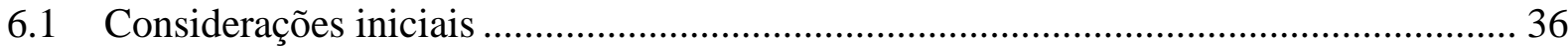

6.2 Desenvolvimento - Levantamento Bibliográfico ....................................................... 36

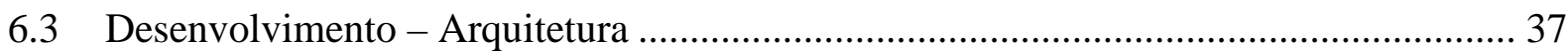

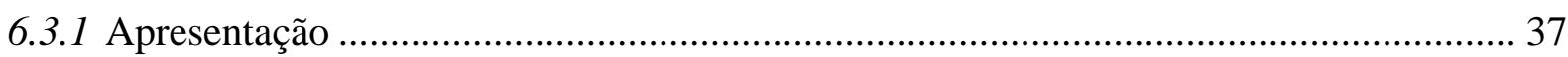

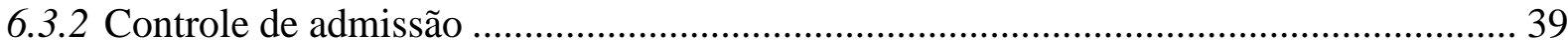

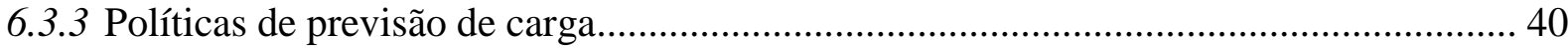

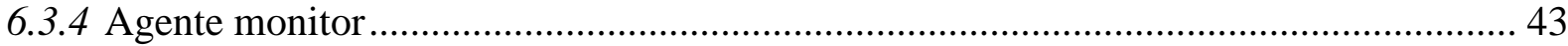

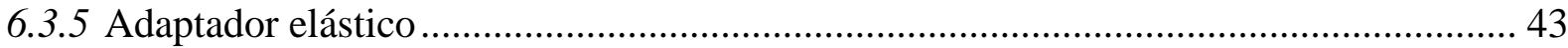

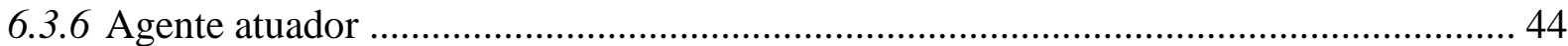

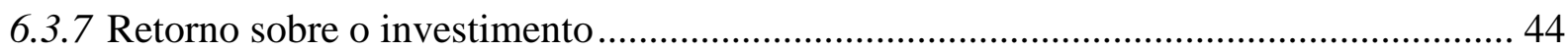

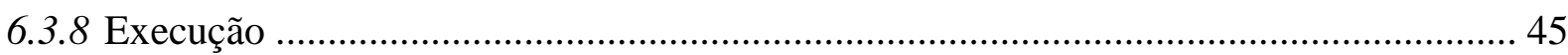

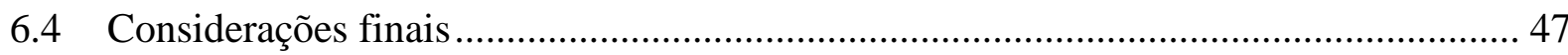

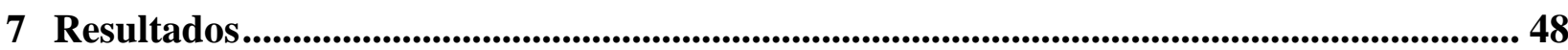

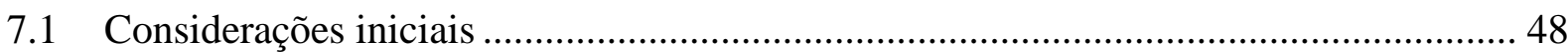

7.2 Fase 1: Resultados para escolha do modelo de previsão ............................................... 48

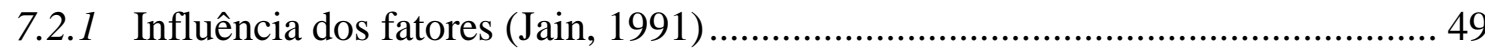


7.2.2 Previsão de carga de trabalho com treinamento de 60 dias e prazo de 120 dias. 52

7.3 Fase 2: Avaliação de desempenho da reconfiguração em 15 períodos .......................... 56

7.4 Fase 3: Avaliação de desempenho da reconfiguração em 170 períodos ........................ 64

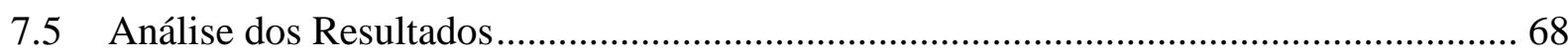

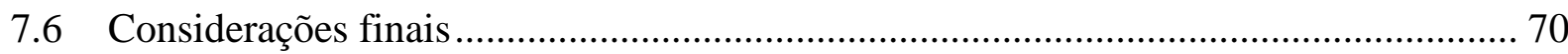

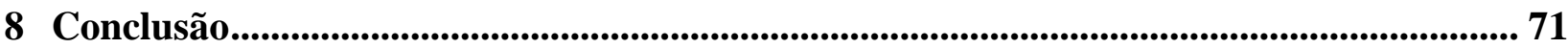

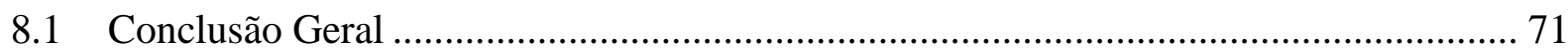

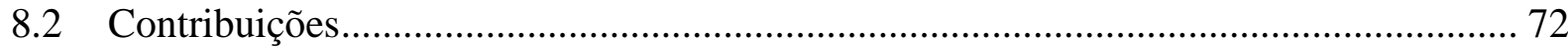

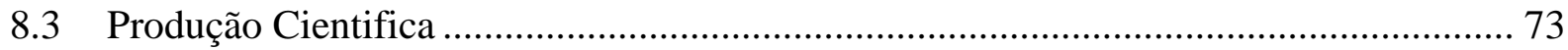

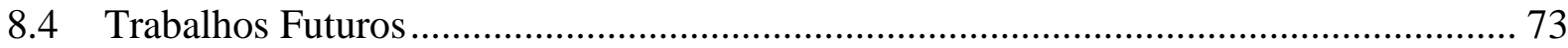

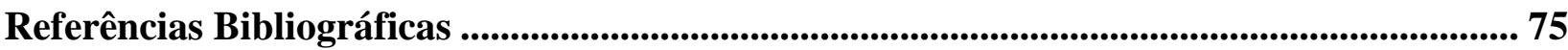




\section{AGRADECIMENTOS}

Agradeço ao meu orientador Prof. ${ }^{\circ}$ Marcos José Santana, que acreditou na proposta desta pesquisa e jamais poupou esforços no sentido de me ajudar a realizá-la. Agradeço sua criteriosa orientação para a satisfatória realização deste trabalho. Não me esqueço aqui de sua esposa, Prof. ${ }^{a}$ Regina Helena Carlucci Santana, que sempre se mostrou disposta a contribuir com a pesquisa, oferecendo em diversas oportunidades dicas de encaminhamento. Agradeço por me mostrarem o caminho da ciência. Muito obrigado!

Minha gratidão ao meu amigo de laboratório e companheiro nesta pesquisa Luis Nakamura, que gentilmente me convidou para este projeto, ajudando em todos os momentos. Sua intervenção e colaboração contriburam para a concretização deste projeto. Deixo aqui o agradecimento.

Aos professores, funcionários e colegas da Pós-Graduação do ICMC, principalmente ao professor Júlio Estrella pelas contribuições relacionadas com documentação. Aos professores Amilcar Carelli e Júlio Estrella, que gentilmente compuseram minha banca de qualificação, pelas sugestões significativas relacionadas a minha pesquisa e que nortearam para o estado que se conclui hoje. Agradecimentos também ao professor Celso Hirata que, juntamente com o professor Júlio compuseram minha banca de defesa.

Agradeço meus amigos do Instituto de Medicina Social e Criminologia de São Paulo (IMESC) pela ajuda e o incentivo. Agradeço especialmente ao meu diretor Domingos Silveira de Jesus e a minha superintendente Dra. Márcia Pereira Dobarro Facci pela compreenção nos momentos que tive que me ausentar do serviço para realizar este projeto.

Aos meus pais Abimael e Cleusa por terem me dado carinho, educação, ensinado valores e por acreditarem em mim. Agradeço a vocês que, em vários momentos, renunciaram seus sonhos para realizarem o meu. Hoje (e sempre) partilho com vocês a alegria de ser quem eu sou. Obrigado por me amarem e me tornarem o homem que sou.

Agradeço a minha esposa Cíntia que foi meu maior incentivo. Quando tudo parecia sem sentido você me deu amor e a compreenção necessária para continuar a caminhar. Graças a você e sua persistência hoje concluo este trabalho já almejando o próximo. Agradeço meu filho Yan que com seu sorriso me tira toda tristeza e alivia meu dia. 
Acima de tudo, agradeço a Deus pelo amor incondicional que Tens por mim, por sempre estar do meu lado, me protegendo e guiando meus passos. Obrigado por mais esta conquista Senhor.

Quero agradecer também à FAPESP pelo apoio financeiro concedido para a realização deste trabalho. 
"Mestre não é quem sempre ensina, mas quem de repente aprende"Grande Sertão: Veredas - João Guimarães Rosa 


\section{RESUMO}

A gestão eficaz de recursos computacionais em nuvem está diretamente ligada a gerir corretamente o desempenho das aplicações hospedadas na Máquina Virtual (Virtual Machine - VM), criando um ambiente capaz de controlá-la e redimensionar recursos de Memória, Disco, CPU e outros que se façam necessários, individualmente em resposta a carga de trabalho. Neste trabalho considerase também a gestão eficaz a qual é possível realizar o retorno sobre o investimento realizado para a contratação do serviço de IaaS. Nesta pesquisa de mestrado, foi proposto o gerenciamento da infraestrutura computacional em nuvem, através de dois modelos que facilitam o provisionamento auto-adaptativo de recursos em um ambiente virtualizado: alocação de recursos utilizando modelo para previsão da carga de trabalho futura e a gestão auto-adaptativa de capacidade utilizando agentes computacionais para monitorarem constantemente as VMs. Além disso, é proposto o retorno do investimento, que trata a relação entre o valor que o cliente contratou do serviço de IaaS e o quanto efetivamente ele está utilizando. Desta forma, a cada período é contabilizado a taxa do valor gasto em unidades monetárias. Para contemplar esta proposta, foram desenvolvidos algoritmos que são o núcleo de todo gerenciamento. Também foram realizados experimentos e os resultados mostram a capacidade do autogerenciamento das máquinas virtuais, com reconfiguração dinâmica da infraestrutura através de previsões baseadas em histórico e também da reconfiguração e monitoramento com o uso de agentes computacionais. Após a análise e avaliação dos resultados obtidos nos experimentos, é possível afirmar que houve uma significativa melhora da reconfiguração dos recursos com agentes computacionais se comparado a reconfiguração com previsão de carga futura. 


\section{ABSTRACT}

The efficient management of computational resources in the cloud is directly linked to correctly manage the performance of the applications hosted in the virtual machine (Virtual Machine VM), creating an environment able to control it and resize features Memory, Disk, CPU and others resources, individually in response to workload. This work is also considered effective management which is possible to realize the return on investment for hiring the IaaS service. This Master thesis, is proposed the management of computing infrastructure in the cloud, using two models that facilitate self-adaptive resource provisioning in a virtualized environment using resource allocation model to predict the future workload and adaptive self-management capacity utilizing computational agents to continuously monitor the VMs. Furthermore, it is proposed return on investment, which is the ratio between the value that the client hired the IaaS service and how effectively it is using. Thus, each period is accounted for the rate of the amount spent in monetary units. To address this proposal, were developed algorithms that are the core of all management. Experiments were also conducted and the results show the ability of self-management for virtual machines with dynamic reconfiguration of infrastructure through predictions based on historical and also the reconfiguration and monitoring with the use of computational agents. After the analysis and evaluation of the results obtained in the experiments, is possible say that there was a significant improvement in reconfiguration of resources with computational agents compared with the workload forecast. 


\section{LISTA DE FIGURAS}

Figura 1 - Análise de uso de recurso computacional ..............................................................................26

Figura 2 - Escopo da arquitetura principal envolvendo projeto de mestrado e doutorado................................... 38

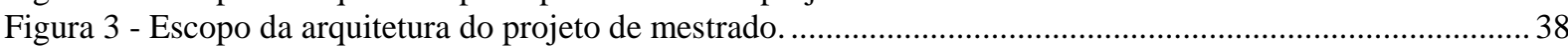

Figura 4 - Diagrama de Sequência: Controle de Admissão .......................................................................... 39

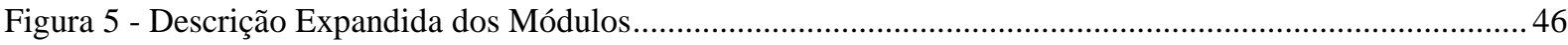

Figura 6 - Influência de fatores para a variável de resposta EMQ .............................................................. 50

Figura 7 - Influência de fatores para a variável de resposta Desvio Padrão .....................................................5 51

Figura 8 - Previsão de carga de trabalho para 120 dias com treinamento de 60 dias utilizando MME ................53

Figura 9 - Previsão de carga de trabalho para 120 dias com treinamento de 60 dias utilizando Holt-Winter ....... 54

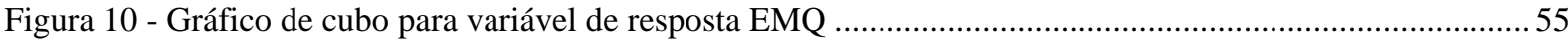

Figura 11 - Gráfico de cubo para variável de resposta Desvio Padrão .............................................................55

Figura 12 - Experimento 1: Memória, sem previsão e sem monitor..............................................................59

Figura 13 - Experimento 1: Disco, sem previsão e sem monitor ..................................................................59

Figura 14 - Experimento 2: Memória, com previsão e com monitor...............................................................6 60

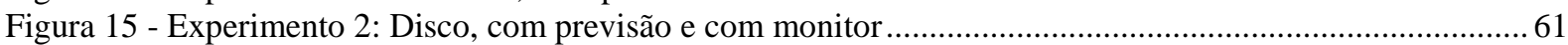

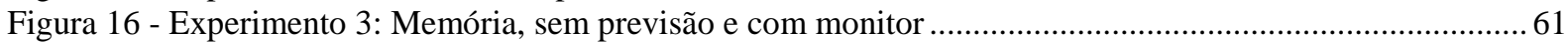

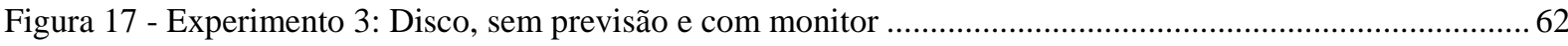

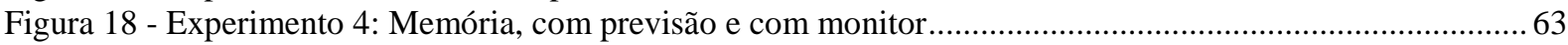

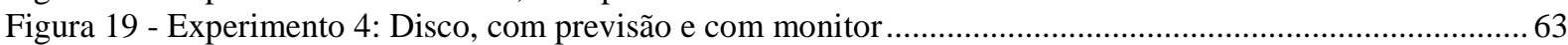

Figura 20 - Experimento1: Memória, Sem Previsão e Sem Monitor...............................................................64

Figura 21 - Experimento1: Disco, Sem Previsão e Sem Monitor ..................................................................64

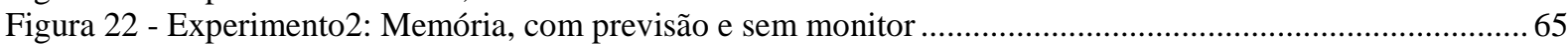

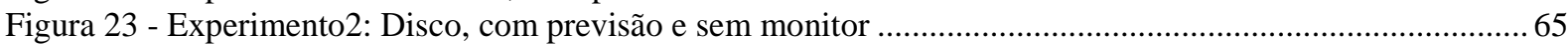

Figura 24 - Experimento3: Memória, Sem previsão e com monitor ...............................................................66 66

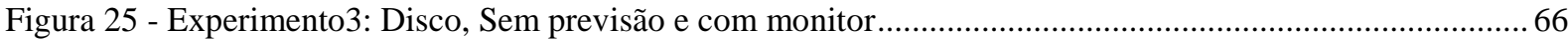

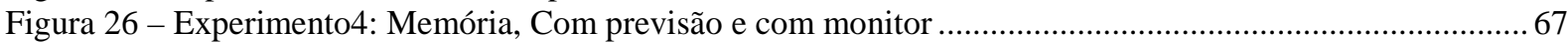

Figura 27 - Experimento4: Disco, Com previsão e com monitor ................................................................6 67 


\section{LISTA DE TABELAS}

Tabela 1 - Trabalhos relacionados e recursos a contemplar .......................................Erro! Indicador não definido. Tabela 2 - Fatores e níveis......................................................................................Erro! Indicador não definido.

Tabela 3 - Valores para a variável de resposta EMQ ...............................................Erro! Indicador não definido.

Tabela 4 - Valores para a variável de resposta Desvio Padrão..................................Erro! Indicador não definido.

Tabela 5 - Cálculos ROI .....................................................................................Erro! Indicador não definido.

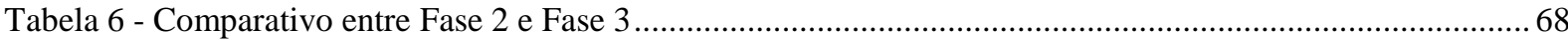




\section{LISTA DE SIGLAS}

$\begin{array}{ll}\text { TI } & \text { Tecnologia da Informação } \\ \text { CPU } & \text { Central Processing Unit } \\ \text { HD } & \text { Hard Disk } \\ \text { KVM } & \text { Kernel-based Virtual Machine } \\ \text { IaaS } & \text { Infrastructure as a Service } \\ \text { PaaS } & \text { Platform as a Service } \\ \text { SaaS } & \text { Software as a Service } \\ \text { SO } & \text { Sistema Operacional } \\ \text { MV } & \text { Máquina Virtual } \\ \text { MHW } & \text { Modelo Holt-Winter } \\ \text { EMQ } & \text { Erro Médio Quadrático }\end{array}$




\section{Introdução}

\subsection{Contextualização}

Os computadores tradicionais acompanham de forma desigual o avanço da tecnologia de software, o que obriga muitas vezes os usuários comuns e principalmente organizações empresariais, a optarem por arquiteturas de sistemas distribuídos, visando o aperfeiçoamento do ambiente computacional e a diminuição de custos.

Considerando a velocidade do crescimento de aplicações cada vez mais complexas aliada ao processamento e armazenamento de dados cada vez mais dependentes de hardware mais robustos, as organizações se deparam com um cenário em que são obrigadas a trocarem seus computadores e servidores, renovando a infraestrutura computacional periodicamente, gerando altos custos financeiros. Além disso, há a preocupação com backups, manutenções, licenças de software e principalmente de profissionais capacitados e sempre atualizados com as novas tecnologias do mercado.

Analisando esse contexto e conforme descrito por Souza (SOUZA et. al., 2010), a Computação em Nuvem deixa de ser apenas um conceito e passa a ser uma realidade aplicável de tecnologia, fornecendo os componentes básicos de Tecnologia da Informação (TI) como armazenamento de dados, processamento e memória como uma "mercadoria”, por meio de servidores especializados por um baixo custo.

\subsection{Motivação}

Segundo Maluli (MALULI, 2010), o consumo de energia elétrica pelos servidores em datacenters e dos equipamentos relacionados à Tecnologia da Informação (TI) ultrapassa a margem de $60 \%$ do consumo médio das empresas em todo mundo, sendo que em média uma máquina física é utilizada de $5 \%$ a $15 \%$, entre seus picos e baixas, ficando o restante do tempo ociosa (MALULI, 2010). Como em uma organização há diversos servidores e computadores conectados a eles, certamente os recursos computacionais estão sendo subutilizados, gerando gasto de energia para manter um recurso em estado de ociosidade. 
Nesse contexto (economia de energia e ociosidade de servidores), a organização tem a opção de virtualizar seus servidores. Com isso, todo processamento estará alocado em um servidor principal na nuvem e, se uma máquina física utiliza cerca de $15 \%$ em seu pico de todo recurso computacional, várias máquinas virtuais dentro de um único servidor tendem a equilibrar os picos e baixas de utilização das máquinas (MALULI, 2010).

Em outro contexto, as organizações em geral passam por períodos de maior uso de recursos computacionais. Isso ocorre em razão de demandas sazonais como, por exemplo, a emissão de folha de pagamento de funcionários, o aumento de produtividade em determinado período do ano ou até mesmo o menor uso de recursos computacionais (por exemplo, no fim de semana quando nenhum ou poucos funcionários trabalham).

Não é satisfatório para uma organização pagar mensalmente por um recurso que não utilizou em sua totalidade, sendo esta uma questão de desperdício financeiro em um investimento que não está sendo utilizado totalmente.

Outra análise está relacionada com as aplicações on-line como YouTube, Flickr, FaceBook que apresentam carga de trabalho dinâmica dependendo de fatores previsíveis como tendências, periodicidade ou eventos programados, onde tais fatores são provisionados por meio de recursos próativos, já esperados e alocados anteriormente mediante a previsão de modelos fundamentados em uma base de conhecimento passado.

Provisionamento de recursos proativo exige modelos de previsões futuros e proporciona maior segurança, pois é conhecida (ou esperada) uma determinada carga de utilização. Por outro lado, pode surgir um volume inesperado e altos picos de utilização da aplicação sem prévio conhecimento. Quando neste caso a carga não pode ser prevista, há a necessidade da infraestrutura computacional se estender para que o serviço da aplicação não necessite ser interrompido ou haver queda do sistema. Por outro lado, surge a necessidade da infraestrutura diminuir os recursos oferecidos caso a utilização dos mesmos esteja superestimada (TIRADO et. al., 2011) (MALULI, 2010).

Observou-se a necessidade de mecanismos de reconfiguração dinâmica da infraestrutura computacional, sem a interferência humana, onde se permite aumentar e diminuir a capacidade do servidor contratado quando a demanda aumentar ou diminuir. Assim, a empresa economizará energia (apesar deste não ser o foco principal do trabalho), utilizará de forma adequada os recursos computacionais da infraestrutura contratada (evitando muitos momentos ociosos) e pagará um custo coerente com os recursos virtualizados utilizados no período determinado. 


\subsubsection{Objetivo}

Ao se tratar de Computação em Nuvem, muitas vantagens e características positivas são apontadas. Entretanto, a aplicabilidade deste conceito envolve diversos problemas como segurança, alta disponibilidade, consumo de energia, entre outros. Neste trabalho busca-se o foco em dois problemas que se complementam:

- Recurso subutilizado (ociosidade): o número de máquinas contratadas será relativamente grande e o investimento está direcionado a recursos não utilizados. Por exemplo, o recurso computacional máximo da nuvem que ela utiliza corresponde a dois computadores e ambos ficam ociosos, com pouco ou nenhuma atividade (TIRADO et. al., 2011).

- Falta de Recurso: em algum momento a organização precisará de mais recursos computacionais, por exemplo, memória. Uma opção apresentada é entrar em contato com o provedor do serviço de Computação em Nuvem e solicitar a atualização no tamanho da memória. Essa atualização pode não ser automática e obriga a organização a aguardar um determinado prazo de tempo que pode ser de horas ou até mesmo dias (BRANTNER et. al., 2008).

Este projeto de mestrado tem como finalidade pesquisar e contribuir com a comunidade acadêmica e científica apresentando soluções para a gestão eficaz dos recursos computacionais em nuvem. Esse objetivo será alcançado através da adoção de conceitos de elasticidade computacional, auxiliada por agentes computacionais, dando uma resposta ágil à carga de trabalho do usuário comum ou de organizações empresariais.

\subsubsection{Objetivo específico}

Considerando as motivações que levam a esse estudo e à aplicabilidade a posteriori, o objetivo deste projeto é desenvolver uma arquitetura voltada para a elasticidade da nuvem computacional através da reconfiguração dinâmica do ambiente virtualizado com a mínima necessidade da interferência humana, contribuindo com o autogerenciamento da infraestrutura computacional e com a melhor utilização dos recursos, que será feita por agentes computacionais e políticas de demanda de recurso baseadas em previsão e/ou monitoramento.

Toda a reconfiguração da infraestrutura será transparente aos usuários que continuarão utilizando as máquinas virtualizadas sem interrupções e sem notarem a troca do contexto. Para os 
experimentos que avaliam a arquitetura proposta neste mestrado, foram criadas máquinas virtuais, hospedadas em provedores de serviços, que executam Web Services responsáveis pela geração de carga de trabalho que é imposta pelos clientes.

\subsection{Trabalhos relacionados}

No trabalho (TIRADO et. al., 2011) os autores realizaram uma análise da carga de trabalho de um portal de música, propondo uma infraestrutura web elástica capaz de se adaptar dinamicamente de acordo com as variações de carga e demanda.

Os experimentos foram realizados em uma arquitetura de serviço web organizado em três niveis: dispather que consiste de servidores que recebem as requisições dos usuários; os web services que possuem a lógica da aplicação e recebem as solicitações do dispatcher, recupera os dados armazenados nos back-ends e servem o dispatcher; e o storage backend que é o local onde estão armazenadas as músicas. De acordo com as características da aplicação, cada uma recebe uma demanda intensiva de recursos específicos (disco, processador, etc) tornando-se um gargalo e propagando a degradação do desempenho de uma camada para a aplicação inteira.

Para solucionar esse problema, os autores propõem o agrupamento de dados realizando uma previsão de acesso futuro com base em um histórico de acessos, colocando os conteúdos mais populares e correlacionados em um mesmo servidor. Esse modelo facilita a busca, pois os artistas mais ouvidos certamente estarão nos mesmos servidores, os quais terão maior capacidade de recursos do que os artistas menos populares.

A infraestrutura se adapta de acordo com a previsão de carga de trabalho com base em um modelo de média móvel autoregressivo (ARMA) que, segundo (TIRADO et. al., 2011), "ajuda a fazer cumprir um provisionamento de recursos mais eficiente", capturando tendências e padrões de sazonalidade. Nos resultados desses experimentos, o erro de previsão foi de $6 \%$.

Dawoud (DAWOUD et. al., 2011) propõe uma arquitetura de máquinas virtuais elásticas, a qual será responsável pela escalabilidade dos recursos de uma MV dinamicamente de acordo com a carga de trabalho. Na escalabilidade dinâmica dos recursos, o núcleo elástico do hypervisor de máquinas virtuais é dimensionado por linguagens de programação sem interromper ou reiniciar os serviços. Como em (TIRADO et. al., 2011) os autores consideram uma arquitetura de aplicação web com: camada web, camada de aplicativo e camada de banco de dados. A dependência entre as camadas nesta proposta é novamente um gargalo, então o primeiro passo apontado pelo autor é prever 
em qual momento pode ocorrer o estrangulamento (maior número de acessos ou maior utilização de recursos) e em seguida realizar a escala dinâmica dos recursos disponíveis.

Segundo os autores, implementações atuais da Amazon EC2 e GoGrid recebem as solicitações dos usuários e direcionam para um balanceador de carga o qual encaminha a requisição para uma MV disponível. Um controlador monitora o desempenho de cada MV, expandindo ou reduzindo os recursos, porém tal tarefa não é executada em tempo real. O projeto do autor também constitui de um controlador monitorando o desempenho de cada camada. Entretanto, se as métricas de desempenho como processador exceder um determinado limite, o controlador de recursos de máquina virtual aumenta em tempo de execução os recursos da máquina virtual daquela camada para manter um sistema com um desempenho aceitável.

Rao et. al. (2011) apresentam o iBallon, um framework genérico que utiliza um algoritmo de reforço de aprendizagem que permite a alocação automática dos recursos computacionais de uma MV. Um agente computacional em um host físico é o responsável por gerenciar os recursos das MVs em tempo de execução. O agente computacional decide o quanto cada MV terá de capacidade de acordo com histórico anterior. O mecanismo de aprendizagem permite que cada MV aprenda sua política de gestão de capacidade de acordo com feedbacks enviados pelo nó do agente de aprendizagem e aumente ou decremente seus recursos automaticamente.

As organizações por todo mundo vêem a Computação em Nuvem como uma tendência transformadora de ter sua infraestrutura computacional distribuída e compartilhada, principalmente devido aos cortes de custo com mão de obra em TI e atualização/manutenção de software e hardware (DEXTRA, 2010) (AMAZON, 2010) (ARMBRUST et. al., 2009) (CARVALHO, 2010). Um dos grandes contratempos dos fornecedores de infraestrutura como serviço é a comunicação entre os departamentos financeiro e de TI. Enquanto o primeiro deseja reduzir custo e obter um retorno de investimentos, o segundo por sua vez, está sempre considerando investimentos em novas tecnologias, que nem sempre possuem valores acessíveis e fáceis de se encaixarem no orçamento de qualquer empresa. Em muitos casos, é crítico para o departamento de TI que está considerando a adoção da nuvem mostrar para o departamento financeiro que há possibilidade de obter retorno sobre o investimento realizado para os negócios da empresa.

Skilton (SKILTON, 2010) apresenta o ROI (Return on Investment ou retorno sobre o investimento), onde os fornecedores de serviço em nuvem podem analisar e desenvolver planos de negócios e implantar uma infraestrutura de serviços de forma mais rápida e pró-ativa. Em seus estudos Skilton apresenta uma série de considerações sobre possíveis formas de se construir uma infraestrutura em nuvem e mensurar o ROI, que é colocado como parte do processo de planejamento para a 
implementação de uma nuvem. Com isso, as empresas começarão a tirar vantagens sobre a Computação em Nuvem.

O ROI aplicado na Computação em Nuvem trará vantagens para os fornecedores e clientes de serviços em nuvens, pois ambos terão controle do quanto foi investido na infraestrutura e quanto está sendo o retorno. Com esta metodologia, ambos os lados saberão se o investimento está sendo satisfatório, se é necessário e possível financeiramente aumentar recursos, ou se não está tendo um retorno favorável e sendo assim haverá a necessidade de diminuir os recursos computacionais disponíveis.

Sousa (Sousa et. al., 2010) apresentam três principais desafios para desenvolver um ambiente em nuvem totalmente autônoma:

Desenvolvimento de um sistema autônomo para nuvens: de acordo com os autores, um sistema autônomo para nuvem deve monitorar o comportamento e desempenho do ambiente virtualizado, sendo capaz de tratar questões de tolerância a falhas, reconfiguração automática de software promovendo a elasticidade e o balanceamento da carga de trabalho através da modelagem de previsão de carga futura.

Políticas para computação em nuvem: os autores apresentam como principal desafio conceber políticas de alto nível que capturem tanto aspectos técnicos como os objetivos do negócio, pois consideram que as políticas devem representar as propriedades dos sistemas autônomos e o comportamento, objetivos, adaptação e interação entre eles, assim como relação entre a influência externa (usuário) e a demanda do sistema.

Monitoramento de ambientes em nuvem: para os autores, a principal questão é como gerenciar de forma automática os recursos disponíveis e a carga de trabalho do sistema para garantir a qualidade do serviço e melhorar a utilização destes recursos. Técnicas de monitoramento adaptativas e dinâmicas deverão ser desenvolvidas para tratar esta questão.

A Tabela 1 exibe alguns trabalhos relacionados citados anteriormente e o que cada um contempla. As lacunas não preenchidas na maior parte dos trabalhos foram contempladas no decorrer desta pesquisa.

Os trabalhos citados anteriormente foram aqui colocados por possuírem os principais aspectos da pesquisa realizada. Outros trabalhos foram estudados e os seus resultados permitiram evoluir no decorrer do desenvolvimento dos módulos do projeto como em (Jarraya, 2012) que disserta sobre segurança em ambiente na nuvem, principalmente por inconsistências que possam surgir no momento de uma reconfiguração da infraestrutura ou migração de máquinas. 
Apesar de não ser o objetivo deste trabalho, a segurança permite garantir que, após ser reconfigurada ou migrada, a máquina continue a fornecer serviços. (Jarraya, 2012) em sua pesquisa especificou métricas para uma reconfiguração ou migração de máquinas segura.

Tabela 1 - Trabalhos Relacionados

\begin{tabular}{|c|c|c|c|c|c|c|c|c|c|}
\hline & $\mathbf{1}$ & $\mathbf{2}$ & $\mathbf{3}$ & $\mathbf{4}$ & $\mathbf{5}$ & $\mathbf{6}$ & $\mathbf{7}$ & $\mathbf{8}$ & $\mathbf{9}$ \\
\hline (TIRADO, et al., 2011) & $\mathrm{X}$ & & $\mathrm{X}$ & & $\mathrm{X}$ & & & & \\
\hline (DAWOUD, et. al., 2011) & & $\mathrm{X}$ & & $\mathrm{X}$ & & & & & \\
\hline (RAO, et al., 2011) & & $\mathrm{X}$ & & & & $\mathrm{X}$ & $\mathrm{X}$ & & \\
\hline (SKILTON, 2010) & & & & & & $\mathrm{X}$ & & & $\mathrm{X}$ \\
\hline Projeto & $\mathrm{X}$ & $\mathrm{X}$ & $\mathrm{X}$ & $\mathrm{X}$ & $\mathrm{X}$ & $\mathrm{X}$ & $\mathrm{X}$ & $\mathrm{X}$ & $\mathrm{X}$ \\
\hline
\end{tabular}

(1) Previsão de demanda, (2) Elasticidade em tempo de execução, (3) Aplicação web, (4) Monitor, (5) Sazonalidade e tendência, (6) IaaS, (7) Computação Autônoma, (8) Agentes Computacionais, (9) Controle orçamentário.

\subsection{Organização da Monografia}

Esta monografia de mestrado está dividida da seguinte forma:

O Capítulo 2 trata do conceito de computação em nuvem que é um assunto altamente difundido e fonte de várias pesquisas em academias e organizações por todo mundo.

O Capítulo 3 engloba questões fundamentais e diretas sobre computação autônoma, apresentando os agentes computacionais que no projeto, dentre outras finalidades, serão responsáveis por monitorar máquinas virtuais. Cabe ao framework Jade oferecer um ambiente propício para o trabalho com multiagentes. Tal framework também será tratado no mesmo capítulo.

O Capítulo 4 apresenta brevemente considerações a respeito de pontos fundamentais da previsão da demanda como o agrupamento de dados formando séries temporais, as possíveis sazonalidades e tendências encontradas nessas séries e, por fim, uma explicação sobre previsão de demanda.

O Capítulo 5 tem como conteúdo principal o Retorno Sobre Investimento dentro do conceito de Controle Financeiro.

O Capítulo 6 dissetará a respeito do projeto, toda a sua estrutura e seus módulos.

No Capítulo 7 está contida a metodologia e algumas ferramentas que são utilizadas.

O Capítulo 8 apresenta os resultados dos experimentos e avaliação dos dados obtidos. 
Por fim, é apresentada a conclusão sobre o projeto como um todo, as contribuições alcançadas e sugestões para trabalhos futuros. 


\section{Computação em nuvem}

\subsection{Considerações iniciais}

A Computação em Nuvem surgiu a partir da necessidade das organizações de construir uma infraestrutura computacional complexa, deixando a cargo de terceiros o controle de toda arquitetura computacional, utilizando plataformas computacionais em nuvem contratada como serviços, permitindo uma utilização transparente de todo recurso computacional.

Nas empresas, computadores simples de baixa capacidade podem ser utilizados para se conectarem a uma máquina virtual na nuvem e utilizarem o serviço contratado. No fornecedor do serviço concentra-se todo o controle como backups, manutenção e controles de acesso. Assim, os usuários e as empresas passaram a acessar os serviços sob demanda e independente de localização, o que aumenta a quantidade de serviços disponíveis.

Com a Computação em Nuvem, todas as questões relacionadas a hardware, backup, segurança, entre outros fatores são de responsabilidade do provedor do serviço. O usuário pode adquirir recursos computacionais de acordo com suas necessidades (sob demanda), bastando apenas entrar em contato com o provedor.

Considerando ainda a proposta de Computação em Nuvem, a organização não precisará se preocupar com perda de dados ou indisponibilidade, pois se houver falha em qualquer componente na estrutura computacional em nuvem, o provedor do serviço é responsável por substituí-lo e tornar os dados disponíveis em tempo hábil (BRANTNER, 2008).

\subsection{Conceitos}

A Computação em Nuvem é dividida em vários conceitos diferentes, cada uma caracterizando formas diferentes de se aplicar e utilizar este conceito. As três principais tipologias são:

- SaaS (Software como um Serviço) - Softwares de propósitos específicos são disponibilizados na Internet. Como os softwares (aplicações) estão na Web, o usuário pode acessá-los a partir de qualquer lugar e a qualquer momento, permitindo maior integração entre unidades de 
empresas ou de serviços. Como exemplo cita-se o Google Docs, oferecendo softwares como editores de texto e planilhas eletrônicas (CIURANA, 2009);

- PaaS (Plataforma como um Serviço) - Oferece uma plataforma para desenvolvimento e teste de aplicações na nuvem. Como exemplo cita-se o Google App Engine (CIURANA, 2009).

- IaaS (Infraestrutura como um Serviço) - Neste tipo de nuvem, toda infraestrutura de hardware primária como processamento, memória e armazenamento é oferecida aos utilizadores como um serviço virtual sob demanda (RAO, BU, et al., 2011). Com isso é permitida a utilização de boas soluções de tecnologia sem a necessidade de investimentos por parte do cliente, em computadores de alta qualidade e sem se preocupar com o hardware que possui (PINHEIRO, 2010). O foco deste trabalho de mestrado está centrado nesse tipo de nuvem.

\subsection{Elasticidade em nuvem}

O ambiente computacional local possui diversas desvantagens, entre elas em relação ao dimensionamento de recursos computacionais. Se uma organização em determinado período do mês precisar, por exemplo, de mais recursos de disco no seu servidor, ela terá que adquirir um novo dispositivo de disco com maior capacidade.

Para manter os recursos computacionais funcionando com o esperado, os administradores devem prover recursos adequados que acompanhem as flutuações da demanda de carga de trabalho exigida. O excesso de recurso computacional (por exemplo, muito disco ou muita memória) implica que em algum momento ele ficará ocioso, pois será muito recurso para pouca demanda, gerando prejuízo de investimento na arquitetura computacional. Por outro lado, recursos computacionais limitados deixam a arquitetura computacional mais lenta, gerando a insatisfação do cliente (DAWOUD, TAKOUNA e MEINEL, 2011).

A correta utilização dos recursos oferecidos em uma infraestrutura computacional é um dos principais fatores por trás do êxito da implantação da Computação em Nuvem Elástica. Uma infraestrutura mal gerenciada pode levar a custos enormes, o que seria ainda maior que o custo da implantação física (KHATUA, 2010).

A atualização de hardware implica em excesso de recursos, conforme apresentado na Figura 1. Porém, em algum momento o hardware atual não será capaz de lidar com a demanda real o que resulta em degradação e necessidade de nova atualização para acompanhar a demanda. 


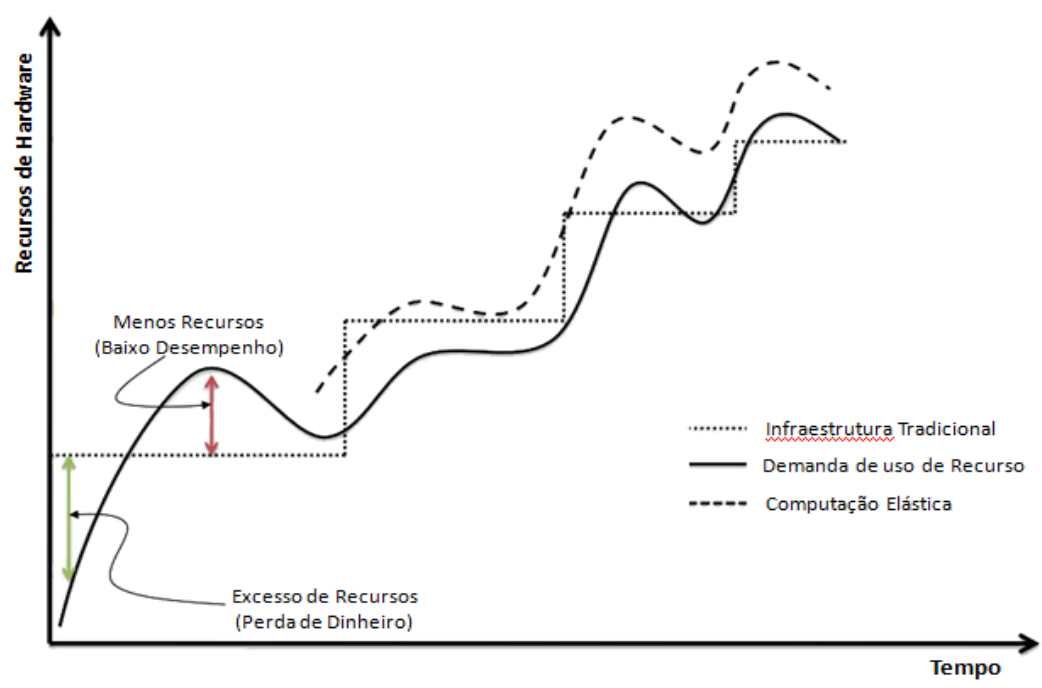

Figura 1 - Análise de uso de recurso computacional

Fonte: Adaptado de (DAWOUD, TAKOUNA e MEINEL, 2011)

Conforme se observa na Figura 1, a infraestrutura tradicional não acompanha o avanço da demanda por recurso computacional, ocasionando em alguns momentos de baixo desempenho (pouco recurso) e em outros acarretando ociosidade e perda de investimento (muito recurso para pouca demanda).

A computação elástica em nuvem acompanha através de monitoramento por agentes computacionais toda a demanda requerida em um dado momento, sempre com o propósito de oferecer uma infraestrutura ágil, escalável e dinâmica, sem a interferência humana diretamente.

A elasticidade da Computação em Nuvem possui aspectos distintos quando vista pelo consumidor e pelo provedor de serviço. O usuário (consumidor) está interessado apenas em ter um ambiente funcional, sem se preocupar com as tecnologias empregadas. Já o provedor tem todo o foco e atenção voltada para a operação dos algoritmos que fazem a elasticidade acontecer (IBM, 2009).

O fornecimento de recurso computacional adequado é estudado por vários autores. Khatua (KHATUA, 2009) propõe duma previsão de carga de trabalho em uma infraestrutura computacional onde há incerteza da demanda. Mattess (MATTESS, 2010) propõe um algoritmo heurístico para acomodar demandas pontuais, permitindo que uma infraestrutura estática seja dimensionada para lidar com um aumento de carga.

A elasticidade neste trabalho é tratada do ponto de vista do provedor de serviços, através do fornecimento de recursos sob incerteza da demanda computacional requerida pelo usuário, o qual será 
também beneficiado por ter, de forma transparente, uma infraestrutura adaptada a demanda requerida e também uma economia financeira, pois pagará apenas pelos recursos utilizados.

\subsection{Considerações finais}

Com a disseminação do conceito de Computação em Nuvem, o ambiente computacional como um todo evoluiu para fora da empresa, não sendo mais necessário que a mesma possua um servidor e diversas máquinas de alto desempenho dentro do ambiente de trabalho. Basta que a empresa contrate um provedor de serviços de Computação em Nuvem que ofereça, como caso deste projeto, a infraestrutura de hardware como serviço.

Para alguns usuários, a computação em nuvem soa como uma fonte inesgotável e com disponibilidade infinita de recursos computacionais, porém em seu estado original ela possui um limite físico de hardware em um dado momento. Este projeto visa aumentar os recursos em tempo de execução para que o cliente utilize seu serviço contratado sem muitos problemas de falta de recursos (por exemplo, lentidão de processamento) por meio da monitoração e aplicação da elasticidade, que será realizada pelos agentes computacionais dentro do conceito de computação autônoma conforme consta no capítulo 3. 


\section{Computação autônoma}

\subsection{Considerações iniciais}

Sistemas computacionais enfrentam um rápido crescimento de tamanho e complexidade. Em 2001 a IBM (CORRÊA, 2008) publicou um manifesto onde destacava que com o passar dos tempos os sistemas tenderiam a ficar cada vez mais complexos, ocasionando dificuldade para se trabalhar com esses softwares (instalação, configuração, otimização e manutenção) devido à inevitável falta de capacidade humana para os gerenciarem (CORRÊA, 2008). Para tratar esse tipo de problema, foi proposto (pela própria IBM) o conceito de Computação Autônoma, que abrange sistemas capazes de se autogerenciarem dado um conjunto abstrato de objetivos definidos pelo administrador. O termo faz conotação com o sistema nervoso biológico, que é responsável pelo controle de funções vitais e, por ser autônomo, é capaz de adaptar o corpo humano às suas necessidades e às necessidades geradas pelo ambiente.

Em 2001 o problema visto pela IBM era a falta de profissionais qualificados no ambiente de TI e a possível saturação da capacidade técnica em vista ao grande avanço tecnológico. No fim da mesma década em 2010, algumas estatísticas do trabalho nos Estados Unidos (Bureau of Labor Statistics) sugeriram que havia cerca de 260.000 trabalhadores na área de TI no país, contudo esse número estaria em constante e leve declínio (DOBSON, 2010). Nos primeiros anos desta década a falta de profissionais na área de TI ainda persiste. Atualmente no Brasil é possível encontrar vagas de emprego na área de TI com salários próximos ou iguais aos dos Estados Unidos, porém o problema da falta de profissionais especializados e constantemente atualizados permanece em todo mundo uma década após o manifesto da IBM (ANGELO, 2011). Portanto, uma alternativa é aliar o conceito de Computação em Nuvem e de Computação Autônoma a fim de combater a escassez de profissionais na área de TI.

\subsection{Definição}

A Computação Autônoma provê mecanismos para se autogerenciar sem a necessidade de intervenções externas. Ressalta-se que autogerência não é desempenhada involuntariamente (diferentemente do corpo humano que se adapta involuntariamente aos estímulos frente a alguma necessidade). O autogerenciamento ocorre através de tarefas delegadas aos sistemas pelo 
administrador, de acordo com políticas adaptativas que determinam o tipo de ação a ser executada em diferentes situações (CORRÊA, 2008).

O sistema autônomo resume-se nas propriedades gerais apontadas pela IBM como necessárias para que um sistema computacional complexo alcance o objetivo de autogerenciamento. Para atingir tal objetivo, é necessário cumprir os quatro requisitos essenciais (CORRÊA, 2008):

Autoconfiguração: propriedade de o sistema ajustar-se automaticamente a novas circunstâncias percebidas durante seu próprio funcionamento de acordo com políticas pré-definidas ou com o apoio de processos de Autocura, Auto-Otimização ou Autoproteção. Esta propriedade será a única pesquisada e utilizada dentro do escopo deste projeto.

Autocura: propriedade de o sistema ser capaz de detectar, diagnosticar e recuperar-se de falhas automaticamente;

Auto-Otimização: propriedade do sistema que o torna capaz de monitorar e ajustar automaticamente seus recursos computacionais satisfazendo a demanda do usuário.

Autoproteção: propriedade de o sistema ser capaz de identificar e defender-se de ataques acidentais ou maliciosos.

O objetivo da computação autônoma não é retirar o papel representado pelo homem, mas sim, automatizar processos repetitivos e também se preparar para casos inesperados como um ataque ao sistema.

\subsection{Agentes computacionais}

Para que o ambiente computacional se caracterize como autônomo, são utilizados agentes computacionais. Há diversas definições sobre agentes, onde cada autor define de acordo com suas aplicações desenvolvidas e suas linhas de pesquisa. Segundo Jennings (BIGUS, 2002) um agente é um sistema computacional capaz de agir com autonomia flexível visando a atingir os objetivos para os quais foi projetado.

A programação de sistemas multiagentes é uma técnica de desenvolvimento de sistemas distribuídos, e neste contexto há questões de como distribuir as várias partes de um sistema, como realizar a comunicação entre elas e principalmente, como administrá-las.

Os agentes são entidades de software persistentes, atômico, com comportamento autônomo, capazes de realizar a percepção do ambiente, adaptáveis a mudanças, com capacidade de assumir metas e desenvolvidos para serem dedicados a um propósito específico (COPPIETERS, 2005). 


\subsection{Considerações finais}

Neste projeto as ações dos agentes são: monitorar a utilização dos recursos de cada máquina virtual (agente monitor); efetuar o processo de elasticidade da infraestrutura de acordo com as políticas (agente elástico); realizar previsão (agente previsor).

A comunicação entre agentes é o que garante ao sistema ser considerado como autônomo pois atividades desenvolvidas pelo homem e passíveis de serem desempenhadas por esses agentes, serão aplicadas com o objetivo de garantir a autonomia do sistema, garantindo principalmente o autoconfiguração. Para a comunicação e interação entre agentes será utilizado o framework Jade. 


\section{Previsão de Demanda}

\subsection{Considerações iniciais}

Para se realizar uma previsão, primeiramente é necessário que os valores observados se encontrem dispostos na forma seqüencial e ordenados cronologicamente, formando um conjunto denominado série temporal. Este capítulo apresenta conceitos relacionados a séries temporais bem como implicações como sazonalidade e tendência que podem ou não serem encontradas nessas séries. As principais questões deste capítulo são: “existem técnicas de previsão específica para cada tipo de série?” e “como é o comportamento destas técnicas?”. Buscou-se na literatura respostas para estas e outras questões.

\subsection{Séries temporais}

De acordo com (Latorre, 2001) série temporal é um conjunto de observações realizadas de forma seqüencial ao longo de um período definido, tendo como principal característica a dependência entre os dados vizinhos. Essa dependência é o foco principal da análise e modelagem da série de dados onde a ordem das observações é relevante e crucial.

Ehlers (Ehlers, 2012) menciona como principal característica das séries temporais a importância da ordem cronológica das observações, uma vez que observações vizinhas são dependentes uma das outras, diferentemente de modelos de regressão onde a ordem cronológica não importa.

Dados provindos de séries temporais surgem de diversos campos do conhecimento como economia (bolsa de valores), indústria (controle de processo de produção), meteorologia (temperatura diária), entre outros.

\subsection{Sazonalidade e Tendência}

Algumas séries temporais assumem um comportamento que tende a repetir a cada intervalo $\mathrm{t}$ do tempo o que se denomina sazonalidade (Latorre, 2001). Por exemplo, o site de gerenciamento acadêmico de uma faculdade tende a ter maior pico de acesso em períodos de fim de semestre como Julho e Dezembro, momentos estes onde os professores lançam as notas e os alunos podem visualizálas. Em Agosto e Janeiro, certamente o número de acesso é reduzido, visto que estes períodos são 
subsequentes às férias. Assim, pode-se observar um padrão que tende a se repetir por longos anos, exceto haja alguma alteração na divulgação de notas ou no ano letivo.

Não existe uma definição concreta sobre o que é tendência. Ehlers (Ehlers, 2012) diz que tendência é a característica global que uma série pode possuir de crescimento ou diminuição com possíveis padrões.

A série temporal pode assumir crescimento ou diminuição linear ou exponencial. No exemplo do site de gerenciamento acadêmico, considere que a cada semestre seja esperado um aumento, por exemplo, de 300 novos acessos ao site da instituição. Este é um crescimento linear. Por outro lado, a instituição estima que a cada ano o aumento do número de acesso terá, por exemplo, um fator 2,2 sobre o valor total de acessos do ano anterior. Este será um crescimento exponencial. Ambos são exemplos de tendências, seja por crescimento linear ou exponencial.

\subsection{Previsão}

A previsão da demanda é a base para o planejamento estratégico da produção, vendas, finanças, entre outros. Permite que administradores desses sistemas antevejam o futuro e planejem adequadamente suas ações. Conforme (Marins, 2012), existem cinco etapas para se elaborar um modelo de previsão:

- Objetivo do Modelo: Definir a razão pela qual se necessita realizar a previsão;

- Coleta e Análise de Dados: Identificar e desenvolver a técnica de previsão que melhor se adapte. Quanto mais dados históricos forem coletados e analisados, mais confiável será a técnica de previsão e o resultado obtido;

- Seleção da técnica de previsão: técnicas qualitativas privilegiam principalmente dados subjetivos, os quais são difíceis de representar numericamente e são provindos de opiniões e palpites pessoais. Técnicas quantitativas envolvem análise numérica dos dados passados, sem relação de opiniões ou palpites pessoais. Como exemplos de técnicas quantitativas estão as séries temporais;

- Obtenção das previsões: com o uso das técnicas de previsões sob os dados passados das séries temporais, se obtêm as projeções futuras da demanda.

- Monitoração do modelo: consiste em acompanhar e analisar o comportamento dos dados previstos frente aos dados observados. Espera-se que a técnica de previsão gere valores acima e abaixo dos reais observado. O erro acumulado deve ser comparado com um múltiplo do desvio médio absoluto por meio da fórmula: 


$$
\text { DMA }=\left(\sum\left|\mathrm{D}_{\text {observado }}-\mathrm{D}_{\text {previsto }}\right|\right) / \mathrm{n}
$$

Onde: n é o conjunto total de observações e DMA é o Desvio Médio Absoluto.

Algumas áreas do conhecimento usam as séries temporais com o objetivo de fazer previsões de valores futuros, porém a presença de tendências e variação sazonal são considerados fatores complicadores e podem ser difíceis de estimar ou remover.

As cinco etapas listadas estão presentes no Capítulo 5 referente à proposta do projeto.

Como existem objetivos diversos, cada conjunto de observações que formam uma série temporal requer o uso de técnicas específicas, seja para previsão com ou sem tendência e/ou sazonalidade, ou apenas para confrontar duas séries distintas (Ehlers, 2012).

\subsection{Considerações finais}

Prever futuras oscilações e comportamentos sazonais é fundamental para o correto funcionamento do sistema dentro do objetivo proposto. O sistema é capaz de prever a demanda futura de um dado cliente e ajustar a infraestrutura computacional de acordo com a previsão. Com isso, o cliente já inicia suas atividades com o minimo necessário para que o trabalho seja executado sem interpéries e contratempos. 


\section{Controle Financeiro}

\subsection{Considerações iniciais}

O Controle Financeiro é uma metodologia empregada para que o cliente que contratou o serviço na nuvem tenha conhecimento do quanto está gastando do valor investido. O retorno sobre o investimento ou ROI (Return on Investiment) é uma das alternativas para o controle financeiro, pois permite ao cliente conhecer o quanto está gastando, evitando gastos desnecessários.

\subsection{Retorno Sobre o Investimento}

No escopo deste trabalho de mestrado, o ROI trata a relação entre o valor financeiro que o cliente contratou do serviço de IaaS e o quanto ele está utilizando deste valor. A cada período é contabilizado a taxa do valor gasto em Unidades Monetárias.

De acordo com (Linthicum, 2013), os cálculos de ROI da computação em nuvem da maioria dos servidores de IaaS, são "simplificações drásticas dos problemas que a nuvem pode resolver" e acaba por "enganar as informações financeiras tanto para a TI quanto para as unidades de negócio ".

Neste projeto, são propostas duas fases para a obtenção do ROI. A primeira fase para o cálculo do ROI deve começar antes de adquirir o serviço na nuvem, momento oportuno para as empresas conhecerem todos os gastos envolvidos desde a implantação dos serviços em nuvem (envio dos dados, treinamento) até o final do contrato (ISACA, 2013). Essa primeira fase é feita antes da implantação e se deve conhecer alguns custos que são ocultos como, por exemplo, despesas inesperadas envolvendo a migração inicial dos sistemas para a nuvem e questões relacionadas com o fim do contrato do serviço e a necessidade de trazer de volta para a empresa os dados que estavam na nuvem, bem como converte-los, segundo o relatório da Information Systems Audit and Control Association (ISACA) (ISACA, 2013).

Ao conhecer os gastos ocultos citados, a empresa estará apta a tomar a decisão de contratar ou não os serviços de computação em nuvem. Em alguns casos, os gastos ocultos podem ser maiores se comparados com a implantação local de um departamento de tecnologia de informação na empresa. Se a empresa adotar a computação em nuvem, o ROI será calculado de acordo com a elasticidade da arquitetura, mediante a uma tarifa por transferência de Megabytes (MB). 
A elasticidade da arquitetura proposta permite que a infraestrutura se reconfigure de acordo com as necessidades do cliente que terá sempre a configuração necessária dos recursos de Disco, CPU e Memória.

A segunda fase proposta neste trabalho de mestrado para o cálculo do ROI é considerar as diferentes necessidades dos clientes através da aplicação da elasticidade computacional. Desta forma, a taxa cobrada não será por hora de uso, mas sim, pela carga de trabalho utilizada por dia, sendo mais justo com o cliente que só pagará o que usar e no dia em que usar, fornecendo melhor resultado para o ROI.

O ROI é dividido em duas categorias: o tempo que levará (quantos períodos levarão) para o cliente obter o retorno do investimento e o quanto o cliente possui disponível do valor investido no período atual recebendo o retorno do investimento.

Como exemplo dos resultados obtidos em um dos experimentos, no segundo período foi gasto 8,2\% do valor investido e, se continuar nesta tendência, em 12,1 períodos o cliente terá utilizado, sem disperdicio, os 15mil UM investidos inicialmente. Assim se segue. No $15^{\circ}$ período o cliente terá gasto 53,5\% do valor efetivo total, ou seja, tudo aquilo que foi gasto, entre elevações e quedas da carga de trabalho. Porém, não foi gasto tudo, pois precisaria de mais 1,6 períodos para que fosse possível utilizar todos os 20mil UM.

\subsection{Considerações finais}

Dentro do projeto são utilizados dois termos "Investimento" e "Rentabilidade". Trata-se de investimento, pois, o cliente contratou um serviço na nuvem para ter um resultado melhor do que a infraestrutura inloco, com o objetivo de se ter menos prejuízo possível em todas as esferas. Rentabilidade é o retorno esperado de um investimento descontando custos, tarifas e inflação. No projeto, espera-se que o valor investido seja utilizado em 100\% dentro do período definido. 


\section{METODOLOGIA}

\subsection{Considerações iniciais}

Neste capítulo está contida a descrição do desenvolvimento do projeto proposto, bem como as ferramentas utilizadas para monitorar o sistema. O projeto tem como principal linguagem de programação a Java, e possui como ferramenta de auxílio o framework Jade que trabalha diretamente com sistemas multiagentes e bibliotecas nativas do Linux.

\subsection{Desenvolvimento - Levantamento Bibliográfico}

O primeiro estágio de desenvolvimento foi realizar o levantamento bibliográfico e o estado da arte a fim de estudar e analisar as arquiteturas que possibilitam a elasticidade sem intervenção humana em uma infraestrutura virtualizada, sendo a mesma capaz de se reconfigurar, promovendo a alocação dinâmica de recursos. Após este estudo inicial, deu-se início a modelagem e desenvolvimento do sistema proposto. Também nessa primeira fase, constou o estudo de modelos de previsão de carga para o desenvolvimento de políticas a serem aplicadas no projeto.

Foram desenvolvidos três algoritmos que são responsáveis pela alocação de recursos, os dois primeiros serão baseados em Média Móvel Exponencial e Modelo de Holt-Winter e o terceiro baseado em Monitoração constante da demanda computacional.

Para que seja possível monitorar e executar o autogerenciamento da infraestrutura virtualizada, foi necessário o desenvolvimento de elementos autônomos que compõe o sistema. Alguns pesquisadores apontam o uso de agentes computacionais como sendo esses elementos autônomos (Stathis, 2010) (Brazier, 2009) (Caprarescu, 2009). Eles gerenciam a si próprios a obter informações dos seus sensores de acordo com as políticas e acordos estabelecidos com outro elemento autônomo. Essa proposta foi mantida neste projeto desde o início e os elementos autônomos são representados por agentes computacionais. Esses agentes contam com recursos e ferramentas para realizar a monitoração. A extração de dados foi realizada pelos sensores dos agentes e os dados são utilizados em tempo de execução para promover uma arquitetura dinâmica. Segue alguns exemplos de funções/aplicativos que podem ser utilizados como ferramentas para coleta de dados no Linux: 
- cpufreq-selector: permite ajustar a freqüência do processador via sistema operacional. pode ser alterada para uma frequência pré-estabelecida (--governor= "powersave", “performance”, etc) ou para uma freqüência específica (--freq= “frequência em kHz”);

- top: fornece uma visão dinâmica em tempo real de um sistema em execução. É possível coletar informações sobre a carga de CPU, Memória e Swap. Além de verificar quais processos estão sendo executados e quem os executaram, esta ferramenta permite verificar os estados dos processos (executando, parados, dormindo, zumbis);

- vmstat: exibe relatórios com estatísticas sobre threads de kernel, processos, memória, paginação, IO bloco, traps e atividade do processador.;

- virt-top: exibe a estatística de máquinas virtualizadas, sendo similar ao top do Linux em máquinas convencionais;

- virt-manager: responsável pelo gerenciamento por parte do administrador e o objetivo é minimizar o trabalho deste profissional.

Tanto o virt-top como a virt-manager utilizam a API libvirt que trabalha com os mais diversos tipos de tecnologias de virtualização (Xen, KVM, VMWare, Virtual Box, entre outras). Com essas ferramentas os agentes são capazes de monitorar e gerenciar as máquinas virtuais (ligar, desligar, reiniciar, etc).

\subsection{Desenvolvimento - Arquitetura}

\subsubsection{Apresentação}

Este projeto de mestrado está relacionado ao projeto de doutorado de Luis Hideo Vasconcelos Nakamura (Processo FAPESP n ${ }^{\circ}$ 2011/12670-5), e que ambos os projetos se complementam, sendo este projeto mais atuante na parte de autoconfiguração de arquiteturas virtualizadas.

A figura 2 apresenta a arquitetura composta pelo projeto de doutorado e de mestrado. O conteúdo envolvido pela linha tracejada preta é a parte que cabe ao projeto de mestrado e o restante envolvido em vermelho é incubido ao projeto de doutorado.

O projeto de mestrado tem a finalidade de gerenciar a infraestrutura por meio da reconfiguração dos recursos das máquinas virtuais. O projeto de doutorado utilizará de regras para tomadas de decisão por meio do emprego da ontologia, propondo assim qualidade no serviço prestado. 
A figura 3 apresenta a arquitetura do projeto de mestrado com os módulos que o compõe. Cada módulo será explicado neste capítulo.

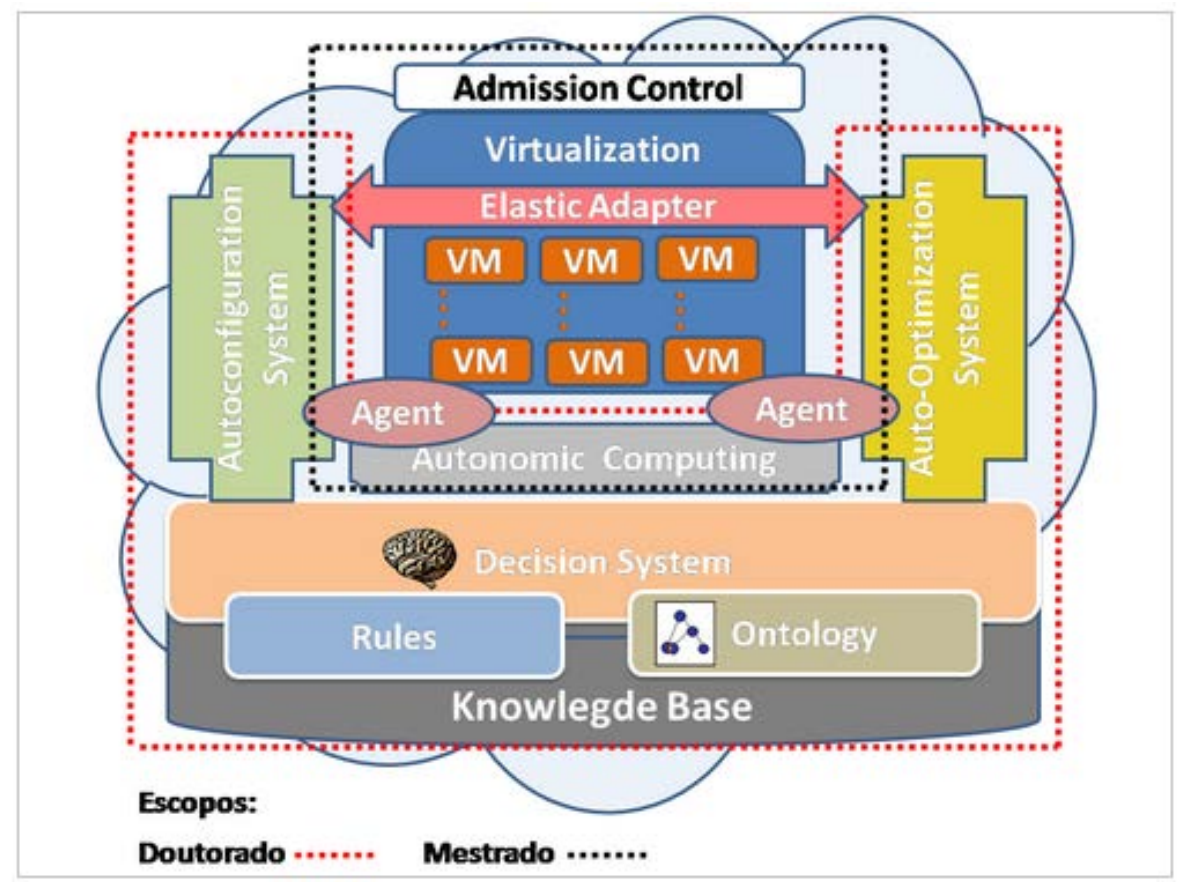

Figura 2 - Escopo da arquitetura principal envolvendo projeto de mestrado e doutorado.

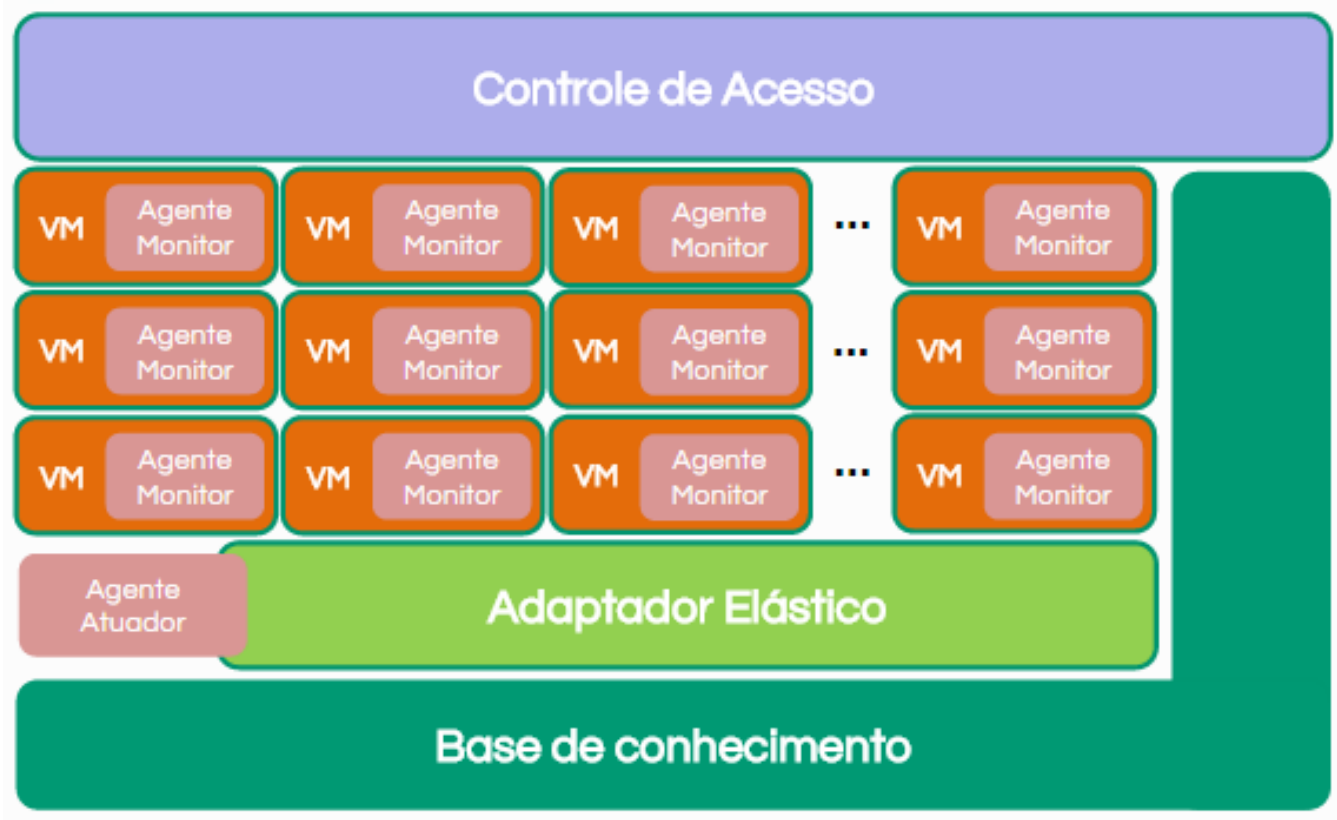

Figura 3 - Escopo da arquitetura do projeto de mestrado. 


\subsubsection{Controle de admissão}

Módulo responsável por receber as requisições dos usuários e liberar ou não seu acesso à máquina virtual. A figura 4 é o diagrama de sequencia do módulo de controle de admissão.

- Verificar se existe máquina virtual disponível para ser utilizada pelo cliente;

o Se houver, o controle de admissão consulta o módulo de políticas orçamentárias, e caso o saldo do cliente esteja positivo, libera o acesso do cliente para a máquina virtual. Em seguida ele registra a informação da nova requisição em uma base de conhecimento (a qual será utilizada para a verificação de históricos).

o Se houver máquina virtual disponível, mas o crédito estiver baixo, o cliente será informado sobre isso através de um relatório; se não houver mais crédito, a requisição do cliente será negada;

o Se não houver máquina virtual disponível, isso significa que a infraestrutura física chegou ao seu limite e o controle de admissão deve então bloquear o acesso por um curto intervalo de tempo até que haja recursos disponíveis. Nesse caso, um relatório informando a indisponibilidade será encaminhado ao administrador da infraestrutura.

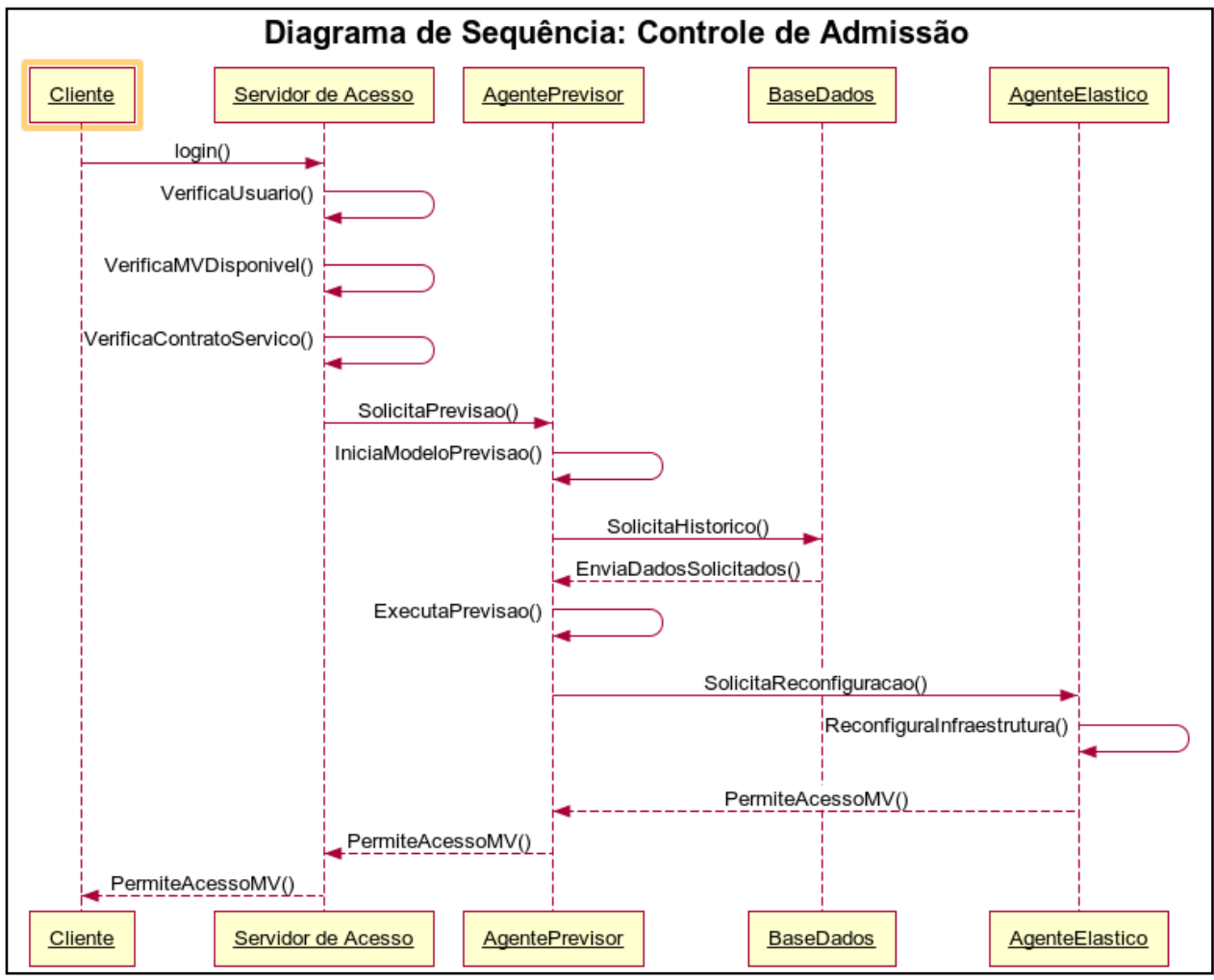

Figura 4 - Diagrama de Sequência: Controle de Admissão 


\subsubsection{Políticas de previsão de carga}

Este módulo tem como finalidade gerar uma previsão de curto a longo prazo da possível demanda a ser requisitada.

São duas técnicas a serem utilizadas: média móvel exponencial (MME) e modelo de HoltWinter que aqui será tratado como MHW .

A MME elimina grandes oscilações de valores, filtrando apenas o movimento principal através da utilização da média móvel simples (Corrar e Teóphilo, 2004). A MME foi escolhida por dar mais ênfase aos valores mais recentes, dando pesos maiores para esses valores e menores para valores mais antigos, que serão esquecidos mais rapidamente, possibilitando que o valor observado esteja mais próximo do resultado previsto anteriormente.

A fórmula para este cálculo é dada por:

- Média Móvel Exponencial: $\mathrm{MME}_{\mathrm{x}}=\mathrm{ME}_{(\mathrm{x}-1)}+\mathrm{K}_{\mathrm{x}}\left\{\operatorname{Fech}_{(\mathrm{x})}-\mathrm{ME}_{(\mathrm{x}-1)}\right\}$

Onde:

$\mathrm{MME}_{\mathrm{x}}$ representa a média móvel exponencial no dia x;

$\mathrm{ME}_{(\mathrm{x}-1)}$ representa a média móvel exponencial no dia $\mathrm{x}-1$;

Constante $\mathrm{K}=\{2 /(\mathrm{N}+1)\}$;

N é o número de dias para os quais se quer o cálculo;

Fech = é o fechamento atual ou valor atual;

O modelo de Holt-Winter possui um comportamento diferente da MME e é explicado na literatura como um método destinado ao tratamento de demandas como séries temporais que apresentam tendências e sazonalidade (Corrar e Teóphilo, 2004). Segundo Lewis (Lewis, 1997), a demanda que é baseada pela tendência e sazonalidade é composta dos elementos:

- Nível: é estacionário sem tendência e sazonalidade, mas pode possuir alguma variação aleatória;

- Tendência: é adicionado ao elemento de nível;

- Sazonalidade: é adicionado aos elementos de nível e tendência.

Para calcular a previsão, Makridakis (Makridakis et al., 1998) apresenta as seguintes fórmulas:

- Nível: $\mathrm{L}_{\mathrm{t}}=\alpha\left(\mathrm{Y}_{\mathrm{t}} / \mathrm{S}_{\mathrm{t}-\mathrm{s}}\right)+(1-\alpha)\left(\mathrm{L}_{\mathrm{t}-1}+\mathrm{b}_{\mathrm{t}-1}\right)(2.1)$ 
- Tendência: $b_{t}=\beta\left(L_{t}-L_{t-1}\right)+(1-\beta)\left(b_{t-1}\right)(2.2)$

- Sazonalidade: $\mathrm{S}_{\mathrm{t}}=\gamma\left(\mathrm{Y}_{\mathrm{t}} / \mathrm{L}_{\mathrm{t}}\right)+(1-\gamma)\left(\mathrm{S}_{\mathrm{t}-\mathrm{s}}\right)(2.3)$

- Previsão: $F_{t+m}=\left(L_{t}+b_{t} m\right)\left(S_{t-s+m}\right)(2.4)$

Onde:

$\mathrm{L}_{\mathrm{t}}$ representa o elemento nível para o período t;

$b_{t}$ representa o elemento tendência para o período t;

$S_{t}$ representa o elemento sazonalidade para o período t;

$\mathrm{F}_{\mathrm{t}+\mathrm{m}}$ representa o valor da previsão para o período m;

$\mathrm{Y}_{\mathrm{t}}$ representa o valor observado no período t;

s é o intervalo de tempo da sazonalidade;

m é o número do período previsto;

$\alpha, \beta$ e $\gamma$ são constantes que representam respectivamente ajustes de nível, tendência e sazonalidade, com valores entre 0 e 1 . Este modelo é ideal para previsão de médio a longo prazo.

Para realizar a previsão utilizando o modelo de Holt-Winter, desenvolveu-se um algoritmo denominado HW1 em Java, utilizando arquivo XML.

O HW1 possui todos os cálculos necessários para conhecer o valor da previsão e é dividido em duas etapas. A primeira é responsável por obter o primeiro valor para nível, para a tendência e para a sazonalidade. Um exemplo, deseja-se obter uma previsão para o $6^{\circ}$ período após cinco períodos consecutivos. Neste exemplo, calcula-se o elemento nível, tendência e sazonalidade dos 5 primeiros períodos e, o resultado de cada um será utilizado para obter a previsão do $6^{\circ}$ período.

O pseudocódigo a seguir apresenta a forma de se obter esses três elementos. Essa etapa é importante pois é responsável por obter os três principais elementos que compõem a série temporal.

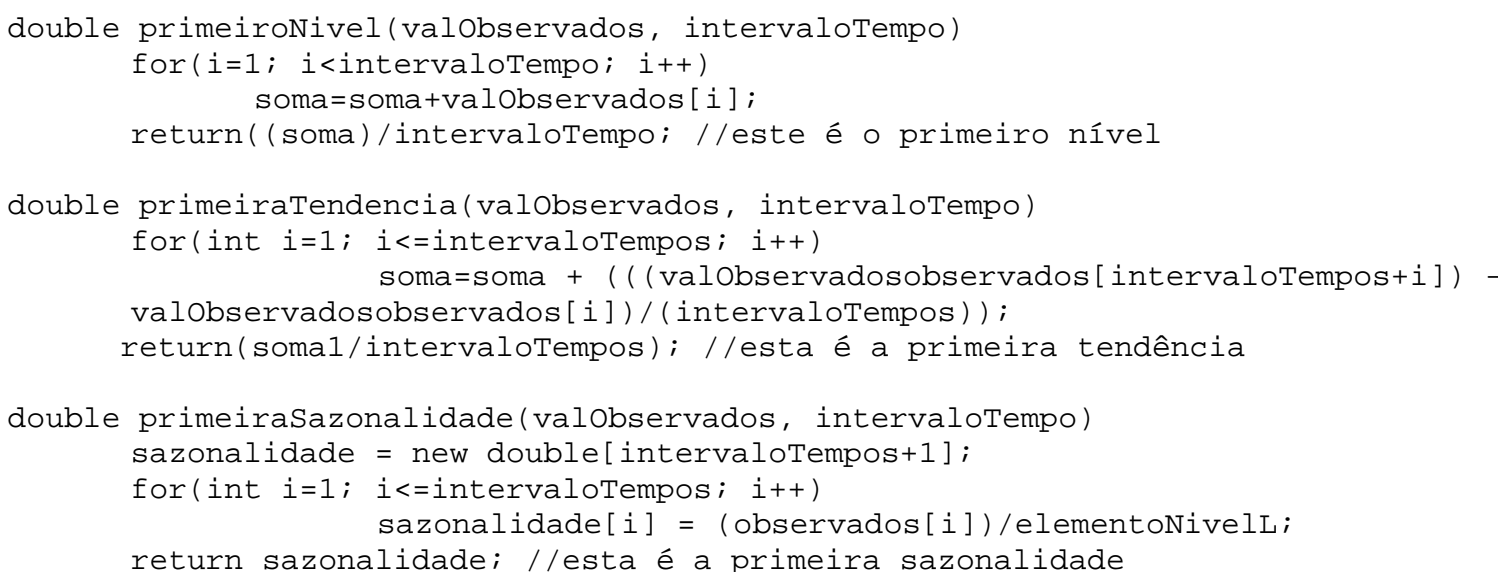


Obtido os três elementos, a segunda etapa será responsável por obter o valor da previsão. Lopes (Lopes, 2002) concluiu em seus experimentos de previsão de peças em estoque que os métodos exponenciais possuem vantagem sobre métodos mais simples como médias móveis. Barbosa (Barbosa, 2005) por sua vez, utilizou médias móveis e métodos exponenciais na previsão da demanda de álcool e concluiu que médias móveis apresentam menor Erro Médio Quadrático (EMQ) do que os métodos exponenciais, apresentando melhores resultados. Esses são dois casos de previsão de demanda, entretanto para o primeiro os métodos exponenciais tiveram melhores resultados do que para o segundo. Conclui-se então que não existe a técnica ideal global, mas sim, a técnica certa para cada caso de estudo.

Assim, dentre as técnicas existentes, foram selecionadas duas para a realização dos experimentos deste projeto: Média Móvel Exponencial e Holt-Winter. É importante ressaltar que para as duas técnicas serão considerados alguns prazos já conhecidos e classificados na literatura (ADVFN, 2012), sendo eles: curtíssimo (5 e 13 dias), curto (14 e 25 dias), médio (26 e 74 dias), longo (75 a 200 dias).

Conforme será visto no capítulo sobre Experimentos e Resultados, o modelo de previsão escolhido foi o de Holt-Winter. O seguinte algoritmo foi desenvolvido para o modelo de Holt-Winter com a finalidade de obter a previsão de carga de trabalho. Ele utiliza as três variáveis obtidas no algoritmo apresentando anteriormente.

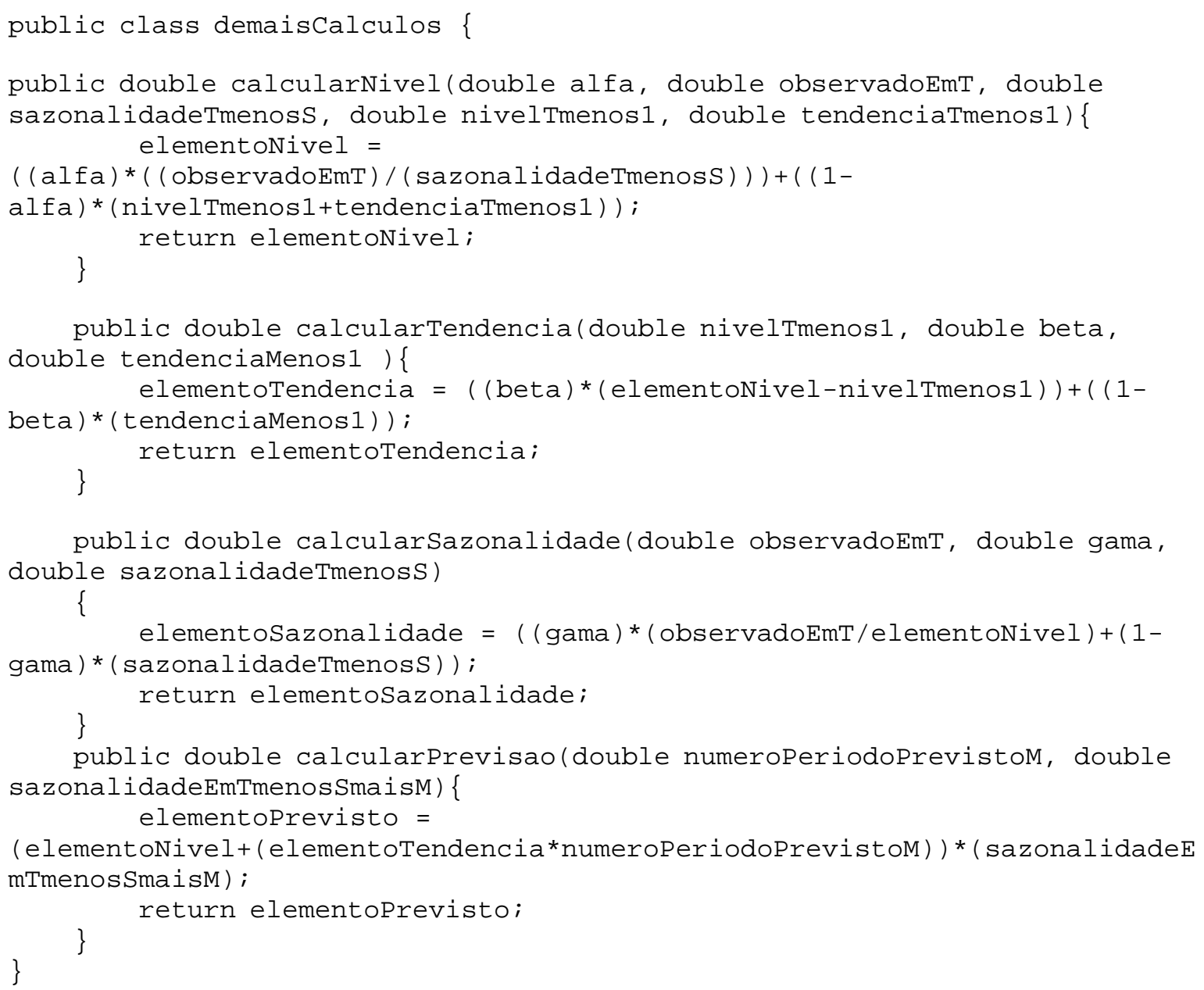




\subsubsection{Agente monitor}

Na arquitetura existe um conjunto de máquinas virtuais para que o cliente possa acessá-las. Cada máquina em uso tem a supervisão e o acompanhamento dos Agentes Monitores que têm as seguintes responsabilidades:

- Verificar constantemente a carga de trabalho imposta pelo cliente, por exemplo, verificar o quanto está utilizando de disco, memória e processamento;

- Verificar se o recurso está sendo bem utilizado, sem ociosidade ou se a carga de trabalho é maior que os recursos disponíveis, causando assim lentidão;

o Se houver ociosidade, o Agente Monitor de Recurso envia uma mensagem para o Adaptador Elástico sobre o estado atual da infraestrutura a fim de diminuir o recurso ocioso;

o Se houver pouco recurso disponível, o Agente Monitor de Recurso envia uma mensagem para o Adaptador Elástico informado sobre a necessidade de aumentar o recurso que está sendo insuficiente.

\subsubsection{Adaptador elástico}

Após o Agente Monitor informar o que é necessário ser feito, caberá ao Adaptador Elástico analisar o tipo de requisição:

Ociosidade de recurso: o adaptador elástico verifica a quantidade ideal que deve diminuir do recurso, deixando uma capacidade suficiente para execução.

Excesso de carga de trabalho (falta de recurso): ele verifica na mensagem que o Agente Monitor enviou, o quanto de recurso que a carga de trabalho está exigindo. Após isso o Adaptador Elástico poderá estender o recurso virtualmente na própria máquina virtual ou ligar novas máquinas virtuais e balancear a demanda entre elas.

O Adaptador elástico é responsável pela gestão auto-adaptativa de capacidade de recursos. Foi utilizado o conceito de agentes computacionais que está inserido nos principais tópicos de Computação Autônoma. Com ele a infraestrutura será capaz de se adaptar com as cargas de trabalho em tempo real. Todo monitoramento e reconfiguração da VM será em tempo de execução, evitando que o usuário necessite parar seus trabalhos para que haja a reconfiguração. 


\subsubsection{Agente atuador}

O Agente atuador têm duas ações definidas:

- De tempos em tempos (de acordo com o definido pelo administrador), é gerado um log de acesso o qual é inserido na Base de Conhecimento com todas as informações referente à demanda utilizada naquele dado momento;

- Realizar as alterações necessárias requisitadas pelo adaptador elástico.

\subsubsection{Retorno sobre o investimento}

Um monitor financeiro está presente na arquitetura e sua função é constantemente verificar a utilização dos recursos e, no final do período de uso, fornecer um relatório sobre o quanto foi gasto do valor contratado (investido), o quanto ainda pode se utilizar do valor contratado e se o uso dos recursos está sendo consciente ou inconsciente (dentro ou acima do valor contratado).

Para o ROI foram desenvolvidas neste projeto as seguintes fórmulas para os cálculos propostos no conceito de controle financeiro:

$$
\begin{aligned}
& v g=\sum_{p d c}^{v c-(t * m b u)} \\
& \text { rest }=\sum_{p d c}^{v c-\left(\frac{v c}{p d c}\right)-v g} \\
& \text { rent }=\text { rest } / v c(3.3)
\end{aligned}
$$

Onde,

vc: é o valor do contrato;

t: é a tarifa aplicada;

mbu: é a quantidade de MB utilizados no período (dia) calculado;

pdc: é a quantidade de períodos (dias) de duração do contrato; 
A fórmula 3.1 retorna o valor gasto no período contratado. A fórmula 3.2 é o quanto ainda pode se utilizar do valor investido. A fórmula 3.3 é a porcentagem de uso do valor contratado, que permite informar se o uso dos recursos e do valor investido está sendo consciente ou inconsciente. Para os experimentos, considerou o período de duração do contrato (pdc) igual a 15 dias, o valor da taxa $(\mathrm{t})$ igual a 0.5 unidades monetárias (média do valor cobrado pelos principais provedores) e o valor contratado (vc) igual a 15.000 unidades monetárias.

\subsubsection{Execução}

A execução inicia-se a partir do cliente que realiza uma solicitação de acesso para consumir o Web Service da Máquina Virtual. A Figura 5 apresenta a organização expandida dos módulos, apresentando as principais classes (retângulos). A explicação da execução está descrita a seguir.

No cliente existe o StressClient, responsável por ler um arquivo XML. Este por sua vez, contém uma série temporal com as cargas de trabalho para stressar a máquina virtual.

Assim que o cliente realiza uma solicitação, se houver máquina virtual disponível a mesma será liberada para o uso, independente de sua configuração.

Na máquina virtual existem o WebServiceStress e o Agente Monitor. O primeiro é responsável por executar 3 benchmarks (Processador, Disco e Memória) conforme a carga imposta pelo cliente. O WebServiceStress recebe a cada período, uma carga de trabalho e esta carga é executada repetidas vezes até o final do período. 


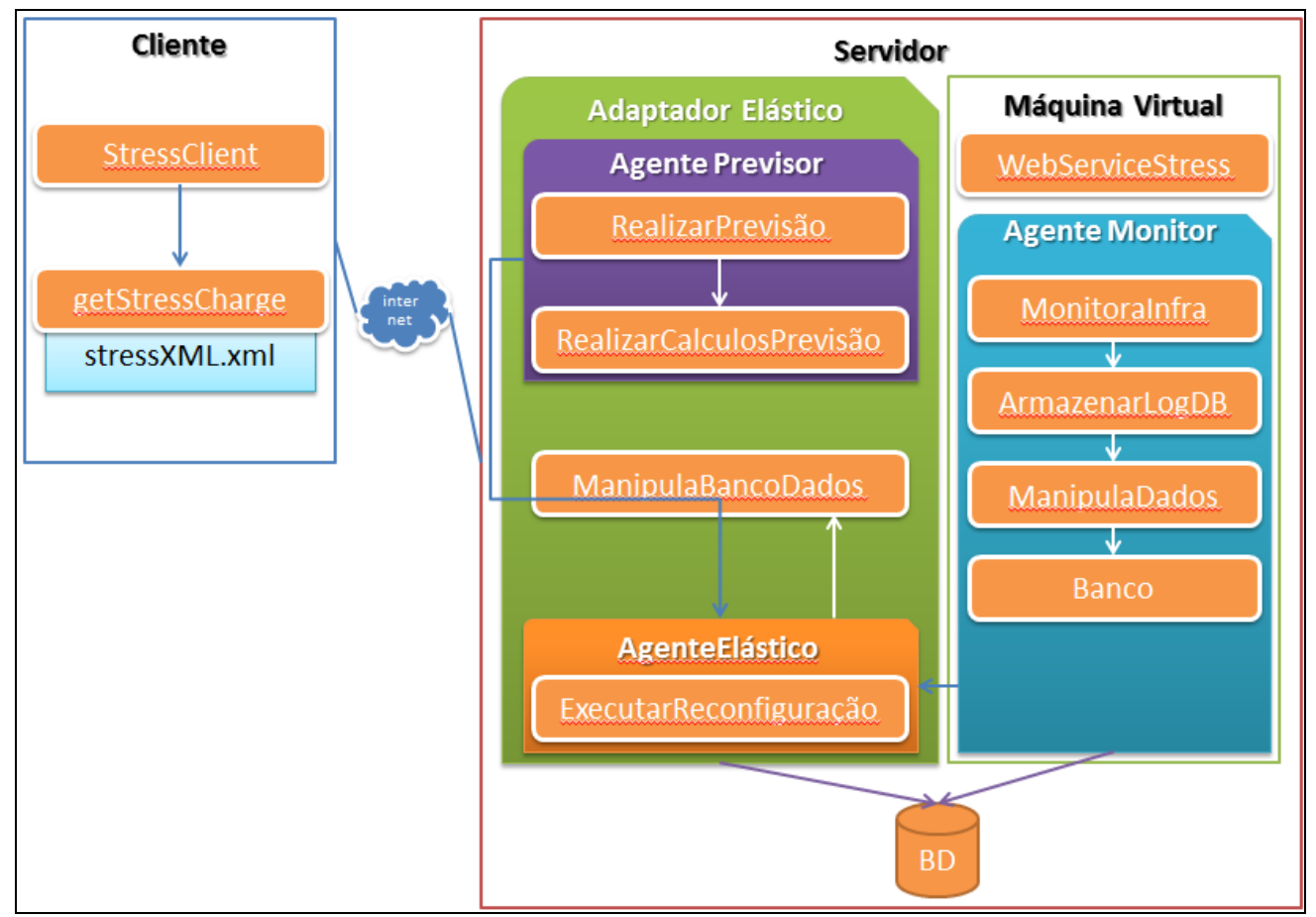

Figura 5 - Descrição Expandida dos Módulos

Durante todo o tempo que o WebServiceStress está em execução, o Agente Monitor verifica o uso dos recursos da máquina virtual e os grava no banco de dados. Esses dados gravados servirão como base para previsões futuras.

No instante que a máquina virtual é ligada, o Agente Monitor é acionado pelo crontab do linux, o mesmo também é responsável por acionar o WebServiceStress, além dos scripts em shell que verificam a memória, o disco e o Processador.

O Adaptador Elástico é responsável por realizar a previsão e a reconfiguração da infraestrutura. Ele está no mesmo servidor da Máquina Virtual, porém sua localização é independente, sendo possível executá-lo através de qualquer terminal, para isso seria necessário apenas realizar comandos remotos de reconfiguração.

O Adaptador Elástico está em constante execução e também é iniciado pelo crontab, comando que agenda tarefas a serem executadas pelo sistema operacional (Linux) periodicamente (Suryawanshi, 2014). Assim que iniciado, ele chama o Agente Previsor que, por sua vez, realizará todos os cálculos para a previsão. Assim que previsto o valor de reconfiguração para o próximo período, o Agente Previsor o envia para o Agente Elástico que por sua vez executa a reconfiguração da 
máquina virtual e grava a nova capacidade do recurso (memória, disco, processador) no banco de dados.

Toda a arquitetura é dividida em módulos, assim, as partes trabalham de forma independente. Outra característica é que o Agente Monitor executa a reconfiguração diversas vezes dentro do mesmo período. Entretanto, o Agente Previsor executa apenas uma vez no início do período. Além disso, o Agente Previsor e o Agente Monitor são dois módulos distintos e, como seus nomes dizem, um é responsável apenas pela previsão e o outro responsável apenas por monitorar o uso dos recursos, respectivamente.

\subsection{Considerações finais}

Foram apresentadas duas políticas de previsão de carga: Modelo Holt-Winter e Média Móvel Exponencial. Ainda nesta dissertação de mestrado, no Capítulo 8, é apresentada a avaliação de desempenho de ambas as políticas realizadas em um cenário real.

A previsão, juntamente com a interação entre os agentes computacionais são a base para o conceito de elasticidade proposta neste trabalho. Enquanto a previsão inicializa a infraestrutura de acordo com utilizações passadas baseada em históricos, os agentes serão responsáveis por monitorar e aplicar as devidas alterações nos recursos disponíveis. 


\section{Resultados}

\subsection{Considerações iniciais}

Na primeira fase do projeto, escolheu-se avaliar o desempenho de dois modelos de previsão de demanda computacional: Holt-Winter e Média Móvel Exponencial. Os resultados serão apresentados na seção 7.2. Como resultado desses experimentos o modelo de previsão Holt-Winter foi o escolhido para uso neste projeto.

Na segunda fase, foram realizados experimentos que deram origem a um artigo publicado no “Nineteenth IEEE Symposium On Computers And Communications (ISCC 2014)” (DIAS, 2014). Estes experimentos validaram a proposta de gerenciamento da infraestrutura em nuvem e os modelo de previsão e de monitoramento da infraestrutura. Essa fase se caracteriza pela avaliação de desempenho dos algoritmos para reconfiguração da infraestrutura. Também nessa fase iniciou-se a abordagem do conceito de ROI (Return On Investiment) e os experimentos com os respectivos resultados estão no subcapítulo 7.3.

A terceira e última fase cujos experimentos estão apresentados na seção 7.4 contemplou a previsão, monitoramento e o ROI, porém, considerou um número maior de períodos e várias sazonalidades dentro de uma série temporal.

\subsection{Fase 1: Resultados para escolha do modelo de previsão}

Conforme o objetivo apresentado no Capítulo 1, este projeto contribui com a elasticidade em nuvem, e para tanto, um dos métodos a serem utilizados é a previsão da demanda computacional.

Foram realizados experimentos para a análise do desempenho de duas técnicas (aqui denominadas políticas) de previsão de demanda diferentes: Média Móvel Exponencial e o modelo de Holt-Winter, para que fosse possível conhecer o comportamento de cada uma.

Para a validação dessas políticas foi escolhido a base de registro de acessos do site da Pontifícia Universidade Católica de Minas Gerais campus de Poços de Caldas com autorização do senhor Prof. MSc. Cláudio Corrêa e o período observado compreende do dia $1^{\circ}$ de Janeiro de 2012 até o dia 28 de Julho de 2012 totalizando 210 dias de observação. 
O valor a ser previsto é a taxa de transferência diária em Gigabytes realizada no portal que, entre outras funcionalidades, tem acesso dos professores para lançar notas e proporciona ao aluno visualizar seu desempenho escolar.

O uso de políticas já caracterizadas pela literatura como ideais para séries com e sem sazonalidade fornecem maior confiabilidade para que fosse realizada uma avaliação de desempenho, possibilitando uma comparação justa a fim de um único objetivo que é a previsão ideal.

A Tabela 2 apresenta os três fatores e os dois níveis para cada fator, com experimento analítico totalmente fatorial (Jain, 1991), totalizando oito testes. Por se tratar de experimento analítico, o número de repetições dos testes não modifica o resultado, uma vez que gerado o cálculo da previsão mediante a uma fórmula matemática, o resultado será sempre o mesmo por experimento.

Tabela 2 - Fatores e Níveis

\begin{tabular}{|c|c|}
\hline Fatores & Níveis \\
\hline \multirow{2}{*}{ Política } & Média Móvel Exponencial \\
\cline { 2 - 2 } & Holt-Winter \\
\hline \multirow{2}{*}{$\begin{array}{c}\text { Janela de } \\
\text { Treinamento }\end{array}$} & 30 Dias \\
\cline { 2 - 2 } & Médio (50 dias) \\
\hline \multirow{2}{*}{ Prazo } & Longo (120 dias) \\
\cline { 2 - 2 } & \\
\hline
\end{tabular}

\subsubsection{Influência dos fatores (Jain, 1991)}

O Erro Médio Quadrático é uma das principais variáveis de resposta obtida nos testes, pois é a diferença entre o valor observado e o valor previsto que no fim resulta na média dos erros.

É possível observar na Figura 6 que o fator que mais tem influência sobre o Erro Médio Quadrático são as políticas. Essa forte influência de mais de 30\% já era esperada uma vez que ambas políticas são destinadas para tipos diferentes de séries temporais: com sazonalidade e com tendência, e sem sazonalidade e sem tendência. 


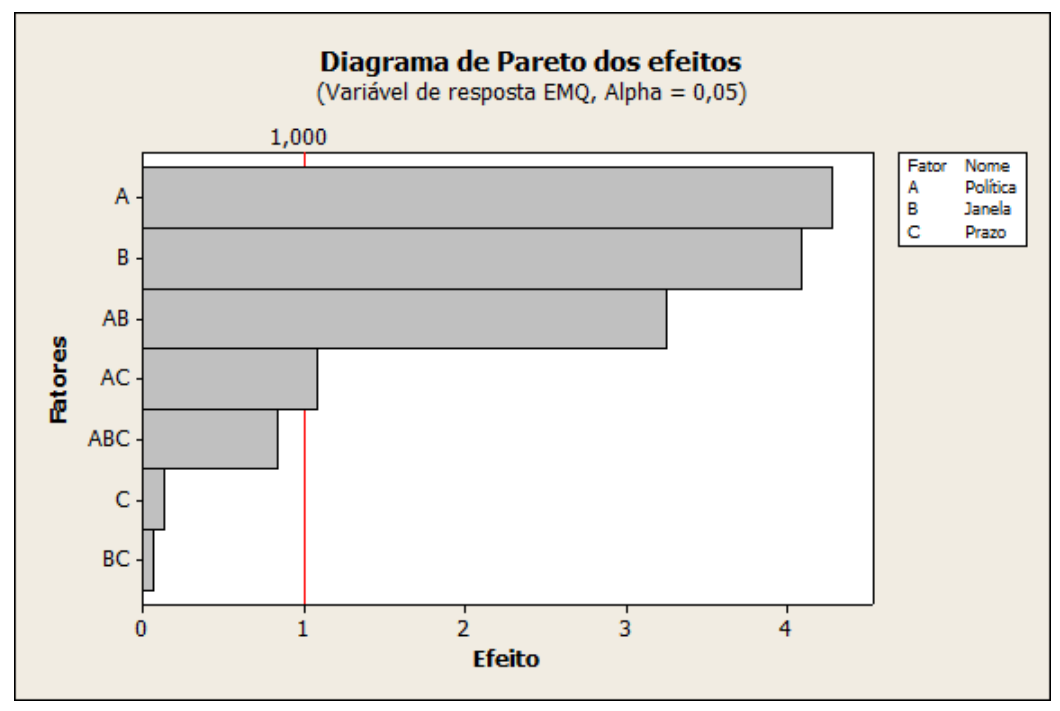

Figura 6 - Influência de fatores para a variável de resposta EMQ

A política Holt-Winter foi a que apresentou os piores valores para o Erro Médio Quadrático conforme pode ser observado nas tabelas 3 e 4 . Os experimentos 3 e 7, ambos utilizam as mesmas janelas de treinamento e prazo, modificando apenas o fator política. No experimento 3, onde utilizouse a Média Móvel Exponencial, foi obtido o menor Erro Médio Quadrático 1,32, enquanto que com o HoltWinter obteve-se o valor de 10,47, o pior entre todos. Pela tabela 4 é possível observar essa diferença.

Em todos os experimentos o modelo de Holt-Winter obteve maior Erro Médio Quadrático que a Média Móvel Exponencial, o que afetou diretamente o valor do desvio padrão onde o HoltWinter também teve valores maiores que a Média Móvel Exponencial.

Tabela 3 - Valores para variável de resposta EMQ

\begin{tabular}{|c|c|c|c|c|}
\hline \multirow{2}{*}{ Experimentos } & \multicolumn{3}{|c|}{ Fatores } & Respostas \\
\cline { 2 - 5 } & Políticas & Janela & Prazo & EMQ \\
\hline 1 & MME & 30 & médio & 1,39 \\
\hline 2 & MME & 30 & longo & 1,43 \\
\hline 3 & MME & 60 & médio & 1,32 \\
\hline 4 & MME & 60 & longo & 3,18 \\
\hline 5 & HW & 30 & médio & 2,66 \\
\hline 6 & HW & 30 & longo & 2,22 \\
\hline 7 & HW & 60 & médio & 10,77 \\
\hline 8 & HW & 60 & longo & 8,79 \\
\hline
\end{tabular}


Tabela 4 - Comparativo entre variável de resposta EMQ na Média Móvel Exponencial (ME) e no HoltWinter (HW)

\begin{tabular}{|c|c|}
\hline \multicolumn{2}{|c|}{ Variáveis de Resposta } \\
\hline EMQ (MME) & EMQ (HW) \\
\hline 1,39 & 2,66 \\
\hline 1,43 & 2,22 \\
\hline 1,32 & 10,77 \\
\hline 3,18 & 8,79 \\
\hline
\end{tabular}

A influência dos três fatores sob o desvio padrão também não foi diferente. A política também é a que mais contribuiu para os valores finais do desvio padrão. Porém aqui cabe uma observação, enquanto na Figura 6 a política e o tamanho da janela de treinamento influenciaram no valor do Erro Médio Quadrático, na Figura 7 a política e a interação política e janela influenciaram muito no resultado do desvio padrão, respectivamente $44,3 \%$ e 34,48\%. O fator prazo teve uma influência de apenas $0,08 \%$ sob o desvio padrão, enquanto que para a Erro Médio Quadrático a influência foi de $0,08 \%$.

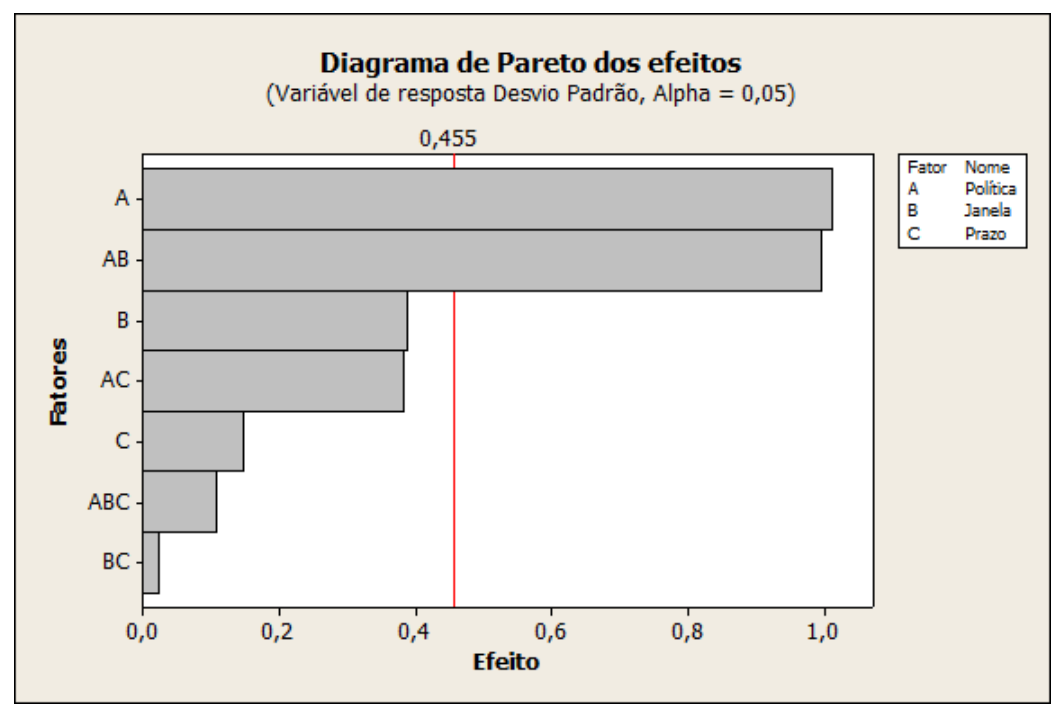

Figura 7 - Influência de fatores para a variável de resposta Desvio Padrão 
Tabela 5 - Valores para variável de resposta Desvio Padrão

\begin{tabular}{|c|c|c|c|c|}
\hline \multirow{2}{*}{ Experimentos } & \multicolumn{3}{|c|}{ Fatores } & Respostas \\
\cline { 2 - 5 } & Políticas & Janela & Prazo & $\begin{array}{c}\text { Desvio } \\
\text { Padrão }\end{array}$ \\
\hline 1 & MME & 30 & médio & 1,03 \\
\hline 2 & MME & 30 & longo & 1,09 \\
\hline 3 & MME & 60 & médio & 0,29 \\
\hline 4 & MME & 60 & longo & 0,95 \\
\hline 5 & HW & 30 & médio & 1,32 \\
\hline 6 & HW & 30 & longo & 1,17 \\
\hline 7 & HW & 60 & médio & 2,47 \\
\hline 8 & HW & 60 & longo & 2,79 \\
\hline
\end{tabular}

Tabela 6 - Comparativo entre variável de resposta Desvio Padrão na Média Móvel Exponencial (ME) e no Holt-Winter (HW)

\begin{tabular}{|c|c|}
\hline \multicolumn{2}{|c|}{ Variáveis de Resposta } \\
\hline Desvio Padrão (MME) & Desvio Padrão (HW) \\
\hline 1,03 & 1,32 \\
\hline 1,09 & 1,17 \\
\hline 0,29 & 2,47 \\
\hline 0,95 & 2,79 \\
\hline
\end{tabular}

As Tabelas 5 e 6 apresentam a variável de resposta desvio padrão. Nelas é possível observar que o desvio padrão foi maior no modelo de Holt-Winter, o que era esperado conforme observou-se nas Tabelas 3 e 4 onde o Erro Médio Quadrático para esta política também foi alta. A tabela 6 apresenta o comparativo dos valores do desvio padrão para ambas políticas.

\subsubsection{Previsão de carga de trabalho com treinamento de 60 dias e prazo de 120 dias}

Na Figura 8, utilizando a política de Média Móvel Exponencial, não houve uma previsão de demanda futura, mas sim, uma previsão do provável comportamento dessa demanda. Para o projeto de mestrado este tipo de resultado se torna inviável, uma vez que busca-se obter uma previsão fiel que acompanhe a tendência da série temporal e que seja capaz de indicar o melhor valor da demanda para alocação dos recursos que serão necessários para suportá-la. Assim, mesmo o Erro Médio Quadrático 
sendo menor para todos os experimentos com Média Móvel Exponencial, não pode-se atribuir que ela é a melhor política de previsão para este tipo de série temporal que possui características de sazonalidade e tendência.

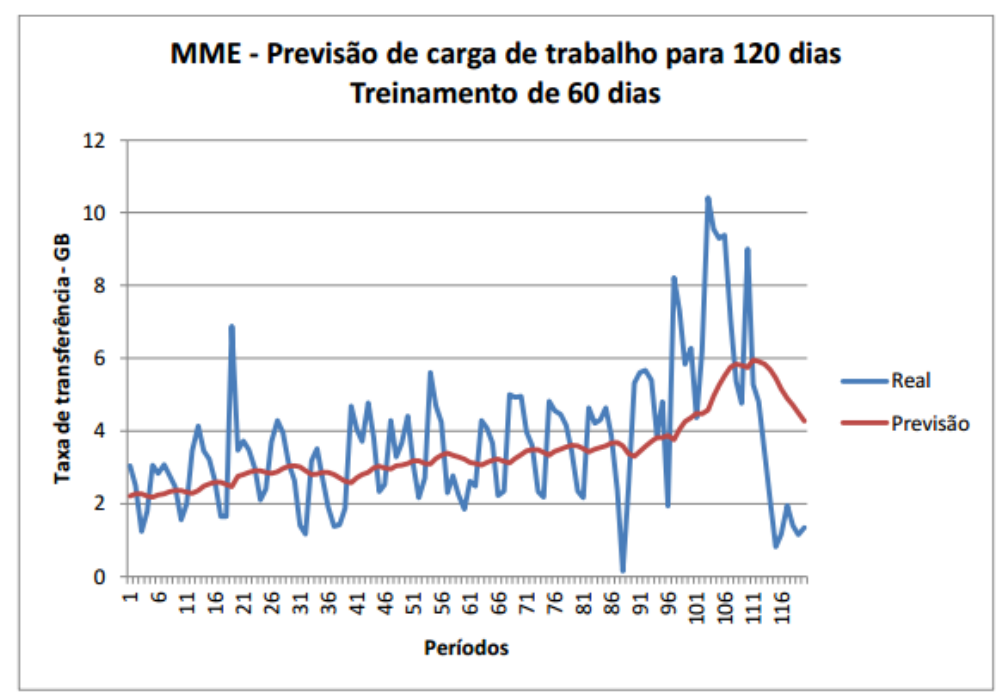

Figura 8 - Previsão de carga de trabalho para 120 dias com treinamento de 60 dias utilizando MME

A Figura 9 apresenta uma previsão para o longo prazo de 120 dias. A linha vermelha sofre oscilações, porém diferentemente do experimento da Figura 8, na Figura 9 o desvio padrão foi de 2,47 e o Erro Médio Quadrático foi de 8,79. Ainda na Figura 9 é possível observar que, com o decorrer dos períodos, a previsão começa a se ajustar aproximando-se do valor observado.

O período de treinamento de 60 dias apresentou uma variação grande, pois iniciou nas férias de janeiro e terminou no começo do mês de março, então a média da taxa de transferência que no início era de 1,01 GB, passou para 1,85 GB, o que justifica os picos previstos entre os períodos 95 e 102. 


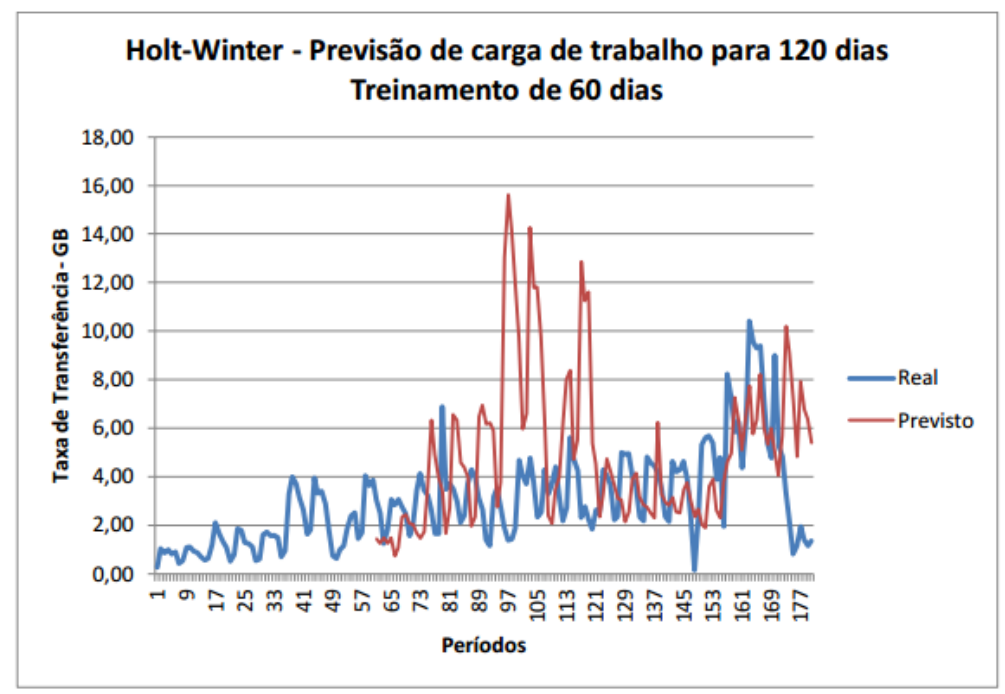

Figura 9 - Previsão de carga de trabalho para 120 dias com treinamento de 60 dias utilizando Holt-Winter

Com os gráficos apresentados, verificou-se que a Média Móvel Exponencial obteve o menor desvio padrão e o menor erro médio quadrático para todos os experimentos realizados, principalmente analisando os experimentos 3 e 4 onde são exibidos seus melhores resultados. No entanto, este tipo de política de previsão de carga torna-se inviável para este trabalho de mestrado, uma vez que se busca obter uma previsão fiel que acompanhe a tendência da série temporal e que seja capaz de indicar o melhor valor da demanda para alocação dos recursos que serão necessários para suportá-la. Vale ressaltar que para os experimentos 1 e 2 onde a previsão da Média Móvel Exponencial acompanha a demanda de requisições, só obteve-se este resultado devido ao fator de correção da previsão (alfa) ser próximo de $1(0,78)$ e estar quase anulando o verdadeiro sentido da Média Móvel Exponencial, a suavização de valores extremos. No entanto, a Média Móvel Exponencial é um excelente indicador para a expectativa da carga que será processada, ou seja, se a carga será alta ou baixa para um determinado período, sem indicar o seu valor preciso.

Por outro lado, com a política de previsão Holt-Winter que se caracteriza por realizar suavização exponencial em séries temporais com sazonalidade e/ou tendências, validou-se que se a janela de treinamento é maior que o período a ser previsto, o melhor resultado será inviabilizado pois, de acordo com este modelo, a janela de treinamento deve ser menor e o tempo de previsão tem que ser de médio a longo prazo para um resultado ideal. Isso pode ser comprovado no Gráfico 4 que apresenta uma previsão para o longo prazo de 120 dias, onde esta previsão sofre oscilações e é perfeitamente possível observar que, com o decorrer dos períodos, ela começa a se ajustar aproximando-se do valor observado tornando-se um eficiente método de previsão de carga que deve ser melhor explorado no projeto de mestrado. 
As Figuras 10 e 11 (Gráfico de Cubo ${ }^{1}$ ) melhor caracterizam este ajuste em relação ao valor observado. ${ }^{1}$ Para o EMQ, o MHW com janela de 60 dias em médio prazo estava em 10,77, porém em longo prazo o valor diminuiu caindo para 8,77. Conclui-se com isso que com o passar do tempo o EMQ tende a diminuir. O mesmo é válido dizer sobre o gráfico do desvio padrão.

Os gráficos apresentam melhores resultado para a política de MME, porém conforme aumenta o prazo de previsão, pior é o resultado tanto do EMQ quanto de Desvio Padrão.

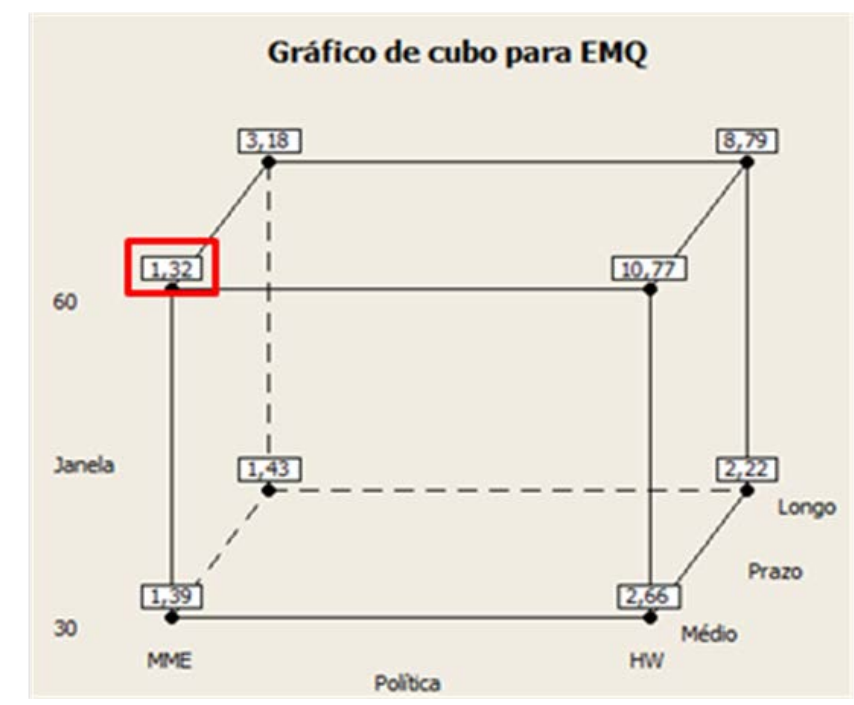

Figura 10 - Gráfico de cubo para variável de resposta EMQ

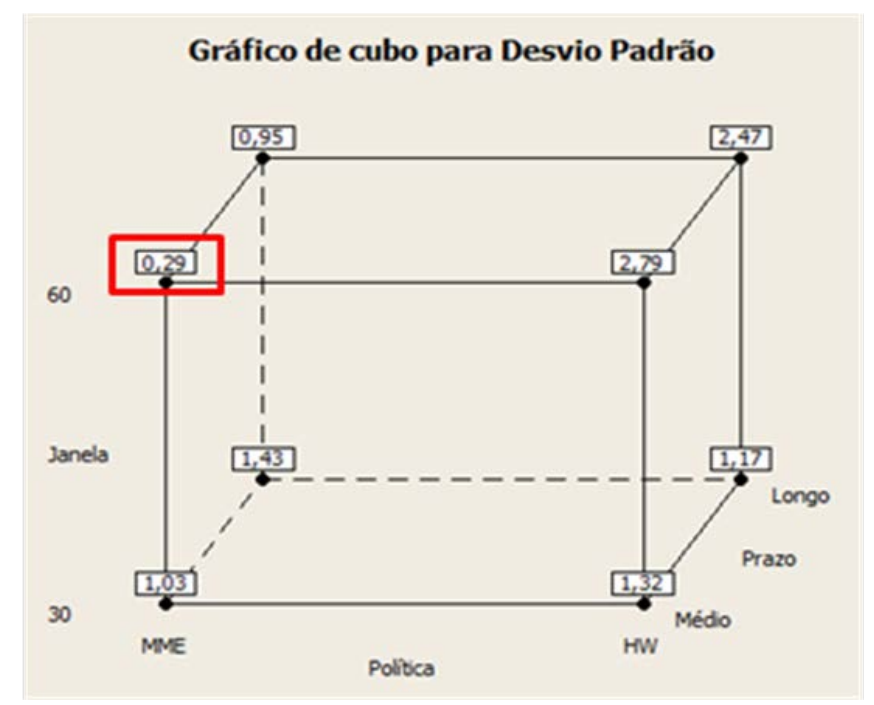

Figura 11 - Gráfico de cubo para variável de resposta Desvio Padrão

\footnotetext{
1 O Gráfico de Cubo foi gerado no Minitab® 15. Para detalhamento é sugerido consultar o manual.
} 


\subsection{Fase 2: Avaliação de desempenho da reconfiguração em 15 períodos}

Para estes experimentos, foi criada uma série temporal com 15 períodos (dias) distintos. Também existem dois tipos de reconfiguração, como já visto anteriormente: Previsão e Agente Monitor. Para os experimentos, considerou avaliar os dispositivos Memória e Disco. Os experimentos foram realizados considerando os fatores e níveis da Tabela 7. As variáveis de resposta foram Erro Médio Percentual, Erro Quadrático Médio e Valor de Unidades Monetárias Efetivamente Consumidas.

Tabela 7 - Fatores e Níveis

\begin{tabular}{|c|c|}
\hline Fatores & Níveis \\
\hline \multirow{2}{*}{ Dispositivo } & Memória \\
\cline { 2 - 2 } & Disco \\
\hline \multirow{2}{*}{ Monitor } & Com \\
\cline { 2 - 2 } & Sem \\
\hline \multirow{2}{*}{ Previsão } & Com \\
\cline { 2 - 2 } & Sem \\
\hline
\end{tabular}

Foi assumido que a variável "Disponível” corresponde ao valor previsto (ou reconfigurado segundo o agente monitor) e a variável "Observado" é a carga de trabalho imposta (o valor que foi consumido do recurso).

A diferença entre o valor disponível e observado será amontoado e dará o Erro Médio Quadrático, que cálcula o erro da previsão frente a carga de trabalho. O Erro percentual médio é o erro percentual do valor observado comparando-o com o valor disponível. Quanto menor este valor, melhor é a previsão (ou monitoramento).

O Erro Quadrático Médio e o Erro Médio Percentual são parecidos mas são destinados para fins diferentes. O primeiro avalia a diferença entre uma previsão e o valor observado possibilitando uma medida de precisão, enquanto o segundo mede a porcentagem do erro em relação ao valor real. O EQM é um modo de escolher o melhor estimador, no caso temos dois: previsão e monitor. 
O ROI é dividido em duas categorias: o tempo que levará (quantos períodos levarão) para que o cliente obtenha o retorno do investimento e o quanto o cliente está no período atual recebendo do retorno do investimento.

A tabela 8 apresenta os resultados do ROI nos experimentos. Cada linha é um período. Neste experimento foram investidos 15mil UM (Unidades Monetárias). Na primeira linha do experimento Sem Previsão e Sem Monitor observa-se que, se continuar com a mesma carga de trabalho, em 19,8 períodos o cliente terá o retorno dos 15mil UM investidos, assim, em 19,8 períodos o valor investido será utilizado da forma correta, sem ociosidade e sem excessos. A segunda coluna (Rentabilidade) não tem nenhuma relação direta com a primeira. A rentabilidade indica que, no primeiro período o cliente (Contratante) utilizou 5\% do valor investido, ou seja, dos 20mil contratado, no primeiro período ele já gastou 750 UM.

Tabela 8 - Cálculos do ROI

\begin{tabular}{|c|c|}
\hline \multicolumn{2}{|c|}{$\begin{array}{c}\text { Sem Monitor e } \\
\text { Sem Previsão }\end{array}$} \\
\hline Período ROI & Rentabilidade \\
\hline 19,8 & 5 \\
\hline 12,1 & 8,2 \\
\hline 8,89 & 11,24 \\
\hline 6,69 & 14,93 \\
\hline 5,52 & 18,09 \\
\hline 4,63 & 21,58 \\
\hline 4 & 24,96 \\
\hline 3,45 & 28,98 \\
\hline 3,06 & 32,62 \\
\hline 2,7 & 36,54 \\
\hline 2,51 & 39,75 \\
\hline 2,3 & 43,36 \\
\hline 2,14 & 46,7 \\
\hline 2 & 49,2 \\
\hline $\mathbf{1 , 6}$ & $\mathbf{5 3 , 2 5}$ \\
\hline
\end{tabular}




\begin{tabular}{|c|c|}
\hline \multicolumn{2}{|c|}{$\begin{array}{c}\text { Com Monitor e } \\
\text { Sem Previsão }\end{array}$} \\
\hline Período ROI & Rentabilidade \\
\hline 11,68 & 9 \\
\hline 6,18 & 16 \\
\hline 4,48 & 22 \\
\hline 3,51 & 28 \\
\hline 2,92 & 34 \\
\hline 2,48 & 40 \\
\hline 2,15 & 46 \\
\hline 1,9 & 53 \\
\hline 1,63 & 61 \\
\hline 1,44 & 69 \\
\hline 1,3 & 77 \\
\hline 1,2 & 83 \\
\hline 1,12 & 89 \\
\hline 1,05 & 95 \\
\hline $\mathbf{0 , 9 9}$ & $\mathbf{1 0 1}$ \\
\hline
\end{tabular}

\begin{tabular}{|c|c|}
\hline \multicolumn{2}{|c|}{$\begin{array}{c}\text { Com Monitor e } \\
\text { Com Previsão }\end{array}$} \\
\hline Período ROI & Rentabilidade \\
\hline 12,14 & 8 \\
\hline 6,9 & 14 \\
\hline 4,9 & 20 \\
\hline 3,8 & 26 \\
\hline 3,16 & 32 \\
\hline 2,68 & 37 \\
\hline 2,31 & 43 \\
\hline 2 & 49 \\
\hline 1,7 & 58 \\
\hline 1,5 & 66 \\
\hline 1,4 & 72 \\
\hline 1,3 & 78 \\
\hline 1,2 & 84 \\
\hline 1,12 & 89 \\
\hline $\mathbf{1 , 0 5}$ & $\mathbf{9 5}$ \\
\hline
\end{tabular}

De forma geral, o cliente tinha 15 mil UM para gastar em 15 períodos, o que seria cerca de 1000 UM para gastar por período. O melhor caso sempre será gastar 1000 UM por período para que, no final dos 15 contratados tenha sido gasto todo o valor investido sem desperdicio ou falta. Porém no primeiro período não foram gastos os $1000 \mathrm{UM}$, logo, se ainda haviam 14 períodos adiante, (o algoritmo corretamente pressupõe que a tendência é continuar a gastar apenas 1000 UM por período) com a sobra o algoritmo apresenta que o valor que se tem investido é para mais 19,8 períodos e que, neste período atual foi gasto $5 \%$.

No segundo período foi gasto 8,2\% do valor investido e, se continuar como está, em 12,1 períodos o cliente terá utilizado, sem disperdicio, os $15 \mathrm{mil}$ UM. Assim se segue. No $15^{\circ}$ período terá gasto 53,5\% do valor total. Porém, não foi gasto tudo, pois precisaria de mais 1,6 períodos para que fosse possível utilizar todo os $20 \mathrm{mil}$. Se no primeiro período foi gasto $5 \%$ isso quer dizer que, de todo o valor investido o cliente utilizou ou "recuperou" 5\%, essa então é a rentabilidade.

Foram 15 períodos por experimento e cada período ficou em execução por 5 minutos. A simulação foi feita utilizando um cliente que requisita o benchmark em um Web Service. São 2 tipos de benchmark: para disco (leitura, escrita, releitura, reescrita e remoção de arquivo) e para memória, onde são criados vetores de string de 8bytes cada. Para a requisição dos benchmarks: o cliente envia, de forma senoidal, 15 valores da seguinte forma: 5, 10, 15, 20, 25, 20, 15, 10, 5, 5, 10, 15, 20, 25, 20. 
No Web Service existe um gerador de números aleatórios. A carga, ou seja, o tamanho do arquivo ou a quantidade de vetores é definida por período multiplicando o valor enviado pelo cliente vezes o valor aleatório gerado. A variável aleatória permite que a cada execução, o gráfico do observado (ou seja, a carga de trabalho imposta) seja diferente.

O primeiro experimento foi realizado sem previsão e sem monitor e é observado nos gráficos das Figuras 12 e 13.

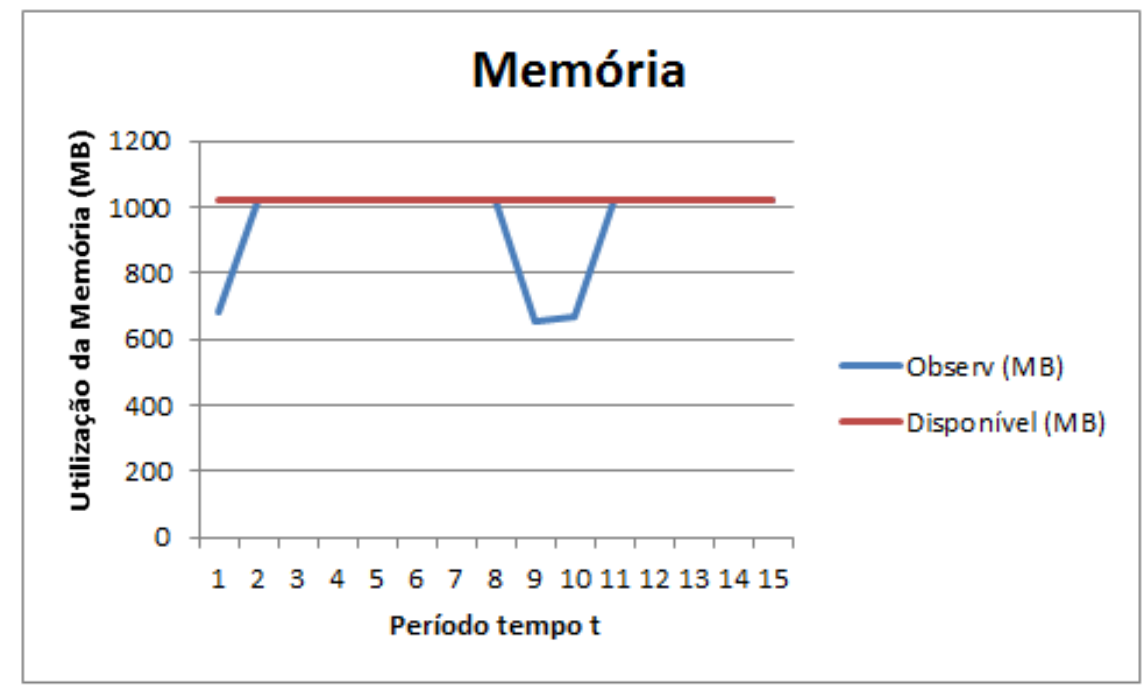

Figura 12 - Experimento 1: Memória, sem previsão e sem monitor

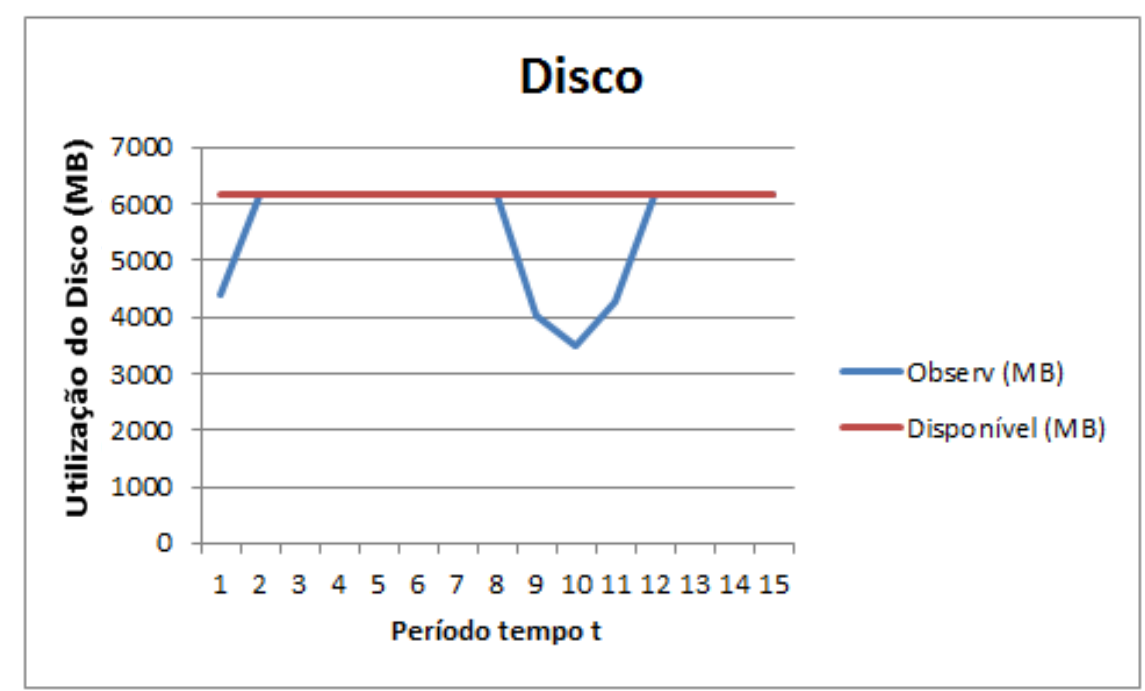

Figura 13 - Experimento 1: Disco, sem previsão e sem monitor

A linha vermelha é o valor disponível. A Memória apresenta 1GB de capacidade disponível e o Disco 6GB de capacidade disponível. A linha azul foi a carga de trabalho senoidal observada no decorrer de 15 períodos. Em dois momentos a linha azul é interrompida, isso ocorre pois houve falta de recurso de Memória e de Disco. Em relação ao retorno sobre o valor investido, no final dos 15 
períodos o cliente gastou 53\% do que havia contratado, disperdiçando 47\% do valor investido ou 9400 unidades monetárias (Tabela 5).

O segundo experimento considerou a execução apenas da previsão. Conforme observa-se nos gráficos das Figuras 14 e 15. Nestes gráficos a linha vermelha da capacidade disponível não é fixa como no primeiro experimento. Aqui os recursos Memória e Disco tiveram suas capacidades previstas através de histórico e o mecanismo de reconfiguração permitiu atender a todas as requisições como pode ser visto pela linha azul. Neste experimento, no final do $15^{\circ}$ período o cliente gastou efetivamente 92\% do valor contratado, deixando de gastar 8\% (Tabela 5). O Erro Médio Percentual (EMP), que mede a porcentagem de erro em relação ao valor real foi de 17.92\% para a Memória e de 31.44\% para o Disco. Pelo gráfico nota-se a distância entre as curvas dos valores observados e disponíveis, essa diferença é calculada pelo Erro Quadrático Médio (EQM). O EQM foi de 247.78 e 1640.85 para a Memória e para o Disco respectivamente.

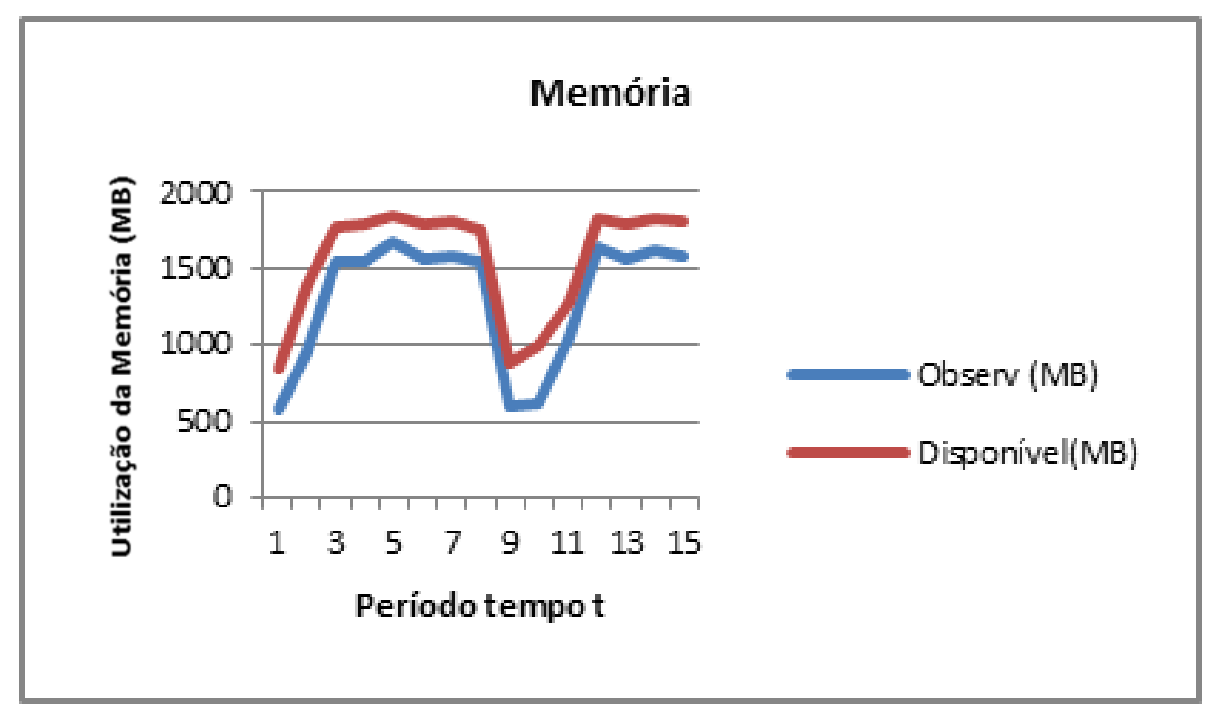

Figura 14 - Experimento 2: Memória, com previsão e com monitor 


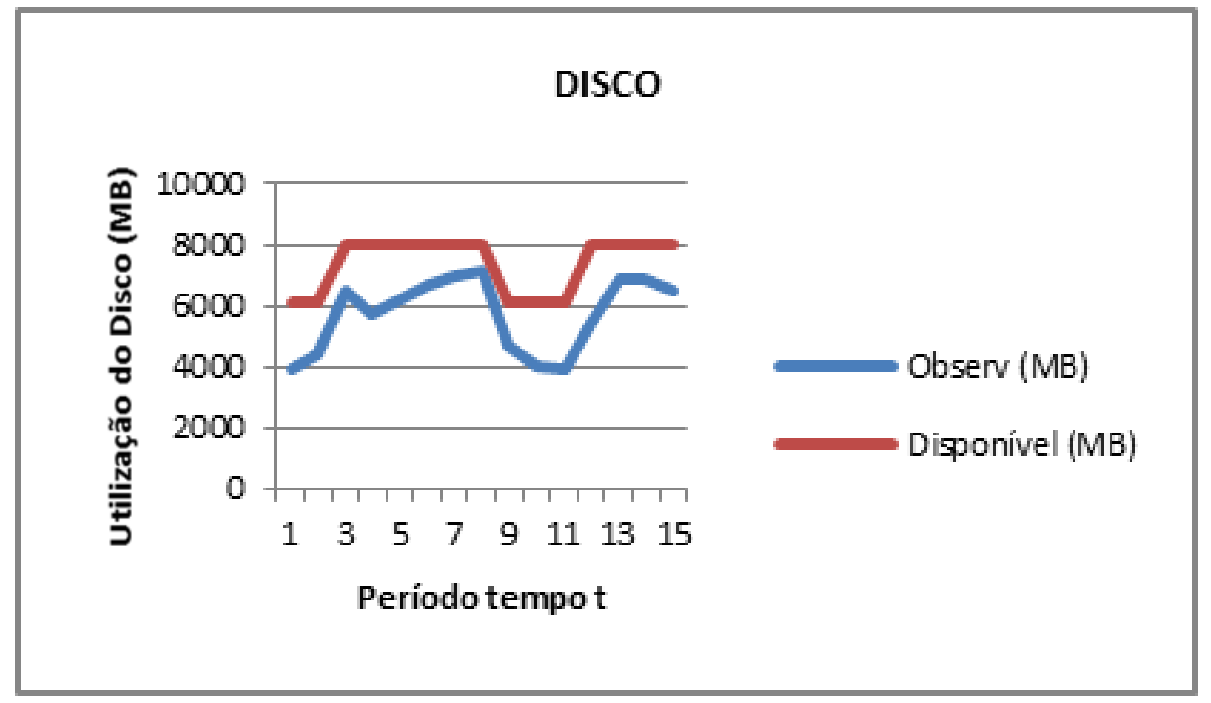

Figura 15 - Experimento 2: Disco, com previsão e com monitor

A previsão reconfigura os recursos da VM no início do período. O terceiro experimento verificou o comportamento da VM durante o monitoramento da carga de trabalho imposta. Desta forma, considerou apenas o uso do Agente Monitor, não aplicando a previsão, e o resultado é o observado nos gráficos das Figuras 16 e 17.

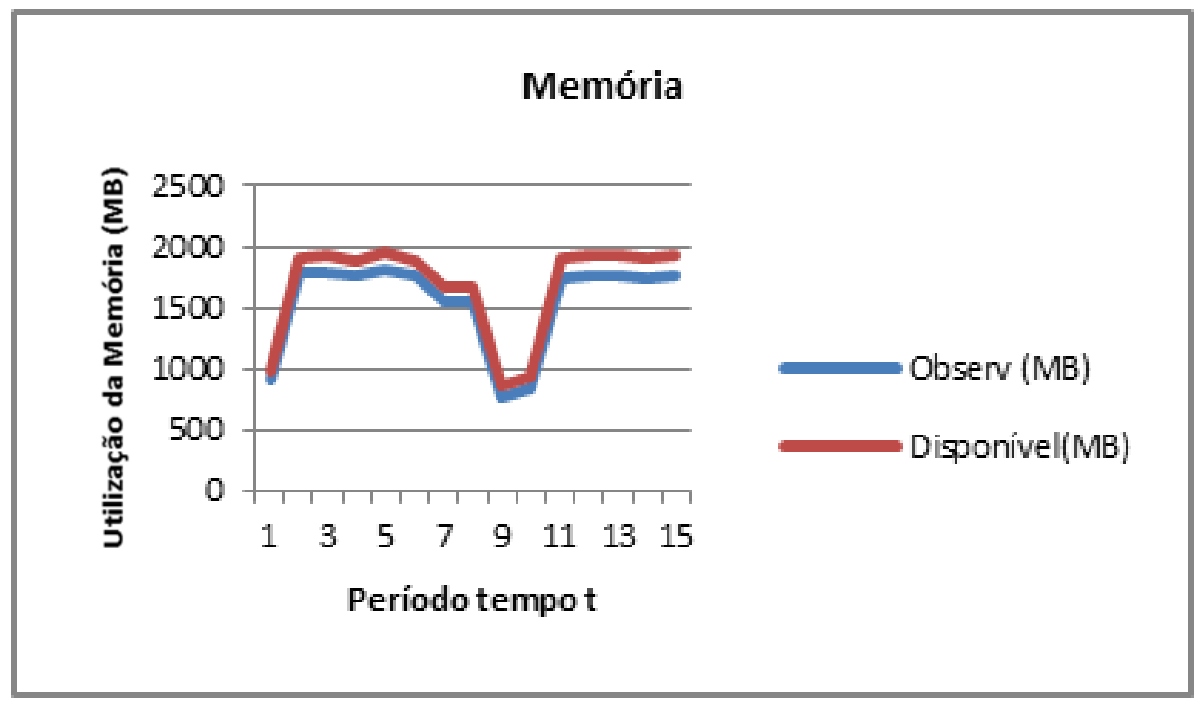

Figura 16 - Experimento 3: Memória, sem previsão e com monitor 


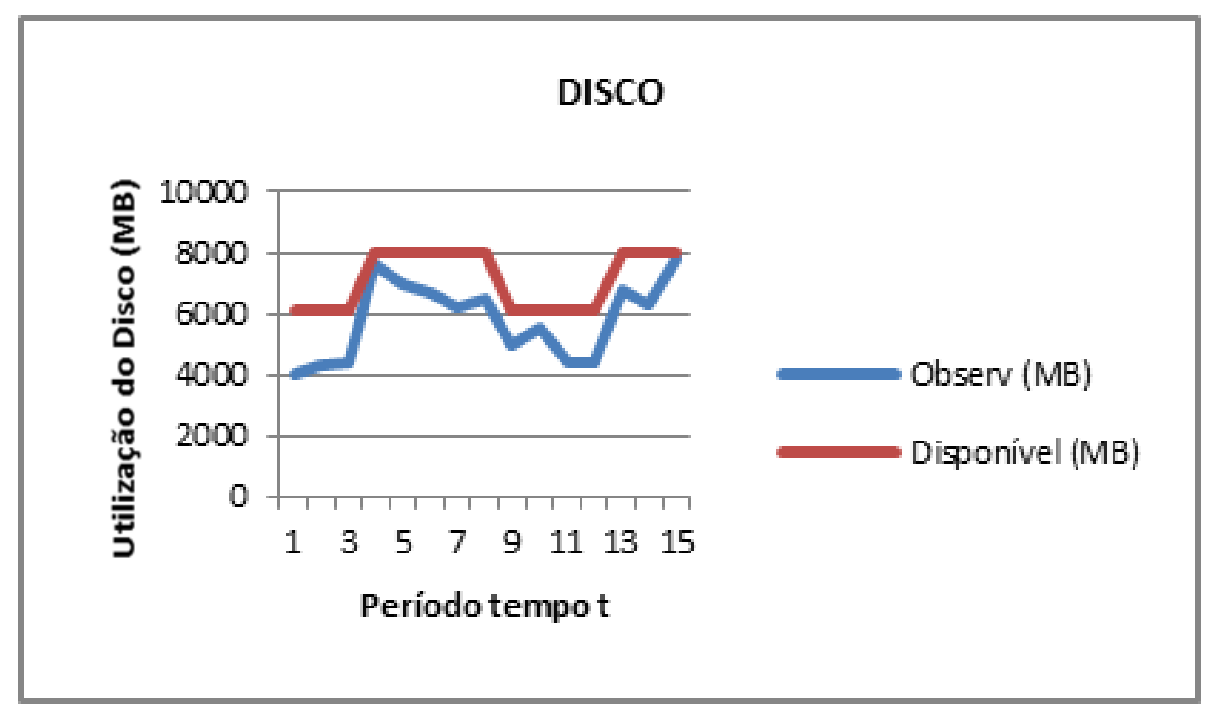

Figura 17 - Experimento 3: Disco, sem previsão e com monitor

Tanto para o Disco quanto para a Memória, o agente foi capaz de monitorar o uso dos recursos, propondo uma nova reconfiguração para estes recursos que satisfez a carga de trabalho imposta. Especificamente para a Memória no gráfico da Figura 16 houve uma aproximação maior do valor observado e do valor disponível, em comparação com o gráfico da Figura 14. Essa aproximação, expressa numericamente, mostra que para este experimento o EQM foi de 125.45 para a Memória e 1345.69 para o Disco e o EMP foi respectivamente de 7.60\% e 26.00\% para a Memória e Disco. Em média, o uso do agente monitor proporcionou que os dados observados (para a Memória) se aproximassem 49\% do valor disponível neste experimento em relação ao experimento anterior. Essa aproximação média foi maior para os dados observados em relação ao disponível no Disco, que se aproximaram $17.9 \%$. Isso ocorre, pois neste experimento o agente monitor está constantemente verificando a utilização dos recursos e realizando a reconfiguração, diferente do segundo experimento no qual a reconfiguração é apenas no início do dia e não considera as cargas de trabalho que ocorrem durante todo o tempo até a próxima previsão. No final do $15^{\circ}$ período foi gasto efetivamente $100 \%$ do valor aplicado, isso se deve pela maior aproximação do valor observado frente ao valor disponível (Tabela 5).

Foi executado um quarto experimento no qual foi proposto o uso da previsão (experimento 2) e também o uso dos agentes computacionais (experimento 3). Os resultados obtidos são observados nos gráficos das Figuras 18 e 19. 


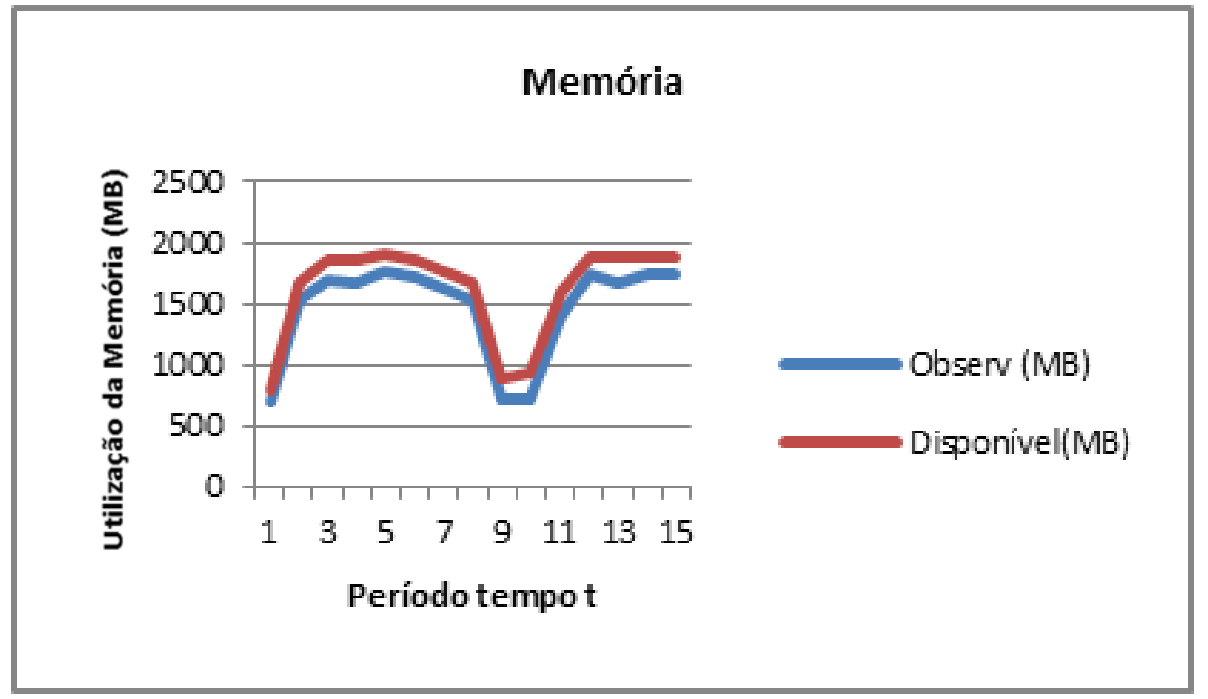

Figura 18 - Experimento 4: Memória, com previsão e com monitor

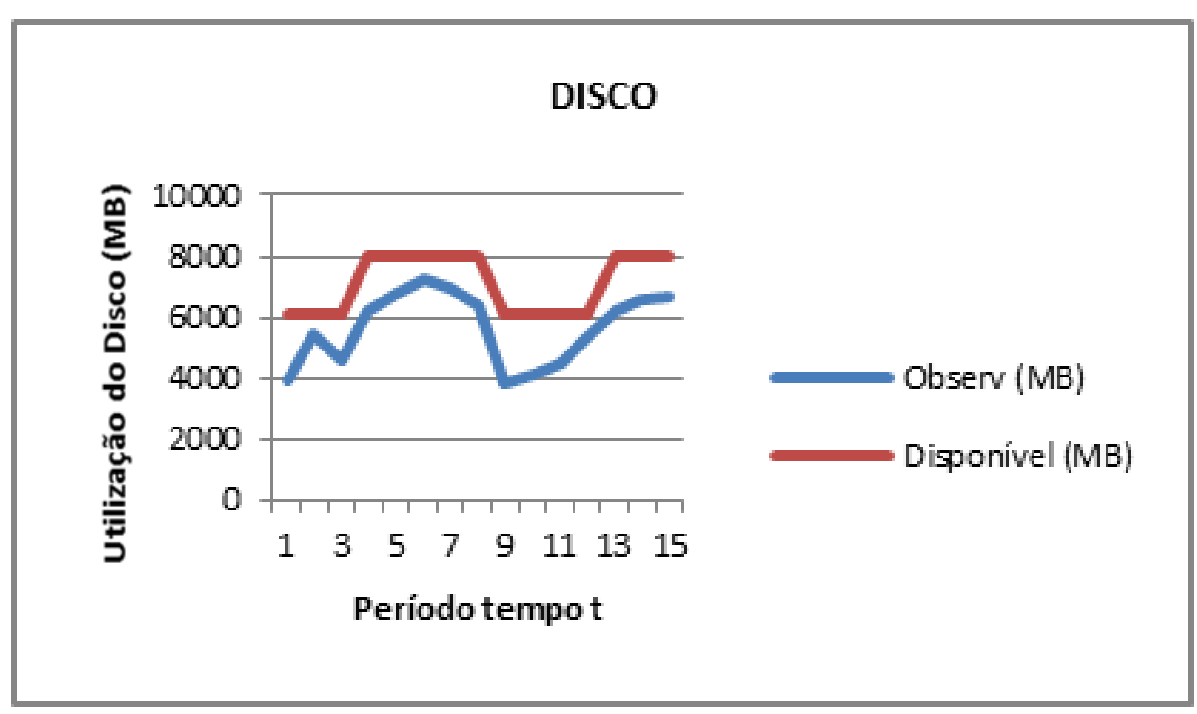

Figura 19 - Experimento 4: Disco, com previsão e com monitor

Neste último experimento o EQM foi respectivamente de 156.29 e 1480.24 para a Memória e Disco. O EMP da Memória e do Disco foi respectivamente de 10.33\% e 28.69\% para Memória e Disco. Em relação ao experimento 2 houve uma aproximação de 36.92\% e de $9.78 \%$ respectivamente para Memória e Disco em relação ao experimento 2, considerando uma melhora relativa. Se comparado o experimento 4 com o experimento 3, houve um afastamento de $24 \%$ e $10 \%$ respectivamente para os recursos Memória e Disco. O afastamento ocorre devido a previsão que, no início do período estipula cargas mais baixas ou mais altas do que a necessária. Cabe então ao agente monitor realizar o ajuste de acordo com a carga de trabalho que está ocorrendo naquele dado instante. Neste experimento o cliente gastou efetivamente 95\% do valor investido (Tabela 5). 


\subsection{Fase 3: Avaliação de desempenho da reconfiguração em 170 períodos}

Na fase 3, a carga de trabalho é fixa e se difere da fase 2 que teve auxílio de uma variável aleatória. Foi considerado o valor investido para o ROI de 1 milhão UM.

Sem o uso de previsão e de monitor, a capacidade máxima dos recursos memória e disco não foram suficientes para suprir as necessidades do cliente que teve suas requisições negadas em alguns momentos conforme observado nos gráficos das Figuras 20 e 21.

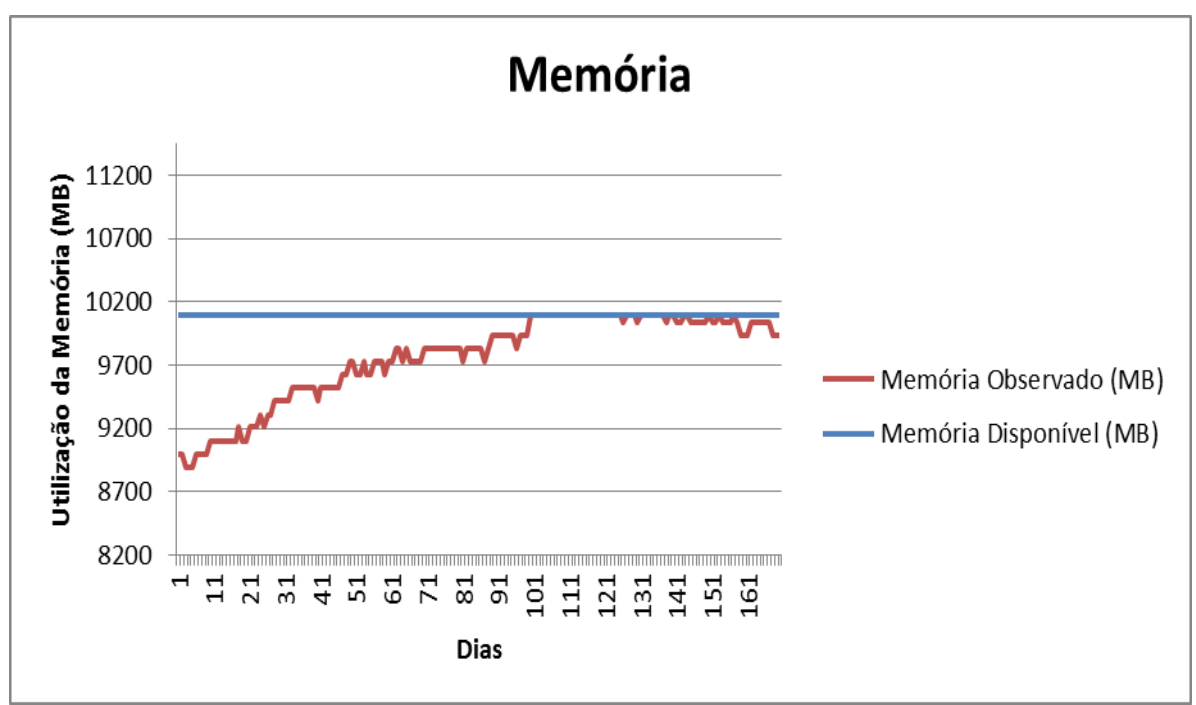

Figura 20 - Experimento1: Memória, Sem Previsão e Sem Monitor

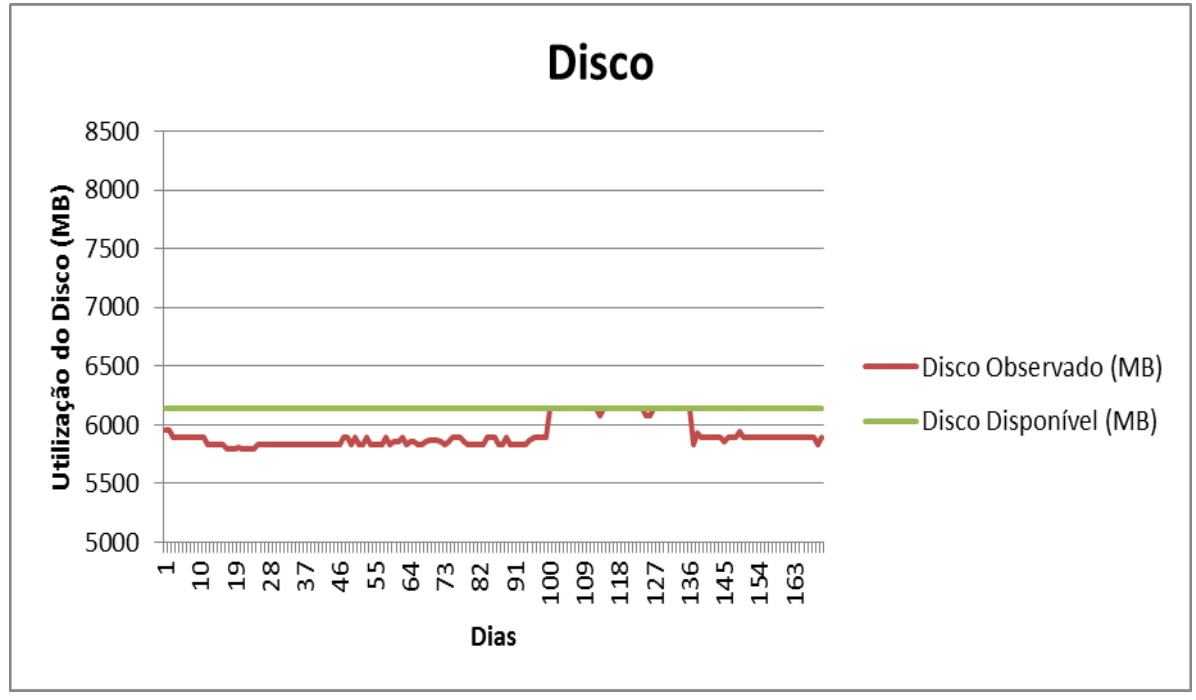

Figura 21 - Experimento1: Disco, Sem Previsão e Sem Monitor 
No experimento 2 (Figuras 22 e 23) foi considerada a mesma carga de trabalho e foi utilizada a previsão sem agente monitor. O EQM foi de 251124 e 337801 respectivamente para memória e disco. O EMP foi de 4,83 e 7,84, respectivamente para memória e disco. Neste experimento, no final do $170^{\circ}$ o cliente gastou $95 \%$ do valor contratado, deixando de gastar 50mil UM. Logo, o cliente investiu neste caso 5\% a mais do que lhe seria necessário. Com o valor restante seria possível suprir, se continuasse nessa tendência, mais 8 períodos.

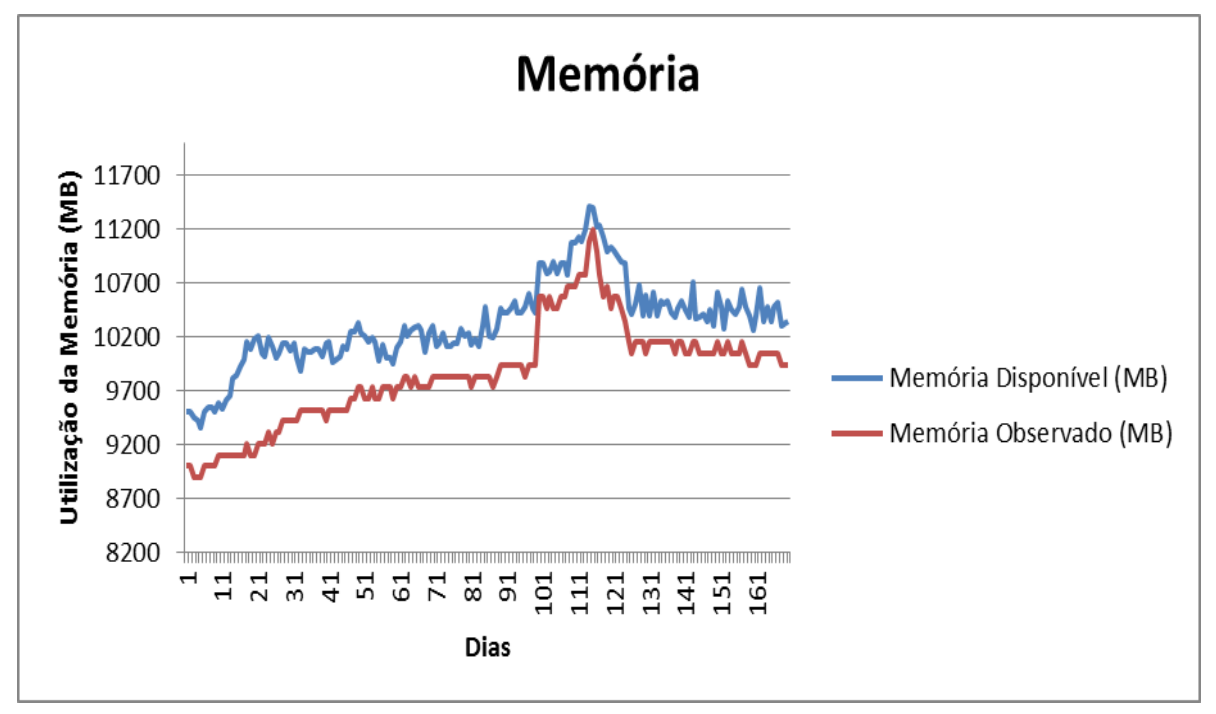

Figura 22 - Experimento2: Memória, com previsão e sem monitor

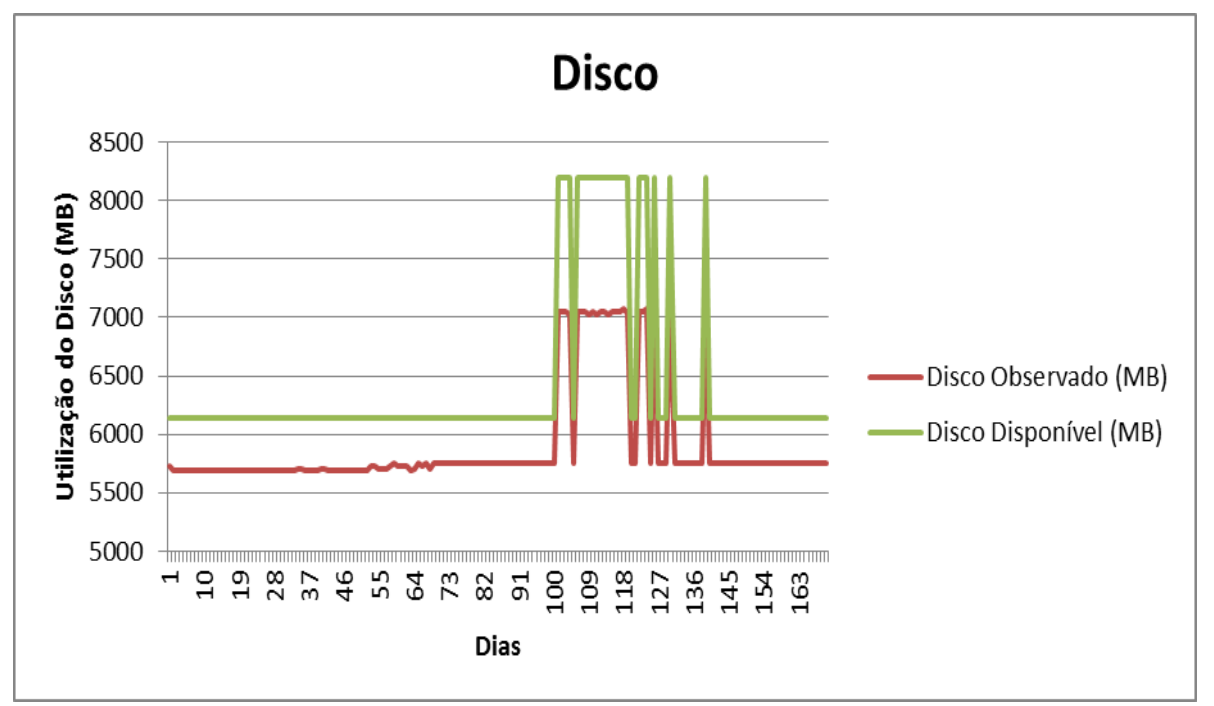

Figura 23 - Experimento2: Disco, com previsão e sem monitor

As figuras 24 e 25 são resultados do experimento 3 sem previsão mas com monitor. Neste experimento, o EQM da memória foi de 59024 e o EMP foi de 2,41\%. Se comparado o resultado do EQM do experimento 2 (Memória) com o experimento 3 (Memória), houve uma aproximação de 
mais de 75\%. O EQM e o EMP baixos são resultados das diversas reconfigurações que ocorrem na infraestutura (memória e disco) durante todo o decorrer do período. O agente monitor é capaz de perceber qualquer evento e realizar a reconfiguração, diferente do uso da previsão que realiza a reconfiguração no início do período apenas não considerando eventos no decorrer do período.

O EQM do disco foi de 174960 e o EMP foi de 5,14\%. Este experimento resultou em uma melhora de 48,2\% para o disco se comparado com o experimento 2. Neste experimento o cliente gastou $98 \%$ do valor contratado, restando $2 \%$ do valor investido para ser gasto. Esse também é um resultado melhor do que o do experimento 2 pois o valor gasto está mais próximo de $100 \%$.

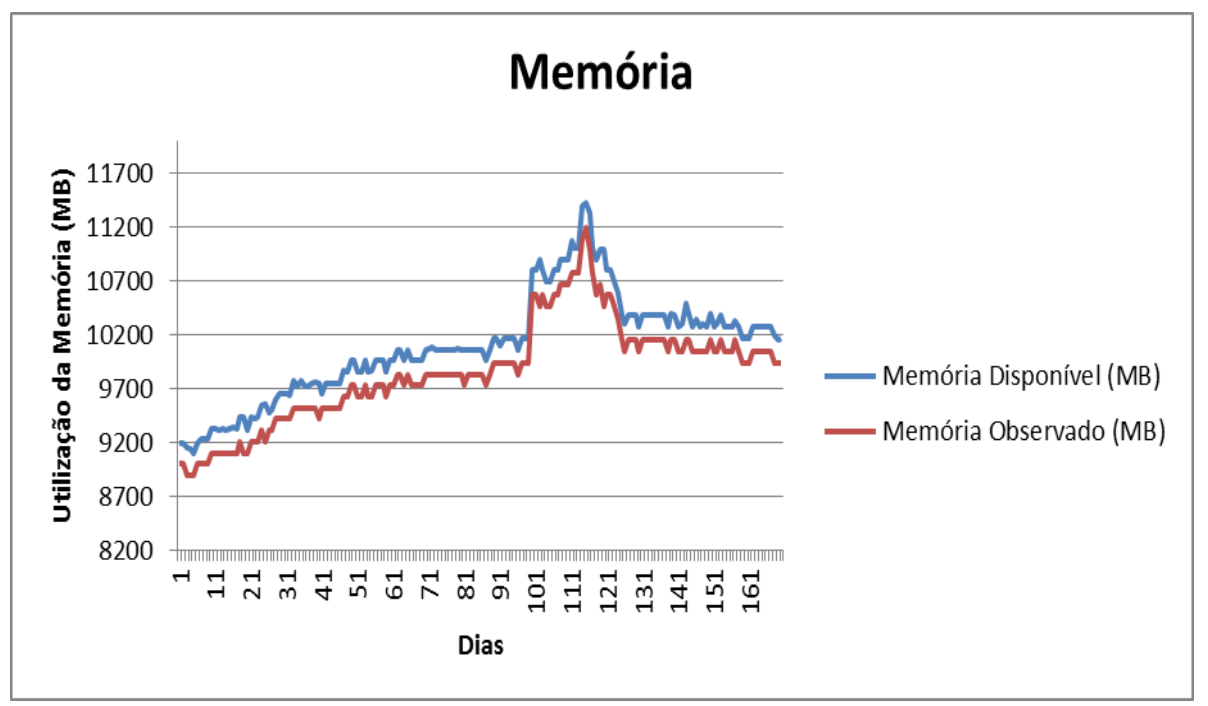

Figura 24 - Experimento3: Memória, Sem previsão e com monitor

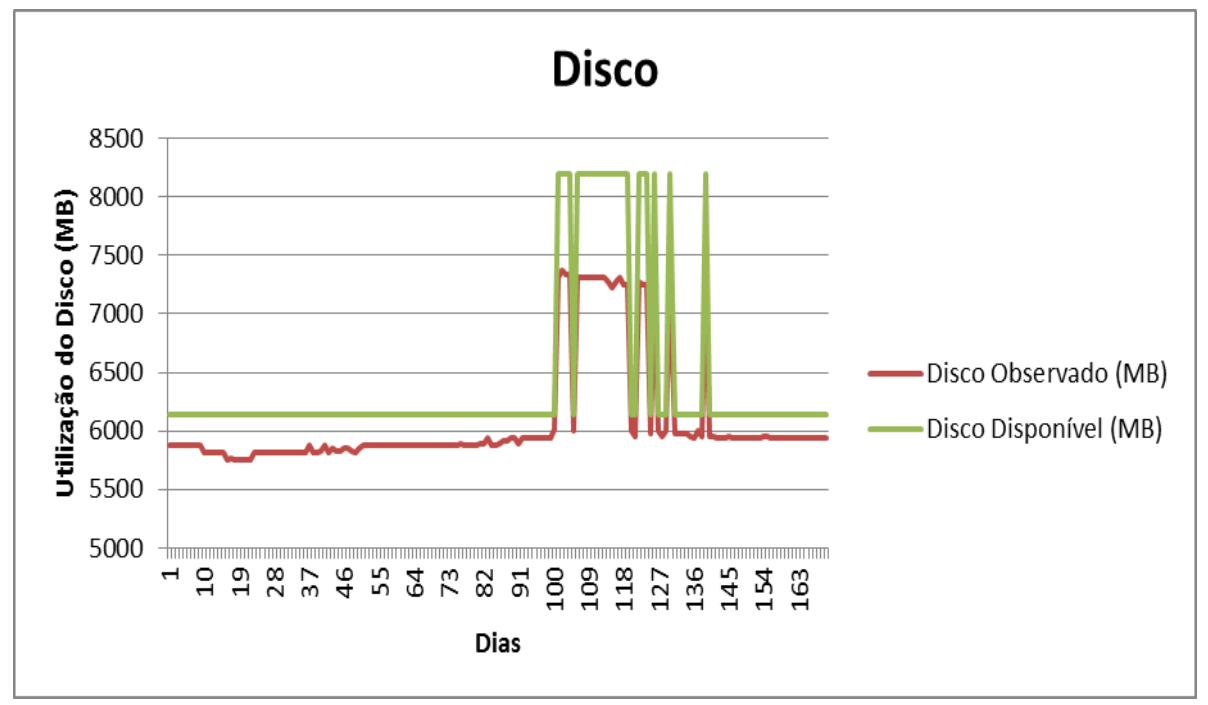

Figura 25 - Experimento3: Disco, Sem previsão e com monitor 
No experimento 4, o último experimento, considerou-se o uso da previsão e do agente monitor o EQM para a memória foi de 248182 e para o disco foi de 189750. Ao confrontar o EQM da memória do experimento 4 com os anteriores, nota-se uma aproximação de 4,98\% para o experimento 2 e um distanciamento de 320,48\% em relação ao experimento 3. Com o disco o EQM no experimento 4 teve um distanciamento de 8,45\% em relação ao experimento 3 e uma aproximação de $43 \%$ em relação ao experimento 2. Esse resultado para o disco ocorre pois no experimento 4 este dispositivo se manteve mais tempo reconfigurado se comparado com o experimento anterior devido a presença do agente monitor.

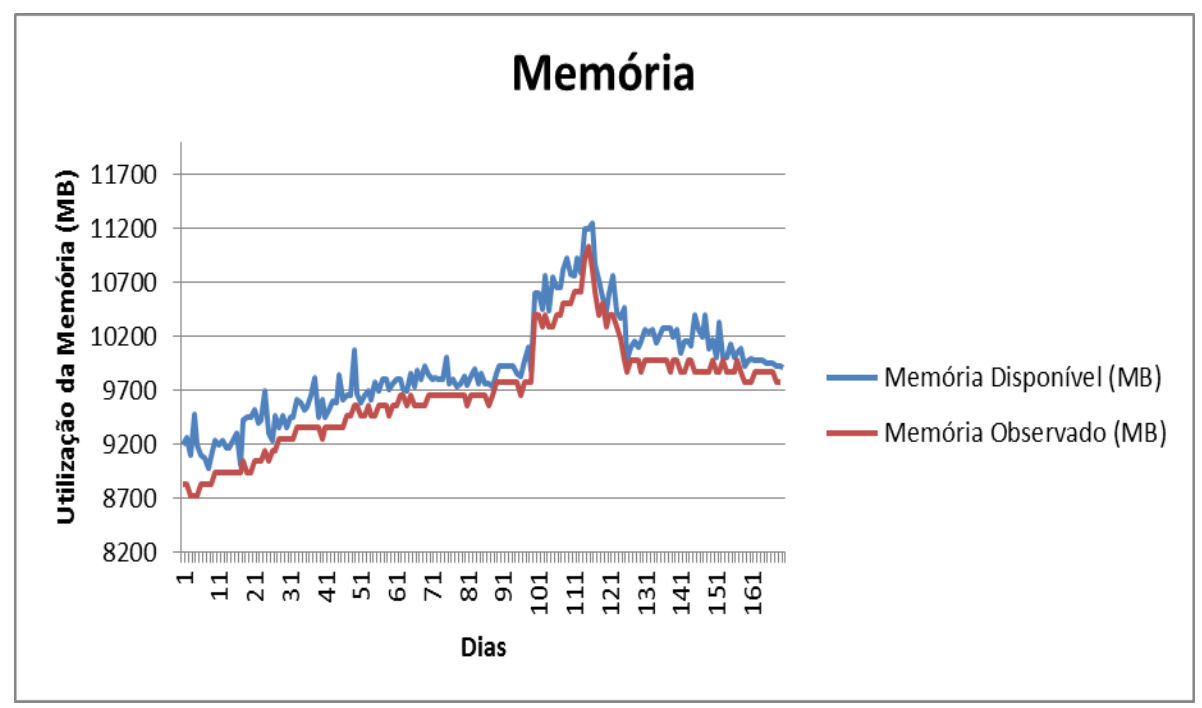

Figura 26 - Experimento4: Memória, Com previsão e com monitor

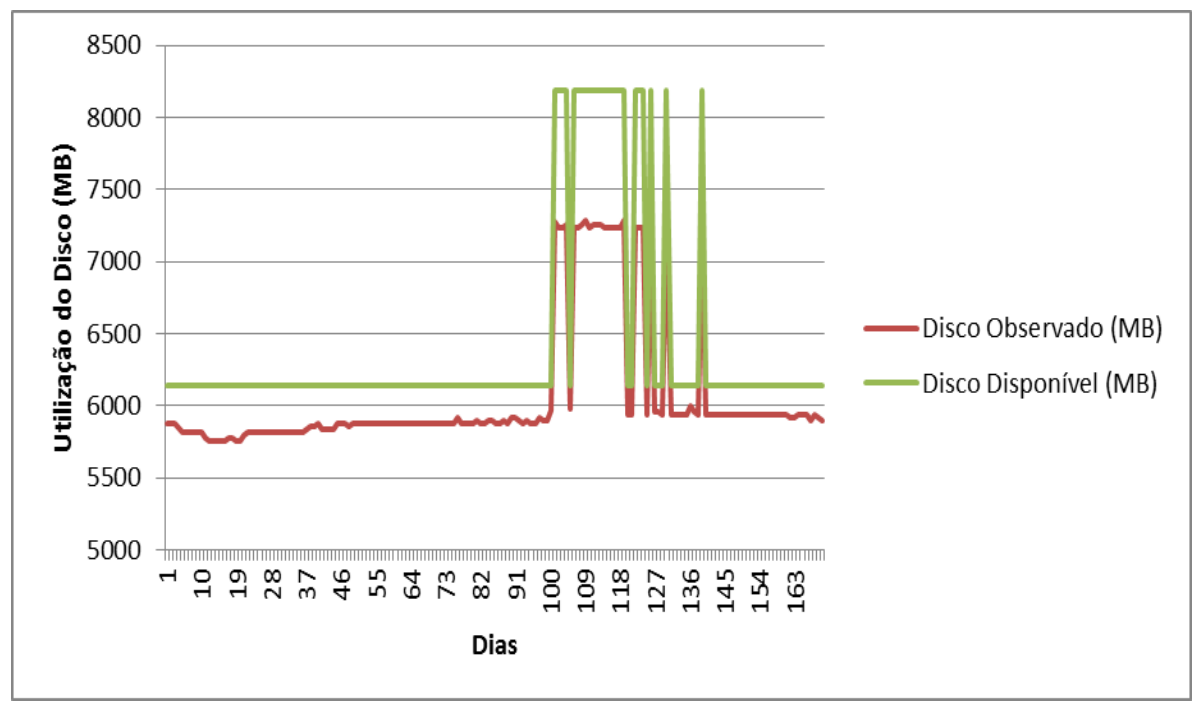

Figura 27 - Experimento4: Disco, Com previsão e com monitor 
A Tabela 6 apresenta um comparativo entre os EMQ nas fases 1 e 2. Tanto na fase 2 como na fase 3 o EMQ foi menor no experimento 3 que foi realizado sem previsão e com agente monitor. O EMQ é um meio de escolher o melhor estimador, neste caso previsão e monitor. A conclusão se previsão é melhor ou pior do que agente monitor só é confiável estatisticamente, se utilizado o EMQ (que é um cálculo que tem exatamente essa finalidade).

Na Tabela 9 observa-se que o agente monitor possibilitou uma melhora significativa na reconfiguração dos recursos, apresentando um menor EMQ em ambas as fases, tanto para disco quanto para memória.

Tabela 9 - Comparativo entre Fase 2 e Fase 3

\begin{tabular}{|c|c|c|c|c|c|c|c|c|}
\hline \multirow{6}{*}{ 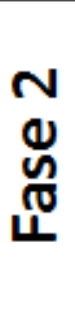 } & & & \multicolumn{3}{|c|}{ Memória } & \multicolumn{3}{|c|}{ Disco } \\
\hline & & & \multirow{2}{*}{$\frac{\text { EQM }}{243,84}$} & \multicolumn{2}{|c|}{ Diferença } & \multirow{2}{*}{$\begin{array}{c}\text { EQM } \\
1571,66\end{array}$} & \multicolumn{2}{|c|}{ Diferença } \\
\hline & Exp1 & $S P-S M$ & & & & & & \\
\hline & Exp2 & $C P-S M$ & 247,78 & 3,94 & $1,62 \%$ & 1640,85 & 69,19 & $4,40 \%$ \\
\hline & Exp3 & $S P-C M$ & 125,45 & 122,33 & $49,37 \%$ & 1345,69 & 295,16 & $17,99 \%$ \\
\hline & Exp4 & $\mathrm{CP}-\mathrm{CM}$ & 156,29 & 30,84 & $24,58 \%$ & 1480,24 & 134,55 & $10,00 \%$ \\
\hline \multirow{2}{*}{\multicolumn{3}{|c|}{$m$}} & \multicolumn{3}{|c|}{ Memória } & \multicolumn{3}{|c|}{ Disco } \\
\hline & & & $E Q M$ & DifeI & ença & $E Q M$ & DifeI & $n c ̧ a$ \\
\hline \multirow{4}{*}{$\begin{array}{l}\mathbf{U} \\
\text { ப் } \\
\mathbf{U}\end{array}$} & Exp1 & $S P-S M$ & 236789 & & & 261703 & & \\
\hline & Exp2 & $C P-S M$ & 251124 & 14335 & $6,05 \%$ & 337801 & 76098 & $29,08 \%$ \\
\hline & Exp3 & $S P-C M$ & 59024 & 192100 & $76,50 \%$ & 174960 & 162841 & $48,21 \%$ \\
\hline & Exp4 & $C P-C M$ & 648182 & 589158 & $998,17 \%$ & 189750 & 14790 & $8,45 \%$ \\
\hline
\end{tabular}

Observa-se ainda que o uso do agente monitor melhorou a reconfiguração realizada pela previsão, uma vez que o EMQ no experimento 4 foi menor se comparado ao EMQ do experimento 2 em todas as fases. Isso ocorre pois, como dito anteriormente, a previsão realiza apenas uma reconfiguração no início do período enquanto o agente monitor constantemente reconfigura a infraestrutura.

\subsection{Análise dos Resultados}

O modelo de Holt-Winter é capaz de acomodar um único ciclo sazonal. Na série temporal utilizada na fase 1 existem 3 ciclos sazonais: férias, início das aulas e período de entrega de notas. O primeiro é um período curto (35 dias), onde possui o menor número de acessos. O segundo é um período maior (cerca de 4 meses) e possui um número de acesso variante em média de 2,4 GB, o terceiro e último é menor período (4 dias) e a média de tráfego é de 9,3GB. 
Como o período de treinamento para o Holt-Winter foi realizado entre dois ciclos sazonais diferentes e como a série temporal possui mais de um ciclo, o valor previsto tende a sofrer grandes oscilações durante um determinado período, porém com o passar do tempo o valor previsto tende a se ajustar com o valor observado ficando bem próximo.

A Média Móvel Exponencial também apresenta um bom resultado, no entanto, é um excelente indicador para a expectativa da carga que será processada, ou seja, se a carga será alta ou baixa para um determinado período, sem indicar o seu valor aproximado ou exato, diferente do Holt-Winter.

A partir dos resultados obtidos na fase 1, foi escolhido a utilização do modelo Holt-Winter para realizar as previsões de demanda.

Os experimentos realizados com os algoritmos de previsão e com os agentes monitores nas fases 2 e 3 proporcionaram uma reconfiguração automática dos recursos da infraestrutura. Desta forma, é possível considerar que a elasticidade da nuvem proposta no início desta pesquisa foi alcançada.

Os primeiros experimentos mostraram que para se conectar a um Web Service o cliente precisa aguardar cerca de 2467ms em média, o restante do tempo é para a VM ser ligada ou sair do estado de suspensa.

Os quatro experimentos seguintes mostraram o comportamento da infraestrutura frente a chegada de carga de trabalho. A menor diferença média entre a carga de trabalho observada e a configuração reconfigurada foi com o uso de monitor sem previsão. Isso ocorre, pois o monitor está constantemente verificando o uso dos recursos e, caso algum deles esteja em estado crítico, automaticamente é solicitada a reconfiguração. Diferentemente do uso de previsão, que apenas reconfigura uma vez no início do período e a próxima será somente no período seguinte.

O retorno sobre o investimento permite ao cliente observar os gastos. Nos experimentos o melhor retorno foi para o uso de monitores sem previsão, pois em todos os períodos o uso dos recursos como Memória e Disco sempre estiveram muito próximos da carga máxima suportada por cada recurso, assim sendo, foi consumido aquilo que era o necessário, sem muitas sobras ou perdas.

Os experimentos da fase 1 e fase 2 validaram os algoritmos de previsão e monitoração. Conhecendo a funcionalidade dos algoritmos desenvolvidos, bem como o uso do retorno sobre o investimento, foi possível propor a utilização de cargas reais de serviços conhecidos como sites de ecommerce e portais web na fase 3 dos experimentos. 
Na fase 2 a carga de trabalho era auxiliada por uma variável randômica, entretanto na fase 3 não houve. A diferença é que, com a carga de trabalho fixa é possível observar melhor a elasticidade e principalmente o comportamento do agente monitor e da previsão, já com a carga de trabalho aleatória é replicado o que ocorre na realidade, pois a carga de trabalho é variável.

\subsection{Considerações finais}

O agente monitor se mostra nos experimentos realizados como um grande mecanismo para reconfiguração da infraestrutura.

Como a previsão é baseada em dados passados ela não trata eventos ocasionais, diferente do agente monitor. Assim sendo, para estes experimentos, de acordo com os dados obtidos, a previsão não é a melhor opção para este caso. Todavia, a previsão torna-se útil para se simular os gastos futuros que o cliente possa ter com o uso da infraestrutura. 


\section{Conclusão}

\subsection{Conclusão Geral}

A gestão de recursos computacionais em nuvem proposto no início deste projeto foi realizada utilizando a elasticidade computacional. Entretanto, diversas atividades de alta relevância foram realizadas, antes mesmo da concepção do projeto e desenvolvimento dos módulos.

Inicialmente foi realizado o levantamento bibliográfico com o objetivo de se conhecer o estado da arte na área. As pesquisas iniciais estavam relacionadas com computação em nuvem e elasticidade computacional. Os resultados dessas pesquisas mostraram que diversos trabalhos estão relacionados à elasticidade, entretanto, em sua maioria, há algum tipo de interferência humana. Desta forma, amparado pelo manifesto da IBM de 2001, observou-se a oportunidade de empregar o uso de Agentes Computacionais que estão contidos dentro do conceito de Computação Autônoma para gerir a infraestrutura computacional.

Após definido os Agentes Computacionais para gerirem a elasticidade da nuvem, o passo seguinte foi conhecer as principais ferramentas que permitissem a reconfiguração da infraestrutura. Alguns comandos em Linux como o virsh possibilitaram a reconfiguração das máquinas virtuais. Posteriormente, as principais técnicas de previsão de carga de trabalho foram estudadas e, durante o levantamento bibliográfico, destacaram-se duas técnicas: Média Móvel Exponencial e Modelo de Holt-Winter, sendo o último a técnica empregada neste trabalho.

O desenvolvimento dos módulos de reconfiguração é uma das contribuições deste trabalho. Foram empregadas duas técnicas para a reconfiguração da infraestrutura, a primeira utilizando monitoramento constante e a segunda realizando a previsão. Outras técnicas de reconfiguração também poderiam ser utilizadas como autoaprendizagem por meio de redes neurais. Mas, optou-se pela previsão e monitoramento, uma vez que possui baixo tempo de latência para a reconfiguração e não é necessária uma base com muitos dados (para a previsão o mínimo é uma janela de 5 a 13 períodos).

Durante as pesquisas, o tópico sobre Retorno Sobre o Investimento despertou a atenção. Sua grande viabilidade é proporcionar um controle financeiro sobre os gastos oriundos do contrato de serviço em nuvem. O Retorno Sobre Investimento, dentro do que se trata sobre Controle Financeiro, 
foi uma funcionalidade adicionada durante o desenvolvimento do projeto e contribuiu com a proposta inicial, uma vez que se encaixa dentro do conceito de gestão eficaz da infraestrutura.

Após a conclusão do desenvolvimento dos módulos, a maior preocupação foi manter o ambiente de teste configurado corretamente para a realização dos testes. O Agente Monitor foi o responsável pela reconfiguração reativa da infraestrutura. Dessa forma, a partir dos experimentos é possível afirmar que, de acordo com os resultados obtidos, houveram significativas melhoras da reconfiguração dos recursos ao executar esse tipo de agente.

Por sua vez, a reconfiguração pró-ativa cuja responsabilidade é da previsão (ou Agente Previsor), não teve um resultado tão positivo quanto ao Agente Monitor, todavia teve resultado relevante dentro do contexto geral, uma vez que diminuiu a ociosidade da infraestrutura em alguns momentos e em outros é capaz de impedir que a carga de trabalho imposta fosse negada por falta de recursos.

Este estudo produziu resultados importantes em relação a Computação em Nuvem, com um enfoque maior na gestão eficaz dos recursos computacionais através do conceito de elasticidade e auxiliada por agentes computacionais e histórico de carga de trabalho, conforme o objetivo inicial desta pesquisa. Os resultados dos experimentos indicam uma melhora na utilização dos recursos, uma vez que, sem o gerenciamento há a ociosidade ou perda das requisições do cliente.

A avaliação de desempenho teve um papel fundamental, servindo não apenas para a verificação do desempenho do projeto, mas também para destacar as vantagens e desvantages dos módulos de reconfiguração (previsão e monitor) dentro da proposta inicial da elasticidade em nuvem.

\subsection{Contribuições}

As principais contribuições deste projeto de mestrado foi o gerenciamento da infraestrutura computacional auxiliada por agentes computacionais dentro do conceito de computação autônoma. O desenvolvimento dos algoritmos de previsão e monitoramento acrescentando também o ROI possibilitou o autogerenciamento da infraestrutura com o mínimo de intervenção humana.

Todos os módulos desenvolvidos são independentes, o que permite que sejam utilizados por outros projetos, por exemplo, o módulo monitor pode ser utilizado para monitorar qualquer outro ambiente. 
Existem outros trabalhos em andamento no grupo de pesquisa que utilizaram os módulos e algoritmos desenvolvidos. Um destes trabalhos está relacionado a propor a qualidade de serviço (QoS) que não foi tratado neste projeto.

Os resultados dos experimentos apontam que, com o gerenciamento proposto utilizando previsão e/ou monitoramento resulta em uma melhora na utilização dos recursos computacionais, uma vez que, sem o gerenciamento, há a ociosidade ou perda das requisições do cliente.

\subsection{Produção Cientifica}

Este projeto de mestrado permitiu a produção de um artigo que foi publicado no evento: "The Nineteenth Ieee Symposium On Computers And Communications". O referido artigo trata do gerenciamento da infraestrutura.

DIAS, A. S.; NAKAMURA, L. H. V.; ESTRELLA, J. C.; SANTANA, M. J.; SANTANA, R. H. C. Providing IaaS Resources Automatically through Prediction and Monitoring Approaches. Proceedings of the nineteenth IEEE Symposium on Computers and Communications, 2014, Madeira, Portugal.

\subsection{Trabalhos Futuros}

As contribuições alcançadas neste projeto foram significativas, entretanto, em sequência ao trabalho desenvolvido, sugere-se a adoção de algumas melhorias para a obtenção de novos resultados, destacando as seguintes sugestões:

- A elasticidade presente neste artigo obtida nos experimentos é a Vertical, ou seja, as VMs são reconfiguradas para expandir ou reduzir seus recursos de acordo com o uso. Como trabalho futuro é proposto a elasticidade Horizontal. Assim, quando uma VM estiver com alta utilização dos recursos, será criada uma nova instância e pode-se ainda realizar a migração da VM atual para a nova instância com maior capacidade;

- O ROI é obtido apenas durante a execução, desta forma o cliente não consegue ter uma perspectiva prévia do quanto gastará durante o período do contrato. Assim, propõe-se o desenvolvimento de uma ferramenta que realize a previsão dos gastos com o objetivo de se estipular, mediante ao banco de dados, o quanto o cliente gastará no final do período contratado; 
- Desenvolvimento de novos algoritmos utilizando redes neurais. Com isso será possível avaliar se é vantajoso a utilização desta técnica frente as apresentadas neste trabalho;

- Aprimorar a proposta de gerenciamento utilizando as regras de ITIL (Information Technology Infrastructure Library) associada ao conceito de DCIM (Data Center Infrastructure Management), desta forma será possível promover melhor gestão da infraestrutura promovendo qualidade no serviço ofertado. 


\section{Referências Bibliográficas}

(ADVFN, 2012) ADVFN. Média móvel exponencial. Disponível em: <http://br.advfn.com/educacional/analisetecnica/media-movel-exponencial> Acesso em 03 ago. 2012.

(ÁLVARES et. al., 2010) ÁLVARES, Alberto; FERREIRA, João. Uma metodologia para integração CAD/CAPP/CAM voltada para manufatura remota de peças rotacionais via web. Imediata, 2010. Disponível em: <gate.lab.unb.br/pub/docs/books/webmachining.graco.unb.br/papers/cadcappcam.pdf > Acesso em: 17 abr. 2012.

(AMAZON, 2010) AMAZON. Visão Geral da Amazon Web Services. Dispoível em: < http://d36cz9buwru1tt.cloudfront.net/pt/wp/AWS+Overview_120610.pdf>. Acesso em: 03 abr. 2012.

(ANGELO, 2011) ANGELO, F. No Brasil, falta de profissionais eleva salários a níveis dos EUA. IT Careers, 2011. Disponível em:

<http://convergenciadigital.uol.com.br/cgi/cgilua.exe/sys/start.htm?infoid=26579\&sid=46> Acesso em: 11 jun. 2011.

(ARMBRUST et. al., 2009) ARMBRUST, Michael; FOX, Armando; GRIFFITH, Rean; JOSEPH, Anthony; KATZ, Randy; KONWINSKI, Andy; LEE, Gunho; PATTERSON, David; RABKIN, Ariel; STOICA, Ion; ZAHARIA, Matei. Above the Clouds: A Berkeley view of cloud computing. Imediata, 2009. Disponível em: < http://www.eecs.berkeley.edu/Pubs/TechRpts/2009/EECS-2009-28.pdf> Acesso em: 29 mar. 2012.

(BARBOSA, 2005) BARBOSA, A. Análise da demanda do álcool utilizando os métodos de suavização exponencial. 2005. Monografia, Departamento de Estatística, Universidade Estadual de Maringá, Maringá, PR.

(BATISTA et al. 2010) BATISTA, A. F. D. M. et al. Principles of Agent-Oriented Programming. [S.l.]: Federal University of ABC (UFABC) - Brazil, 2010.

(BRANTNER et. al., 2008) Brantner, M., Florescu, D., Graf, D., Kossmann, D., and Kraska, T.. Building a database on s3. In Proceedings of the 2008 ACM SIGMOD international conference on Management of data SIGMOD ’08, page 251, New York. ACM Press.

(BRAZIER et. al., 2009) BRAZIER, F.M.T.; KEPHART, J.O.; VAN DYKE PARUNAK, H.; HUHNS, M.N. Agents and Service-Oriented Computing for Autonomic Computing: A Research Agenda Internet Computing, IEEE , vol.13, no.3, pp.82-87, May-June 2009 doi: 10.1109/MIC.2009.51

(CAPRARESCU, 2009) CAPRARESCU, B.A.; PETCU, D. A Self-Organizing Feedback Loop for Autonomic Computing. Future Computing, Service Computation, Cognitive, Adaptive, Content, Patterns, 2009. COMPUTATIONWORLD '09. Computation World pp.126-131, 15-20 Nov. 2009 Doi: 10.1109/ComputationWorld.2009.21

(CARNEIRO et. al., 2010) CARNEIRO, R.; RAMOS,C.. A segurança na preservação e uso das informações na computação nas nuvens. Disponível em: <www.fatecjp.com.br/revista/art-ed02-001.pdf> Acesso em: 20 mar. 2010.

(CARVALHO, 2010) CARVALHO, Paulo Soeiro de. “COMPUTORIZAÇÃO”, “DIGITALIZAÇÃO” E “VIRTUALIZAÇÃO” DA ECONOMIA DOS EUA. Disponível em:

<www.dpp.pt/pages/files/infor_inter_2000_I_V.pdf> Acesso em: 07 mai. 2012.

(CHARLTON et. al., 2010) CHARLTON, P.; MAGOULAS, G.D.; Autonomic Computing and Ontologies to Enable Context-aware Learning Design. Tools with Artificial Intelligence (ICTAI), 2010 22nd IEEE International Conference on, vol.2, no., pp.286-291, 27-29 Oct. 2010 doi: 10.1109/ICTAI.2010.113. 
(CORRAR, 2004) CORRAR, L. J.; THEÓPHILO, C.R. Pesquisa operacional para decisão em contabilidade e administração: contabilometria. São Paulo, SP. Atlas, 2004.

(CORRÊA et. al., 2008) CORRÊA, Sand L., CERQUEIRA, Renato F. G.. Computação Autônoma: uma visão sobre arquiteturas e infraestruturas. Disponível em: Acesso em: 07 abr. 2012.

(DAWOUD et. al., 2011) DAWOUD, Wesam; TAKOUNA, Ibrahim; MEINEL, Christoph. Elastic VM for rapid and optimum virtualized Resources' allocation. Hasso Plattner Institute. Disponível em: <http://ieeexplore.ieee.org/stamp/stamp.jsp?arnumber=06096465> Acesso em: 23 mai. 2012.

(DIAS, 2014) DIAS, A. S. ; NAKAMURA, L. H. V.; ESTRELLA, J. C.; SANTANA, R.H.C.; SANTANA, M.J.. Providing IaaS Resources Automatically through Prediction and Monitoring Approaches. In: IEEE Symposium On Computers And Communications, 2014, Madeira - PT. The Nineteenth Ieee Symposium On Computers And Communications, 2014.

(DEXTRA, 2010) Dextra. Web Services na Integração de Sistemas Corporativos. Disponível em: <http://www.dextra.com.br/empresa/artigos/webservices.htm> Acesso em: 30 mar. 2012.

(DOBSON et. al., 2010) DOBSON, S.; STERRITT, R.; NIXON, P.; HINCHEY, M.; Fulfilling the Vision of Autonomic Computing Computer, vol.43, no.1, pp.35-41, Jan. 2010. doi: 10.1109/MC.2010.14

(EHLERS, 2012) EHLERS, Ricardo. Análise de séries temporais. Disponível em: < http://www.each.usp.br/rvicente/AnaliseDeSeriesTemporais.pdf> Acessado em: 20 nov. 2012.

(ENDREI et. al., 2004) Endrei, M.; Ang, J.; Arsanjani, A.; Chua, S.; Comte, P.; Krogdahl, P.; Luo, M.; Newling, T.; Patterns: Service-Oriented Architecture and Web Services. IBM Redbooks, 2004. Disponível em: <http://www.redbooks.ibm.com/redbooks/pdfs/sg246303.pdf>. Acesso em: 02 abr. 2012.

(ERL, 2009) ERL, Thomas. SOA Princípios de design de serviços. Pearson Prentice Hall PTR, 2009.

(FIPA, 2012) FIPA. Welcome to FIPA!. Disponível em < http://www.fipa.org/>. Acesso em: 10 Out. 2012.

(FATTORETO , 2010) FATTORETO, Vinicius. O que é Cloud Computing (Computação nas Nuvens)?. Disponível em < http://f5infotec.blogspot.com/2010_11_01_archive.html>. Acesso em: 20 nov 2012.

(HUEBSCHER et. al., 2008) HUEBSCHER, M. C.; MC CANN, J. A.. A Survey of Autonomic ComputingDegrees, Models, and Applications. ACM Computing Surveys, 40(3):1-28, 2008.

(IBM, 2001) Autonomic Computing: IBM Perspective on the State of Information Technology. IBM T. J. Watson Labs, NY, 15th October 2001. Presented at AGENDA 2001, Scotsdale, AR., 2001. Disponível em: <http://www.research.ibm.com/autonomic/> Acesso em: 02 abr. 2012.

(JAIN, 1991) Jain, R.. The Art of Computer Systems Performance Analysis: Techniques for Experimental Design, Measurement, Simulation, and Modeling. J. Wiley, 1991, ISBN 0471503363.

(JOSUTTIS, 2008) Josuttis, N. M. SOA na prática - A Arte da Modelagem de Sistemas Distribuídos. 1st. ed. Oreill'y, 2008.

(KHATUA et. al., 2010) KHATUA, S.; GHOSH , A.; MUKHERJEE, N. “Optimizing the Utilization of Virtual Resources in Cloud Environment,” in IEEE Int. Conference on Virtual Environments HumanComputer Interfaces and Measurement Systems (VECIMS), 2010.

(KOMODA, 2006) Komoda, N., Service Oriented Architecture (SOA) in Industrial Systems. Department of Multimedia Engineering. In: 2006 IEEE International Conference on Industrial Informatics, 2006. 
(LEWIS, 1997) LEWIS, C. D. Demand forecasting and inventory control: a computer aided learning approach. New York, USA. John Wiley \& Sons, 1997.

(LOPES, 2002) LOPES, R. D. Previsão de autopeças: estudo de caso em uma concessionária de veículos. 2002. Dissertação, Programa de Pós-Graduação em Engenharia de Produção, Universidade Federal de Santa Catarina, Florianópolis, SC.

(MAKRIDAKIS el. al., 1998) MAKRIDAKIS, S.G.; WHEELWRIGHT, S.C.; HYNDMAN, R.J. Forecasting: methods and applications. 3a. ed. New York, USA. Wiley, 1998.

(MALULI, 2010) MALULI, Arlindo. Virtualização de computadores e a importante queda no consumo de energia. Disponível em: < http://olhardigital.uol.com.br/blog_post/12994> Acesso em: 30 mar. 2012.

(MATTESS et. al., 2010) M. Mattess, C. Vecchiola, and R. Buyya, "Managing Peak Loads by Leasing Cloud Infrastructure Services from a Spot Market,” in 12th IEEE Int. Conference on High Performance Computing and Communications (HPCC), 2010.

(NOGUEIRA at. al, 2010) NOGUEIRA, Matheus Cadori; PEZZI, Daniel da Cunha. A computação agora é nas nuvens. Disponível em: <under-linux.org/attachments/f98/8369d1257953490-invasao-cloud-computing.pdf > Acesso em: 17 abr. 2012.

(PAPAZOGLOU et. al., 2003) Papazoglou, M. P.; Georgakopoulos, D. Service-oriented computing. Commun. ACM, v. 46, n. 10, p. 24-28, 2003.

(PINHEIRO, 2010) PINHEIRO, Fernando. Tipos em Cloud Computing. Disponível em: < http://www.gta.ufrj.br/ensino/eel879/trabalhos_vf_2010_2/fernando/tipos_em_cc.html> Acesso em: 02 abr. 2012.

(RAO et. al.,2011) RAO, Jia; BU, Xiangping; XU, Cheng-Zhong; WANG, Kun. A distributed self-learning approach for elastic provisioning of virtualized cloud resources. 19th Annual IEEE International Symposium on Modelling, Analysis, and Simulation of computer and telecommunication systems. Disponível em: <http://ieeexplore.ieee.org/stamp/stamp.jsp?tp=\&arnumber=6005367> Acesso em: 23 mai. 2012.

(RYDLEWSKI, 2009) RYDLEWSKI, Carlos. Computação sem fronteiras. Revista Veja, ano 42, n. 32, 12 ago. 2009. São Paulo: Abril 2009.

(SEO, 2009) SEO, Carlos E.. Virtualização - Problemas e Desafios. Disponível em:

<http://www.ic.unicamp.br/ ducatte/mo401/1s2009/T2/008278-t2.pdf> Acesso em: 30 mar. 2012.

(SKILTON, 2010) SKILTON, Mark. Building Return on Investment from Cloud Computing. Disponível em: <http://www.opengroup.org/cloud/whitepapers/ccroi/index.htm> Acesso em: 12 jun. 2012.

(SOUZA et. al., 2010) SOUZA, Flávio R. C.; MOREIRA, Leonardo O.; MACHADO, Javam C.. Computação em Nuvem: Conceitos, Tecnologias, Aplicações e Desafios. Disponível em:

<http://www.es.ufc.br/ flavio/files/Computacao_Nuvem.pdf> Acesso em: 29 mar. 2012.

(SOUZA et. al., 2011) SOUZA, Flávio R. C.; MOREIRA, Leonardo O.; MACHADO, Javam C.. Computação em Nuvem Autônoma: Oportunidades e Desafios. Disponível em: <

http://sbrc2011.facom.ufms.br/files/workshops/wosida/ST01_2.pdf > Acesso em: 15 mai. 2012.

(STATHIS, 2010) STATHIS, K. Autonomic computing with self-governed super-agents. Self-Adaptive and Self-Organizing Systems Workshop (SASOW), 2010 Fourth IEEE International Conference on , vol., no., pp.7679, 27-28 Sept. 2010 doi: 10.1109/SASOW.2010.18. 
(STERRITT et. al., 2003) STERRITT, R.; BUSTARD, D.. Autonomic Computing- A Means of Achieving Dependability? In: Proceedings of the 10 th IEEE International Conference and Workshop on the Engineering of Computer-Based System, p. 247-251, Los Alamitos, CA, USA, 2003. IEEE Computer Society.

(SURYAWANSHI, 2014) SURYAWANSHI, P.. Automation of Enterprise Audit Management System. Department of Computer Science. B.V.B. College of Engg \& Technology, Hubli, India. CS \& IT-CSCP 2014. Doi: 105121/csit.2014.4805.

(Tanenbaum, 2003) Tanenbaum, A. S. Redes de computadores. Editora Campus, Tradução da quarta edição, 2003.

(THOMAS et. al., 2003) Thomas, J. P.; Thomas, M.; Ghinea, G. Modeling of web services flow. E-Commerce Technology, IEEE International Conference on, v. 0, p. 391, 2003.

(TIRADO et. al., 2011) TIRADO, Juan M.; HIGUERO, Daniel; ISAILA, Florin; CARRETERO, Jesús. Predictive Data Grouping and Placement for Cloud-based Elastic Server Infrastructures. $11^{\text {th }}$ IEEE/ACM International Symposiym on Cluster, Cloud and Grid Computing, 2011. doi: 10.1109/CCGrid.2011.49

(WHITE et. al., 2004) WHITE, S. R.; HANSON, J. E.; WHALLEY, I.; CHESS, D. M. ; KEPHART , J. O.. An Architectural Approach to Autonomic Computing. In: PROCEEDINGS OF THE INTERNATIONAL CONFERENCE ON AUTONOMIC COMPUTING (ICAC ’04), p. 2-9, Los Alamitos, CA, USA, 2004. I EEE Computer Society. 